\title{
Monetary Stimulus amid the Infrastructure Investment Spree: Evidence from China's Loan-Level Data
}

\author{
Kaiji Chen, Haoyu Gao, Patrick Higgins, Daniel F. Waggoner, and Tao Zha
}

\author{
Working Paper 2020-16a \\ August 2020 (Revised July 2022)
}

\begin{abstract}
We study how a fiscal expansion via infrastructure investment influences the dynamic impacts of monetary stimulus on credit allocation. We develop a two-stage approach and apply it to the Chinese economy with a confidential loan-level dataset that covers all sectors. We find that infrastructure investment significantly weakened monetary policy's transmission to credit allocated to private firms, while reinforcing the monetary effects on loans to state-owned firms. This fiscal-monetary interaction channel is key to understanding the preferential credit access enjoyed by state-owned firms during the stimulus period. Consequently, monetary stimulus crowded out private investment and lowered efficiency in capital allocation.
\end{abstract}

JEL classification: E5, E02, C3, C13

Key words: fiscal expansion, fiscal-monetary policy interaction, transmission of monetary policy, credit allocation, identification, aggregate and firm-specific monetary shocks, crowding-out effects

https://doi.org/10.29338/wp2020-16a

\begin{abstract}
The authors thank Markus Brunnermeier, Lawrence Christiano, Will Cong, Marty Eichenbaum, Zhiguo He, Yi Huang, Eric Leeper, Zheng Liu, Loretta Mester, Sergio Rebelo, Mark Spiegel, Robert Townsend, Shang-Jin Wei, Wei Xiong, and Xiaoyun Yu as well as seminar participants at the Federal Reserve Bank of Cleveland, 2019 International Conference on "Exchange Rates, Monetary Policy, and Frictions" sponsored by Northwestern University, the 2019 AFR Summer Institute in Economics and Finance; the third International Monetary Fund-Atlanta Fed China Workshop; the China International Conference in Macroeconomics; the International Monetary Fund; the Hong Kong Monetary Authority; the second HKUST-Jinan UniversityConference in Macroeconomics; the European Central Bank-Tsinghua Conference on China; the Chinese University of Hong Kong; the University of Virginia; and Princeton University for helpful discussions and comments. Haoyu Gao acknowledges the research support from the National Natural Science Foundation of China (NSFC 71702207 and 71850008). An earlier version of this paper is titled "Impacts of Monetary Stimulus on Credit Allocation and Macroeconomy: Evidence from China." The views expressed here are those of the authors and not necessarily those of the Federal Reserve Bank of Atlanta or the Federal Reserve System. Any remaining errors are the authors' responsibility.
\end{abstract}

Please address questions regarding content to Kaiji Chen, Emory University, 1602 Fishburne Drive , Atlanta, GA 30322-2240, and the Federal Reserve Bank of Atlanta, kaiji.chen@emory.edu; Haoyu Gao, Renmin University of China, Beijing, China, gaohaoyu@ruc.edu.cn; Patrick Higgins, Federal Reserve Bank of Atlanta, 1000 Peachtree Street NE, Atlanta, GA 30309-4470, patrick.higgins@atl.frb.org; Daniel F. Waggoner, Federal Reserve Bank of Atlanta, 1000 Peachtree Street NE, Atlanta, GA 30309-4470, daniel.f.waggoner@atl.frb.org; or Tao Zha, Federal Reserve Bank of Atlanta, 1000 Peachtree Street NE, Atlanta, GA 30309-4470, and Emory University and NBER, zmail@tzha.net.

Federal Reserve Bank of Atlanta working papers, including revised versions, are available on the Atlanta Fed's website at www.frbatlanta.org. Click "Publications" and then "Working Papers." To receive e-mail notifications about new papers, use frbatlanta.org/forms/subscribe. 


\section{INTRODUCTION}

During economic downturns such as the 2008 global financial crisis and the 2020 Covid19 pandemic, central banks around the world (Federal Reserve System, European Central Bank, Bank of Japan, and People's Bank of China) initiated massive monetary stimulus by providing ample liquidity to the banking system in an attempt to bolster bank credit to firms and rescue their sagging economies. At the same time, there was also a significant fiscal expansion to boost domestic demands. A large fiscal expansion is often joined by a "tsunami of bank credit expansion" (Brunnermeier, Sockin, and Xiong, 2017; Leeper, 2019), and expansionary fiscal policy can be used to target bank credit to specific sectors (Bleck and Liu, 2018; Chari, Dovis, and Kehoe, 2020). How is empirical work able to separate the effect of monetary stimulus on the banking system from that of fiscal expansion, and do these sources complement or substitute for each other? These questions are of central importance both in the macro-finance literature and for policymakers.

This paper addresses these questions from the perspective of China, the second largest economy in the world, by exploiting a confidential dataset of loans newly issued by the 17 largest Chinese commercial banks to individual firms over all sectors in the economy from 2007 to 2013. Like many other countries, China suffered a severe economic downturn during the 2008 global financial crisis. Growth of China's real gross domestic product (GDP) plummeted from 13.6\% in 2007Q2 to 6.4\% in 2009Q1 (top chart of Figure 1). In an attempt to stem the sharp fall of aggregate output, the People's Bank of China (PBC) pursued extraordinarily expansionary monetary policy and increased M2 supply by 4.2 trillion RMB in 2009Q1 alone and by a total of 11.5 trillion RMB during the 2009Q1-2009Q3 period. Accordingly, the growth rate of total bank loans rose to more than $25 \%$ during the same period (bottom chart of Figure 1). Meanwhile, the State Council announced an expansionary fiscal plan for the country in November 2008. In particular, the government prioritized infrastructure investment as an effective fiscal tool for stimulating the overall economy. ${ }^{1}$ In contrast to moderate growth of investment in other sectors, the growth rate of infrastructure investment increased to more than 30\% in 2009 (Figure 2). Such a monetary-fiscal policy interaction makes China an ideal case study to gain a general perspective of how a fiscal expansion through infrastructure investment would weaken or strengthen the effect of monetary stimulus on the banking system and the real economy.

Assessing this interactive effect faces a major empirical hurdle: one must identify the portion of infrastructure investment that is not influenced by monetary policy shocks. A failure to purge infrastructure investment of the influence of monetary shocks would result in biased estimates of the effects of monetary stimulus alone and its interaction with fiscal

\footnotetext{
${ }^{1}$ Fiscal policy plays an important role in public investment in general for many economies (Leeper, Walker, and Yang, 2010) and in infrastructure investment in particular for the Chinese economy (Xiong, 2019). Recently, the U.S.'s $\$ 1.2$ trillion Infrastructure Investment and Jobs Act has become a major component of the U.S. fiscal expansion.
} 
expansion. To correct for the endogeneity bias, we develop a two-stage empirical framework. In the first stage, we build a dynamic macro model to disentangle exogenous monetary policy changes from other aggregate shocks in a multi-equation system. This multi-equation macro model enables one to first identify the portion of infrastructure investment driven only by monetary policy shocks and then extract a series of infrastructure investment absent these shocks. $^{2}$ In the second stage, we apply a dynamic panel model to our unique loan-level data and estimate the impacts of monetary stimulus and its interaction with infrastructure investment on bank lending. We show that without the first stage, the estimated effect of monetary policy shocks when interacting with infrastructure investment would be severely biased downward. To our knowledge, this is a new methodological contribution to the macrofinance literature, and this framework can be applied to general issues related to the effects of the interaction between monetary and fiscal policies on the banking system as well as the real economy.

With this empirical framework, we study how credit is allocated between China's stateowned enterprises (SOEs) and non-SOEs in response to monetary stimulus. ${ }^{3}$ Cong, Gao, Ponticelli, and Yang (2019) demonstrate that an increase in bank credit supply during the economic stimulus period favored SOEs because of implicit government guarantees on loans to SOEs. Their study focuses on the overall effect of a credit expansion on loans to SOEs versus non-SOEs without distinguishing whether an increase in the credit supply was through the transmission of monetary policy itself or through the interaction of fiscal expansion with monetary stimulus. An increase of infrastructure investment was a major part of fiscal expansion and the government offered explicit guarantees on loans to SOEs in the infrastructure sector. $\mathrm{Ru}$ (2018) and Xiong (2019) highlight possible spillovers of infrastructure investment to the Chinese economy. Huang, Pagano, and Panizza (2020) find that while local government debt helped SOEs (e.g., local government financing vehicles [LGFVs]) obtain bank loans, it crowded out bank credit to private firms and therefore private investment in the manufacturing sector. Whether a preferential credit treatment for SOEs was an outcome of the effects of monetary stimulus alone or those of the fiscal expansion interacting with the monetary expansion, however, remains an open but important question.

The goal of this paper is two-fold: (a) to decompose the overall effect on credit allocation of monetary stimulus into two components: the fiscal-monetary interaction effect (interactive effect) and the monetary effect absent the fiscal expansion (pure effect), and (b) to assess the critical role of the fiscal-monetary interaction channel in the overall effect of the transmission

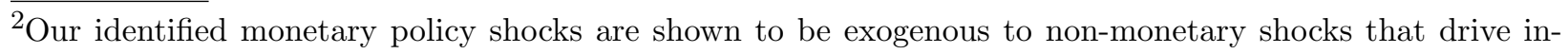
frastructure investment.

${ }^{3}$ The state-owned enterprises are defined as either firms registered as state-owned enterprises or firms with the state as the controlling shareholder or the ultimate controller. See Section III.1 for details. The literature on the Chinese economy has focused on studying how credit and capital are allocated between SOEs and non-SOEs (see, for example, Hsieh and Klenow (2009) and Song, Storesletten, and Zilibotti (2011)).
} 
of monetary policy to credit allocation between SOEs and non-SOEs. Our two-stage empirical framework provides a tool to identify the fiscal-monetary interaction channel. Consistent with the prior literature, we find that the overall effect of monetary stimulus on credit allocation favored SOEs. What is new in our paper is to show that the fiscal-monetary interaction channel is key to understanding the overall effect of monetary policy on preferential credit to SOEs during the stimulus period. Through this channel, infrastructure investment enhanced the transmission of monetary policy to bank loans allocated to SOEs, but dampened that transmission to loans allocated to non-SOEs during the stimulus period. By contrast, the 2009 monetary stimulus absent this fiscal expansion did not expand bank loans in favor of SOEs.

As the fiscal expansion targeted infrastructure projects, how did it affect the transmission of monetary policy to credit allocated to SOEs verus non-SOEs in the infrastructure sector itself as well as in other sectors? We find that while the fiscal expansion enhanced the monetary transmission to the infrastructure sector, ${ }^{4}$ it had a negative spillover effect on bank loans allocated to other sectors, especially to non-SOEs in those sectors. Our estimated interactive effects on bank credit to SOEs in the infrastructure sector are almost twice as much as that for the entire economy, suggesting that the crowding in effect of fiscal expansion on loans to SOEs in the entire economy stems largely from that effect on loans to SOEs in the infrastructure sector. At the same time, the fiscal expansion via infrastructure investment crowded out loans to non-SOEs, but not to SOE credit, in other sectors. For example, the estimated positive effects of monetary stimulus on credit to non-SOEs in real estate is reduced by about 50\%. Our findings suggest that the crowding out effects on non-SOEs stem from those in non-infrastructure sectors.

During the economic stimulus period, fiscal policy targeted certain regions, notably the western region. To examine whether our estimated effects of monetary stimulus may be confounded by these regional effects, we provide a robustness analysis with three different specifications: (i) we construct firm-specific shocks to credit supply engendered by monetary policy and replace aggregate monetary shocks with these firm-specific monetary shocks in the regression; (ii) we include regional fixed effects in the regression to control for possible regional effects; and (iii) we re-estimate the regression with a subsample of firms in regions not explicitly targeted by fiscal policy. Our main findings are robust to these different specifications. In particular, a fiscal expansion dampens the monetary transmission to loans to non-SOEs in non-infrastructure sectors, while enhancing the transmission to infrastructure SOEs.

By modifying the two-sector model of Bleck and Liu (2018) to study the fiscal-monetary interaction effect, we provide a theoretical explanation of how infrastructure investment dampens the monetary transmission to bank loans allocated to non-SOEs in sectors other

\footnotetext{
${ }^{4}$ We follow the literature and define the infrastructure sector as a sector that includes four one-digit industries (see Section II.3 for details).
} 
than infrastructure, while enhancing loans advanced to the infrastructure sector. Through an increase of government-guaranteed loans to infrastructure projects, a large fiscal expansion via infrastructure investment raises the projects' collateral values, which in turn increases the debt capacity of infrastructure firms. This credit expansion helps raise infrastructure investment, which further increases the collateral value of an infrastructure project. Such a positive feedback loop between bank lending and collateral value amplifies an increase in bank credit to infrastructure firms when monetary stimulus expands bank credit. The increase of credit advanced to infrastructure firms raises the cost of funds for firms, especially non-SOEs, in other sectors. As a result, bank loans to non-SOEs in sectors other than infrastructure decline.

Absent the fiscal expansion via infrastructure investment, we find that the pure impacts of the 2009 monetary stimulus on credit allocation favored SOEs in the manufacturing sector but not in the whole economy. One plausible explanation for this difference is preferential credit to capital intensive firms as physical capital is often used as collateral for bank credit. Based on China's institutional facts, SOEs in manufacturing are more likely to be capital intensive than manufacturing non-SOEs; in other sectors such as infrastructure and real estate, capital intensity of SOEs is not necessarily higher than non-SOEs. Consistent with this explanation, we find that conditional on the ownership type, the amount of bank lending depends positively on the ratio of a firm's capital to its employment for both manufacturing and the entire economy.

In the last part of the paper, we address the question of how monetary stimulus was transmitted to the real economy through bank lending. We first estimate the elasticity of capital investment to bank credit by merging the publicly available Chinese Stock Market \& Accounting Research (CSMAR) database (containing business investment information) and our banking database (containing firm-quarter loan information). We then provide a back-ofenvelope calculation of the response of investment to the 2009 monetary stimulus by taking into account both the estimated elasticity of investment to bank credit and the estimated elasticity of bank credit to the 2009 monetary stimulus. For the Chinese economy as a whole, we find that the 2009 monetary stimulus absent the fiscal expansion generated higher investment of non-SOEs. Infrastructure spending, however, dampened the monetary effect on investment of non-SOEs while amplifying that effect on investment of SOEs. Consequently, the overall response of SOEs' investment to the 2009 monetary stimulus was larger than that of non-SOEs' investment. The fiscal-monetary interaction channel, therefore, is the key to understanding the economy-wide impacts of the 2009 monetary stimulus on the allocation of both credit and capital from non-SOEs to SOEs.

Our paper is related to the emerging empirical literature on China's post-2008 economic stimulus plan. The empirical methodology employed by existing studies (Cong, Gao, Ponticelli, and Yang, 2019; Huang, Pagano, and Panizza, 2020, for example) identifies local credit 
shocks without identifying macroeconomic policies that underlie increases in the credit supply. Our approach is developed to disentangle monetary policy from a fiscal expansion via infrastructure investment (the two major components of the 2009 economic stimulus package). With this separation, one is able to identify the fiscal-monetary interaction channel for the overall effect of monetary stimulus on credit allocation. By extending the sample to the entire economy, we establish evidence that infrastructure investment played a central role in the transmission of monetary policy to credit allocation from non-SOEs to SOEs.

Although we use China as a case study for developing our two-stage approach, the approach itself provides a framework for general applications to identifying non-monetary components that exert significant impacts on the transmission of monetary policy. For instance, how a fiscal expansion, such as the recent U.S. infrastructure investment plan, would reinforce or weaken the effects of the Federal Reserve's massive monetary stimulus on U.S. private or small firms in the aftermath of the Covid-19 pandemic is one of the most relevant applications. A major challenge to such an application is that issuance of Treasury securities to finance large government spending during and after this crisis period responded endogenously to the Federal Reserve's interest rate policy. To deal with this endogeneity issue, one can first identify monetary and fiscal policies and then isolate the component of government spending that is driven by fiscal shocks in the first stage. ${ }^{5}$ In the second stage, one can assess how this isolated fiscal component alters the monetary transmission to the credit market. The generality of our empirical strategy is an important contribution of the paper.

How a fiscal expansion influences the transmission of monetary policy to credit allocation to private firms is also a general issue relevant to other economies as well. Although we discuss bank credit to SOEs in the context of China, the policy effect on credit allocation in favor of firms that enjoy the government's implicit or explicit guarantee is of general interest. In the United States, for instance, massive monetary stimulus (quantitative easing) after the 2008 global financial crisis targeted mortgage loans guaranteed by government-sponsored enterprises (Di Maggio, Kermani, and Palmer, 2020). As Besley (2009) notes, "it is possible for central banks to distort the allocation of credit, causing excess credit creation in some areas. Thus, it is important to consider the sectoral credit impact as well as the aggregate effects."

In addition to the literature discussed above, our paper relates to two other strands of literature. One strand studies the impacts of unconventional monetary policy on bank lending. ${ }^{6}$ By "unconventional" we mean monetary stimulus through increases in money supply or

\footnotetext{
${ }^{5}$ The vector autoregressive (VAR) system in our first stage needs to be structured differently and on a case-by-case basis. A recent paper by Caldara and Kamps (2017) discusses the difficulty of identifying U.S. fiscal policy and offers a solution within the structural VAR framework with non-fiscal instruments such as monetary policy shocks.

${ }^{6}$ See, for example, Foley-Fisher, Ramcharan, and Yu (2016), Kandrac and Schlusche (2017), Rodnyansky and Darmouni (2017), Acharya, Eisert, Eufinger, and Hirsch (2019), Cloyne, Ferreira, and Surico (2020), and Chakraborty, Goldstein, and MacKinlay (2020).
} 
liquidity injection instead of lowering interest rates. Most of these previous studies examine the impacts of the Federal Reserve's large scale asset purchases (LSAPs) on the financial market or the credit market during and after the 2008 financial crisis, with a finding that increases of bank credit in response to massive monetary stimulus were disproportionate across different types of firms or loans. The other strand of literature studies the effectiveness of infrastructure investment in the 2009 American Recovery and Reinvestment Act with mixed findings. ${ }^{7}$ Our paper complements these strands of literature by placing a special emphasis on whether infrastructure investment undermines or enhances the effectiveness of monetary policy in channeling bank loans to business investment of private firms, a perspective largely overlooked by the existing literature.

Our finding of positive impacts of infrastructure investment on the transmission of monetary policy to SOE loans and negative impacts on loans to private firms has broad implications, as similar effects of infrastructure investment may apply to other economies in which some firms enjoy the government's implicit guarantee on loans associated with governmentsponsored projects while many other firms do not. As Ramey (2013) notes, "[o]ne of the ways that government purchases may stimulate the economy is that it allows firms (with government contracts) easier access to credit. A key question, though, is whether this credit demand is crowding out loans for other private companies that do not have contracts with the government." Although SOEs are specific to China, firms that have explicit or implicit government guarantees on their borrowings are prevalent in many other economies.

The rest of the paper is organized as follows. Section II provides necessary institutional facts that are highly relevant to our empirical studies. Section III describes the datasets used for our estimation and provides relevant summary statistics. Section IV proposes a two-stage dynamic empirical framework comprised of both macro and micro models. The estimated elasticities and dynamic impacts of the 2009 monetary stimulus on credit allocation are discussed in Section V. Section VI explores other issues related to monetary stimulus. Section VII addresses how important the fiscal-monetary interaction channel is in transmitting a monetary expansion to business investment via bank lending. Section VIII offers concluding remarks.

\section{InstitutionAL BACKGROUND}

II.1. Monetary and fiscal policies prior to 2009. Prior to 1994, China's monetary policy was under inordinate influence of its fiscal authority. Fiscal deficits were primarily financed by the central bank. At the end of 1993, however, the Chinese government announced its decision to decouple monetary policy from fiscal policy completely. On December 25, 1993, the State Council issued the well-known No. 19 notice "Decision of the State Council on Reform of the Financial System." This notice stated the twofold goal of the financial reform. At the macro level, the central bank was to establish a regulatory system that

${ }^{7}$ See, among others, Wilson (2012), Feyrer and Sacerdote (2012), Leduc and Wilson (2013), Conley and Dupor (2013), Leduc and Wilson (2017), Ramey (2019), and Garin (2019). 
was independent of control by the fiscal authority and allowed the monetary authority to implement its policy away from the influence of the fiscal authority. At the micro level, a financial system was established to separate commercial banks' lending business from direct lending from the government through its own policy banks. This separation allowed commercial banks to make loans based on their own profitability.

The People's Bank of China Law enacted in 1995 explicitly forbade the PBC from lending directly to local governments, non-banking firms, or individuals, and from providing loan guarantees to these entities. To strengthen separation of monetary policy from fiscal policy, the PBC was not allowed to purchase government bonds issued by the Ministry of Finance or to finance local government debts. Prior to 2009, moreover, local governments were restrained from tapping loans from commercial banks to finance infrastructure investment.

China's monetary policy has been quantity-based until recently. Unlike monetary policy in the U.S. or other developed countries, the PBC did not target any interest rate but growth of M2 supply set by the State Council and officially announced by the People's Congress each year. For institutional details of how the PBC was successful in utilizing various tools to keep its targeted M2 growth on track, see Chen, Ren, and Zha (2018).

II.2. China's stimulus package in 2009. In response to the 2008 global financial crisis, China implemented a series of stimulus measures to support the government's four trillion RMB investment plan. Although the media focused its attention on the initial four trillion figure itself, actual stimulus measures comprised a combination of the fiscal initiative in various projects and a regime switch of monetary policy to massive liquidity injections into the banking system. ${ }^{8}$

The investment plan announced by Premier Wen Jiabao on 5 November 2008 was to fund a number of investment projects with four trillion RMB (the equivalent of 586 billion USD). The plan targeted seven key areas of investment and the most important area was infrastructure. Investment in infrastructure was funded by 1.87 trillion RMB, which accounted for $46.8 \%$ of all investment funding in the stimulus package. ${ }^{9}$ The infrastructure spending included 1.5 trillion RMB for transport and power infrastructure such as railways, roads, airports, water conservation, and urban power grids, and 0.37 trillion RMB for rural village infrastructure. In the 2009 Report on the Work of Government (RWG), infrastructure investment was given priority for the purpose of boosting domestic demand and sustaining GDP growth. ${ }^{10}$ By contrast, the American Recovery and Reinvestment Act passed in February 2009 authorized only 70 billion out of the 800 billion USD stimulus package to financing investment in infrastructure and transportation (Boehm, 2020).

\footnotetext{
${ }^{8}$ The other stimulus measures included tax cuts and SOE bailouts (Wong, 2011).

${ }^{9}$ The remaining investment funding included 1 trillion RMB for earthquake reconstruction, 0.40 trillion RMB for affordable housing, 0.15 trillion RMB for health and education, and 0.58 trillion RMB for environment protection and technological innovations.

${ }^{10}$ For the details of the State Council's 2009 RWG, see http://www.gov.cn/test/2009-03/16/ content_1260221_2.htm.
} 
Infrastructure projects in China played a shovel-ready role in speedy implementation of the government's fiscal stimulus plan. According to the announcement by the Ministry of Finance, $44.4 \%$ of the central government's planned 908 billion RMB public investment for 2009 was already completed by April 1 of that year, most of which was allocated to infrastructure projects. Although the original stimulus plan was to allocate all funding over 27 months from the fourth quarter of 2008 through 2010, a majority of infrastructure funding was spent by the end of 2009. As can be seen from Figure 2, the year-over-year growth rate of real infrastructure investment in the first three quarters of 2009 reached as high as 36\%. Most of infrastructure investment was initiated by local governments. All infrastructure firms, SOEs and non-SOEs, were encouraged by the central government to actively participate in infrastructure projects (see Section II.3 for detailed discussions).

Although the real estate sector was not part of the post-2008 investment plan, the central government changed various policies in favor of real estate at the end of 2008 and in 2009. In October 2008, for example, the government reduced the minimum mortgage interest rate to $70 \%$ of the benchmark interest rate and the down payment ratio for a second home to $30 \%$ of the purchase price. According to the State Council's No. 27 notice issued in May 2009, the minimum ratio of capital to assets for real estate developers was reduced to $20 \%$.

Another key component of the stimulus package was monetary stimulus. The State Council's 2009 RWG planned an extraordinary increase in M2 to provide ample liquidity to the banking system. As a result, monetary policy switched to an unprecedentedly accommodative regime with year-over-year growth of M2 reaching over $25 \%$ by the end of 2009 (Figure 1). In December 2008, the State Council issued a decree that called on commercial banks to increase lending to key nonfinancial sectors such as infrastructure and encouraged commercial banks to provide credit support for "sound enterprises that faced temporary financial difficulties." 11 With the banking system saturated with M2 liquidity in 2009, the PBC and the China Banking Regulatory Commission (CBRC) in March 2009 jointly issued a notice that called on commercial banks to provide credit support for qualified large-scale central government investment projects by adjusting their loan compositions. ${ }^{12}$

Commercial banks responded to this notice swiftly. For instance, the Industrial and Commercial Bank of China, one of the five largest state banks in China, stated in its 2009 Annual Report: "The bank accelerated adjustment of its credit policies and promoted production innovations by increasing credit support to major customers in infrastructure areas and disbursements of loans for medium-term to long-term quality projects that are in line with the orientation of the state policy of boosting domestic demand." As a result, newly issued bank loans reached 9.6 trillion RMB in 2009, of which 7.1 trillion RMB was allocated to the public sector.

\footnotetext{
${ }^{11}$ For official details, see http://www.csrc.gov.cn/pub/shenzhen/xxfw/tzzsyd/ssgs/zh/ zhxx/201409/t20140918_260555.htm.

${ }^{12}$ See http://www.gov.cn/gongbao/content/2009/content_1336375.htm.
} 
II.3. Funding sources of infrastructure investment. The central government was committed to funding $29.5 \%$ of the four trillion RMB investment plan (1.18 trillion RMB), and over $80 \%$ of this financial commitment from the central government was planned for the year 2009. According to the 2009 RWG, the central government budget deficit of 750 billion RMB in 2009, 570 billion RMB more than the 2008 budget deficit, was to be financed by issuing government bonds. The remaining 2.82 trillion RMB in the investment plan was to be funded by local government budgets, corporate bonds, private funds, and bank loans. This financing arrangement was in contrast to the stimulus program in the U.S., which was funded largely through federal government debt. Under the 1994 Budget Law (i.e. the "Old Budget Law" that was in effect until January 1, 2015), however, a local government in China was prohibited from borrowing from commercial banks or issuing municipal bonds. To meet the funding needs of local governments for implementing the investment plan, the central government issued additional government bonds in the amount of 200 billion RMB for local governments that participated in the investment plan. The total central government deficit was planned to be $3 \%$ of GDP (950 billion RMB).

Most of the literature on China focuses exclusively on the manufacturing sector. Since the infrastructure sector received disproportionately more bank loans for investment projects than did any other sector during the stimulus period, however, it is necessary to conduct a detailed empirical analysis for the economy beyond the manufacturing sector. We follow NBS's Industrial Classification for National Economic Activities, National Industrial Classification (NIC) for short, for our sectoral classification. ${ }^{13}$ For example, the manufacturing sector is classified by NIC code $\mathrm{C}$ and the real estate sector by NIC code $\mathrm{K}$.

The most important sector during the stimulus period was infrastructure. According to the existing literature (Jin, 2012, 2016; Wu, Feng, and Wang, 2016), the infrastructure sector is composed of (1) production and supply of electricity, gas, and water (NIC code D); (2) transportation, storage, and postal service (NIC code G); (3) management of water, conservancy, environment and public facilities (NIC code I); and (d) information transmission, computer services, and software (NIC code N). The manufacturing sector, classified by NIC code $\mathrm{C}$, contains subindustries that manufacture railway, shipping, aerospace, and other transportation equipment (NIC code C37). The infrastructure sector does not include these manufacturing subindustries or other subindustries such as construction of railways, roads, and airports (NIC code E48), but rather transportation subindustries such as railway transportation (NIC code G53), highway transportation (NIC code G54), water transportation (NIC code G55), and aviation transportation (NIC code G56).

The classification of the infrastructure sector by NIC codes D, G, I, and N is consistent with industries targeted by the fiscal plan for the government's four trillion RMB investment

\footnotetext{
${ }^{13}$ See the document that can be accessed with the link http://www.stats.gov.cn/tjsj/tjbz/ hyflbz/201905/P020190716349644060705.pdf. Table S.1 in Appendix A provides a mapping between our classified sectors and NBS's one-digit sectors.
} 
and funded by commercial banks as reported by the PBC. The largest part (1.5 trillion RMB) of the four trillion RMB investment plan was for transportation industries (NIC codes G53G56), not for manufacturing or construction industries (NIC codes C37 and E48). ${ }^{14}$ This fiscal plan was supported by the expansion of bank credit to these industries. According to our loan-level data, bank loans newly issued to transportation industries (NIC codes G53G56) amounted to 1.43 trillion RMB in 2009, while those to manufacturing and construction industries (NIC codes C37 and E48) were less than 680 billion RMB. Moreover, the PBC's official statistics (China Regional Financial Operation Report) reported that the amount of medium and long term bank loans newly issued to infrastructure industries was 2.5 trillion RMB in 2009. ${ }^{15}$ This amount is corroborated by our dataset from the 17 largest commercial banks: newly increased loans for infrastructure industries amounted to 2.14 trillion RMB in 2009.

\section{DATA DESCRIPTION AND SUMMARY STATISTICS}

In this section, we describe the loan-level and firm-level database used for our empirical work and provide summary statistics for both macro and micro data.

III.1. Data description. Our loan-level database covers all newly issued bank loans to borrowers with an annual credit line over 50 million RMB (approximately 8 million USD) from January 2007 to June 2013. The coverage is comprehensive across sectors throughout the economy. ${ }^{16}$ It consists of over 7 million individual loan contracts granted by the 17 largest Chinese banks to more than 160,000 unique firms with a specific identifier (i.e. the 9-digit corporate organization code). The borrowers are located in all 31 provinces and autonomous regions and over 90 two-digit industries according to the Economic Industrial Classification Code. We sum up all individual loans for a particular firm in a given quarter to create a firm-quarter dataset from 2007Q1 to 2013Q2. ${ }^{17}$

The loan variable used throughout the paper is the amount of newly issued loans with maturity greater than three years in each firm-quarter. Most of these loans have a maturity greater than five years for investment purposes. Our micro data on newly issued loans with maturity greater than three years is comparable to the aggregate time series of bank loans for fixed asset investment (FAI), which can be obtained from CEIC (a database for financial

\footnotetext{
${ }^{14}$ See the official document from the central government of China: http://www.gov.cn/gzdt/ 2009-03/06/content_1252229.htm.

${ }^{15}$ See http://www.gov.cn/gzdt/2010-06/08/content_1623341.htm and http://www.gov. $\mathrm{cn} / \mathrm{gzdt} / 2010-01 / 20 /$ content_1515740.htm.

${ }^{16}$ Total outstanding loans from our loan-level data cover at least $80 \%$ of aggregate outstanding amount of nonfinancial corporate loans reported by the NBS.

${ }^{17}$ Our data does not cover shadow banking loans to firms or interbank bonds. As Chen, Ren, and Zha (2018), Chen, He, and Liu (2020), and Amstad and He (2020) show, shadow banking and interbank bonds were not active during the stimulus period. Since neither shadow banking nor the interbank bond market took off until after our sample period, the main message of this paper shall still hold without taking into explicit account firms' financing via shadow banking or interbank bond markets.
} 
and economic indicators). There are, however, two major differences between the CEIC aggregate time series and the aggregate series constructed from our loan-level dataset. One difference is that our micro data excludes bank loans to firms with an annual credit line of less than 50 million RMB while the CEIC macro data includes all investment loans. In this respect, the aggregated loans to infrastructure from our micro data source are less than those from the CEIC's macro data source. In 2010, for example, infrastructure loans as a percent of GDP is $4.59 \%$ from our data source and $4.75 \%$ from the CEIC's data source. On the other hand, loans for FAI from the CEIC's aggregate data source are calculated as an increase of outstanding loans from the outstanding balance in the previous year, while our micro data source provides newly issued bank loans. Since some existing loans may be retired at any given time, the loans aggregated with the bottom-up calculation from our micro data source can be larger than those from the CEIC's aggregate data source. In 2009, for instance, infrastructure loans as a percent of GDP is $6.21 \%$ from our data source and only $4.73 \%$ from the CEIC's data source.

Quarterly data on capital expenditure is obtained from the CSMAR. This database includes all listed firms on both the Shanghai and Shenzhen Stock Exchanges and contains information about bank and firm identifiers. In the investment regression studied in Section VII, we merge our newly issued loan data with the CSMAR firm-level investment data, and the sample period of the merged data is from 2007Q1 to 2013Q2 to be consistent with the bank loan regression studied in the rest of the paper. For the lagged variables in our investment regression, we use the CSMAR data prior to 2007Q1. When selecting a sample for our regressions, we remove an observation if the dependent variable or any of the regressors is missing, or if the denominator in a ratio variable we construct is zero.

For both loan-level and firm-level data, we categorize sampled firms into two groups: SOEs and non-SOEs. We define a firm's ownership type according to its official registration status. ${ }^{18}$ To obtain information of a firm's registration type, we first merge our data with the firm-level panel data from the Chinese Industry Census (CIC) between 1998 and 2013. The CIC database includes all SOEs and non-SOEs with gross sales exceeding five million RMB (the cutoff standard was increased to 20 million RMB in 2011) in the industrial sector (i.e. manufacturing, mining, and utilities). We use firms' registration information from the CIC database to identify the registration type of a firm belonging to the industrial sector.

Although the CIC database has comprehensive coverage of China's industrial firms, it does not cover firms outside the industrial sector. To obtain the registration information of non-industrial sectors, we supplement our data with the information provided by two additional data sources. First, we use the data of the 2008 National Economic Census to identify a non-industrial firm's ownership type. Second, for those with missing information

\footnotetext{
${ }^{18}$ See also Brandt, Van Biesebroeck, and Zhang (2012), Yu (2015), Ma, Qiao, and Xu (2015), Wang and Wang (2015), Bai, Lu, and Tian (2016), Berkowitz, Ma, and Nishioka (2017), and Wu (2018) for using information about a firm's registration type to define SOE.
} 
on ownership type in the census data, we manually search for the firm's registration type in the National Enterprise Credit Information Publicity System (NECIPS). The information provided by the 2008 National Economic Census and the NECIPS enables us to determine whether an unlisted firm is an SOE or not. For listed firms, in addition to the merged information, we also use the ultimate controller information. Taken together, a listed firm is an SOE if the firm's ultimate controller is the central government or a local government, or if the firm's registration type equals "110" (i.e. state-controlled enterprises) or "151" (i.e. solely state-owned enterprises).

III.2. Summary statistics. The top panel of Figure 3 displays the ratio of aggregated newly issued bank loans to GDP. This ratio was, on average, 5.65\% during 2007-2008. During the 2009 monetary stimulus, it increased sharply to $17.24 \%$ in 2009Q2 before it declined afterwards. The increase of newly issued loans was concentrated in the first three quarters of 2009, a period identified by Chen, Ren, and Zha (2018) as monetary stimulus. The bottom panel of Figure 3 displays the net increase in the ratio of newly issued bank loans to GDP for both the aggregate economy and the infrastructure sector relative to their 2007Q1-2008Q4 average levels. For the aggregate economy, the net quarterly increase of newly issued loans from the 2007Q1-2008Q4 average level was on average 9.07\% (3.76\%) of GDP during 2009Q12009Q3 (2009Q4-2010Q4), with a peak value of almost 12\% of GDP in 2009Q2. Thus, the net increase of total newly issued loans during 2009Q1-2010Q4 was 4.97 trillion RMB, consistent with the Chinese government's original four trillion RMB investment plan. The net quarterly increase of newly originated bank loans for infrastructure had a similar pattern during the stimulus period, peaking at 6\% of GDP in 2009Q2 relative to the 2007Q1-2008Q4 average level. From 2009Q1 to 2010Q4, the net increase of bank loans to infrastructure from the 2007Q1-2008Q4 average level was 2.28 trillion RMB or $45.9 \%(2.28 / 4.97)$ of the total net increase of bank loans to the entire economy, consistent with the share of infrastructure investment in the four trillion RMB investment plan. ${ }^{19}$

Figure 4 displays the net increase of bank loans (as a percent of GDP) newly issued to all firms and to SOEs from the 2007-2008 average level for the Chinese economy and its key sectors. Infrastructure accounted for about $50 \%$ of the net increase in total newly originated loans. By contrast, manufacturing accounted for $18 \%$ of the net increase in newly originated bank loans and real estate $12 \%$. The increase of SOE loans relative to total loans was unevenly distributed across sectors. The largest increase in SOE loans occurred in the infrastructure sector, reflecting the government's support and encouragement of commercial banks to finance investment projects in this sector during the 2009 stimulus period.

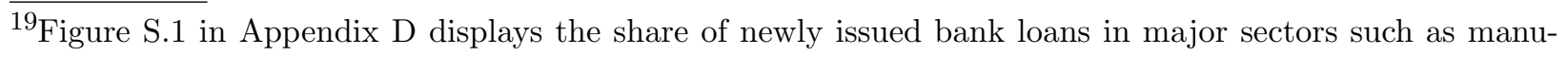
facturing and infrastructure. Clearly, loans to the infrastructure sector were largest among all bank loans during the stimulus period, contributing to between $40 \%$ and $50 \%$ of all newly issued loans for most years in 2007-2013. Only $20 \%-27 \%$ of total loans were allocated to manufacturing, $10 \%-20 \%$ to real estate, and the remaining $12 \%-21 \%$ to the remaining economy.
} 
Table 1 provides summary statistics for our firm-quarter loan sample (see Appendix A for detailed definitions of variables). Both the mean and median of newly issued bank loans in the entire economy are considerably higher than those in manufacturing. The mean and median of assets for an average economy-wide firm, however, are lower than those for an average manufacturing firm, revealing that an average economy-wide firm is more leveraged than an average manufacturing firm. For instance, the average loan size is 143.71 million RMB for an average economy-wide firm with 3,438.37 million RMB assets, in comparison to 121.68 million RMB for an average manufacturing firm with 3821.78 million RMB assets. The guaranteed loan ratio for an average economy-wide firm is lower than an average manufacturing firm. In particular, the median guaranteed loan ratio for an economy-wide firm is only $2.90 \%$, compared to $39.40 \%$ for a manufacturing firm.

A comparison of summary statistics shows significant heterogeneity across major sectors. The median value of a guaranteed fraction of loans for manufacturing firms is over $39 \%$, while the median value is close to zero for firms in other sectors. A loan guarantee by a third party is typically used by a borrower with a lack of asset pledgeability to obtain a particular loan from a bank. Thus, a high fraction of loans guaranteed by third parties suggests that manufacturing firms have more financing difficulties than firms in other sectors. The infrastructure sector has on average the largest loan size (196.94 million RMB), a value significantly higher than that in other sectors. The average loan size (i.e., the loan size per firm-quarter) in the manufacturing sector (121.68 million RMB) is slightly higher than that in the real estate sector (116.96 million RMB), but the opposite was true for the median loan size (60 milion RMB versus 80 million RMB). On average, the infrastructure sector has the largest total assets, the highest leverage ratio, and the highest non-performing loan ratio.

The credit spree in the infrastructure sector influences how bank credit was allocated to non-SOEs in manufacturing as well as in other parts of the economy. Table 2 compares the summary statistics of non-SOEs between the infrastructure sector and the other major sectors. The average size of newly originated loans to non-SOEs is the largest in the infrastructure sector, with 138.83 million RMB per firm-quarter, followed by the real estate sector. Since non-SOEs in infrastructure and real estate are more capital intensive than those in other sectors, these summary statistics indicate that bank loans are more likely to be allocated to capital-intensive non-SOEs than labor-intensive ones. For total assets, leverage, non-performing loans, and the loans-to-assets ratio, non-SOEs in the infrastructure sector have the highest values and the differences between non-SOEs in infrastructure and other sectors was statistically significant at the 0.01 level.

Non-SOEs in sectors other than infrastructure exhibited several distinct characteristics. Non-SOEs in real estate had the largest median sizes of both bank loans and total assets, but the smallest mean size of total assets. By contrast, the median loan size for non-SOEs in manufacturing is the smallest in all major sectors, consistent with the fact that nearly half of 
bank loans received by manufacturing non-SOEs were guaranteed by third parties. Clearly, non-SOEs in manufacturing tended to have poorer credit than those in other sectors.

\section{THE TWO-STAGE DYNAMIC EMPIRICAL FRAMEWORK}

In this section, we develop a two-stage empirical framework to assess the impacts of monetary stimulus on loan allocation between SOEs and non-SOEs and the role of infrastructure spending in monetary transmission. Our framework establishes the nexus between a dynamic panel model and a dynamic macro model. We show that this linkage is essential for estimating the effects of aggregate policy shocks on credit allocation at the firm level. The dynamic panel model in the second stage requires proper controls for aggregate shocks other than monetary policy changes, which are extracted by the dynamic macro model in the first stage. We discuss first the dynamic panel model, which constitutes the core of our empirical framework, and then the dynamic macro model in the first stage.

IV.1. The dynamic panel model in the second stage. In this section, we first propose a quarterly panel regression based on our firm-quarter loan data and then discuss the endogeneity issue that our two-stage approach is designed to address.

IV.1.1. The quarterly panel regression. We begin with key right-hand variables used in the dynamic panel regression. We denote an exogenous monetary policy change by $\varepsilon_{m, t}$, whose construction is discussed in Section IV.2.1, and quarterly growth of infrastructure investment by $g_{\text {infra,t }}$. An individual firm's loan amount, $\mathfrak{b}_{i, j, t}$, is affected by both infrastructure investment growth $g_{\text {infra, } t}$ and monetary policy shock $\varepsilon_{m, t}$. Because the fluctuation of infrastructure investment is partly driven by monetary policy shocks, however, we need to remove the effects of these shocks on infrastructure investment in the first stage of our analysis. This separation is necessary for assessing how infrastructure investment interacts with monetary stimulus on loan allocation to an individual firm $\left(\mathfrak{b}_{i, j, t}\right)$.

We denote quarterly growth of infrastructure investment absent monetary policy shocks by $g_{\text {infra, },}^{o}$. In Section IV.2.2, we provide an analysis of the first stage of our empirical framework and show how to use a structural macro model to extract $g_{\text {infra, } t}^{o}$ from $g_{\text {infra, } t}$. After we separate the monetary effects from other effects in the first stage, we proceed to estimate the following quarterly dynamic panel regression for the $j^{\text {th }}$ type of firm:

$$
\mathfrak{b}_{i, j, t}=c^{i, j}+\rho^{j} \mathfrak{b}_{i, j, t-1}+\sum_{k=0}^{\ell}\left[b_{k}^{j} g_{\text {infra }, t-k}^{o} \varepsilon_{m, t-k}+d_{k}^{j} \varepsilon_{m, t-k}\right]+c_{\chi}^{j \prime} \chi_{t}^{o}+c_{z}^{j \prime} z_{i, j, t-1}+\eta_{i, j, t},
$$

where $j \in\{$ SOEs, non-SOEs, all firms $\}$ is a firm type, $\mathfrak{b}_{i, j, t}=\frac{\mathcal{N}_{i, j, t}}{\mathcal{A}_{i, j, t-1}}$ denotes the borrowings of individual firm $i$ within the $j^{\text {th }}$ type of firms at time $t$, measured as newly issued bank loans $\left(\mathcal{N}_{i, j, t}\right)$ in period $t$ to be divided by firm $i$ 's total assets $\left(\mathcal{A}_{i, j, t-1}\right)$ in period $t-1 .{ }^{20}$ Since

\footnotetext{
${ }^{20}$ We seasonally adjust both new borrowings and assets for each individual firm in the sample. See Appendix A for a detailed description.
} 
a firm can borrow from multiple banks, our firm-level estimation allows one to obtain the monetary effect on the firm's total credit.

The symbol $\chi_{t}^{o}$ denotes a vector of aggregate control variables that are driven by nonmonetary aggregate factors, ${ }^{21} \ell$ is the lag length, $c^{i, j}$ captures firm fixed effects, the vector $z_{i, j, t}$ controls for an array of firm specific characteristics such as the size and leverage of a firm, and the random residual $\eta_{i, j, t}$ is iid distributed. The firm fixed effects control for the unobserved time-invariant firm heterogeneity (e.g. location and industry), which allows one to explore the time variation of bank loans within the same firm.

The coefficients of interest are $b_{k}^{j}$ and $d_{k}^{j}$. The estimate of $b_{k}^{j}$ measures the interactive effect of monetary policy with infrastructure investment, and the estimate of $d_{k}^{j}$ measures the pure effect of monetary stimulus absent the fiscal expansion via infrastructure investment. Thus, the overall effect of a monetary policy shock at time $t-k$ is $=b_{k}^{j} g_{\text {infra,t-k}}^{o}+d_{k}^{j}$. It measures the elasticity of bank credit to a monetary policy shock $\left(\partial(\cdot) / \partial \varepsilon_{m, t-k}\right)$ : how many percentage points bank credit will increase in response to a one percent increase in exogenous quarterly M2 growth. When growth of infrastructure investment $g_{\text {infra, } t-k}^{o}$ is zero, the elasticity becomes the pure effect of monetary stimulus, measured by $d_{k}^{j}$. When there is growth of infrastructure investment, the elasticity is affected by $b_{k}^{j} g_{\text {infra, } t-k}^{o}$. The coefficient $b_{k}^{j}$ is an outcome of second-order partial derivatives $\left(\partial^{2}(\cdot) / \partial g_{\text {infra, },-k}^{o} \partial \varepsilon_{m, t-k}\right)$. It measures how a change in $g_{\text {infra, } t-k}^{o}$ affects the elasticity of bank credit to an exogenous monetary policy shock $\varepsilon_{m, t-k}$. For example, a negative estimate of $b_{k}^{j}$ implies that an increase of infrastructure investment reduces the overall effect of monetary stimulus. In this case, the elasticity of bank credit to a monetary policy shock is smaller than what is implied by the pure effect of a monetary policy shock.

In short, the pure effect captures the impact of monetary stimulus on credit allocation absent the infrastructure spree spurred by non-monetary factors such as fiscal shocks. The interactive effect takes into account how infrastructure investment influences the transmission of monetary stimulus to credit allocation among different types of firms. These two effects constitute the two channels for monetary stimulus to affect a firm's total credit: the monetary transmission channel and the fiscal-monetary interaction channel.

IV.1.2. Endogeneity issue. A key variable in panel regression (1) is $g_{\text {infra, } t-k}^{o}$, which interacts with monetary policy shocks to affect credit allocation. We now show that obtaining $g_{\text {infra }, t-k}^{o}$, infrastructure investment growth absent monetary shocks, is necessary for obtaining the unbiased estimate of $b_{k}^{j}$, the coefficient for the interaction between $g_{\text {infra,t-k}}^{o}$ and $\varepsilon_{m, t-k}$, in the second stage.

In estimation, if one simply uses the observed variable $g_{\text {infra, } t-k}$ as a proxy for $g_{\text {infra, } t-k}^{o}$ for estimation of model (1), both $g_{\text {infra,t-k}}^{m}$ and $g_{\text {infra,t }}^{m} \varepsilon_{m, t-k}$ will enter the regression residual and thus make the residual correlate with interaction terms, where $g_{\text {infra, } t}^{m}$ is the growth rate

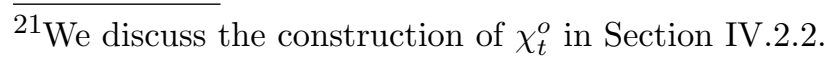


of infrastructure investment driven by monetary policy changes. To see this crucial point, consider a special case in which $\ell=0$. Substituting $g_{\text {infra, } t}$ for $g_{\text {infra, } t}^{o}$ in regression $(1)$, we have

$$
\mathfrak{b}_{i, j, t}=c^{i, j}+\rho^{j} \mathfrak{b}_{i, j, t-1}+b_{0}^{j} g_{\text {infra }, t} \varepsilon_{m, t}+d_{0}^{j} \varepsilon_{m, t}+c_{\chi}^{j \prime} \chi_{t}+c_{z}^{j \prime} z_{i, j, t-1}+\tilde{\eta}_{i, j, t},
$$

where $\tilde{\eta}_{i, j, t}=\eta_{i, j, t}-b_{0}^{j} g_{\text {infra, },}^{m} \varepsilon_{m, t}-c_{\chi}^{j \prime} \chi_{t}^{m}$, the aggregate control vector $\chi_{t}$ is

$$
\chi_{t} \equiv\left[\begin{array}{llllll}
g_{\tilde{y}, t-1} & \pi_{t-1} & g_{\text {infra }, t} & g_{\text {infra }, t-1} & \cdots & g_{\text {infra }, t-\ell}
\end{array}\right]^{\prime},
$$

and $\chi_{t}^{m}$ is the corresponding vector influenced only by monetary policy changes (i.e., $\chi_{t}^{m}=$ $\left.\chi_{t}-\chi_{t}^{o}\right)$. The presence of $b_{0}^{j} g_{\text {infra }, t}^{m} \varepsilon_{m, t}$ in $\tilde{\eta}_{i, j, t}$ creates an attenuation bias of the estimated coefficient $b_{0}^{j}$ toward zero. The presence of $c_{\chi}^{j \prime} \chi_{t}^{m}$ creates additional downward bias if $b_{0}^{j}$ and $c_{\chi}^{j \prime}$ have the same sign. In general, since both regressors $g_{\text {infra, } t} \varepsilon_{m, t}$ and $\varepsilon_{m, t}$ are correlated with the error term $\tilde{\eta}_{i, j, t}$, the estimates of $b_{0}^{j}$ and $d_{0}^{j}$ are biased - a typical endogeneity problem. ${ }^{22}$ To resolve this problem, we first obtain $\varepsilon_{m, t}, g_{\text {infra, },}^{o}$, and aggregate control variables contained in $\chi_{t}^{o}$ prior to estimation of panel regression (1). We then use these non-monetary aggregates in the second-stage panel regression. The next section presents an in-depth analysis of firststage estimation.

IV.2. The macro model in the first stage. The macro model in the first stage is a VAR model that includes both monetary policy and infrastructure investment equations as well as two other equations about feedback between policies and macroeconomic conditions. We first describe the monetary policy equation and use it to obtain exogenous monetary policy shocks, and then discuss the subsystem for the remaining equations of the VAR model, the identification strategy, and a decomposition of macroeconomic variables into monetary and non-monetary components. In a final subsection, we test two key assumptions underlying our identification strategy.

IV.2.1. The monetary policy equation. As stressed in the macro-finance literature, ${ }^{23}$ identification of exogenous monetary policy changes is a first-order issue when assessing the impacts of monetary policy on the real economy in general and the banking system in particular. To obtain these exogenous changes, we use Chen, Ren, and Zha (2018)'s regime-switching monetary policy equation specified as

$$
g_{m, t}=\gamma_{0}+\gamma_{m} g_{m, t-1}+\gamma_{\pi}\left(\pi_{t-1}-\pi^{*}\right)+\gamma_{y, t}\left(g_{y, t-1}-g_{y, t-1}^{*}\right)+\sigma_{m, t} \xi_{m, t},
$$

where $\xi_{m, t}$ is a serially independent random shock with the standard normal distribution, $g_{m, t}=\Delta \log M_{t}$ is quarterly growth of M2 denoted by $M_{t}, \pi_{t}=\Delta \log P_{t}$ is quarterly inflation

\footnotetext{
${ }^{22}$ Appendix $\mathrm{B}$ uses the infrastructure sector as an example to illustrate this endogeneity bias. If one were to omit the first stage and directly estimate second-stage regression (1) by replacing $g_{\text {infra, } t}^{o}$ with $g_{\text {infra, } t}$ and $\chi_{t}^{o}$ with $\chi_{t}$, one would erroneously conclude that fiscal expansion of infrastructure investment would not enhance the positive effect of monetary stimulus on bank credit to infrastructure firms (Table S.2).

${ }^{23}$ See, for example, Christiano, Eichenbaum, and Evans (1999), Morais, Peydro, Roldan-Pena, and RuizOrtega (2019), and Brunnermeier, Palia, Sastry, and Sims (2021).
} 
measured by the consumer price index $(\mathrm{CPI})$ and denoted by $P_{t}, \pi^{*}$ is the average inflation rate targeted by the government, $g_{y, t}=\Delta \log y_{t}$ is quarterly growth of real GDP denoted by $y_{t}$, and $g_{y, t}^{*}=\Delta \log y_{t}^{*}$ is targeted GDP quarterly growth. The time-varying coefficients take the form of

$$
\gamma_{y, t}=\left\{\begin{array}{ll}
\gamma_{y, a} & \text { if } g_{y, t-1}-g_{y, t-1}^{*} \geq 0 \\
\gamma_{y, b} & \text { if } g_{y, t-1}-g_{y, t-1}^{*}<0
\end{array} \quad, \sigma_{m, t}=\left\{\begin{array}{ll}
\sigma_{m, a} & \text { if } g_{y, t-1}-g_{y, t-1}^{*} \geq 0 \\
\sigma_{m, b} & \text { if } g_{y, t-1}-g_{y, t-1}^{*}<0
\end{array} .\right.\right.
$$

The subscript "a" stands for "above the target" and "b" for "below the target." From the estimates obtained by Chen, Ren, and Zha (2018) and described in Appendix C.1, one can construct a measure of total exogenous monetary policy changes, which is composed of three components:

$$
\varepsilon_{m, t}=\varepsilon_{m, t}^{\mathrm{Norm}}+\varepsilon_{m, t}^{\mathrm{Extra}}+\varepsilon_{m, t}^{\mathrm{PolCh}}
$$

where $\varepsilon_{m, t}^{\text {Norm }}=\sigma_{m, a} \xi_{m, t}, \varepsilon_{m, t}^{\text {Extra }}=\left(\sigma_{m, t}-\sigma_{m, a}\right) \xi_{m, t}$, and $\varepsilon_{m, t}^{\text {PolCh }}=\left(\gamma_{y, t}-\gamma_{y, a}\right)\left(g_{y, t-1}-g_{y, t-1}^{*}\right)$. The 2009 monetary stimulus is measured by $\varepsilon_{m, t}^{\text {Stim }}=\varepsilon_{m, t}^{\text {Extra }}+\varepsilon_{m, t}^{\text {PolCh }}$. By construction, $\varepsilon_{m, t}^{\text {Extra }}=0$ and $\varepsilon_{m, t}^{\mathrm{PolCh}}=0$ for the period prior to 2009Q1.

IV.2.2. Subsystem of remaining equations. To derive quarterly growth of infrastructure investment driven by aggregate shocks other than monetary policy changes, we estimate the following unrestricted system of simultaneous equations

$$
A_{0} x_{t}+b_{m, 0} \log M_{t}=c+\sum_{k=1}^{\ell} A_{k} x_{t-k}+\sum_{k=1}^{\ell} b_{m, k} \log M_{t-k}+\xi_{t}
$$

where $c$ is a $3 \times 1$ vector of constant terms, $b_{m, k}$ is a $3 \times 1$ coefficient vector, $A_{k}$ is a $3 \times 3$ coefficient matrix, and

$$
x_{t}=\left[\begin{array}{lll}
\log y_{t} & \log P_{t} & \log i_{\text {infra }, t}
\end{array}\right]^{\prime} .
$$

The vector of other aggregate shocks represented by $\xi_{t}$ is normally distributed with mean zero and identity covariance matrix; these shocks are orthogonal to $\xi_{m, t} \cdot{ }^{24}$

The unrestricted subsystem represented by equation (3) is needed to decompose each of the three macroeconomic variables - GDP growth, inflation, and infrastructure spendinginto two orthogonal components: one driven by monetary shocks and the other driven by non-monetary shocks. This decomposition is necessary to resolve the endogeneity issue in the second stage of the estimation as discussed in Section IV.1.2. Subsystem (3) consists of three equations that determine these three variables. One equation captures the fact that fiscal policy via infrastructure investment may endogenously respond to M2 and other economic conditions such as output growth and inflation. The remaining two equations allow feedback from monetary and fiscal policies to GDP and the aggregate price level.

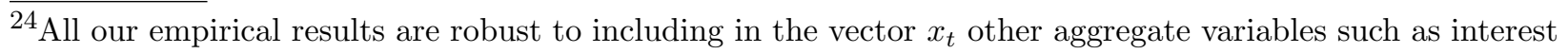
rates and reserves in the banking system. 
To avoid potential model misspecification, we impose the minimum number of assumptions to achieve our identification that separates monetary policy shocks from infrastructure spending. Specifically, monetary policy does not respond to infrastructure spending directly as in equation (2). By contrast, the remaining system represented by equation (3) is unrestricted (i.e., equivalent to a reduced form system) to allow infrastructure investment to depend on monetary policy (M2). This partial identification strategy is based on China's institutional facts. The 1995 People's Bank of China Law explicitly made monetary policy independent of fiscal policy and even prohibited the PBC from purchasing government bonds. Consistent with monetary policy rules used for the United States and many other economies, China's monetary policy rule is not affected directly by fiscal policy. ${ }^{25}$

As discussed in Section II.3, China's 2009 monetary stimulus played a conspicuous role in implementing the government's plan of infrastructure investment and stimulating aggregate demands by expanding bank credit to businesses. Thus, increases in infrastructure investment, GDP, and the aggregate price level are partially driven by expansionary monetary policy. Because we have little a priori knowledge about how China's fiscal policy responds to various economic developments, our minimum identification approach gives us the advantage of allowing infrastructure investment to be influenced by the money supply targeted by monetary policy without imposing potentially incorrect restrictions. As proven in Appendix C.2 (see Proposition C.1 in the appendix), the restrictions imposed on China's monetary policy rule (the quantity-based monetary system) are sufficient for identifying the effects of monetary stimulus, while the rest of the system is able to capture true relationships among monetary policy, infrastructure investment, and other macroeconomic variables with no additional restrictions. In other words, our minimal identification approach is sufficient for identifying the two channels of monetary policy transmission: the (conventional) monetary policy channel and the channel of the interaction between infrastructure investment and monetary stimulus.

Since monetary policy is identified within the whole system, one is able to use equations (2) and (3) (i.e., the monetary policy rule and the rest of the system together) to decompose infrastructure investment, as well as any other variable included in $x_{t}$, into two orthogonal components: one driven only by monetary policy and the other driven by non-monetary factors such as fiscal shocks:

$$
x_{t}=x_{t}^{m}+x_{t}^{o}
$$

where $x_{t}^{m}$ and $x_{t}^{o}$ denote the monetary and non-monetary components of $x_{t}$. The last element in $x_{t}^{o}$ is $\log i_{\text {infra, } t}^{o}$ (the $\log$ series of infrastructure investment absent monetary policy shocks). It follows that

$$
g_{\text {infra }, t}^{o}=\log i_{\text {infra }, t}^{o}-\log i_{\text {infra }, t-1}^{o} .
$$

\footnotetext{
${ }^{25}$ Monetary policy, however, does respond to fiscal policy indirectly through output and therefore infrastructure spending.
} 
In Appendix C.3, we show that $g_{\text {infra, } t}^{o}$ is orthogonal to $\varepsilon_{m, t}$ (Proposition C.2 in the appendix) ${ }^{26}$ In Section IV.4, we test that the estimated $g_{\text {infra, } t}^{o}$ is uncorrelated with the estimated $\varepsilon_{m, t}$.

We calculate aggregate output bar infrastructure investment as $\log \tilde{y}_{t}^{o}=\log y_{t}^{o}-\log i_{\text {infra, },}^{o}$. Note that $\log P_{t}^{o}$ is the second element of vector $x_{t}^{o}$. We calculate quarterly growth rates of $\tilde{y}_{t}^{o}$ and $P_{t}^{o}$ and denote these growth rates by $g_{\tilde{y}, t}^{o}$ (output growth not affected by growth of infrastructure investment) and $\pi_{t}^{o}$. All these variables, denoted by the vector

$$
\chi_{t}^{o} \equiv\left[\begin{array}{llllll}
g_{\tilde{y}, t-1}^{o} & \pi_{t-1}^{o} & g_{\text {infra }, t}^{o} & g_{\text {infra }, t-1}^{o} & \cdots & g_{\text {infra }, t-\ell}^{o}
\end{array}\right]^{\prime},
$$

are used as aggregate controls for the effects of non-monetary aggregate shocks in the secondstage estimation. Since loan demands always move with the general economic condition, bank loans tend to fluctuate with GDP growth. We control for this indirect demand effect through GDP growth by including $g_{\tilde{y}, t-1}^{o}$ in panel regression (1).

IV.3. Dynamic responses to the 2009 monetary stimulus. In this section, we describe how to compute the dynamic impacts of the 2009 monetary stimulus to (a) capture quarterto-quarter changes in the effects of monetary stimulus alone and of its interaction with infrastructure investment and (b) assess quantitatively the relative importance of these two channels - monetary transmission and fiscal-monetary interaction - on the total effects of monetary stimulus on credit allocation.

We first estimate model (1) and denote the estimated coefficients and firm-specific idiosyncratic shock by $\hat{c}^{i, j}, \hat{\rho}^{j}, \hat{d}_{k}^{j}, \hat{b}_{k}^{j}, \hat{c}_{\chi}^{j}, \hat{c}_{z}^{j}$, and $\hat{\eta}_{i, j, t}$. With the estimates $\hat{\rho}^{j}, \hat{d}_{k}^{j}$, and $\hat{b}_{k}^{j}$, we then compute the dynamic responses of a firm's bank credit by feeding three consecutive shocks $\varepsilon_{m, 2009 \mathrm{Q} 1}^{\mathrm{Stim}}, \varepsilon_{m, 2009 \mathrm{Q} 2}^{\mathrm{Stim}}$, and $\varepsilon_{m, 2009 \mathrm{Q} 3}^{\mathrm{Stim}}$ as the values of $\varepsilon_{m, t}, \varepsilon_{m, t+1}$, and $\varepsilon_{m, t+2}$ into the following equation

$$
\mathfrak{b}_{j, t}=\rho^{j} \mathfrak{b}_{j, t-1}+\sum_{k=0}^{\ell}\left[b_{k}^{j} g_{\text {infra }, t-k}^{o} \varepsilon_{m, t-k}+d_{k}^{j} \varepsilon_{m, t-k}\right]
$$

with $\varepsilon_{m, t+k}=0$ for $k>2, \varepsilon_{m, t-k}=0$ for $k>0, g_{\text {infra, } t}^{o}=g_{\text {infra,2009Q1 }}^{o}, g_{\text {infra, } t+1}^{o}=g_{\text {infra,2009Q2 }}^{o}$, and $g_{\text {infra, } t+2}^{o}=g_{\text {infra,2009Q3 }}^{o}$. When computing and reporting the dynamic responses of $\mathfrak{b}_{j, t}$, we set $t=1, t+1=2$, etc., where $t=1$ corresponds to 2009Q1. In this computation, $\mathfrak{b}_{j, t}$ does not depend on $j$, and we set $\mathfrak{b}_{j, t-1}=0$ because the dynamic responses are the same regardless of the values of $\mathfrak{b}_{j, t-1}$ in our linear projections. The firm-level dynamic responses to the monetary stimulus during the 2009Q1-2009Q3 period are expressed as percentage changes of newly issued loans over the firm's assets. A dynamic response corresponds to a change in a firm's bank credit (as a share of the firm's assets) relative to its 2007-2008 average level. This response is decomposed into two components. The first component is the effect of infrastructure investment interacting with monetary stimulus. This component is obtained by setting $d_{k}^{j}=0$. The second component is the effect of monetary stimulus absent

${ }^{26}$ See also Proposition C.3 in Appendix C.3 for a proof of decomposition (4). 
the fiscal expansion via infrastructure investment, which is computed by setting $b_{k}^{j}=0$. The overall effect of monetary stimulus is a simple sum of these two components.

To generate $90 \%$ probability (credible) intervals for dynamic responses, we take the Bayesian approach. Appendix C.4 describes the technical details of how to generate posterior distributions of regression coefficients. Given each random draw of coefficients $\rho^{j}, \hat{b}_{k}^{j}$, and $\hat{d}_{k}^{j}$, we compute 1500 random paths of dynamic responses and tabulate the $90 \%$ probability interval of each dynamic response.

IV.4. Empirical validity of identifying assumptions. In this section, we validate two assumptions that underlie our partial identification strategy. The first is that China's monetary policy is not affected directly by fiscal policy, while infrastructure investment, together with other macroeconomic variables, are potentially affected by the money supply. The second assumption is that even with our partial identification, the estimated non-monetary component of infrastructure investment is orthogonal to monetary policy shocks.

To validate the first assumption, we regress the M2 growth series on $g_{\text {infra, } t}^{o}$ and a constant term. If infrastructure investment should enter the monetary policy rule directly, one would find the coefficient of $g_{\text {infra, } t}^{o}$ on the right side of the regression statistically significant. As the left panel of Table 3 shows, however, this estimated coefficient is statistically insignificant. This result supports our identifying assumption that China's monetary policy does not directly respond to infrastructure investment. In Section V.4, we construct a bank-specific credit change driven by monetary policy for each of the seventeen banks in our sample and regress these bank-specific monetary shocks on $g_{\text {infra, },}^{o}$. The coefficients of $g_{\text {infra, },}^{o}$, as shown in Table 4, are statistically insignificant for all but one bank.

To determine whether infrastructure investment and other macroeconomic variables are endogenous to monetary policy shocks, we compute the counterfactual paths of output by feeding in a sequence of three exogenous shocks $\varepsilon_{m, t}^{\text {Stim }}$ for $t=2009$ Q1, 2009Q2, 2009Q3, as described in Section IV.2.1. It is evident from Figure 5 that the effects of this three-quarter monetary stimulus lasted for almost two years before they became negligible by the beginning of 2011 (the long-run impact). A comparison of Figure 1 (the top chart), Figure 2, and Figure 5 reveals that the 2009 monetary stimulus explained $66 \%$ of the increase in GDP growth and $54 \%$ of the increase in infrastructure investment from 2008Q4 to 2009Q4. The remaining increases in GDP and infrastructure investment were driven by non-monetary shocks. These results bespeak not only the endogeneity of infrastructure investment and other macroeconomic variables to monetary policy shocks, but also the need to extract non-monetary components from these macroeconomic variables for the second-stage panel regression.

Our two-stage analysis relies crucially on the model property that the infrastructure investment series $g_{\text {infra, } t}^{o}$ extracted in the first stage is orthogonal to monetary policy changes 
(see Proposition C.2 in Appendix C.3). To verify the empirical validity of this model property, we regress $g_{\text {infra, } t}^{o}$ on the constant term, $g_{\text {infra, } t-1}^{o}$, and $\varepsilon_{m, t}$. The estimated coefficient of $\varepsilon_{m, t}$ is statistically insignificant (right panel of Table 3), confirming that shocks driving infrastructure investment are orthogonal to monetary policy shocks. This orthogonality, as Section IV.1.2 shows, is critical for obtaining an unbiased estimate of the effect on loan allocation of the interaction between infrastructure spending and monetary stimulus in the second stage.

\section{IMPACTS OF MONETARY STIMULUS ON CREDIT ALLOCATION}

In this section, we provide empirical evidence on dynamic impacts of the 2009 monetary stimulus on credit allocation. Since the prior literature has placed almost an exclusive emphasis on SOEs versus non-SOEs in the Chinese economy, we use this demarcation of SOE versus non-SOE throughout the paper to maintain comparability with the literature.

V.1. Decomposing the overall effect of monetary stimulus. Our empirical framework allows one to decompose the overall effect of monetary stimulus into the fiscal-monetary interactive effect and the monetary effect absent the fiscal expansion. Table 5 reports the estimated coefficients in panel regression (1) for the entire Chinese economy. Since our dynamic panel regression allows monetary policy to have lagged (dynamic) effects, both contemporaneous and lagged estimates are reported. ${ }^{27}$ Toward the bottom of each column in the table, we report the cumulative effect as the sum of the estimated coefficients across periods and the overall effect as the sum of the cumulative interactive effect and the cumulative pure effect.

Before discussing the effects of monetary stimulus on credit allocation to SOEs versus nonSOEs, it is informative to estimate the average effects of monetary stimulus on bank credit to all firms. For an average firm in the economy, the overall effect of monetary shocks on its bank loans is significantly positive (toward the bottom of column 1 in Table 5): a one percent exogenous increase in M2 growth translates into an increase in bank credit to the average firm by 1.188 percentage points (as a share of the firm's total assets). A decomposition into the fiscal-monetary interactive effect and the pure monetary effect indicates that without fiscal expansion, a one percent increase in the exogenous money supply would increase bank loans to the average firm by 1.337 percentage points. The difference between 1.337 and 1.188 percentage points measures a dampening effect of the fiscal expansion on the monetary transmission to bank credit. ${ }^{28}$

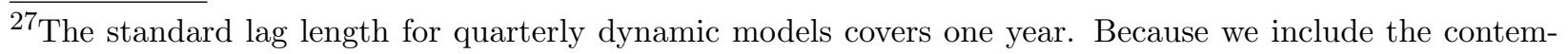
poraneous monetary stimulus at $k=0$, we set $\ell=3$ so that the effective lag length is four quarters. This lag length is more than sufficient as most estimated coefficients for $\ell \geq 2$ are statistically insignificant.

${ }^{28}$ For an average firm, the two-period lagged interactive effect (the estimate of $b_{2}$ ), as well as the cumulative interactive effect $\sum_{k} b_{k}$, is negative and statistically significant.
} 
How does monetary stimulus affect credit allocation between SOEs and non-SOEs? To connect with the literature, we first compare the overall effects of monetary stimulus between SOEs and non-SOEs. As reported in columns 2 and 3 of Table 5, a one percent increase in exogenous quarterly M2 growth translates into a 1.635 percentage-point increase in bank lending to an average SOE, in contrast to a 1.051 percentage-point increase for an average non-SOE with the difference between these two effects statistically significant at the 0.01 level. Figure 6 displays the dynamic responses to the 2009 monetary stimulus of bank loans to an average SOE and an average non-SOE during the stimulus period. The top left panel shows that the overall effect of monetary stimulus on bank credit to SOEs was higher than non-SOEs, with an average increase of 2.71 versus 2.13 percentage points for 2009Q1-2009Q3. Accordingly, during 2009Q1-2009Q4, the difference of the responses of bank credit to monetary stimulus between non-SOEs and SOEs is persistently negative (top right panel of the figure). Thus, overall economic stimulus favored SOEs in credit allocation; both regression estimates and dynamic responses show that SOEs benefited more than non-SOEs from the credit expansion during the economic stimulus period, consistent with the finding of the prior literature (Cong, Gao, Ponticelli, and Yang, 2019, for example).

How important is a fiscal expansion in accounting for the overall effect of monetary stimulus on credit allocation? The top part of columns 2 and 3 of Table 5 show that a fiscal expansion via infrastructure investment influences monetary effects on bank lending to SOEs differently from non-SOEs. The estimated interaction coefficients for SOE loans are significantly positive both contemporaneously and with one lag. By contrast, the interactive effects for non-SOEs are negative both on impact and in lagged periods. Accordingly, the cumulative interactive effect for SOEs is 4.774, while its counterpart for non-SOEs is -4.070 , both statistically significant at the 0.01 level. These results indicate that a fiscal expansion via infrastructure investment dampens monetary effects on bank credit to non-SOEs while enhancing these effects on loans to SOEs.

The dynamic impacts of infrastructure investment on the monetary transmission are displayed in the middle row of Figure 6. The effects of infrastructure spending, interacting with monetary stimulus, on bank credit to SOEs were positive for the first four quarters (2009Q1-2009Q4), while these effects on loans to non-SOEs were negative (middle left panel of the figure). The resulting difference between bank loans to SOEs and non-SOEs was highly significant for 2009Q1-2009Q4 (middle right panel).

The pure monetary effect contributes to the overall effect differently than does the interactive effect. As shown in the middle part of columns 2 and 3 of Table 5, the estimated effects of monetary policy alone on bank loans to SOEs are smaller than non-SOEs on impact and with lags. The cumulative pure effect indicates that a one percent increase in exogenous quarterly M2 growth translates into a 1.256 percentage-point increase in bank lending to 
an average SOE. By contrast, the cumulative response of bank credit allocated to an average non-SOE is 1.374 percentage points. ${ }^{29}$ Taken together, the fiscal-monetary interaction strengthens the response of SOE loans to monetary stimulus from 1.256 to 1.635 percentage points, while weakening the responses of non-SOE loans from 1.374 to 1.051 percentage points. Consistent with these estimated results reported in Table 5, the monetary stimulus alone generated an increase in bank credit to non-SOEs at least as strong as SOEs in 2009 (bottom left panel of Figure 6); there was no statistically significant difference between SOE and non-SOE responses (bottom right panel). ${ }^{30}$ Accordingly, for the Chinese economy, the fiscal-monetary interaction plays a central role in preferential credit access enjoyed by SOEs.

In summary, we find that for the Chinese economy, the overall effect of the 2009 monetary stimulus on bank credit to SOEs was higher than non-SOEs. The fiscal-monetary policy interaction is the key channel for the monetary stimulus to expand bank credit that favored SOEs.

V.2. The fiscal-monetary interaction channel. To understand how the fiscal-monetary interaction channel works, it is essential to understand how the fiscal expansion via infrastructure investment strengthened the effects of the 2009 monetary stimulus on bank credit to SOEs (crowding in effects) while dampening the monetary effects on loans to non-SOEs (crowding out effects). Infrastructure firms, encouraged by the central government to actively participate in infrastructure-related projects, enjoyed preferential credit access with explicit or implicit government guarantees. To see this point, we provide evidence on whether there were such crowding in effects on loans to firms in the infrastructure sector.

Columns 1 and 2 of Table 6 report the estimated results for SOEs and non-SOEs in the infrastructure sector. The estimated interactive effects on bank credit to SOEs are positive at the 0.01 significance level both on impact and in one lag (column 1 of the table). These effects are almost twice as large as those for the Chinese economy as a whole; thus, infrastructure investment had a much stronger enhancing effect on the transmission of monetary policy to SOE loans in the infrastructure sector than in other parts of the economy. The cumulative interactive effect on bank credit to non-SOEs in the infrastructure sector is statistically insignificant (column 2), although the effects are significantly positive on impact and in one lag. The fiscal expansion via infrastructure investment, therefore, strengthens the monetary transmission to SOE loans and at the same time does not weaken this transmission to nonSOE loans in infrastructure sector. ${ }^{31}$

\footnotetext{
${ }^{29}$ This result is consistent with Li, Liu, Peng, and Xu (2020), who use a branch-level dataset from one large bank in China and find that a relaxation of monetary policy did not increase the probability for the bank to lend to SOEs before 2013 (the year when China joined the Basel III Accord).

${ }^{30}$ Table S.3 in Appendix D reports the numerical values for Figure 6 and the corresponding significance levels.

${ }^{31}$ Huang, Pagano, and Panizza (2020) argue that private investment in industries more exposed to public infrastructure projects was less likely to be crowded out by local government debts than private investment in projects that were not related to infrastructure. By participating in infrastructure projects sponsored and
} 
The above elasticity evidence is corroborated by the estimated dynamic responses of bank loans to changes in fiscal-monetary policy interaction (top row of Figure 7). Infrastructure spending had a strong positive impact on the transmission of monetary policy into both SOE and non-SOE loans at least for the first two quarters of 2009; the impacts on loans to non-SOEs relative to those on SOE loans are statistically insignificant for the 2009Q12009Q3 period (top right panel of Figure 7). ${ }^{32}$ In short, infrastructure spending significantly amplified the impacts of the 2009 monetary stimulus on bank credit to infrastructure firms, especially SOEs in the infrastructure sector.

We now analyze the spillover interactive effects to sectors other than infrastructure. As discussed earlier, a large increase of infrastructure investment amplified the transmission of monetary policy and caused disproportionate credit allocation to infrastructure firms, especially SOEs; and this fiscal expansion via infrastructure investment dampened the expansionary monetary effect on bank credit to non-SOEs in other sectors of the economy. Columns 4 and 6 of Table 6 show that for both manufacturing and real estate sectors, the fiscal-monetary policy interaction significantly crowded out bank credit to non-SOEs. For the manufacturing sector, the estimated elasticities for the interactive effects on an average non-SOE are negative and statistically significant for the second and third periods (column 4). The resultant cumulative effect indicates that an increase of infrastructure investment attenuates, significantly, the transmission of monetary policy to non-SOE loans. For the real estate sector, infrastructure investment hampers this monetary transmission with negative interactive effects estimated at the 0.01 significance level contemporaneously and in two lags (column 6). The magnitude of the resultant cumulative interactive effect on non-SOE loans is significantly negative $(-25.99)$. By contrast, the cumulative interactive effect on SOE loans in both manufacturing and real estate is statistically insignificant (columns 3 and 5). ${ }^{33}$

These elasticity results are confirmed by the estimated dynamic responses of SOE and non-SOE loans in the manufacturing and real estate sectors (middle and bottom rows of Figure 7). For the manufacturing sector, although the difference in interactive effects on SOEs versus non-SOEs is statistically insignificant (middle right panel), the infrastructure investment spree significantly weakened monetary effects on bank credit to non-SOEs in the third and fourth quarters of 2009, while exerting no statistically significant effect on credit to SOEs (middle left panel). For real estate, infrastructure spending reduced monetary impacts on bank credit to non-SOEs by $50 \%$ with an average decline of 2.88 percentage

supported by the central and local governments, therefore, bank credit to non-SOEs in the infrastructure sector was less likely to be crowded out by infrastructure spending than that in other sectors.

${ }^{32}$ See also columns 1-3 of Table S.5 in Appendix D, which report the numerical values of these dynamic response.

${ }^{33}$ As shown in Appendix D, the finding that a fiscal expansion dampened the transmission of monetary policy to non-SOE credit, but not to SOE credit, holds for the remaining economy as well. 
points in 2009Q1-2009Q3, whereas it had no statistically significant effect on the monetary transmission to SOE loans except for the third quarter of 2019 (bottom left panel). ${ }^{34}$

To summarize, we find that (1) in the infrastructure sector, the fiscal-monetary policy interaction enhances the effect of monetary stimulus on bank credit to SOEs, without dampening the effects on non-SOEs; (2) in sectors other than infrastructure, an increase of infrastructure investment severely weakened the transmission of monetary policy to non-SOE loans during 2009Q1-2009Q3, but had no significant effect on SOE loans. Taken together, these results provide solid evidence that the spree of infrastructure investment reduced loanable funds for non-SOEs in sectors other than infrastructure, while SOEs were spared the credit squeeze because of government guarantees they enjoyed. In Section V.5, we offer a theoretical explanation of this evidence.

V.3. The effects of monetary stimulus absent fiscal expansion. In this section, we address the following questions: absent the fiscal expansion via infrastructure investment, what would have been the pure effect of monetary stimulus on credit allocation to SOEs versus non-SOEs in different sectors? Similar to the pure monetary effects on the whole economy, expansionary monetary policy alone did not lead to preferential credit to SOEs in the infrastructure sector (columns 1 and 2 of Table 6). Except on impact, the estimated pure effects of a monetary policy shock on bank credit to non-SOEs are as strong as those on SOE loans, resulting in cumulative pure effects that are close in magnitude (1.396 for nonSOEs versus 1.369 for SOEs). For the real estate sector, the estimated effects of monetary policy alone on non-SOE loans are significantly stronger than the effects on SOE loans both contemporaneously and in lags, with the cumulative effect more than three times as large (3.105 for non-SOEs versus 0.839 for SOEs, columns 5 and 6 of the table). The manufacturing sector, however, has an opposite result. On bank credit allocated to SOEs, the pure effects of monetary stimulus are positive at the 0.01 significance level both contemporaneously and with a lag, with magnitudes much larger than the effects on credit to non-SOEs. Accordingly, the cumulative pure effect of monetary stimulus on SOEs (1.177) is considerably larger than that on non-SOEs (0.716).

These results are corroborated by the dynamic responses to the 2009 monetary stimulus of credit allocation between SOEs and non-SOEs, as shown in Figure 8. For the infrastructure sector, the effects of monetary stimulus alone on bank credit to SOEs and non-SOEs were very similar for the first four quarters of 2009, with an average of 2.27 versus 2.38 percentage points (top row of the figure). For the real estate sector, the 2009 monetary stimulus alone generated significantly more bank credit allocated to non-SOEs than to SOEs, with an average increase of 5.79 percentage points in non-SOE loans versus 1.94 percentage points in

\footnotetext{
${ }^{34}$ The interactive effects on credit to non-SOEs, relative to credit to SOEs, were significantly negative with an average difference of 2 percentage points (bottom right panel of Figure 7 as well as column 2 of Table S.6 in Appendix D).
} 
SOE loans in 2009Q1-2009Q3. ${ }^{35}$ For the manufacturing sector, however, SOEs received more bank loans than non-SOEs did, with an average increase of about 2.36 percentage points in bank credit to SOEs over the first three quarters of 2009, almost twice the average increase for non-SOEs during the same period (1.19 percentage points). ${ }^{36}$

To summarize, we find that similar to the monetary effects on the entire economy, the 2009 monetary stimulus alone would not have expanded bank credit preferential to SOEs in the infrastructure sector or the real estate sector if there had been no fiscal expansion. This result is in contrast to the manufacturing sector, in which SOEs enjoyed preferential credit access even without fiscal expansion. In Section VI.1, we offer one plausible explanation for the estimated pure effects of monetary stimulus.

V.4. Robustness analysis. During the economic stimulus period, region-specific fiscal policy targeted China's western region (e.g., a large government transfer to the province of Sichuan after the 2008 earthquake). Such region-specific policy could potentially confound or contaminate our estimated effects of monetary stimulus.

To address this potential problem, we use an alternative strategy to identify changes in the supply of credit that were driven by monetary policy shocks. It exploits heterogeneity in firms' exposure to changes in different banks' credit supply caused by monetary policy shocks. An individual firm's exposure is weighted by banks' pre-stimulus market shares of total loans made to this firm, with the assumption that the borrower-lender relationship is persistent over time. Hence, a credit supply shock to a subset of banks, with which the firm had a relationship during the pre-stimulus period, would change the total bank credit supply to this particular firm during the stimulus period. The use of each bank's pre-stimulus loan share as a weight to construct firm-level exposure helps purge changes in credit supply of unobserved macroeconomic factors, other than monetary policy shocks, that may influence the supply of credit. ${ }^{37}$

To incorporate the variations in firm-specific exposure to bank credit into our framework, we first expand our macro model in the first stage with 17 time series of bank loans, where each additional time series corresponds to total (aggregated) loans newly issued by an individual bank in our sample from 2007Q1 to 2013Q2. In this stage, we estimate the expanded VAR system and use the estimated system to construct a counterfactual quarterly series of bank loans driven only by monetary policy shocks for each of the 17 banks. We denote this

\footnotetext{
${ }^{35}$ The change of bank credit to non-SOEs, relative to loans to SOEs, peaked at 4.61 percentage points in 2009Q2. See the bottom right panel of Figure 8 and column (1) of Table S.6 in Appendix D.

${ }^{36}$ The estimates reported in column 1 of Table S.4 in Appendix D show much smaller responses of bank loans to non-SOEs than the responses of SOE loans in 2009Q1-2009Q3.

${ }^{37}$ Since bank loan shares vary substantially across firms, this identification strategy, in the spirit of the "Bartik instrument," is based on the observation that some banks increased lending more than others during the stimulus period. See Greenstone, Mas, and Nguyen (2020) and Cong, Gao, Ponticelli, and Yang (2019) for applications of a similar identification strategy to construct shocks to bank credit supply.
} 
quarterly series by $\mathcal{N}_{b, t}^{m}$, where $b$ indicates one of the 17 banks. We follow Cong, Gao, Ponticelli, and Yang (2019) and construct a firm-specific shock that measures a credit increase engendered by monetary policy shocks as

$$
\tilde{\ell}_{i, t}^{m}=\sum_{b \in O_{i}} \omega_{b, i, t=0} \times \ell_{b, t}^{m},
$$

where $\ell_{b, t}^{m}$ is the ratio of $\mathcal{N}_{b, t}^{m}$ to its outstanding amount at the end of quarter $t-1$, and $\omega_{b, i, t=0}$ represents outstanding loans from bank $b$ to firm $i$ divided by total outstanding loans to firm $i$ from all banks with which firm $i$ has a credit relationship (the set $O_{i}$ ) at the initial time $t=0 .{ }^{38}$ In Cong, Gao, Ponticelli, and Yang (2019), firm-specific shocks are constructed by excluding loans located in the same city as firm $i$ and those operating in the same industry as firm $i$. This exclusion is needed to deal with the endogeneity issue created by credit demand factors. The advantage of our approach is that there is no need to exclude banklevel exposure in the city of the firm in question because exogenous changes in monetary policy are obtained in the first stage.

As in our baseline regression, the key identifying assumption for constructing firm-specific credit supply changes driven by monetary policy is that changes in the bank credit supply driven by monetary policy are not affected by fiscal policy. To validate this assumption, we regress each of the 17 bank-specific time series of credit supply changes driven by monetary policy shocks on both non-monetary shocks to infrastructure investment and monetary policy shocks. As Table 4 shows, the coefficient of $g_{\text {infra, } t}^{o}$ is insignificant for all banks except one bank at the 0.1 significance level. Hence, changes in our identified bank-specific credit supply are orthogonal to non-monetary shocks to infrastructure investment. The coefficient of $g_{m, t}$, by contrast, is positive and significant for 12 out of 17 banks, confirming the predictive power of monetary policy shocks on changes in identified bank-specific credit supply.

In the second stage, we use the constructed firm-specific shock $\tilde{\ell}_{i, t}^{m}$ to estimate the following panel regression:

$$
\mathfrak{b}_{i, j, t}=c^{i, j}+\rho^{j} \mathfrak{b}_{i, j, t-1}+\sum_{k=0}^{\ell}\left[b_{k}^{j} g_{\text {infra }, t-k}^{o} \tilde{\ell}_{i, t-k}^{m}+d_{k}^{j} \tilde{\ell}_{i, t-k}^{m}\right]+c_{\chi}^{j \prime} \chi_{t}^{o}+c_{z}^{j \prime} z_{i, j, t-1}+\eta_{i, j, t} .
$$

The key coefficients of interest are again $b_{k}^{j}$ and $d_{k}^{j}$, which capture the interactive and pure effects of credit supply shocks driven by monetary policy. The interpretation of $b_{k}^{j}$ and $d_{k}^{j}$, however, is fundamentally different from the previous interpretation. In our baseline specification, the coefficient $b_{k}^{j}$ represents the elasticity of bank loans to a fiscal expansion interacting with monetary stimulus and $d_{k}^{j}$ the elasticity of bank loans to monetary policy alone. The dynamic impacts to an aggregate shock is the focus of the paper. In this specification, $\tilde{\ell}_{i, t}^{m}$ is a firm-specific shock, $b_{k}^{j}$ represents the elasticity of bank loans to a firm-specific

\footnotetext{
${ }^{38}$ Note that a change in log outstanding loans is an approximation to $\ell_{b, t}^{m}$. Following Cong, Gao, Ponticelli, and Yang (2019), we set the initial time to 2006Q4 for the pre-stimulus period, 2008Q4 for the stimulus period, and 2010Q4 for the post-stimulus period.
} 
credit supply shock interacting with infrastructure investment, and $d_{k}^{j}$ represents the elasticity of bank loans to this firm-specific shock absent the fiscal expansion. Because $\tilde{\ell}_{i, t}^{m}$ is a firm-specific shock, the estimated elasticity reflects only a cross-sectional effect by differencing out the aggregate effect. For these cross-sectional effects, therefore, our robustness analysis focuses on the sign and significance of estimates of elasticity coefficients $b_{k}^{j}$ and $d_{k}^{j}$ for an average firm.

The regression results, reported in Table 7, reinforce our previous findings. First, infrastructure investment dampens the monetary effect on bank credit allocated to non-SOEs in manufacturing and real estate, but enhances the monetary transmission to bank loans advanced to all infrastructure firms. In the manufacturing and real estate sectors, the cumulative interactive effects are negative and statistically significant for non-SOEs (columns 4 and 6 of the table), but statistically insignificant for SOEs (columns 3 and 5), in line with the previous finding that a fiscal expansion dampens the monetary transmission to non-SOE loans in sectors other than infrastructure. The interactive effects on loans to both SOEs and non-SOEs in the infrastructure sector are positive, with the magnitude for SOEs larger than for non-SOEs (columns 1 and 2). ${ }^{39}$ This result is consistent with our previous finding that a fiscal expansion strengthens the monetary transmission to SOE loans and does not weaken this transmission to non-SOE loans in the infrastructure sector.

Second, monetary stimulus alone favors bank lending to manufacturing SOEs, but not SOEs in the infrastructure and real estate sectors. For an average manufacturing SOE, one can see from column 3 of Table 7 that a one percent increase in the supply of credit generated by expansionary monetary policy is associated with a 0.24 percentage-point increase in the firm's borrowings; for an average manufacturing non-SOE, the corresponding increase is only 0.11 percentage point (columns 3 and 4 of the table). For the real estate sector, the cumulative pure effect on loans to non-SOEs is 0.317 percentage point while this effect on loans to non-SOEs is only 0.191 (columns 5 and 6). For the infrastructure sector, SOEs are not favored; the estimated cumulative pure effect on loans to SOEs is 0.24 percentage point, while this effect on loans to non-SOEs is 0.33 percentage point (columns 1 and 2).

In summary, when aggregate monetary policy shocks are replaced by firm-specific shocks to credit supply driven by monetary policy, our robust result supports the previous finding that the fiscal-monetary interaction is a key channel for monetary policy to exert influence over credit allocation between SOEs and non-SOEs during the stimulus period.

For further robustness analysis, we run two additional regressions. In our baseline specification, we use firm fixed effects to control for the unobserved firm-level heterogeneity that may capture loan demands by a particular firm. Although firm fixed effects should absorb region fixed effects on credit to firms, we add province fixed effects as an additional control variable to panel regression (1). We use the three-stage approach of Plümper and Troeger

\footnotetext{
${ }^{39}$ Unlike our previous result, the cumulative crowding in effect of infrastructure investment on bank credit to non-SOEs in the infrastructure sector is statistically significant.
} 
(2007) as discussed in Greene (2012, chapter 11). The results yield minor changes with this additional control (cf. Table 6 and Table S.7 in Appendix D). In our second additional specification, we re-estimate panel regression (1) by excluding the province of Sichuan, the most important province in the western region. Our previous findings and conclusions are robust to this exclusion (cf. Table 6 and Table S.8 in Appendix D). ${ }^{40}$

V.5. Understanding the fiscal-monetary interaction channel. The preceding sections show that a fiscal expansion via infrastructure investment dampened the effects of the 2009 monetary stimulus on credit allocation to non-SOEs in the manufacturing and real estate sectors, while enhancing the monetary effects on firms in the infrastructure sector. In this section, we propose one plausible theory to explain the dampening interactive effects of infrastructure investment on loans to non-SOEs in sectors other than infrastructure.

Our theoretical mechanism is based on a positive feedback loop among bank lending, investment, and collateral values of infrastructure firms. Firms in the infrastructure sector benefit from government guarantees of their bank credit, which increases bank credit to these firms. This credit increase helps raise infrastructure investment, which increases the collateral value of an infrastructure project. An increase in the collateral enables more lending and investment to take place for infrastructure firms. Since an increase of investment in infrastructure firms tends to raise the borrowing costs of firms in sectors outside of infrastructure, it dampens the transmission of expansionary monetary policy to allocation of bank credit to non-SOEs that have no implicit government guarantees of their loans.

The model, a modified version of Bleck and Liu (2018) and presented formally in Appendix E, focuses on how a fiscal expansion weakens the monetary effect on loan allocation between two sectors. In this section, we provide a simple description of the model. In the model, the economy is composed of two sectors: the infrastructure sector and the noninfrastructure sector. We assume that entrepreneurs in the non-infrastructure sector do not enjoy government guarantees of debt repayments. ${ }^{41}$ Each sector contains a continuum of entrepreneurs that differ in the amount of external funds needed to carry out identical investment projects. As in the standard financial contract literature (Kiyotaki and Moore, 1997; Jermann and Quadrini, 2012, for example), the maximum amount of borrowing by an entrepreneur is constrained by the collateral value of a project. The equilibrium project (asset) value is determined in the secondary asset market in which an entrepreneur funds the project with internal funds (the net cash flow of the entrepreneur operating the project in the last period) as well as external funds such as bank loans.

\footnotetext{
${ }^{40}$ Credit allocation or misallocation across regions, however, is an important topic for further study in future research.

${ }^{41}$ For simplicity, the model abstracts from SOEs in the non-infrastructure sector. In the actual economy, with implicit government guarantees, the borrowing costs of these SOEs are insensitive to changes in bank credit to the infrastructure sector.
} 
In the absence of a fiscal expansion, an increase in the total credit supply as a result of monetary stimulus lowers the cost of borrowing for entrepreneurs in both sectors. Accordingly, bank credit for entrepreneurs in both sectors increases. The presence of the fiscal expansion, with explicit guarantees of debt repayments for projects in the infrastructure sector, raises the borrowing capacity of entrepreneurs in the infrastructure sector and in turn increases infrastructure investment by allowing more entrepreneurs to operate their projects. The increase of investment furthers raises collateral values of projects and enables more loans allocated to the infrastructure sector. As a result, there is a positive feedback loop among bank lending, investment, and the collateral value of the infrastructure sector.

When monetary stimulus expands available bank credit, this positive feedback loop amplifies bank credit advanced to the infrastructure sector. ${ }^{42}$ An increase in bank credit in turn pushes up the borrowing costs of entrepreneurs in the non-infrastructure sector. Since these entrepreneurs do not have implicit government guarantees of their loans, the loan volume decreases with rising costs as in the standard model. In other words, bank loans to these entrepreneurs in the non-infrastructure sector increase less than when there is no fiscal expansion, as the fiscal expansion dampens the monetary effect on credit allocated to these entrepreneurs.

In short, our model illustrates how a fiscal expansion via infrastructure enhances governmentguaranteed loans to infrastructure firms but dampens the effects of monetary stimulus on credit allocated to non-SOEs in the non-infrastructure sector.

\section{Further ANALYSIS}

There are two important questions related to our empirical findings about the effects of monetary policy on credit allocation: (i) what is the man driver of the effects of monetary stimulus alone on credit allocation between SOEs and non-SOEs? (ii) how did the effects of monetary policy during the stimulus period differ from those during the pre-stimulus period. In this section, we address these two issues in turn.

\section{VI.1. Role of capital intensity for the pure effects of monetary stimulus. While} there may be many explanations for the differential impacts of monetary stimulus on credit allocation between SOEs and non-SOEs across sectors, one plausible explanation is a different composition of capital intensive firms in each sector. The rationale for this explanation is as follows. With expansionary monetary policy absent fiscal expansion, banks tend to extend credit to capital intensive (CI) firms, which have more collateral to pledge than non-capital intensive (NCI) firms (e.g., labor intensive firms). A large fraction of SOEs in the manufacturing sector are capital intensive, while the opposite is true for manufacturing

\footnotetext{
$\overline{42}$ According to Bai, Hsieh, and Song (2016), infrastructure investment during the stimulus period was more than twice the planned amount. For example, actual investment in transportation and powered infrastructure was 3.18 trillion RMB, most of which were financed by bank loans, while the planned amount of investment was 1.5 trillion RMB.
} 
non-SOEs. Since the late 1990s, the government's "Grasp the Large and Let Go the Small" program for manufacturing industries has been designed to retain capital intensive SOEs but encourage small non-capital intensive SOEs to be privatized. This transition, however, did not happen in other sectors. On the contrary, for example, infrastructure and real estate have become the government's two favored or strategic sectors since the late 1990s. Many non-SOEs in these sectors are indeed capital intensive.

Table S.9 in Appendix D.1 reports the mean and median values of these ratios for SOEs and non-SOEs in manufacturing and other sectors at the end of 2008. ${ }^{43}$ Panel A reports the mean and median values of capital intensity for SOEs and non-SOEs in different sectors. In the manufacturing sector, SOEs were more capital intensive than non-SOEs for both mean and median values. The opposite was true for real estate; that is, non-SOEs were more capital intensive than SOEs in this sector. For infrastructure firms, the results are mixed: SOEs were on average more capital intensive than non-SOEs by the mean measure, but less capital intensive by the median measure.

From our firm-quarter data, we categorize a firm into one of the two groups: the CI group in which firms' capital-to-labor ratios are above the median of the distribution of capital-tolabor ratios in the entire economy and the NCI group in which firms' capital-to-labor ratios are below the median of this distribution. Panels B and C of Table S.9 in Appendix D.1 report the mean and median values of capital intensity for SOEs and non-SOEs within the CI and NCI groups. For a given ownership type in each sector, capital intensity of CI firms is always higher than that of NCI firms. For SOEs in the manufacturing sector, for instance, the mean value of capital intensities of CI firms (450.82) is significantly larger than that of NCI firms (59.24). Within the NCI group, the mean values of capital intensities for SOEs and non-SOEs are close to each other in all sectors. The difference in mean values of capital intensities between SOEs and non-SOEs in the manufacturing sector is 224.97 within the CI group, but only 13.63 within the NCI group. A similar result holds for the infrastructure and real estate sectors. Within the CI group, the mean value of capital intensities for manufacturing non-SOEs (225.84) is not only smaller than the counterpart for manufacturing SOEs (450.82), but also smaller than the mean value of capital intensities for non-SOEs in infrastructure (796.21) and in real estate (2044.2). In other words, non-SOEs in infrastructure and real estate are capital intensive, and indeed more capital intensive than non-SOEs in manufacturing.

To quantify the role of capital intensity in the estimated effect of monetary stimulus alone, we allow this effect to vary across the distribution of capital intensities by extending

\footnotetext{
${ }^{43}$ Constructing a comprehensive measure of capital intensity to be comparable across different sectors or industries is an empirically challenging task that deserves a future study. One main issue is data availability. Our loan-level data, for example, does not contain information about a firm's fixed assets or compensation expenses.
} 
our empirical specification as follows

$$
\begin{aligned}
\mathfrak{b}_{i, j, t}= & c^{i, j}+\rho^{j} \mathfrak{b}_{i, j, t-1}+\sum_{k=0}^{\ell} \sum_{g=1}^{2} I\left(\mathrm{CI}_{i, j, t=0} \in g\right)\left[d_{g, k}^{j} \varepsilon_{t-k}^{m}+b_{g, k}^{j} g_{\text {infra }, t-k}^{o} \varepsilon_{t-k}^{m}\right] \\
& \sum_{k=0}^{\ell} \sum_{g=1}^{2} \alpha_{g, k} I\left(\mathrm{CI}_{i, j, t=0} \in g\right)+c_{\chi}^{j \prime} \chi_{t}^{o}+c_{z}^{j \prime} z_{i, j, t-1}+\eta_{i, j, t} .
\end{aligned}
$$

where $\mathrm{CI}_{i, j, t=0}$ represents capital intensity of a particular firm $i$ of type $j(j \in\{\mathrm{SOE}$, non-SOE $\}$ ), measured as the ratio of total assets to total employees in the firm. To avoid the endogeneity of capital intensity to the credit expansion during the stimulus period, we use the firm's 2008 (pre-stimulus) level of capital intensity. ${ }^{44}$ The indicator function takes a value of one if CI falls into a particular group or bin of the distribution. Coefficients $d_{g, k}^{j}$ and $b_{g, k}^{j}$ are now indexed by group $g$, where $g=1$ denotes the CI group and $g=2$ the NCI group.

Table 8 reports the estimated results for the pure monetary effects on bank loans to firms grouped by capital intensity in the manufacturing sector as well as in the whole economy. For both SOEs and non-SOEs, the pure monetary effects on loans to CI firms were higher than those on loans to NCI firms. For example, column 1 shows that for manufacturing SOEs, the estimated pure effects of monetary stimulus on NCI firms are statistically insignificant for most periods. By contrast, the pure monetary effects on loans to capital intensive SOEs are significant in almost all periods, and their cumulative pure monetary effect is more than twice as much as that on loans to non-capital intensive SOEs (1.960 versus 0.732 with the difference statistically significant at the 0.1 level, bottom part of column 1 of the table). A similar finding holds for manufacturing non-SOEs: the cumulative pure monetary effect on capital intensive non-SOEs is larger than its counterpart for non-capital intensive nonSOEs (0.931 versus 0.647, bottom part of column 2), although the difference is statistically insignificant. After controlling for ownership type, therefore, monetary policy alone had stronger effects on loans allocated to CI firms than those to NCI firms, especially for SOEs.

Within the group of CI manufacturing firms, the pure monetary effects on bank lending to SOEs were higher than lending to non-SOEs in three periods (top part of columns 1 and 2 of Table 8 and the first row of Figure 9), resulting in a cumulative 1.960 percentage-point increase for loans to SOEs versus 0.931 for loans to non-SOEs (bottom part of columns 1 and 2 of Table 8). Within the group of NCI manufacturing firms, the pure monetary effects on loans to SOEs did not differ statistically from those on loans to non-SOEs (second row of Figure 9). This result is consistent with the fact that within the group of NCI manufacturing firms, SOEs and non-SOEs had a similar level of capital intensity (Panel C of Table S.9 in Appendix D.1).

\footnotetext{
${ }^{44}$ We examine the correlation of capital intensity with several potential covariates, such as equity share and market concentration, in Appendix F. For various measures of equity share and market concentration, we find that the correlation of our measured capital intensity with these variables is close to zero.
} 
The estimated results for the whole economy show a similar role of capital intensity in explaining the differential effects of monetary stimulus alone on credit allocation between SOEs and non-SOEs. For both SOEs and non-SOEs, the pure monetary effects on loans to CI firms were stronger than those on loans to NCI firms for most periods (columns 3 and 4 of Table 8). The cumulative effect on loans to CI firms were stronger than that on loans to NCI firms, with the difference statistically significant at the 0.05 level for SOEs and the 0.01 level for non-SOEs. Within the group of CI firms, although the pure monetary effects on loans to non-SOEs were larger than their SOE counterparts, the difference is statistically significant only for 2009Q1 (right column and third row of Figure 9). This finding is consistent with the fact that within the group of CI firms, both SOEs and non-SOEs in the infrastructure and real estate sectors have a high level of capital intensity (Panel B of Table S.9 in Appendix D.1). Within the group of NCI firms in the economy as a whole, on the other hand, the pure monetary effects on loans to SOEs and non-SOEs are statistically indistinguishable (bottom part of columns 3 and 4 of Table 8, and fourth row of Figure 9), consistent with the fact that within this group, the level of capital intensity is similar between SOEs and non-SOEs (Panel C of Table S.9 in Appendix D.1). ${ }^{45}$

VI.2. Effects of monetary policy in the pre-stimulus and stimulus periods. We follow Cong, Gao, Ponticelli, and Yang (2019) to study how the transmission of monetary policy to credit allocation evolved over time across three periods: the pre-stimulus period (2007-2008), the stimulus period (2009-2010), and the post-stimulus period (2011-2013). To make our results comparable to those of Cong, Gao, Ponticelli, and Yang (2019), we apply our constructed firm-specific shocks $\tilde{\ell}_{i, t}^{m}$ to estimation of the following firm-quarter regression:

$$
\begin{aligned}
& \mathfrak{b}_{i, c, j, t}=\alpha_{c}+\alpha_{j}+\alpha_{t}+\beta_{1} \tilde{\ell}_{i, t}^{m} \times \text { StateShare }_{i, t=0} \\
& +\beta_{2} \tilde{\ell}_{i, t}^{m} \times \text { StateShare }_{i, t=0} \times I(\text { stimulus }) \\
& +\beta_{3} \tilde{\ell}_{i, t}^{m} \times \text { StateShare }_{i, t=0} \times I(\text { post }) \\
& +\beta_{4} \tilde{\ell}_{i, t}^{m}+\beta_{5} \tilde{\ell}_{i, t}^{m} \times I(\text { stimulus })+\beta_{6} \tilde{\ell}_{i, t}^{m} \times I(\text { post }) \\
& +\beta_{7} \text { StateShare }_{i, t=0} \\
& +\beta_{8} \text { StateShare }_{i, t=0} \times I(\text { stimulus })+\beta_{9} \text { StateShare }_{i, t=0} \times I(\text { post }) \\
& +c_{z}^{\prime} z_{i, t-1}+\eta_{i, c, j, t}
\end{aligned}
$$

where $\mathfrak{b}_{i, c, j, t}$ represents new loans to firm $i$ (as a share of the firm's total assets) in two-digit industry $j$ and city $c$ at quarter $t$. The coefficients $\alpha_{c}, \alpha_{j}$, and $\alpha_{t}$ represent city, industry, and time fixed effects. The variable StateShare ${ }_{i, t=0}$ is the state share of firm $i$ in the initial period (the initial period is specified as in Cong, Gao, Ponticelli, and Yang (2019)). The time dummy I(stimulus) indicates the period 2009-2010, and $I$ (post) 2011-2013. The vector $z_{i, t-1}$ is a list of firm-level control variables. Cong, Gao, Ponticelli, and Yang (2019) find

\footnotetext{
$\overline{{ }^{45} \text { Our results }}$ are insensitive to whether the cut-off median value is sector-dependent or economy-wide.
} 
that for the manufacturing sector, the estimated $\beta_{1}$ is negative in the pre-stimulus period, but the estimated $\beta_{2}$ is positive and highly significant in the stimulus period.

To be comparable to their finding (Cong, Gao, Ponticelli, and Yang, 2019, column 6 of Table 6), we merge the loan data with the Annual Survey of Industrial Firms to obtain the state share for each firm in the manufacturing sector, ${ }^{46}$ and estimate equation (9). Our estimated results are consistent with their findings. In particular, $\beta_{1}$ is statistically insignificant, suggesting that bank credit allocation did not favor manufacturing SOEs in the pre-stimulus period. But $\beta_{2}$ is positive and highly significant at the 0.05 level, suggesting that SOEs enjoyed preferential access to bank credit during the stimulus period (right panel of Table S.15 in Appendix G). Unlike Cong, Gao, Ponticelli, and Yang (2019), our firm-specific shock isolates a credit supply change induced by monetary policy. Consistent with their findings, however, the estimated impacts of this alternative credit supply shock on loan allocation in the stimulus period differ from those in the pre-stimulus period. ${ }^{47}$

\section{Assessing the Importance of THE BANK CREDIT CHANNEL TO INVESTMENT}

In the preceding sectors, we analyze the impacts of monetary stimulus and its interaction with infrastructure investment on bank credit to SOEs and non-SOEs. How important is the bank credit channel in the transmission of monetary policy to firm investment? One cannot answer this question by simply replacing the firm-level loan variable with firm-level investment in equation (1), because the estimated effects include those through channels other than the bank credit channel in response to monetary stimulus (e.g., an increase of liquidity in financial markets other than the banking system, such as the bond market and the stock market).

Our paper emphasizes the bank credit channel of monetary policy transmission to credit allocation. In this section, we assess the importance of this bank credit channel to investment in two steps. We first estimate the elasticity of investment to bank credit, using a merged data set that incorporates investment information in CSMAR and our loan-level information for individual firms. We then provide a back-of-the-envelope calculation of the response of investment to monetary stimulus, taking into account both the elasticity of investment to bank credit and the elasticity of bank credit to monetary stimulus.

VII.1. Elasticity of investment to bank credit. We merge our loan-level data with the CSMAR firm-level data and estimate the response of investment to changes in bank credit with the regression:

$$
\mathfrak{i}_{i, j, t}=c^{i, j}+\alpha_{\mathcal{L}}^{j} \Delta \log \mathcal{L}_{i, j, t}+\alpha_{\mathcal{I}}^{j} \mathcal{I}_{09-10} \Delta \log \mathcal{L}_{i, j, t}+c_{\chi}^{j \prime} \chi_{t-1}+c_{z}^{j \prime} z_{i, j, t-1}+\eta_{i, j, t},
$$

\footnotetext{
${ }^{46}$ The sample of Cong, Gao, Ponticelli, and Yang (2019) includes mining firms, but the results change little when these firms are removed from the regression.

${ }^{47}$ In Appendix $\mathrm{G}$, we discuss the feasibility issue related to obtaining the data on companies' state shares in the entire economy.
} 
where $\mathfrak{i}_{i, j, t}$ is firm $i$ 's investment (divided by the firm's total nominal assets in the previous period), $j \in\{$ SOEs, non-SOEs, all firms $\}, \mathcal{L}_{i, j, t}$ represents the outstanding credit to firm $i$ (so that $\Delta \log \mathcal{L}_{i, j, t}$ is approximately equal to the ratio of newly issued loans to the outstanding credit in the previous period), and $\mathcal{I}_{09-10}$ is an indicator function that returns one when time $t$ falls within the years 2009-2010 and zero otherwise. The inclusion of this dummy variable allows us to obtain the potential nonlinear effects of bank credit to firm investment during the stimulus period and at the same time makes it comparable to the existing findings in the literature. The coefficient $c^{i, j}$ captures firm fixed effects, which not only absorb sector fixed effects but also allow us to exploit within-firm variation to avoid the endogeneity problem due to potential omitted variables such as heterogeneous investment opportunities across firms with various degrees of government guarantees on loan repayments. The vector $\chi_{t-1}=\left[g_{y, t-1}, \pi_{t-1}\right]^{\prime}$ controls for macroeconomic effects (i.e. the effects of quarterly inflation $\left(\pi_{t-1}\right)$ and a quarterly change of output $\left(g_{y, t-1}\right)$ in the previous period), the vector $z_{i, j, t}$ controls for an array of firm specific characteristics such as the size and leverage of a firm, and the random residual $\eta_{i, j, t}$ is iid distributed.

Since a majority of listed firms are in the manufacturing sector, it is infeasible to accurately estimate the elasticity of investment to bank credit for each of other major sectors. We are able to compare, however, the elasticity of investment to bank credit between the manufacturing sector and the entire economy. This comparison allows us to shed light on a potential heterogeneity of investment sensitivity to bank loans between manufacturing and other major sectors in the economy. Table 9 reports the estimated results of regression (10). For an average manufacturing firm, column 1 reports the estimated elasticity of investment to bank credit in both normal and stimulus periods. In the normal period, it is positive at the 0.01 significance level; in the stimulus period, it is positive at the 0.1 significance level. Columns 2 and 3 reveal that investment sensitivity is different for the two types of firms. In the normal period, the elasticity of an average SOE's investment to bank credit is statistically insignificant, suggesting that the financial constraints on SOEs were largely unbinding. By contrast, the elasticity of an average non-SOE's investment to bank credit is estimated to be positive at the 0.01 significance level. According to our estimate, a one percent increase of bank credit to non-SOEs increases their investment, on average, by about 0.1 percentage point (as a share of assets). This result implies that non-SOEs were, on average, more credit-constrained than SOEs during the normal period; the credit constraint made non-SOEs' investment more sensitive to bank credit.

In the stimulus period, however, the result for investment sensitivity to bank credit is reversed. The estimated coefficient for SOEs is positive at the 0.05 significance level. Its magnitude reveals that a one percent increase in bank credit raised investment by 0.2 percentage point. Summing the estimated coefficients for both normal and stimulus periods, one can see that during the stimulus period, a one percent increase in bank credit led to a total increase of 0.22 percentage point in an average SOE's investment (as a share of its total 
assets). For non-SOEs, the estimated coefficient for the interaction term between bank loans and the stimulus period dummy is insignificant, suggesting that during the stimulus period, an increase in bank credit would not lead to an extra increase in investment. The overall elasticity of an average non-SOE's investment to bank credit, however, is statistically significant at the 0.01 level, implying that during the stimulus period, a one percent increase in bank credit increased investment of an average non-SOE by 0.176 percentage point. Taken together, the overall elasticity of an average SOE's investment to bank credit during the stimulus period is higher than the counterpart for non-SOEs, a result opposite of the finding for the normal period. Our estimated results for manufacturing firms are consistent with the existing evidence that in response to the 2008 global financial crisis, the government allocated more credit to SOEs than non-SOEs in the manufacturing sector and "artificially directed state-owned firms to sustain investment" (Cong, Gao, Ponticelli, and Yang, 2019).

Do our findings for the manufacturing sector carry over to the entire economy? This question is particularly relevant because non-SOEs in other sectors such as infrastructure enjoyed implicit government guarantees of their loans as discussed in the preceding sections. Columns 4 to 6 of Table 9 report the estimated results for the entire economy. For an average firm in the entire economy, as shown in column 4, the estimated investment sensitivity to bank credit during the normal period is close to the estimate for the manufacturing sector (0.097 versus 0.106$)$. The investment elasticity for the entire economy during the stimulus period, however, differs substantially from the estimate for the manufacturing sector $(0.231$ versus 0.077 ). Moreover, the estimate 0.231 is statistically significant at the 0.01 level while the estimate 0.077 is only significant at the 0.1 level.

Columns 5 and 6 compare SOEs and non-SOEs for the entire economy. For the normal period, the estimated elasticities of investment to bank credit for both SOEs and non-SOEs are similar in magnitude to those in the manufacturing sector: the investment sensitivity is insignificant for SOEs but significant at the 0.01 level for non-SOEs so that a one percent increase in bank credit to non-SOEs translated into an increase of 0.103 percentage point in their investment (cf. 0.114 percentage point for the manufacturing sample).

For the stimulus period, while the estimated investment sensitivity for SOEs in the entire economy is similar to the manufacturing counterpart (0.181 versus 0.197$)$, the estimate for non-SOEs in the entire economy differs substantially from the manufacturing sample $(0.243$ versus 0.062). Consequently, the overall investment elasticity to bank credit is 0.346 for non-SOEs, higher than that for SOEs (0.212). This finding is opposite of the result for the manufacturing sector and reveals that non-SOEs, on average, played a more important role in translating bank credit into physical investment than SOEs did in the economy as a whole.

VII.2. The bank credit channel of monetary policy to investment. This section assesses the importance of the bank credit channel through which monetary stimulus increases 
investment. We decompose the investment response to monetary stimulus into two components: the response to an increase in infrastructure investment interacting with monetary stimulus, and the response to monetary stimulus absent this fiscal expansion.

The effect of monetary stimulus on investment through the bank credit channel is calculated according to

$$
\frac{\partial \mathfrak{i}_{j, t}}{\partial \varepsilon_{m, t}^{\text {Stim }}} \approx \frac{\partial \mathfrak{b}_{j, t}}{\partial \varepsilon_{m, t}^{\text {Stim }}} \frac{\partial \mathfrak{i}_{j, t}}{\partial \Delta \log \mathcal{L}_{j, t}} \frac{\mathcal{A}_{j, t-1}}{\mathcal{L}_{j, t-1}},
$$

where $j \in\{$ SOEs, non-SOEs, all firms $\}$, the left-hand derivative is the average investment response of firms of type $j$ to monetary stimulus, $\partial \mathfrak{b}_{j, t}$ is the average change in newly issued credit to firms of type $j$ (as a share of its total assets), $\frac{\partial \mathfrak{i}_{j, t}}{\partial \Delta \log \mathcal{L}_{j, t}}$ is $\alpha_{\mathcal{L}}^{j}+\alpha_{\mathcal{I}}^{j}$ (the estimated overall investment elasticity to bank credit to firms of type $j$ during the stimulus period), $\mathcal{A}_{j, t-1}$ is the average assets of firms of type $j$ in time $t-1$ (2008Q4), and $\mathcal{L}_{j, t-1}$ is the average outstanding amount of credit to firms of type $j$ in time $t-1$ (2008Q4). The first right side term in equation (11) is obtained from the dynamic responses of bank loans to monetary stimulus as computed in Section V; the second right side term is reported in the "Overall investment sensitivity" row of Table 9 . The ratio $\frac{\mathcal{A}_{j, t-1}}{\mathcal{L}_{j, t-1}}$ is an adjustment term for obtaining a percentage increase in investment (as a share of firm assets) in response to monetary stimulus.

Table 10 reports annualized percentage changes of investment in response to the 2009 monetary stimulus in the manufacturing sector versus the entire economy. For the manufacturing sector, monetary stimulus resulted in an increase in investment, on average, by 2.689 percentage points for all firms on an annual basis $(1.157 \times 0.183 \times 3.176 \times 4)$. The increase in SOEs' investment $(8.393=2.018 \times 0.223 \times 4.664 \times 4)$, however, was more than four times the increase in non-SOEs' investment $(1.978=1.071 \times 0.176 \times 2.624 \times 4)$.

In the entire economy, investment for all firms increased, on average, by $8.763(2.270 \times$ $0.328 \times 2.947 \times 4)$ percentage points on an annual basis in response to the 2009 monetary stimulus, more than triple the investment increase of all manufacturing firms (2.689). Two factors explain this result: a larger response of bank credit to monetary stimulus (2.270 versus 1.157 ) and a larger elasticity of investment to bank credit ( 0.328 versus 0.183$)$ for the entire economy than those estimates for the manufacturing sector. The entire economy was also different from the manufacturing sector for SOEs versus non-SOEs. Although the response of SOEs' investment to monetary stimulus was still stronger than the response of non-SOEs' investment $(9.217=2.709 \times 0.212 \times 4.017 \times 4$ versus $7.410=2.132 \times 0.346 \times 2.515 \times 4)$, the difference was much reduced in comparison to the manufacturing sector. Moreover, the investment response of non-SOEs to monetary stimulus in the entire economy was close to four times stronger than the response in the manufacturing sector (7.410 versus 1.978$).{ }^{48}$

\footnotetext{
${ }^{48}$ The response to monetary stimulus of bank credit to non-SOEs and the investment elasticity to bank credit in the entire economy were also larger than those in the manufacturing sector (2.132 versus 1.071 and 0.346 versus 0.176$)$.
} 
Table 11 reports the decomposition of the investment response to the 2009 monetary stimulus on an annual basis for the entire economy. When infrastructure spending interacted with monetary stimulus, investment fell by $0.630(-0.163 \times 0.328 \times 2.947 \times 4)$ percentage point (column 1 of the table). Monetary stimulus absent this fiscal expansion, however, increased investment of all firms by $9.393(2.433 \times 0.328 \times 2.947 \times 4)$ percentage points $($ column 2$)$. Thus, the positive response of investment was entirely attributable to monetary stimulus alone. Absent its interaction with infrastructure spending, the 2009 monetary stimulus would have spawned an increase of non-SOEs' investment by $8.714(2.507 \times 0.346 \times 2.515 \times 4)$ percentage points, larger than the corresponding counterfactual increase in SOEs' investment $(7.630=2.242 \times 0.212 \times 4.017 \times 4)$.

The spree of infrastructure investment had opposite impacts on the transmission of monetary policy to investment of SOEs versus investment of non-SOEs. Interacting with monetary stimulus, infrastructure spending brought an additional increase in SOEs' investment by $1.587(0.466 \times 0.212 \times 4.017 \times 4)$ percentage points, but reduced investment of non-SOEs by $1.304((-0.375) \times 0.346 \times 2.515 \times 4)$ percentage points (column 1 of Table 11$)$. As a result, the 2009 monetary stimulus generated an overall response of SOEs' investment larger than that of non-SOEs' investment (9.217 versus 7.410 in column 3 of the table).

VII.3. Summary and implications on capital misallocation. We summarize the preceding results. Through the bank credit channel, the 2009 monetary stimulus absent fiscal expansion generated higher investment of non-SOEs than investment of SOEs, but the spree of infrastructure spending dampened the monetary effect on investment of non-SOEs while amplifying this effect on investment of SOEs. As a result, an overall response of SOEs' investment was larger than that of non-SOEs' investment. The 2009 monetary stimulus caused both credit and capital allocations from non-SOEs to SOEs; the infrastructure investment spree, driven by non-monetary shocks, played a central role in these allocations.

Against the backdrop of these findings, it is worth examining whether the fiscal-monetary interaction channel is associated with lower efficiency of capital allocation. Several studies have used the sample of manufacturing firms to document that SOEs have lower capital productivity than private firms in China (e.g., Hsieh and Song (2015) and Cong, Gao, Ponticelli, and Yang (2019)). We expand the sample to the entire economy, as we did for the investment regression. Table 12, based on our own data on listed firms, confirms this stylized fact with alternative measures of the average product of capital (APK) for SOEs and non-SOEs. Consistent with the finding in the prior literature, we find the APK lower for SOEs than for non-SOEs in the manufacturing sector by both mean and medium measures. As one moves beyond the manufacturing sector to study the entire economy, the dispersion of APKs between SOEs and non-SOEs becomes even larger, with the mean or median productivity for SOEs much lower than that for private firms. This result is robust to two different measures of the APK. During the stimulus period, therefore, bank credit and physical capital were allocated to SOEs with lower efficiency of production. 


\section{CONCLUSION}

We construct a firm-quarter dataset from our loan-level data and use this unique dataset to estimate the effects of monetary policy and its interaction with infrastructure spending on bank credit as well as investment. A two-stage estimation approach is developed to identify the fiscal-monetary interaction channel of monetary stimulus and examine how this channel affects the overall effect of monetary stimulus on credit allocation. Our key finding for the Chinese economy is that an increase of infrastructure investment significantly weakened the transmission of monetary policy to non-SOE loans, while reinforcing monetary effects on SOE credit. The fiscal-monetary interaction channel is key to understanding the preferential credit access enjoyed by SOEs during the stimulus period.

A fiscal expansion via infrastructure investment amplified positive monetary effects on credit to SOEs in the infrastructure sector and did not weaken those effects on credit to non-SOEs in this sector. At first glance, the fiscal expansion seemed to achieve its goal of enhancing the monetary transmission to credit allocated to the infrastructure sector. In the end, however, the spree of infrastructure investment had adverse impacts on investment of non-SOEs in the entire economy by crowding out their bank loans generated by the 2009 monetary stimulus. The resulting capital misallocation was an unintended consequence of fiscal expansion on the monetary transmission.

In recent years, there has been a resurgence of interest in using infrastructure investment to boost economic growth in China as well as in the United States. How to make infrastructure spending a priority in investment plans of local governments was discussed in a series of Chinese government meetings in the first half of 2020. The 2020 Report on the Work of Government called for "pursuing a more proactive and impactful fiscal policy" for financing infrastructure investment and set the tone for loosening monetary policy through "a variety of tools ... to enable M2 money supply and aggregate financing to grow at notably higher rates than last year." In the United States, Congress has passed a massive infrastructure investment package, which became a law at the end of 2021. How such a fiscal expansion will alter the effectiveness of monetary policy in channeling funds from commercial banks into private firms in sectors other than infrastructure is one of the most relevant and urgent questions. Our current work provides a concrete step toward further research on how the interaction between monetary and fiscal policies can influence the credit channel in particular and the banking system in general. 
TABLE 1. Loan size and firm-specific characteristics for all firms in the firmquarter loan data

\begin{tabular}{|c|c|c|c|c|c|}
\hline & Mean & Median & Std. dev. & $\mathrm{P} 25$ & P75 \\
\hline & \multicolumn{5}{|c|}{ The entire economy } \\
\hline Loan & 143.71 & 74.90 & 275.16 & 30.00 & 183.34 \\
\hline Assets & 3438.37 & 914.43 & 5974.40 & 335.30 & 3077.50 \\
\hline & $61.43 \%$ & $59.97 \%$ & 26.1 & $44.42 \%$ & $75.06 \%$ \\
\hline NPL & $0.42 \%$ & $0.00 \%$ & 5.98 & $0.00 \%$ & $0.00 \%$ \\
\hline \multirow[t]{2}{*}{ Guarantee } & $32.26 \%$ & $2.90 \%$ & $40.18 \%$ & $0.00 \%$ & $69.62 \%$ \\
\hline & \multicolumn{5}{|c|}{ Infrastructure } \\
\hline Loar & 196.94 & 99.00 & 398.67 & 40.00 & 200.00 \\
\hline Ass & 4367.05 & 1316.57 & 6713 & 391.73 & 4602.29 \\
\hline & $6.14 \%$ & & & $49.28 \%$ & $79.77 \%$ \\
\hline NPL & $0.70 \%$ & $0.00 \%$ & $7.71 \%$ & $0.00 \%$ & $0.00 \%$ \\
\hline \multirow[t]{2}{*}{ Guarantee } & $29.89 \%$ & $1.06 \%$ & $39.26 \%$ & $0.00 \%$ & $61.53 \%$ \\
\hline & \multicolumn{5}{|c|}{ Manufacturing } \\
\hline & 21.68 & 60.00 & 193.19 & 30.00 & 150.00 \\
\hline & 821.78 & 970.00 & 646 & 331.00 & 3497.68 \\
\hline & & & & $46.59 \%$ & $72.52 \%$ \\
\hline & $0.28 \%$ & $0.00 \%$ & 4.8 & $0.00 \%$ & $0.00 \%$ \\
\hline \multirow[t]{2}{*}{ Guarantee } & $44.65 \%$ & $39.40 \%$ & $41.07 \%$ & $0.00 \%$ & $91.41 \%$ \\
\hline & \multicolumn{5}{|c|}{ Real estate } \\
\hline & & & 126.52 & 40.00 & 170.00 \\
\hline & 1920.56 & 698.36 & 3729.43 & 320.85 & 1702.20 \\
\hline & & $56.12 \%$ & $25.66 \%$ & $40.20 \%$ & $71.84 \%$ \\
\hline & & $0.00 \%$ & & $0.00 \%$ & $0.00 \%$ \\
\hline \multirow[t]{2}{*}{ Guarantee } & $24.10 \%$ & $0.00 \%$ & $38.27 \%$ & $0.00 \%$ & $43.96 \%$ \\
\hline & \multicolumn{5}{|c|}{ The remaining economy } \\
\hline & & 57.60 & 146.04 & 25.00 & 131.25 \\
\hline & 2575.59 & 697.03 & 5010.70 & 291.12 & 1991.46 \\
\hline & $56.62 \%$ & $54.15 \%$ & $26.47 \%$ & $38.40 \%$ & $70.77 \%$ \\
\hline & $0.31 \%$ & $0.00 \%$ & $5.08 \%$ & $0.00 \%$ & $0.00 \%$ \\
\hline Guarantee & $27.56 \%$ & $0.00 \%$ & $38.69 \%$ & $0.00 \%$ & $55.19 \%$ \\
\hline
\end{tabular}

Notes: Each of the variables reported in the table is the quarterly average for each firm over the sample period. The acronym "NPL" stands for non-performing loans as a fraction of the total loans, "Guarantee" is a fraction of total loans guaranteed by third-parties, "Std. dev." stands for standard deviation, P25 is the 25th percentile, and P75 is the 75th percentile. Loan size is in million RMB. Assets are total assets in million RMB. Leverage is expressed as a ratio of total liabilities over total assets. 
TABLE 3. Monetary policy and infrastructure investment

\begin{tabular}{c|l|c||c|l|c}
\hline \hline & \multicolumn{2}{|c||}{ Dependent variable: $g_{m, t}$} & & \multicolumn{2}{c}{ Dependent variable: $g_{\text {infra }, t}^{o}$} \\
\hline Regressor & Estimate & Standard error & Regressor & Estimate & Standard error \\
\hline Constant & $0.035^{* * *}$ & 0.002 & $g_{\text {infra }, t-1}^{o}$ & $0.457^{* * *}$ & 0.164 \\
$g_{\text {infra }, t}^{o}$ & 0.105 & 0.064 & $\varepsilon_{m, t}$ & 0.292 & 0.514 \\
\hline \hline
\end{tabular}

Notes: The superscript ${ }^{* * *}$ represents the 0.01 significance level. The constant term in the regression on the right panel of the table is statistically insignificant.

TABLE 4. Regression of bank-specific loans driven by monetary policy shocks, $\ell_{b, t}^{m}$, on growth of infrastructure investment, $g_{\text {infra, },}^{o}$.

\begin{tabular}{|c|c|c|c|c|c|c|}
\hline Dependent variable & $\ell_{b=1, t}^{m}$ & $\ell_{b=2, t}^{m}$ & $\ell_{b=3, t}^{m}$ & $\ell_{b=4, t}^{m}$ & $\ell_{b=5, t}^{m}$ & $\ell_{b=6, t}^{m}$ \\
\hline \multirow{2}{*}{$g_{\text {infra }, t}^{O}$} & -0.318 & 0.657 & -0.205 & 0.265 & 0.298 & 1.792 \\
\hline & $(1.062)$ & $(0.622)$ & $(0.481)$ & $(0.389)$ & $(0.296)$ & $(1.234)$ \\
\hline \multirow[t]{2}{*}{$g_{m, t}$} & 2.990 & $5.899^{* * *}$ & $6.461^{* * *}$ & $7.314^{* * *}$ & $4.908^{* * *}$ & $7.640^{*}$ \\
\hline & $(3.461)$ & $(2.028)$ & $(1.567)$ & $(1.267)$ & $(0.965)$ & $(4.022)$ \\
\hline \multirow[t]{3}{*}{ Constant } & $0.185^{* * *}$ & $0.154^{* * *}$ & $0.071^{* * *}$ & $0.095^{* * *}$ & $0.120^{* * *}$ & $0.286^{* * *}$ \\
\hline & $(0.038)$ & $(0.022)$ & $(0.017)$ & $(0.014)$ & $(0.011)$ & $(0.044)$ \\
\hline & $\ell_{b=7, t}^{m}$ & $\ell_{b=8, t}^{m}$ & $\ell_{b=9, t}^{m}$ & $\ell_{b=10, t}^{m}$ & $\ell_{b=11, t}^{m}$ & $\ell_{b=12, t}^{m}$ \\
\hline \multirow[t]{2}{*}{$g_{\text {infra }, t}^{o}$} & 7.261 & $0.270^{*}$ & -0.036 & -0.136 & -0.429 & -0.004 \\
\hline & $(5.977)$ & $(0.156)$ & $(0.604)$ & $(0.480)$ & $(5.171)$ & $(0.655)$ \\
\hline \multirow[t]{2}{*}{$g_{m, t}$} & 3.940 & $2.061^{* * *}$ & 2.426 & $5.617^{* * *}$ & 4.450 & $7.464^{* * *}$ \\
\hline & $(19.484)$ & $(0.507)$ & $(1.968)$ & $(1.566)$ & $(16.859)$ & $(2.135)$ \\
\hline \multirow[t]{3}{*}{ Constant } & $0.398^{*}$ & $0.081^{* * *}$ & $0.114^{* * *}$ & $0.100^{* * *}$ & $0.514^{* *}$ & $0.142^{* * *}$ \\
\hline & $(0.216)$ & $(0.006)$ & $(0.022)$ & $(0.017)$ & $(0.187)$ & $(0.024)$ \\
\hline & $\ell_{b=13, t}^{m}$ & $\ell_{b=14, t}^{m}$ & $\ell_{b=15, t}^{m}$ & $\ell_{b=16, t}^{m}$ & $\ell_{b=17, t}^{m}$ & All banks \\
\hline \multirow[t]{2}{*}{$g_{\text {infra }, t}^{o}$} & 0.089 & 2.023 & -0.525 & 0.257 & 0.466 & -0.057 \\
\hline & $(0.456)$ & $(1.941)$ & $(0.556)$ & $(1.179)$ & $(0.907)$ & $(0.233)$ \\
\hline \multirow[t]{2}{*}{$g_{m, t}$} & $3.449^{* *}$ & $31.970^{* * *}$ & $3.453^{*}$ & $11.968^{* * *}$ & 4.281 & $3.899^{* * *}$ \\
\hline & (1.487) & $(6.327)$ & $(1.811)$ & $(3.842)$ & $(2.958)$ & $(0.761)$ \\
\hline \multirow[t]{2}{*}{ Constant } & $0.128^{* * *}$ & $0.291^{* * *}$ & $0.129^{* * *}$ & $0.211^{* * *}$ & $0.151^{* * *}$ & $0.102^{* * *}$ \\
\hline & $(0.016)$ & $(0.070)$ & $(0.020)$ & $(0.043)$ & $(0.033)$ & $(0.008)$ \\
\hline
\end{tabular}

Notes: The subscript $b=i$ in $\ell_{b=i, t}^{m}$ for $i=1, \ldots, 17$ represents the $i^{\text {th }}$ bank in our sample. The superscript * represents the 0.1 significance level, ${ }^{* *} 0.05$ level, and ${ }^{* * *} 0.01$. 
TABLE 5. Estimation results for the effects of aggregate monetary stimulus from dynamic panel regression (1): the Chinese economy

\begin{tabular}{|c|c|c|c|}
\hline Monetary effect & $\begin{array}{l}\text { All firms } \\
\text { (1) }\end{array}$ & $\begin{array}{l}\text { SOEs } \\
(2)\end{array}$ & $\begin{array}{l}\text { Non-SOEs } \\
\text { (3) }\end{array}$ \\
\hline$b_{0}:$ interactive & $\begin{array}{l}-0.135 \\
(0346)\end{array}$ & $1.534^{* *}$ & $\begin{array}{l}-0.688^{*} \\
(0413)\end{array}$ \\
\hline$b_{1}$ : interactive & $\begin{array}{c}0.097 \\
(0.435)\end{array}$ & $\begin{array}{c}2.483^{* * *} \\
(0.780)\end{array}$ & $\begin{array}{l}-0.696 \\
(0.520)\end{array}$ \\
\hline$b_{2}:$ interactive & $\begin{array}{c}-1.800^{* * *} \\
(0.437)\end{array}$ & $\begin{array}{l}-0.119 \\
(0.784)\end{array}$ & $\begin{array}{c}-2.341^{* * *} \\
(0.522)\end{array}$ \\
\hline$b_{3}:$ interactive & $\begin{array}{l}-0.043 \\
(0.379)\end{array}$ & $\begin{array}{c}0.876 \\
(0.681)\end{array}$ & $\begin{array}{l}-0.345 \\
(0.452)\end{array}$ \\
\hline$d_{0}:$ pure & $\begin{array}{c}0.485^{* * *} \\
(0.032)\end{array}$ & $\begin{array}{c}0.444^{* * *} \\
(0.058)\end{array}$ & $\begin{array}{r}0.501^{* * *} \\
(0.038)\end{array}$ \\
\hline$d_{1}:$ pure & $\begin{array}{r}0.493^{* * *} \\
(0.034)\end{array}$ & $\begin{array}{c}0.478^{* * *} \\
(0.061)\end{array}$ & $\begin{array}{c}0.501^{* * *} \\
(0.041)\end{array}$ \\
\hline$d_{2}:$ pure & $\begin{array}{r}0.191^{* * *} \\
(0.029)\end{array}$ & $\begin{array}{r}0.174^{* * *} \\
(0.052)\end{array}$ & $\begin{array}{c}0.199^{* * *} \\
(0.034)\end{array}$ \\
\hline$d_{3}:$ pure & $\begin{array}{r}0.168^{* * *} \\
(0.024)\end{array}$ & $\begin{array}{c}0.160^{* * *} \\
(0.043)\end{array}$ & $\begin{array}{c}0.173^{* * *} \\
(0.029)\end{array}$ \\
\hline$\sum_{k} b_{k}:$ interactive & $\begin{array}{l}-1.882^{*} \\
(1.010)\end{array}$ & $\begin{array}{l}4.774^{* * *} \\
(1.812)\end{array}$ & $\begin{array}{c}-4.070^{* * *} \\
(1.205)\end{array}$ \\
\hline$\sum_{k} d_{k}:$ pure & $\begin{array}{l}1.337^{* * *} \\
(0.064)\end{array}$ & $\begin{array}{l}1.256^{* * *} \\
(0.115)\end{array}$ & $\begin{array}{c}1.374^{* * *} \\
(0.076)\end{array}$ \\
\hline $\begin{array}{l}\text { Overall effect: } \bar{g}_{\text {infra }} \sum_{k} b_{k} \\
+\sum_{k} d_{k}\end{array}$ & $\begin{array}{r}1.188^{* * *} \\
(0.062)\end{array}$ & $\begin{array}{c}1.635^{* * *} \\
(0.111)\end{array}$ & $\begin{array}{c}1.051^{* * *} \\
(0.073)\end{array}$ \\
\hline \# of observations & 157895 & 40549 & 117346 \\
\hline Fixed effects & Yes & Yes & Yes \\
\hline Firm-level controls & Yes & Yes & Yes \\
\hline Aggregate controls & Yes & Yes & Yes \\
\hline
\end{tabular}

Notes: This table reports the results of regressions in which the dependent variable is a firm-quarter observation of newly issued bank credit to a firm, scaled by the firm's total nominal assets. The right-hand variables include contemporaneous and lagged monetary policy shocks and their interactions with the respective growth rates of infrastructure investment. These variables are obtained from the first-stage estimation. The firm-level control variables include the NPL ratio, the guarantee ratio, assets, and the leverage ratio, all lagged by one period. The aggregate control variables include lagged GDP growth net of infrastructure investment, lagged inflation, and contemporaneous and lagged growth rates of infrastructure investment, all of which are obtained from the first-stage estimation. Columns 2 and 3 report the estimates based on the subsamples of SOEs and non-SOEs in the entire economy, and column 1 reports the estimates using the sample of all firms in the entire economy. The average growth rate of $g_{\text {infra, } t}^{o}$ in the fiscal expansion period is denoted by $\bar{g}_{\text {infra }}$. The values in parentheses are standard errors. The difference between the overall effects on SOEs non-SOEs is statistically significant at the 0.01 level. The superscript * represents the 0.1 significance level, ${ }^{* *} 0.05$, and ${ }^{* * *} 0.01$. 
TABLE 6. Estimation results for the effects of aggregate monetary stimulus from dynamic panel regression (1): key sectors

\begin{tabular}{|c|c|c|c|c|c|c|}
\hline \multirow[b]{2}{*}{ Monetary effect } & \multicolumn{2}{|c|}{ Infrastructure } & \multicolumn{2}{|c|}{ Manufacturing } & \multicolumn{2}{|c|}{ Real estate } \\
\hline & $\begin{array}{l}\text { SOEs } \\
(1)\end{array}$ & $\begin{array}{c}\text { Non-SOEs } \\
(2)\end{array}$ & $\begin{array}{l}\text { SOEs } \\
(3)\end{array}$ & $\begin{array}{c}\text { Non-SOEs } \\
\text { (4) }\end{array}$ & $\begin{array}{l}\text { SOEs } \\
(5)\end{array}$ & $\begin{array}{c}\text { Non-SOEs } \\
(6)\end{array}$ \\
\hline$b_{0}:$ interactive & $\begin{array}{c}3.196^{* * *} \\
(1.111)\end{array}$ & $\begin{array}{c}3.117^{* * *} \\
(0.972)\end{array}$ & $\begin{array}{c}0.512 \\
(1.396)\end{array}$ & $\begin{array}{l}-0.303 \\
(0.361)\end{array}$ & $\begin{array}{l}-1.514 \\
(2.160)\end{array}$ & $\begin{array}{c}-7.673^{* * *} \\
(1.413)\end{array}$ \\
\hline$b_{1}$ : interactive & $\begin{array}{c}4.028^{* * *} \\
(1.394)\end{array}$ & $\begin{array}{c}4.646^{* * *} \\
(1.221)\end{array}$ & $\begin{array}{l}-1.786 \\
(1.758)\end{array}$ & $\begin{array}{c}0.061 \\
(0.456)\end{array}$ & $\begin{array}{l}-1.989 \\
(2.722)\end{array}$ & $\begin{array}{c}-11.690^{* * *} \\
(1.778)\end{array}$ \\
\hline$b_{2}$ : interactive & $\begin{array}{c}0.485 \\
(1.402)\end{array}$ & $\begin{array}{c}-2.206^{*} \\
(1.231)\end{array}$ & $\begin{array}{l}-2.066 \\
(1.757)\end{array}$ & $\begin{array}{c}-1.067^{* *} \\
(0.455)\end{array}$ & $\begin{array}{r}-5.515^{* *} \\
(2.716)\end{array}$ & $\begin{array}{c}-7.486^{* * *} \\
(1.791)\end{array}$ \\
\hline$b_{3}:$ interactive & $\begin{array}{c}1.095 \\
(1.220)\end{array}$ & $\begin{array}{l}-1.563 \\
(1.069)\end{array}$ & $\begin{array}{c}1.488 \\
(1.519)\end{array}$ & $\begin{array}{c}-0.972^{* *} \\
(0.394)\end{array}$ & $\begin{array}{l}-0.145 \\
(2.356)\end{array}$ & $\begin{array}{c}0.858 \\
(1.548)\end{array}$ \\
\hline$d_{0}:$ pure & $\begin{array}{c}0.448^{* * *} \\
(0.104)\end{array}$ & $\begin{array}{c}0.362^{* * *} \\
(0.091)\end{array}$ & $\begin{array}{c}0.470^{* * *} \\
(0.129)\end{array}$ & $\begin{array}{c}0.232^{* * *} \\
(0.034)\end{array}$ & $\begin{array}{c}0.343^{*} \\
(0.201)\end{array}$ & $\begin{array}{c}1.288^{* * *} \\
(0.132)\end{array}$ \\
\hline$d_{1}:$ pure & $\begin{array}{c}0.461^{* * *} \\
(0.110)\end{array}$ & $\begin{array}{c}0.515^{* * *} \\
(0.096)\end{array}$ & $\begin{array}{c}0.506^{* * *} \\
(0.138)\end{array}$ & $\begin{array}{c}0.211^{* * *} \\
(0.036)\end{array}$ & $\begin{array}{c}0.551^{* * *} \\
(0.212)\end{array}$ & $\begin{array}{c}1.190^{* * *} \\
(0.140)\end{array}$ \\
\hline$d_{2}:$ pure & $\begin{array}{l}0.218^{* *} \\
(0.092)\end{array}$ & $\begin{array}{c}0.230^{* * *} \\
(0.081)\end{array}$ & $\begin{array}{c}0.123 \\
(0.115)\end{array}$ & $\begin{array}{c}0.189^{* * *} \\
(0.030)\end{array}$ & $\begin{array}{c}0.029 \\
(0.180)\end{array}$ & $\begin{array}{c}0.313^{* * *} \\
(0.118)\end{array}$ \\
\hline$d_{3}:$ pure & $\begin{array}{c}0.242^{* * *} \\
(0.077)\end{array}$ & $\begin{array}{c}0.290^{* * *} \\
(0.067)\end{array}$ & $\begin{array}{c}0.078 \\
(0.097)\end{array}$ & $\begin{array}{c}0.084^{* * *} \\
(0.025)\end{array}$ & $\begin{array}{l}-0.085 \\
(0.149)\end{array}$ & $\begin{array}{c}0.314^{* * *} \\
(0.097)\end{array}$ \\
\hline$\sum_{k} b_{k}:$ interactive & $\begin{array}{c}8.803^{* * *} \\
(3.239)\end{array}$ & $\begin{array}{c}3.993 \\
(2.840)\end{array}$ & $\begin{array}{l}-1.853 \\
(4.058)\end{array}$ & $\begin{array}{c}-2.281^{* *} \\
(1.052)\end{array}$ & $\begin{array}{l}-9.164 \\
(6.299)\end{array}$ & $\begin{array}{c}-25.991^{* * *} \\
(4.130)\end{array}$ \\
\hline$\sum_{k} d_{k}:$ pure & $\begin{array}{c}1.369^{* * *} \\
(0.206)\end{array}$ & $\begin{array}{c}1.396^{* * *} \\
(0.179)\end{array}$ & $\begin{array}{c}1.177^{* * *} \\
(0.259)\end{array}$ & $\begin{array}{c}0.716^{* * *} \\
(0.067)\end{array}$ & $\begin{array}{l}0.839^{* *} \\
(0.400)\end{array}$ & $\begin{array}{c}3.105^{* * *} \\
(0.262)\end{array}$ \\
\hline \# of observations & 16721 & 35765 & 5773 & 49726 & 1380 & 13570 \\
\hline Fixed effects & Yes & Yes & Yes & Yes & Yes & Yes \\
\hline Firm-level controls & Yes & Yes & Yes & Yes & Yes & Yes \\
\hline Aggregate controls & Yes & Yes & Yes & Yes & Yes & Yes \\
\hline
\end{tabular}

Notes: This table reports the results of regressions in which the dependent variable is a firm-quarter observation of newly issued bank credit to a firm, scaled by the firm's total nominal assets. The right-hand variables include contemporaneous and lagged monetary policy shocks and their interactions with the respective growth rates of infrastructure investment. These variables are obtained from the first-stage estimation. The firm-level control variables include the NPL ratio, the guarantee ratio, assets, and the leverage ratio, all lagged by one period. The aggregate control variables include lagged GDP growth net of infrastructure investment, lagged inflation, and contemporaneous and lagged growth rates of infrastructure investment, all of which are obtained from the first-stage estimation. The values in parentheses are standard errors. The superscript ${ }^{*}$ represents the 0.1 significance level, ** 0.05 , and $* * * 0.01$. 
TABLE 7. Estimation results of the effects of firm-specific monetary stimulus for dynamic panel regression (7): key sectors

\begin{tabular}{l|cc|cc|cc}
\hline \hline & \multicolumn{2}{|c|}{ Infrastructure } & \multicolumn{2}{c|}{ Manufacturing } & \multicolumn{2}{c}{ Real estate } \\
Monetary effect & SOEs & Non-SOEs & SOEs & Non-SOEs & SOEs & Non-SOEs \\
\hline$b_{0}$ : interactive & 0.400 & $0.757^{* * *}$ & 0.103 & -0.111 & -0.088 & $-1.401^{* * *}$ \\
$b_{1}$ : interactive & $(0.244)$ & $(0.228)$ & $(0.323)$ & $(0.079)$ & $(0.454)$ & $(0.286)$ \\
& $1.359^{* * *}$ & $1.850^{* * *}$ & 0.270 & 0.099 & 0.778 & $-1.402^{* * *}$ \\
$b_{2}$ : interactive & $(0.303)$ & $(0.285)$ & $(0.407)$ & $(0.099)$ & $(0.571)$ & $(0.352)$ \\
& 0.268 & $-0.558^{* *}$ & -0.481 & $-0.203^{* *}$ & $-1.136^{* *}$ & $-0.881^{* * *}$ \\
$b_{3}$ : interactive & $(0.296)$ & $(0.279)$ & $(0.395)$ & $(0.096)$ & $(0.547)$ & $(0.332)$ \\
& -0.084 & -0.383 & 0.074 & $-0.261^{* * *}$ & -0.122 & 0.213 \\
$d_{0}$ : pure & $(0.249)$ & $(0.236)$ & $(0.335)$ & $(0.081)$ & $(0.458)$ & $(0.275)$ \\
& $0.079^{* * *}$ & $0.082^{* * *}$ & $0.094^{* * *}$ & $0.035^{* * *}$ & 0.064 & $0.145^{* * *}$ \\
$d_{1}$ : pure & $(0.022)$ & $(0.021)$ & $(0.029)$ & $(0.007)$ & $(0.041)$ & $(0.025)$ \\
& $0.071^{* * *}$ & $0.119^{* * *}$ & $0.096^{* * *}$ & $0.031^{* * *}$ & $0.108^{* *}$ & $0.111^{* * *}$ \\
$d_{2}:$ pure & $(0.023)$ & $(0.021)$ & $(0.031)$ & $(0.007)$ & $(0.042)$ & $(0.026)$ \\
& 0.027 & $0.069^{* * *}$ & 0.023 & $0.037^{* * *}$ & 0.032 & 0.027 \\
$d_{3}$ : pure & $(0.020)$ & $(0.018)$ & $(0.026)$ & $(0.006)$ & $(0.037)$ & $(0.022)$ \\
& $0.060^{* * *}$ & $0.059^{* * *}$ & 0.029 & $0.011^{* *}$ & -0.014 & $0.034^{*}$ \\
\hline$\sum_{k} b_{k}$ : interactive & $(0.016)$ & $(0.015)$ & $(0.022)$ & $(0.005)$ & $(0.030)$ & $(0.019)$ \\
\hline$\sum_{k} d_{k}:$ pure & $1.943^{* * *}$ & $1.665^{* *}$ & -0.034 & $-0.476^{* *}$ & -0.569 & $-3.471^{* * *}$ \\
& $(0.694)$ & $(0.655)$ & $(0.928)$ & $(0.225)$ & $(1.289)$ & $(0.794)$ \\
$\#$ of observations & $0.237^{* * *}$ & $0.330^{* * *}$ & $0.241^{* * *}$ & $0.114^{* * *}$ & $0.191^{* *}$ & $0.317^{* * *}$ \\
\hline Fixed effects & $(0.042)$ & $(0.039)$ & $(0.056)$ & $(0.013)$ & $(0.076)$ & $(0.045)$ \\
Aggregate controls & 14720 & 32729 & 5313 & 46782 & 1219 & 12351 \\
\hline \hline
\end{tabular}

Notes: This table reports the results of regressions in which the dependent variable is a firm-quarter observation of newly issued bank credit to a firm, scaled by the firm's total nominal assets. The right-hand variables include contemporaneous and lagged firm-specific monetary shocks constructed by equation (6) and their interactions with changes in infrastructure investment. These variables are obtained from the first-stage estimation. The firm-level control variables include the NPL ratio, the guarantee ratio, assets, and the leverage ratio, all lagged by one period. The aggregate control variables include lagged GDP growth net of infrastructure investment, lagged inflation, and contemporaneous and lagged growth rates of infrastructure investment, all of which are obtained from the first-stage estimation. The values in parentheses are standard errors. The superscript ${ }^{*}$ represents the 0.1 significance level, ${ }^{* *} 0.05$, and ${ }^{* * *} 0.01$. 
TABLE 8. Pure monetary effects on firms grouped by capital intensity

\begin{tabular}{|c|c|c|c|c|}
\hline \multirow[b]{2}{*}{ Monetary effect } & \multicolumn{2}{|c|}{ Manufacturing } & \multicolumn{2}{|c|}{ Entire Economy } \\
\hline & $\begin{array}{l}\text { SOEs } \\
(1)\end{array}$ & $\begin{array}{c}\text { Non-SOEs } \\
(2)\end{array}$ & $\begin{array}{l}\text { SOEs } \\
(3)\end{array}$ & $\begin{array}{c}\text { Non-SOEs } \\
\text { (4) }\end{array}$ \\
\hline$d_{C, 0}$ & $\begin{array}{l}0.579^{* *} \\
(0.270)\end{array}$ & $\begin{array}{c}0.292^{* * *} \\
(0.081)\end{array}$ & $\begin{array}{c}0.418^{* * *} \\
(0.094)\end{array}$ & $\begin{array}{c}0.650^{* * *} \\
(0.058)\end{array}$ \\
\hline$d_{C, 1}$ & $\begin{array}{c}0.438^{* * *} \\
(0.158)\end{array}$ & $\begin{array}{r}0.204^{* * *} \\
(0.039)\end{array}$ & $\begin{array}{c}0.400^{* * *} \\
(0.113)\end{array}$ & $\begin{array}{c}0.381^{* * *} \\
(0.056)\end{array}$ \\
\hline$d_{C, 2}$ & $\begin{array}{c}0.755^{* * *} \\
(0.275)\end{array}$ & $\begin{array}{l}0.210^{* *} \\
(0.082)\end{array}$ & $\begin{array}{r}0.464^{* * *} \\
(0.097)\end{array}$ & $\begin{array}{c}0.640^{* * *} \\
(0.060)\end{array}$ \\
\hline$d_{C, 3}$ & $\begin{array}{c}0.188 \\
(0.224)\end{array}$ & $\begin{array}{c}0.226^{* * *} \\
(0.067)\end{array}$ & $\begin{array}{l}0.181^{* *} \\
(0.081)\end{array}$ & $\begin{array}{c}0.240^{* * *} \\
(0.050)\end{array}$ \\
\hline$d_{N, 0}$ & $\begin{array}{c}0.056 \\
(0.192)\end{array}$ & $\begin{array}{c}0.218^{* * *} \\
(0.057)\end{array}$ & $\begin{array}{l}0.132^{*} \\
(0.068)\end{array}$ & $\begin{array}{c}0.231^{* * *} \\
(0.042)\end{array}$ \\
\hline$d_{N, 1}$ & $\begin{array}{c}0.441^{* * *} \\
(0.167)\end{array}$ & $\begin{array}{c}0.199^{* * *} \\
(0.041)\end{array}$ & $\begin{array}{r}0.410^{* * *} \\
(0.116)\end{array}$ & $\begin{array}{c}0.383^{* * *} \\
(0.058)\end{array}$ \\
\hline$d_{N, 2}$ & $\begin{array}{c}0.145 \\
(0.138)\end{array}$ & $\begin{array}{c}0.177^{* * *} \\
(0.034)\end{array}$ & $\begin{array}{c}0.170^{*} \\
(0.096)\end{array}$ & $\begin{array}{c}0.132^{* * *} \\
(0.048)\end{array}$ \\
\hline$d_{N, 3}$ & $\begin{array}{c}0.090 \\
(0.117)\end{array}$ & $\begin{array}{c}0.052^{*} \\
(0.029)\end{array}$ & $\begin{array}{l}0.158^{*} \\
(0.081)\end{array}$ & $\begin{array}{c}0.126^{* * *} \\
(0.040)\end{array}$ \\
\hline$\sum_{k} d_{C, k}$ & $\begin{array}{l}1.960^{* * *} \\
(0.574)\end{array}$ & $\begin{array}{c}0.931^{* * *} \\
(0.168)\end{array}$ & $\begin{array}{l}1.462^{* * *} \\
(0.234)\end{array}$ & $\begin{array}{c}1.912^{* * *} \\
(0.137)\end{array}$ \\
\hline$\sum_{k} d_{N, k}$ & $\begin{array}{l}0.732^{* *} \\
(0.312)\end{array}$ & $\begin{array}{c}0.647^{* * *} \\
(0.083)\end{array}$ & $\begin{array}{c}0.870^{* * *} \\
(0.181)\end{array}$ & $\begin{array}{c}0.872^{* * *} \\
(0.093)\end{array}$ \\
\hline$\sum_{k} d_{C, k}-\sum_{k} d_{N, k}$ & $\begin{array}{l}1.229^{*} \\
(0.679)\end{array}$ & $\begin{array}{c}0.285 \\
(0.198)\end{array}$ & $\begin{array}{l}0.592^{* *} \\
(0.289)\end{array}$ & $\begin{array}{c}1.039^{* * *} \\
(0.165)\end{array}$ \\
\hline \# of observations & 4899 & 42435 & 24426 & 100648 \\
\hline Fixed effects & Yes & Yes & Yes & Yes \\
\hline Firm-level controls & Yes & Yes & Yes & Yes \\
\hline Aggregate controls & Yes & Yes & Yes & Yes \\
\hline
\end{tabular}

Notes: This table reports the results of regressions in which the dependent variable is a firm-quarter observation of newly issued bank credit to a firm, scaled by the firm's total nominal assets. The right-hand variables include contemporaneous and lagged monetary policy shocks and their interactions with the respective growth rates of infrastructure investment. These variables are obtained from the first-stage estimation. The subscript " $N$ " in coefficient $d_{N, k}$ indicates non-capital intensive and " $C$ " in coefficient $d_{C, k}$ indicates capital intensive. The firm-level control variables include the NPL ratio, the guarantee ratio, assets, and the leverage ratio, all lagged by one period. The aggregate control variables include lagged GDP growth net of infrastructure investment, lagged inflation, and contemporaneous and lagged growth rates of infrastructure investment, all of which are obtained from the first-stage estimation. The values in parentheses are standard errors. The superscript ${ }^{*}$ represents the 0.1 significance level, ${ }^{* *} 0.05$, and ${ }^{* * *} 0.01$. 


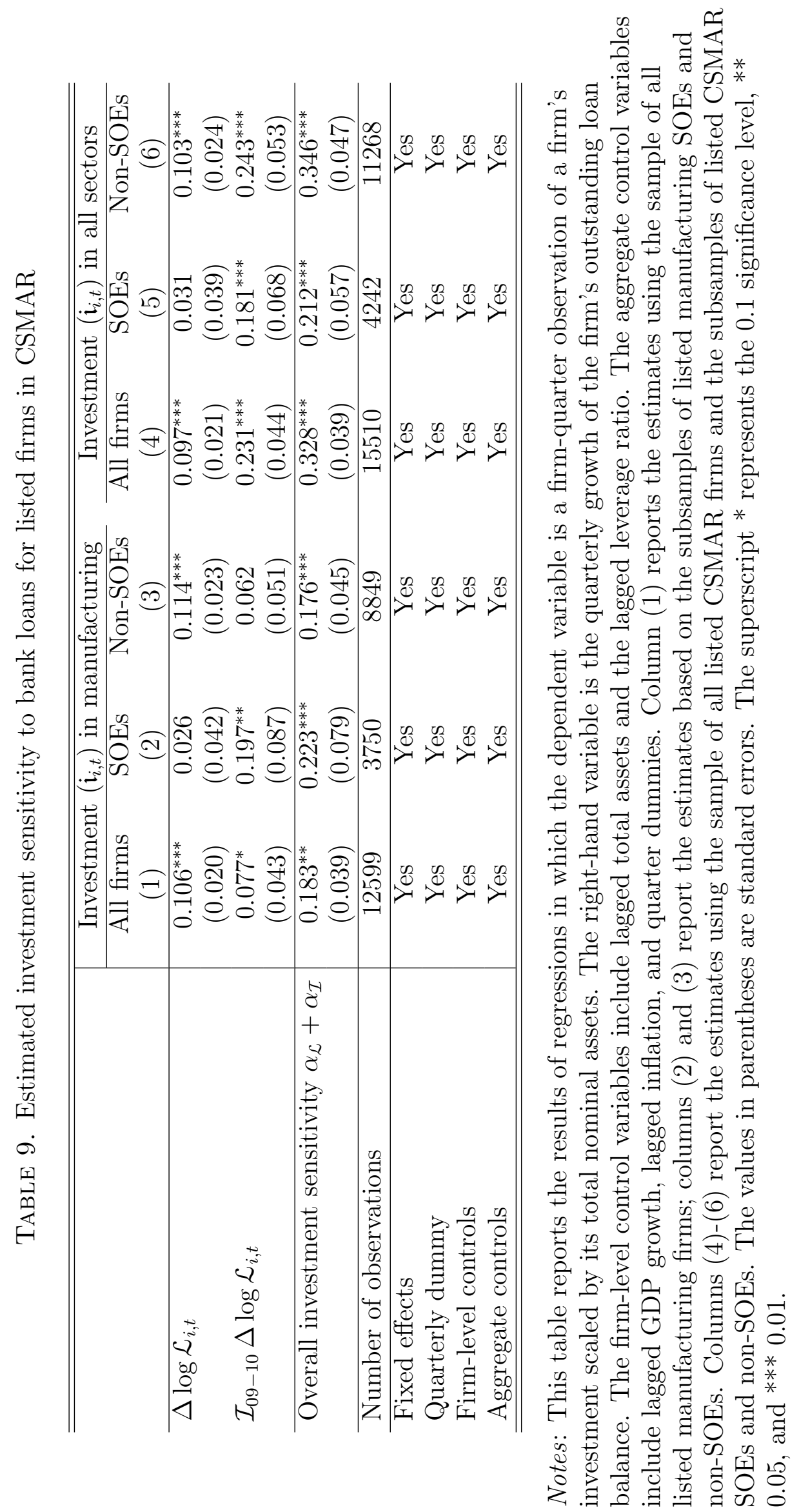


TABLE 10. Impacts of the 2009Q1-2009Q3 monetary stimulus on investment

\begin{tabular}{l|c|c}
\hline \hline & Manufacturing & The entire economy \\
\hline SOEs & 8.393 & 9.217 \\
Non-SOEs & 1.978 & 7.410 \\
All firms & 2.689 & 8.763 \\
\hline
\end{tabular}

Notes: The values, expressed in percentage points, represent increases of investment as a share of the firm's assets.

TABLE 11. Decomposition of the monetary effect on investment in the entire economy

\begin{tabular}{l|c|c|c}
\hline \hline & $\begin{array}{c}\text { Interactive } \\
(1)\end{array}$ & $\begin{array}{c}\text { Pure } \\
(2)\end{array}$ & $\begin{array}{c}\text { Overall } \\
(3)\end{array}$ \\
\hline SOEs & 1.587 & 7.630 & 9.217 \\
Non-SOEs & -1.304 & 8.714 & 7.410 \\
All firms & -0.630 & 9.393 & 8.763 \\
\hline \hline
\end{tabular}

Notes: The values, expressed in percentage points, represent increases of investment as a share of the firm's assets.

TABLE 12. Capital productivity of SOEs versus non-SOEs

\begin{tabular}{c|c|c|c|c|c|c|c|c}
\hline \hline & \multicolumn{3}{|c|}{ Manufacturing } & \multicolumn{3}{c}{ The entire economy } \\
\hline & \multicolumn{2}{|c|}{ SOEs } & \multicolumn{2}{c|}{ Non-SOEs } & \multicolumn{2}{c}{ SOEs } & \multicolumn{2}{c}{ Non-SOEs } \\
\hline Productivity & Mean & Median & Mean & Median & Mean & Median & Mean & Median \\
\hline Value-added $/ K$ & 64.94 & 40.30 & 94.83 & 57.52 & 60.86 & 36.76 & 104.54 & 54.72 \\
Revenue $/ K$ & 401.45 & 250.97 & 570.63 & 284.51 & 371.11 & 223.71 & 607.14 & 269.67 \\
\hline \hline
\end{tabular}

Notes: "Value-added" is proxied by total operating income (equal to the difference of total revenue (item B001100000) and operating expenses (item B001201000)). "Revenue" is measured as total revenue (item B001100000). The symbol $K$ stands for physical capital, which is the sum of net fixed assets and the disposal of fixed assets (item A001212000 + item A001215000). Thus, it measures property, plant, and equipment (all net). All item numbers in parentheses refer to CSMAR.

Source: CSMAR. 

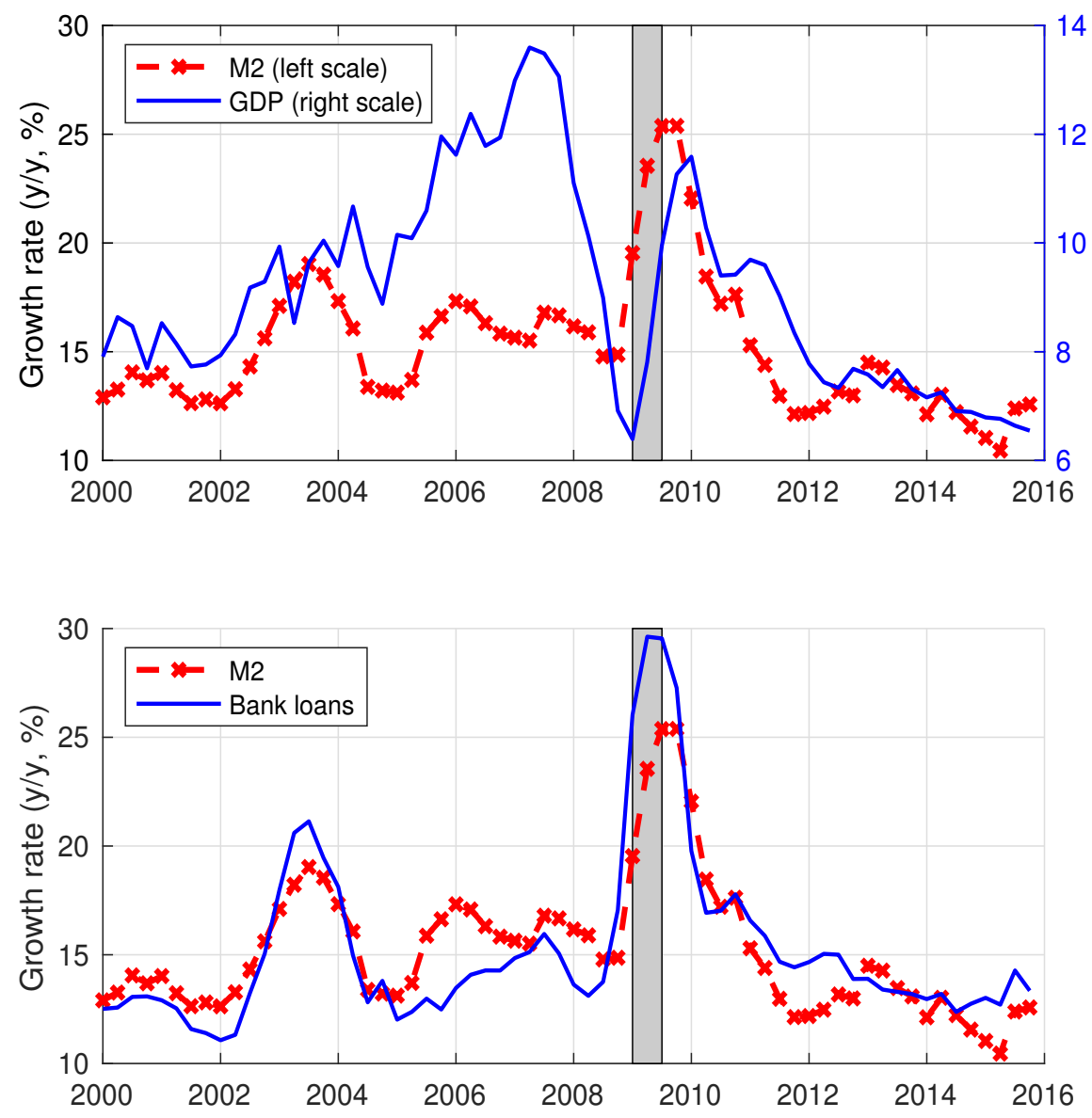

FiguRE 1. The time series of annual growth rates of GDP, M2, and bank lending. Notes: The shaded bar marks the monetary stimulus period of 2009Q12009Q3. 


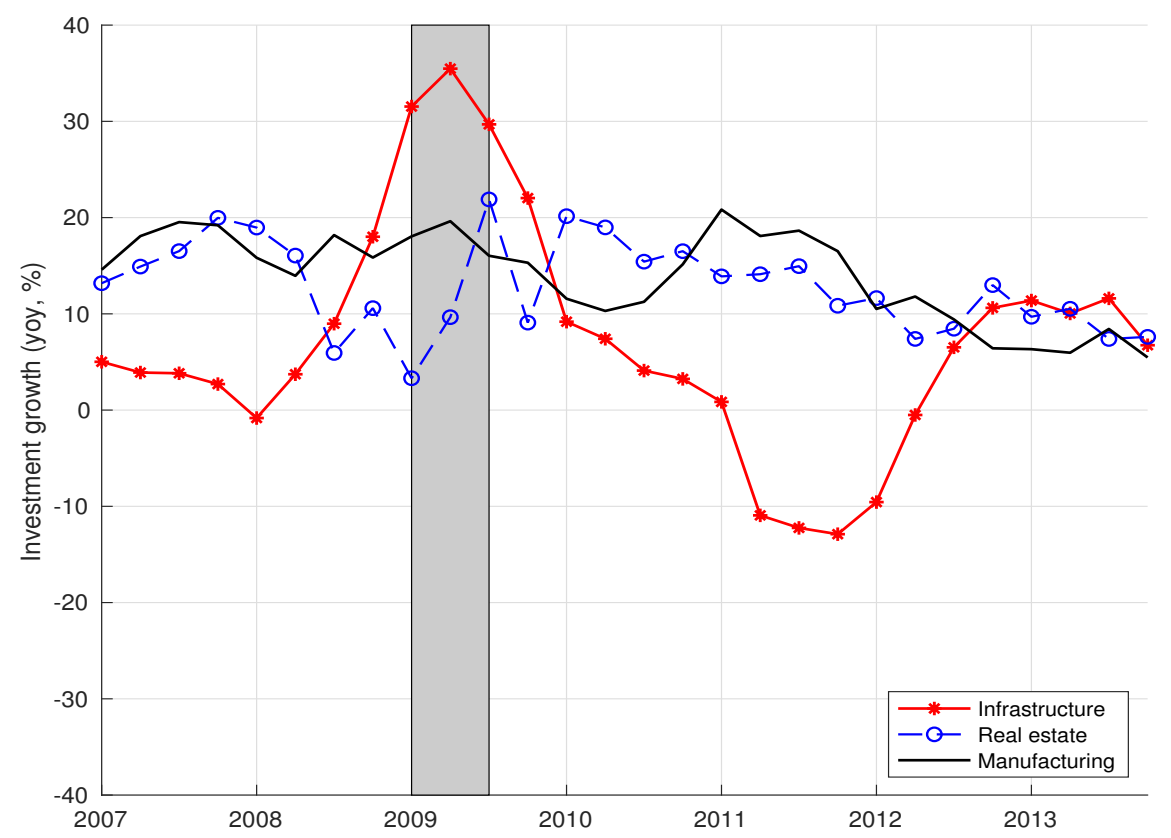

FIGURE 2. Real investment in various sectors. Notes: All series are deflated by the GDP deflator. The shaded bar marks the monetary stimulus period of 2009Q1-2009Q3.
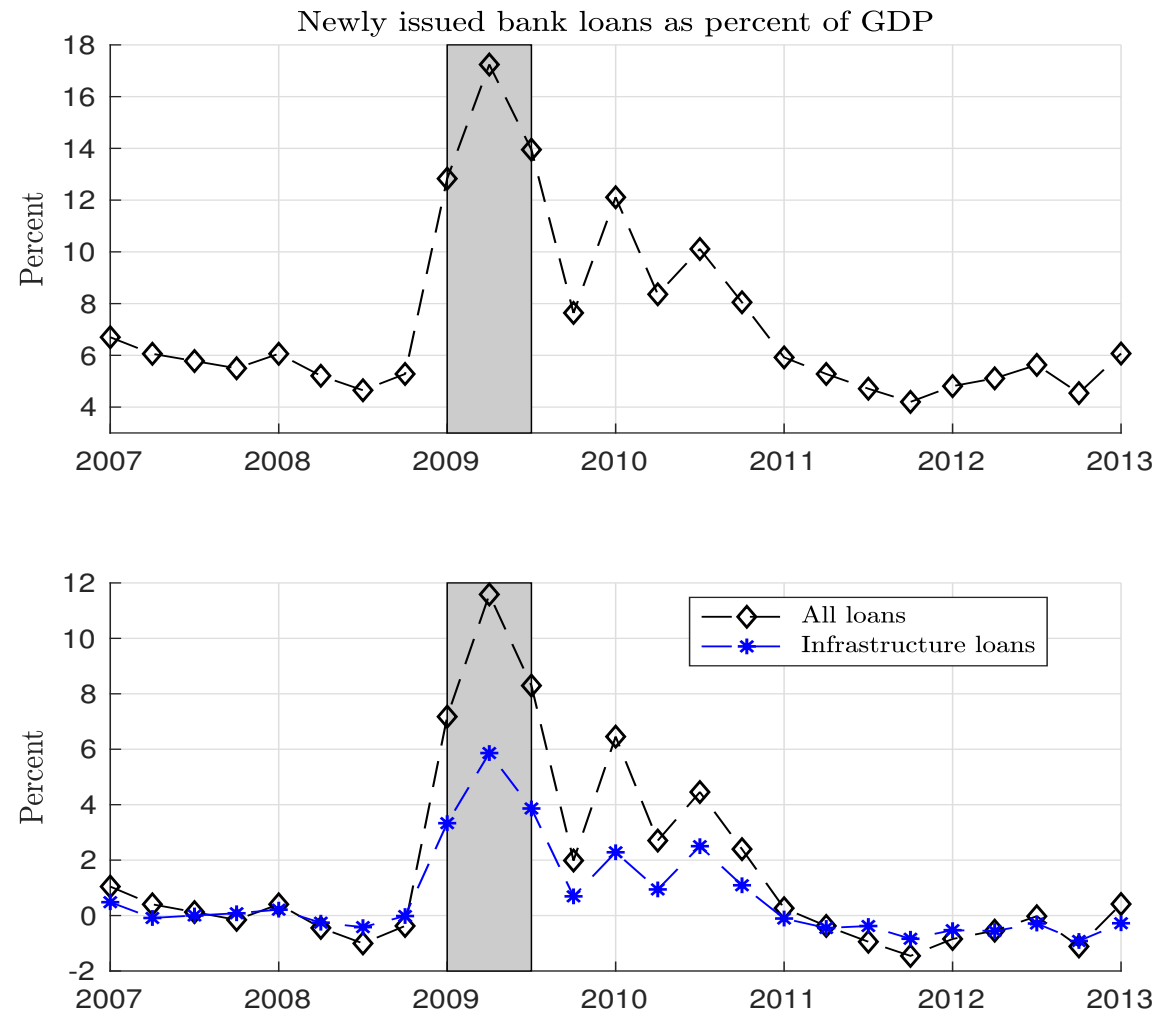

FIGURE 3. Newly originated bank loans as a percent of GDP. Notes: The top chart shows all newly issued loans as a percent of GDP. The bottom chart displays the increase of loan volumes (as a percent of GDP) from the average level in 2007Q1-2008Q4. Each time series is aggregated up from the loan-level data. The shaded bar marks the monetary stimulus period of 2009Q1-2009Q3. 

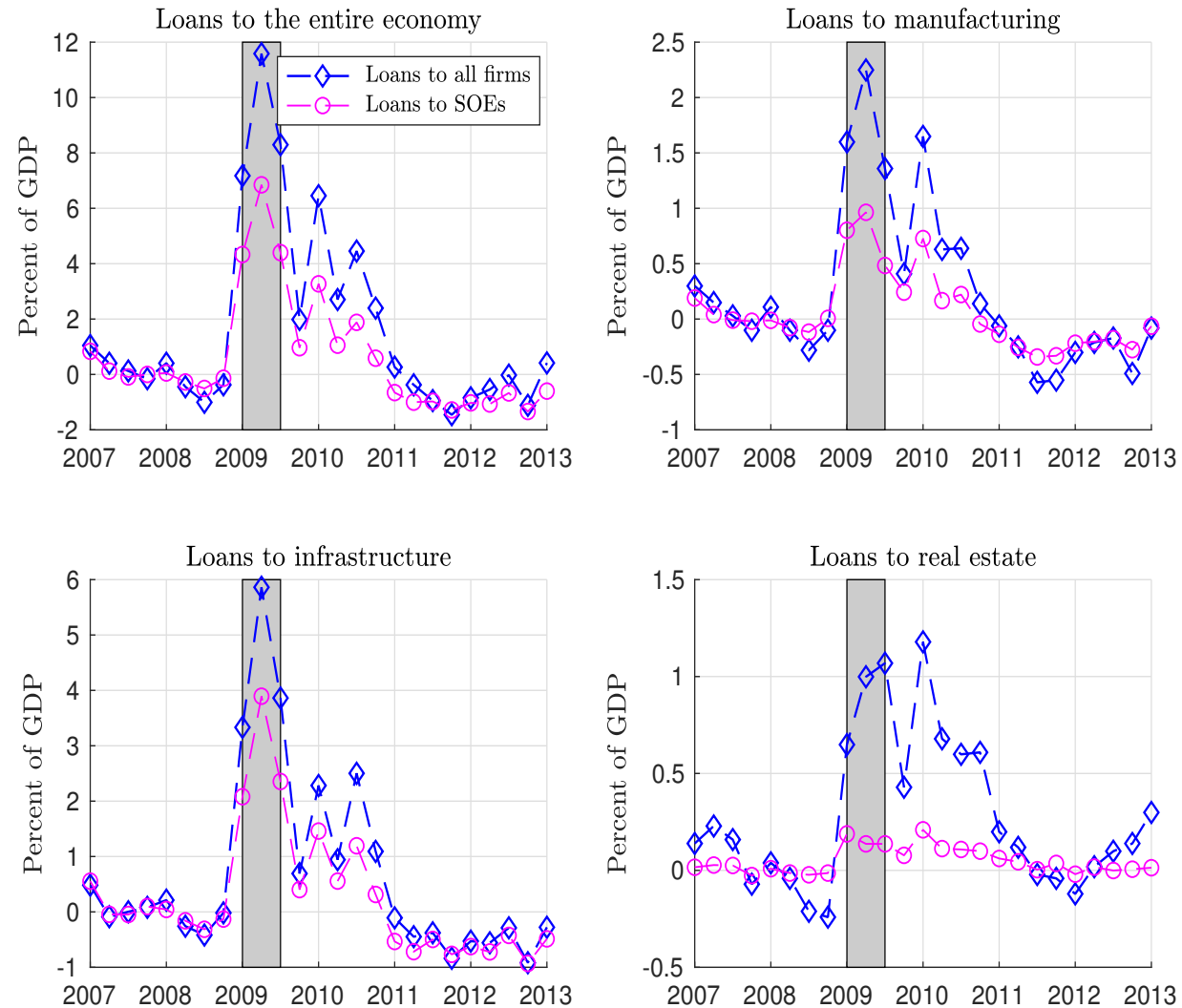

FIgURE 4. Newly originated bank loans to all firms and to SOEs as a percent of GDP in the economy and key sectors. Notes: The time series is aggregated up from the firmquarter data for each subplot. Each loan value (as a percent of GDP) is an increase from an average loan value in 2007Q1-2008Q4. The shaded bar marks the monetary stimulus period of 2009Q1-2009Q3.

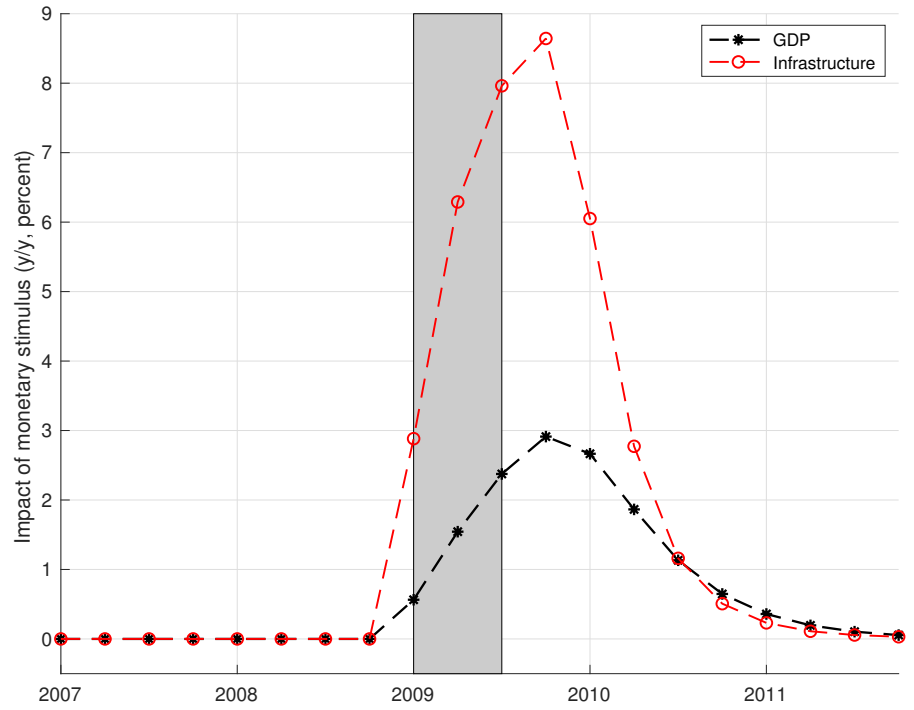

FIGURE 5. Counterfactual historical paths of year-over-year growth rates of real GDP and real infrastructure investment from the first-stage macro model. Notes: Both series are deflated by the GDP deflator. The shaded bar marks the monetary stimulus period of 2009Q1-2009Q3. The counterfactual path is driven by exogenous monetary changes only. 
The entire economy
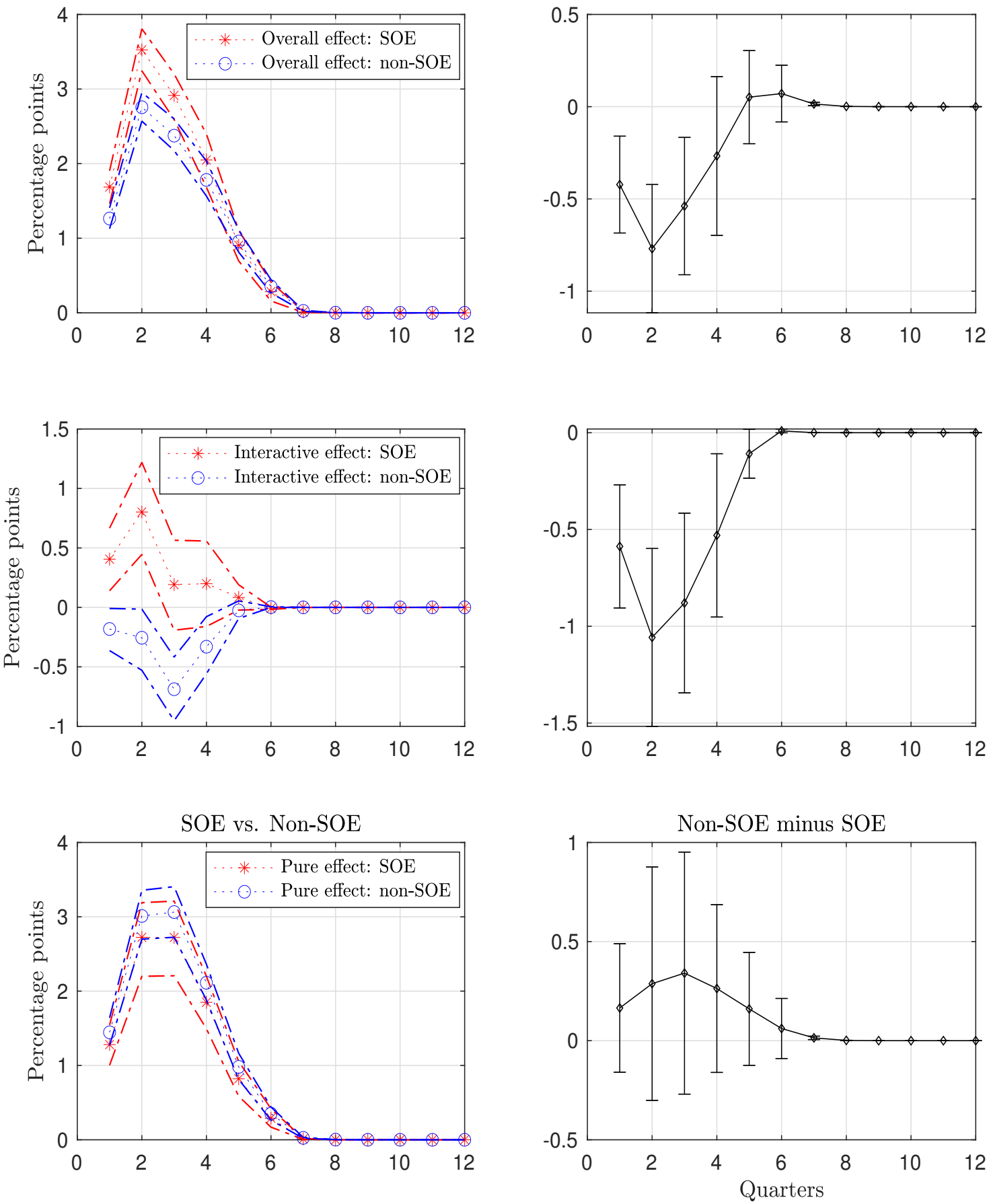

Figure 6. The left column displays dynamic impacts of overall monetary stimulus, along with two channels: (1) monetary interaction with infrastructure investment on bank loans to an average SOE firm and an average non-SOE firm and (2) pure monetary effect (no interaction). The right column displays the non-SOE loan response relative to the SOE loan response. Notes: The dynamic responses are expressed as percentage changes from the initial quarter 0 (i.e., changes from the non-stimulus period). Dash-dotted lines and error bars represent the corresponding .90 probability bands. Quarter 1 corresponds to 2009Q1 and quarter 12 corresponds to 2011Q4. 
Fiscal-monetary interactive effect
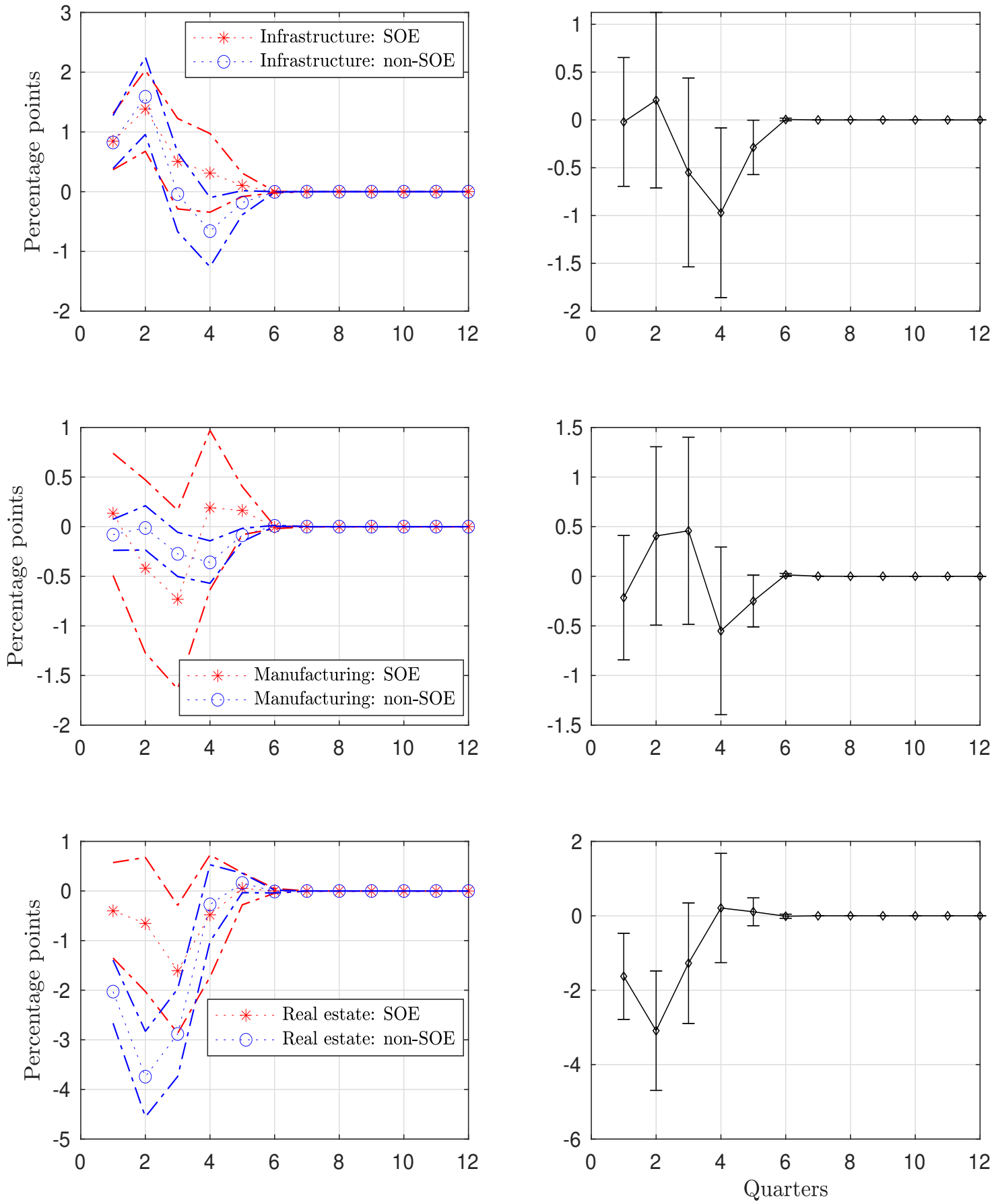

FiguRE 7. The left column displays dynamic impacts of monetary stimulus interacting with infrastructure investment on bank loans to an average SOE firm and an average non-SOE firm. The right column displays the non-SOE loan response relative to the $\mathrm{SOE}$ loan response. Notes: The dynamic responses are expressed as percentage changes from the initial quarter 0 (i.e., changes from the non-stimulus period). Dash-dotted lines and error bars represent the corresponding .90 probability bands. Quarter 1 corresponds to 2009Q1 and quarter 12 corresponds to 2011Q4. 
Pure monetary effect
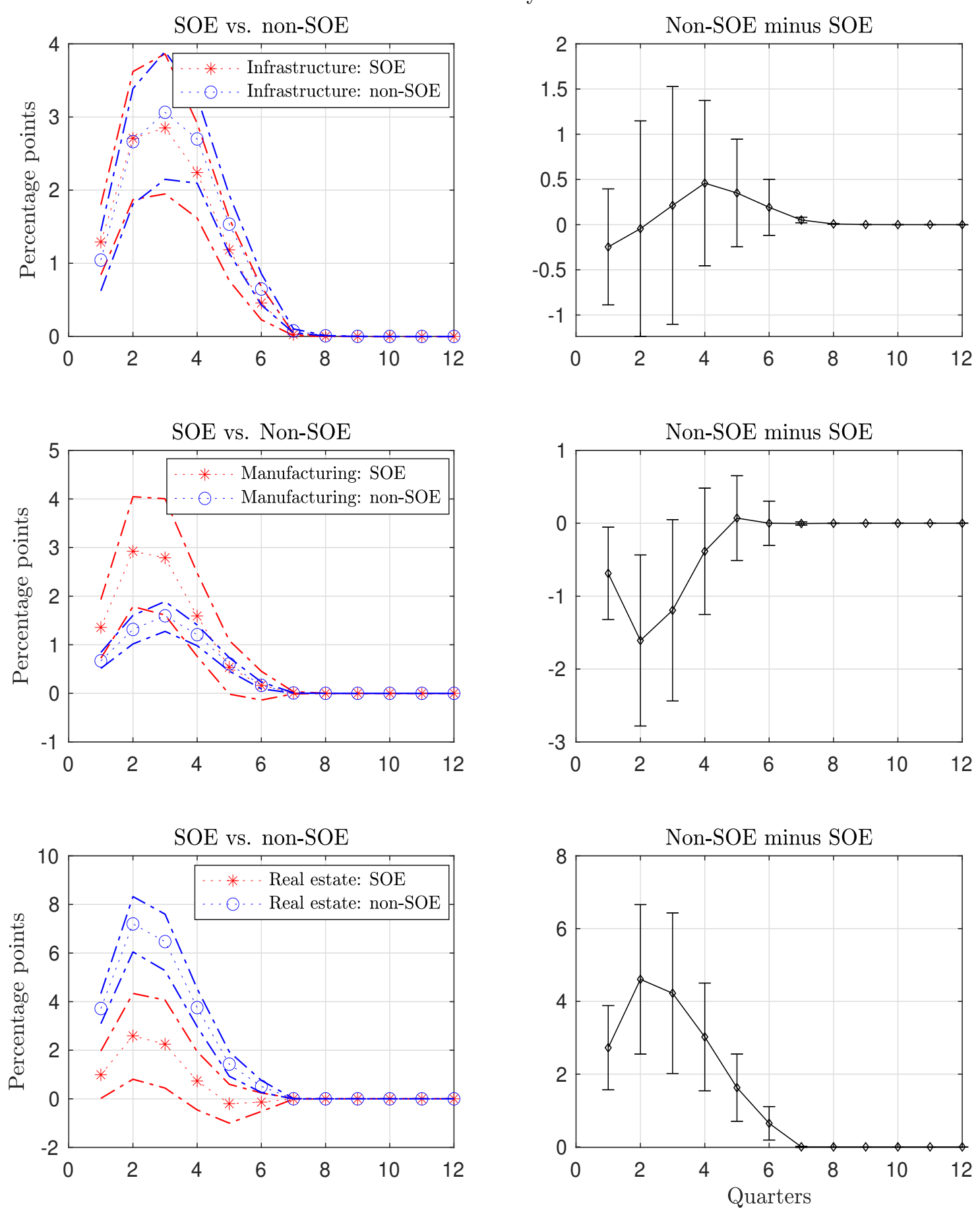

FiguRE 8. The left column displays pure impacts of monetary stimulus on bank loans to an average SOE firm and an average non-SOE firm. The right column displays the non-SOE loan response relative to the SOE loan response. Notes: The dynamic responses are expressed as percentage changes from the initial quarter 0 (i.e., changes from the non-stimulus period). Dash-dotted lines and error bars represent the corresponding .90 probability bands. Quarter 1 corresponds to 2009Q1 and quarter 12 corresponds to 2011Q4. 

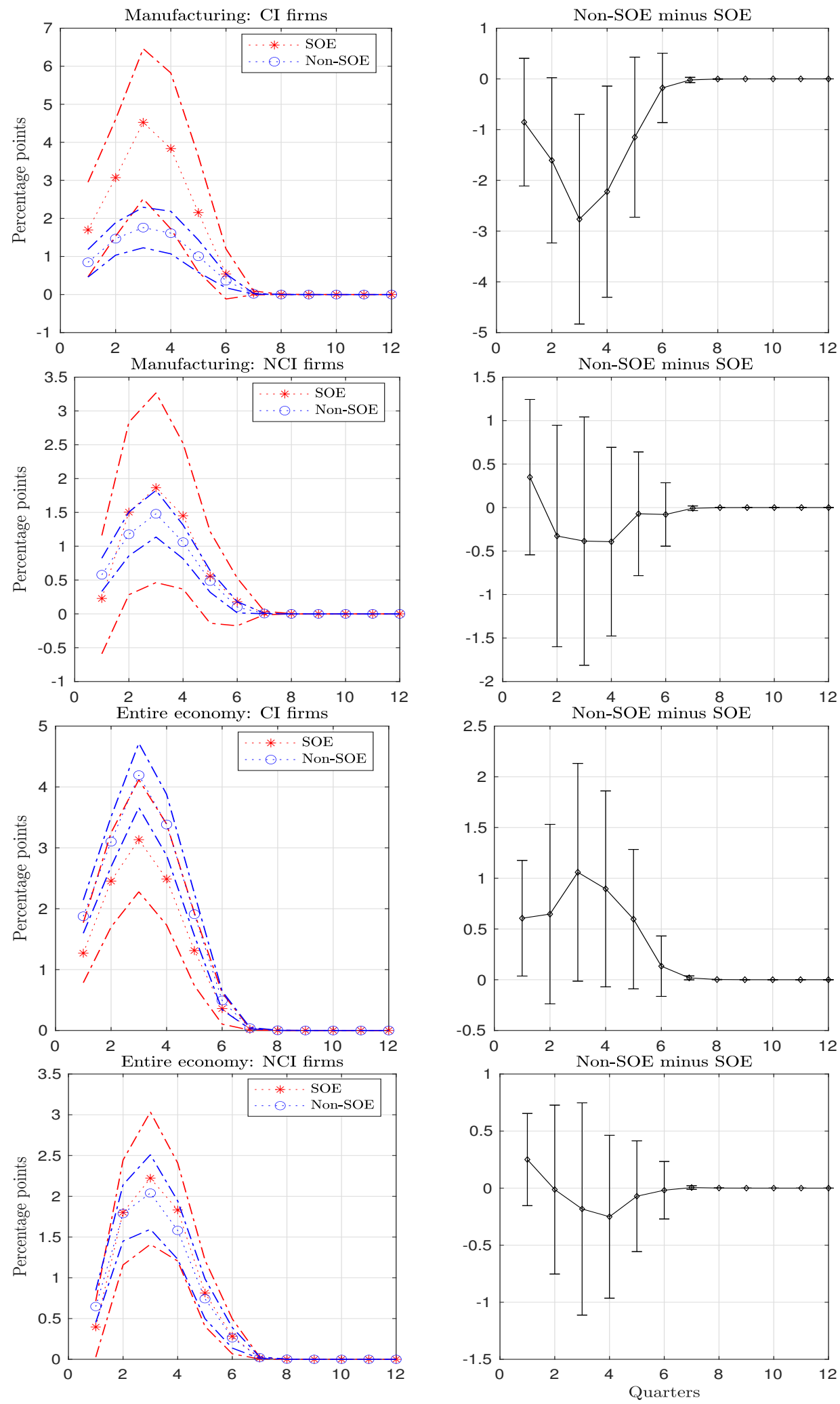

FiguRE 9. The left column displays pure impacts of monetary stimulus on bank loans to an average capital intensive (CI) firm and an average non-capital intensive (NCI) firm. The right column displays the responses of loans to nonSOEs relative to those of loans to SOEs. Notes: The dynamic responses are expressed as percentage changes from the initial quarter 0 (i.e., changes from the non-stimulus period). Dash-dotted lines and error bars represent the corresponding .90 probability bands. Quarter 1 corresponds to 2009Q1 and quarter 12 corresponds to 2011Q4. 


\section{REFERENCES}

Acharya, V. V., T. Eisert, C. Eufinger, and C. Hirsch (2019): "Whatever It Takes: The Real Effects of Unconventional Monetary Policy," Review of Financial Studies, 32, 1-53.

Amstad, M., and Z. He (2020): "Chinese Bond Market and Interbank Market," in Handbook of China's Financial System, ed. by M. Amstad, G. Sun, and W. Xiong. Princeton University Press, Princeton, New Jersey.

Bai, C.-E., C.-T. Hsieh, and Z. M. Song (2016): "The Long Shadow of a Fiscal Expansion," Brookings Papers on Economic Activity, Fall, 129-181.

Bai, Y., D. Lu, And X. Tian (2016): "Do Financial Frictions Explain Chinese Firms' Saving and Misallocation?," Unpublished Manuscript.

Bańbura, M., D. Giannone, and L. Reichlin (2010): "Large Bayesian Vector Autoregressions," Journal of Applied Econometrics, 25(1), 71-92.

Berkowitz, D., H. Ma, and S. Nishioka (2017): "Recasting the Iron Rice Bowl: The Reform of China's State-Owned Enterprises," Review of Economics and Statistics, 99, 735-747.

Besley, T. (2009): "Comment on "Interpreting the Unconventional U.S. Monetary Policy of 2007-09"," Brookings Papers on Economic Activity, 40.

Bleck, A., ANd X. LiU (2018): "Credit Expansion and Credit Misallocation," Journal of Monetary Economics, 94, 27-40.

Boemm, C. E. (2020): "Government Consumption and Investment: Does the Composition of Purchases Affect the Multiplier?," Journal of Monetary Economics, pp. 80-93.

Box, G. E. P., G. M. Jenkins, G. C. Reinsel, and G. M. Luung (2015): Time Series Analysis: Forecasting and Control. Wiley, Hoboken, New Jersey, 5th edn.

Brandt, L., J. Van Biesebroeck, and Y. Zhang (2012): "Creative Accounting or Creative Destruction? Firm-level Productivity Growth in Chinese Manufacturing," Journal of Development Economics, 97, 339-351.

Brunnermeier, M., D. Palia, K. A. Sastry, and C. A. Sims (2021): "Feedbacks: Financial Markets and Economic Activity," American Economic Review, 111, 1845-1879, DOI: $10.1257 /$ aer.20180733.

Brunnermeier, M. K., M. Sockin, and W. Xiong (2017): "China's Gradualistic Economic Approach: Does It Work for Financial Development?," American Economic Review Papers $\&$ Proceedings, 107, 608-613.

Caldara, D., and C. Kamps (2017): "The Analytics of SVARs: A Unified Framework to Measure Fiscal Multipliers," Review of Economic Studies, 84, 83-103.

Chakraborty, I., I. Goldstein, and A. MacKinlay (2020): "Monetary Stimulus and Bank Lending," Journal of Financial Economics, 136, 189-218. 
Chang, C., K. Chen, D. F. Waggoner, and T. Zha (2016): "Trends and Cycles in China's Macroeconomy," NBER Macroeconomics Annual 2015, 30, 1-84, University of Chicago Press.

Chari, V. V., A. Dovis, And P. J. Kehoe (2020): "On the Optimality of Financial Repression," Journal of Political Economy, 128(2), 710-739.

Chen, K., J. Ren, And T. Zha (2018): "The Nexus of Monetary Policy and Shadow Banking in China," American Economic Review, 108(12), 3891-3936.

Chen, Z., Z. He, And C. Liu (2020): "The Financing of Local Government in China: Stimulus Loan Wanes and Shadow Banking Waxes," Journal of Financial Economics, $137,42-71$.

Christiano, L. J., M. S. Eichenbaum, and C. L. Evans (1999): "Monetary Policy Shocks: What Have We Learned and To What End?," in Handbook of Macroeconomics, ed. by J. B. Taylor, and M. Woodford, vol. 1A, pp. 65-148. North-Holland, Amsterdam, Holland.

Cloyne, J., C. Ferreira, and P. Surico (2020): "Monetary Policy when Households have Debt: New Evidence on the Transmission Mechanism," Review of Economic Studies, $87,102-129$.

Cong, L. W., H. Gao, J. Ponticelli, and X. Yang (2019): "Credit Allocation Under Economic Stimulus: Evidence from China," Review of Financial Studies, 32, 3412-3460.

Conley, T. G., And B. Dupor (2013): "The American Recovery and Reinvestment Act: Solely a Government Jobs Program?," Journal of Monetary Economics, 60, 535-549.

Di Maggio, M., A. Kermani, and C. J. Palmer (2020): "How Quantitative Easing Works: Evidence on the Refinancing Channel," Review of Economic Studies, 87, 14981528.

Feyrer, J., And B. Sacerdote (2012): "Did the Stimulus Stimulate? Effects of the American Recovery and Reinvestment Act," NBER Working Paper 16759.

Foley-Fisher, N., R. Ramcharan, and E. Yu (2016): "The Impact of Unconventional Monetary Policy on Firm Financing Constraints: Evidence from the Maturity Extension Program," Journal of Financial Economics, 122, 409-429.

Garin, A. (2019): "Putting America to Work, Where? Evidence on the Effectiveness of Infrastructure Construction as a Locally Targeted Employment Policy," Journal of Urban Economics, 111, 108-131.

Greene, W. H. (2012): Econometric Analysis. Pearson, London, United Kingdom, seventh edn.

Greenstone, M., A. Mas, And H.-L. Nguyen (2020): "Do Credit Market Shocks Affect the Real Economy? Quasi-experimental Evidence from the Great Recession and "Normal" Economic Times," American Economic Journal: Economic Policy, 12(1), 200-225.

Higgins, P. C., and T. Zha (2015): "China's Macroeconomic Time Series: Methods and Implications," Unpublished Manuscript, Federal Reserve Bank of Atlanta. 
Hsieh, C.-T., And P. J. KLenow (2009): "Misallocation and Manufacturing TFP in China and India," Quarterly Journal of Economics, CXXIV(4), 1403-1448.

Hsien, C.-T., And Z. M. Song (2015): "Grasp the Large, Let Go of the Small: The Transformation of the State Sector in China," Brookings Papers on Economic Activity, Spring, 295-346.

Huang, Y., M. Pagano, and U. Panizza (2020): "Local Crowding Out in China," Journal of Finance, 75(6), 2855-2898.

Jermann, U., AND V. QUADRIni (2012): "Macroeconomic Effects of Financial Shocks," American Economic Review, 102(1), 238-271.

JIN, G. (2012): "The Estimation of Chinas Infrastructure Capital Stock," Economic Research Journal (Chinese), 4, 4-14.

(2016): "Infrastructure and Non-infrastructure Capital Stocks in China and Their Productivity: A New Estimate," Economic Research Journal (Chinese), 5, 41-56.

Kandrac, J., And B. Schlusche (2017): "Quantitative Easing and Bank Risk Taking: Evidence from Lending," Finance and Economics Discussion Series 2017-125, Board of Governors of the Federal Reserve System.

Kiyotaki, N., And J. Moore (1997): "Credit Cycles," Journal of Political Economy, $105(2), 211-248$.

Leduc, S., And D. Wilson (2013): "Roads to Prosperity or Bridges to Nowhere? Theory and Evidence on the Impact of Public Infrastructure Investment," NBER Macroeconomics Annual 2012, 27, 89-142, University of Chicago Press.

- (2017): "Are State Governments Roadblocks to Federal Stimulus? Evidence on the Flypaper Effect of Highway Grants in the 2009 Recovery Act," American Economic Journal: Economic Policy, 9, 253-292.

Leeper, E. M. (2019): "Discussion of 'The Role of Market Competition in Fiscal Policy Transmission' by Sophia Chen and Yu Shi," Presentation Slides at the IMF-FRBA China Workshop.

Leeper, E. M., T. B. Walker, and S.-C. S. YAng (2010): "Government Investment and Fiscal Stimulus," Journal of Monetary Economics, 57, 1000-1012.

Li, X., Z. LiU, Y. Peng, And Z. Xu (2020): "Bank Risk-Taking and Monetary Policy Transmission: Evidence from China," Unpublished manuscript.

Ma, H., X. QIAO, ANd Y. Xu (2015): "Job Creation and job Destruction in China During 19982007," Journal of Comparative Economics, 43, 1085-1100.

Morais, B., J. Peydro, J. Roldan-Pena, and C. Ruiz-Ortega (2019): "The International Bank Lending Channel of Monetary Policy Rates and QE: Credit Supply, Reach-for-Yield, and Real Effects," Journal of Finance, LXXIV(1), 55-90.

Plümper, T., And V. E. Troeger (2007): "Efficient Estimation of Time-Invariant and Rarely Changing Variables in Finite Sample Panel Analyses with Unit Fixed Effects," Political Analysis, 15, 124-139, Special Issue: Time-Series Cross-Sectional Analysis. 
Ramey, V. (2013): "Comment on "Roads to Prosperity or Bridges to Nowhere? Theory and Evidence on the Impact of Public Infrastructure Investment", NBER Macroeconomics Annual 2012, 27, 147-153, University of Chicago Press.

Ramey, V. A. (2019): "The Macroeconomic Consequences of Infrastructure Investment," Unpublished Manuscript, University of California at San Diego.

Rodnyansky, A., and O. M. Darmouni (2017): "The Effects of Quantitative Easing on Bank Lending Behavior," Review of Financial Studies, 30, 3858-3887.

Ru, H. (2018): "Government Credit, a Double-Edged Sword: Evidence from the China Development Bank," Journal of Finance, LXXIII, 275-314.

Rubio-Ramírez, J. F., D. F. Waggoner, and T. Zha (2010): "Structural Vector Autoregressions: Theory of Identification and Algorithms for Inference," Review of Economic Studies, 77, 665-696.

Sims, C. A. (1980): "Macroeconomics and Reality," Econometrica, 48(1), 1-48.

Song, Z., K. Storesletten, And F. Zilibotti (2011): "Growing Like China," American Economic Review, 101(1), 196-233.

WANG, J., AND X. WANG (2015): "Capital Misallocation in China: Financial Frictions or Policy Distortions?," Journal of International Economics, 97, 325-338.

Wilson, D. (2012): "Fiscal Spending Jobs Multipliers: Evidence from the 2009 American Recovery and Reinvestment Act," American Economic Journal: Economic Policy, 4, 251282.

Wong, C. (2011): "The Fiscal Stimulus Programme and Public Governance Issues in China," OECD Journal on Budgeting, 2011/3, 1-21, http://dx.doi.org/10.1787/16812336.

Wu, G. L. (2018): "Capital Misallocation in China: Financial Frictions or Policy Distortions?," Journal of Development Economics, 130, 203-223.

Wu, L., Q. FEng, And Z. WAng (2016): "Estimating Productivity of Public Infrastructure Investment," Unpublished Manuscript, Nanyang Technological University.

XIOng, W. (2019): "The Mandarin Model of Growth," Unpublished Manuscript, Princeton University.

YU, M. (2015): "Processing trade, tariff reductions and firm productivity: Evidence from Chinese firms," Economic Journal, 125, 943-988. 


\section{Internet Appendices}

Appendix A provides the data description and the sources. Appendix B discusses the endogeneity bias associated with the estimated results without first-stage estimation. Appendix $\mathrm{C}$ describes technical details of the two-stage estimation procedure and Appendix D provides additional results for the impacts of monetary stimulus. Appendix E develops a theoretical model that focuses on the fiscal-monetary interaction channel through which credit is allocated across sectors. Appendix G discusses issues related to multicollinearity and the difficulty of obtaining the historical data of state share in non-manufacturing sectors.

The tables and figures in appendices are numbered consecutively with S.1 to begin, where $\mathrm{S}$ stands for supplement to be distinguishable from the numbering of tables and figures in the main text.

\section{Appendix A. Data Description And sources}

The methodology of collecting and constructing the quarterly aggregate series is based on Higgins and Zha (2015) and Chang, Chen, Waggoner, and Zha (2016). The main data sources are China's National Bureau of Statistics, the People's Bank of China, and CEIC. The proc X-12 procedure in the SAS software package is used for seasonal adjustment. In our firm-quarter database, we seasonally adjust aggregated new loans and total assets for each sector and each type of firm (e.g., a manufacturing-SOE combination). We then multiply each firm-level variable by the ratio of the seasonally adjusted aggregate to the non-seasonally adjusted aggregate. This method allows us to obtain seasonally adjusted firm-quarter data. Because the sample is short in the time dimension, we use the seasonal $\operatorname{ARIMA}(0,1,1)(0,1,1)_{4}$ model to perform seasonal adjustments. This model is similar to the seasonal ARIMA $(0,1,1)(0,1,1)_{12}$ model, known as the airline model, that Box, Jenkins, Reinsel, and Ljung (2015) used to seasonally adjust monthly airline passenger data. Results without seasonal adjustments are similar to those with seasonal adjustments.

For the firm-quarter loan data across major sectors of the Chinese economy, we follow the NBS's classification. Table S.1 provides a mapping between our four major sectors and NBS's one-digit sectors. We provide, below, a detailed description of the aggregate and firm-quarter variables used in the main text as well as in appendices.

M2: Supply of M2, quarterly average of the monthly series (billions of RMB). For the last monthly observation, we use the level of M2 (CEIC ticker CKSAAC). The 12 monthly observations prior to the last observation are constructed recursively from the monthover-month gross growth rates of CKSAAC each multiplied by a constant adjustment factor. The adjustment factor is chosen so that the 12-month growth rate of the last observed value of our constructed series is equal to the last published 12-month growth rate (CEIC ticker CKSAACA). Once these last 13 observations are determined, we recursively construct the level series back to 1996M4 with the published year-overyear growth rate, back to 1994M12 with the year-over-year growth rate provided by the PBC, and back to 1990M3 with an interpolated year-over-year growth rate 
derived from the quarterly level of M2 (CEIC ticker CKAAC). Sources: NBS, CEIC, People's Bank of China, and Chang, Chen, Waggoner, and Zha (2016).

GDP: Real GDP by value added (billions of 2008 RMB), seasonally adjusted with SAS proc X12. Sources of raw data: NBS and CEIC. Detailed method of construction described in Higgins and Zha (2015).

GDP growth target: Real GDP growth target set by the central government of China. Sources: NBS and CEIC.

CPI: Consumer price index, seasonally adjusted. Constructed by splicing together gross 1month (CEIC ticker CIAHJZ) and 12-month (CEIC ticker CIEA) inflation rates, converting to a quarterly index, and seasonally adjusting with SAS proc X12. Sources: NBS and CEIC.

Infrastructure investment: Gross capital formation for the infrastructure sector. The series, based on the expenditure side of national domestic product, is interpolated by fixed-asset investment and deflated by the investment price index. Sources: NBS and CEIC.

Investment price: The price index of fixed asset investment. Seasonally adjusted with SAS proc X12. Sources of raw data: NBS and CEIC. Primarily based on quarterly CEIC series "CIAHQA: CN: Fixed Asset Inv Price Index: Overall (PY=100)," which starts in 2004Q1. The 2003Q1-2003Q4 levels use corporate goods investment price, which is derived from CEIC ticker CIACWZ "(DC)Corporate Goods Price Index: Investment Goods; Dec1993=100" and CEIC ticker CIQDBAA "CN: Corporate Goods Price Index: Investment Goods; Prev Year=100," with a very small adjustment such that the adjusted 2004Q1 4-quarter growth rate is consistent with CIAHQA.

Assets: A firm's total physical and financial assets. CSMAR item A001000000.

Investment: Cash paid to acquire and construct fixed assets; intangible assets and other long-term assets. CSMAR item C002006000 after undoing year-to-date operation.

Leverage: A firm's leverage defined as a ratio of the firm's total liabilities to its total assets. Ratio of CSMAR item A002000000 to CSMAR item A001000000.

NPL: Non-performing loans. A firm's credit quality defined as the ratio of the firm's outstanding bank loans in lower rating categories (i.e., substandard, doubtful, and loss categories) to its total outstanding bank loans. The international standard loan classification consists of five categories: normal, special-purpose, substandard, doubtful, and loss.

Guarantee: The ratio of a firm's outstanding bank loans with at least one third-party credit guarantor to its total outstanding bank loans. This ratio serves as a proxy to the enhancement of the firm's existing credit. According to the contract, a credit guarantor guarantees to pay a borrower's debt if the borrower defaults on a loan obligation.

\section{Appendix B. Endogeneity Bias Without the two-Stage estimation}

In Section IV.1.2, we argue that if we do not separate monetary and non-monetary effects on growth of infrastructure investment in the first stage, the estimated interactive effect will be biased. As an illustration, we now assess the magnitude of this endogeneity bias in 
the infrastructure sector. If we omit the first stage, we can directly estimate second-stage regression (1) by replacing $g_{\text {infra, } t}^{o}$ with $g_{\text {infra, }, t}$ and $\chi_{t}^{o}$ with $\chi_{t}$.

One can see from Table S.2 that the estimated interactive effects on bank credit to all firms, SOEs, and non-SOEs are biased downward from those for our panel regression in the second stage (cf. columns (5) and (6) of Table 6). As a result, the cumulative interactive effects on loans to all firms or SOEs are estimated to be statistically insignificant, contrary to the cumulative interactive effects in our benchmark regression that are estimated to be significantly positive. Without correcting for the endogeneity bias, therefore, we would erroneously conclude that infrastructure spending driven by non-monetary shocks (e.g., a fiscal stimulation) would not enhance the positive effect of monetary stimulus on bank credit to infrastructure firms.

\section{Appendix C. Technical Details of the estimation procedure}

This section describes technical details of our two-stage estimation procedure. Appendix C.1 discusses the estimation of China's regime-switching monetary policy rule. Appendix C.2 provides details of the first-stage macro model. Appendix C.4 describes how to compute the $90 \%$ probability intervals of dynamic responses.

C.1. Estimating China's monetary policy. For many advanced countries, interest rates are the main instrument used by monetary policy. A common misperception is that this is also true in China. As discussed in Section II.1 and shown in Chen, Ren, and Zha (2018), the PBC implemented the targeted M2 growth rates on a quarterly basis; no other policy variable employed by the PBC, not even market interest rates, was used as the main instrument or target of monetary policy. In fact, because China was an emerging-market economy during our sample period, the exclusive instrument of its quantity-based monetary policy was M2 growth, which was explicitly specified and targeted by the central government.

During the global financial crisis, growth of China's GDP plummeted from $13.6 \%$ in 2007Q2 to 6.4\% in 2009Q1 (top chart of Figure 1). As discussed in the introduction, the Chinese government announced a 4-trillion RMB investment plan to combat the sharp fall of aggregate output growth and this plan was supported through monetary stimulus, which turned out to be larger than the original plan. M2 increased by 4.2 trillion RMB in 2009Q1 alone and by a total of 11.5 trillion RMB during the 2009Q1-2009Q3 period. These three crucial quarters of massive monetary injections are identified by Chen, Ren, and Zha (2018) as a regime-switching period of the monetary policy rule, and the exogenous 2009 monetary stimulus is measured by a sum of policy shocks and the magnitude of a switch of monetary policy to being extraordinarily expansionary. Even though monetary policy is endogenous, the estimated magnitude of its change is exogenous. As reported in Chen, Ren, and Zha (2018), $\pi^{*}$ is set at $0.875 \%$ (i.e., an annualized quarterly rate of $3.5 \%$ ), and the 
estimated coefficients, $\gamma_{m}=0.391, \gamma_{\pi}=-0.397, \gamma_{y, a}=0.183, \gamma_{y, b}=-1.299, \sigma_{m, a}=0.005$, and $\sigma_{m, b}=0.010$, are all statistically significant at the 0.01 level.

C.2. The first-stage macro model. We do not impose any restrictions on subsystem (3) to address the "incredible restrictions" criticism of Sims (1980). Without any restrictions, subsystem (3) is unidentified because the transformed system

$$
\left(Q A_{0}\right) x_{t}+\left(Q b_{m, 0}\right) \log M_{t}=(Q c)+\sum_{k=1}^{\ell}\left(Q A_{k}\right) x_{t-k}+\sum_{k=1}^{\ell}\left(Q b_{m, k}\right) \log M_{t-k}+Q \xi_{t}
$$

where $Q$ is any orthogonal matrix, generates the same dynamics of $x_{t}$ as does the original system (3). Although subsystem (3) is unidentified, the following propositions show that the monetary policy equation is identified and that the whole (macro) system is driven by $n+1$ independent exogenous shocks, where $n=3$ in the main text and the variable $\log i_{\text {infra, } t}$ is the last element of $x_{t}$.

Proposition C.1. When the system represented by (2) and (3) is jointly estimated, monetary policy represented by equation (2) is identified, even though subsystem (3) itself is unidentified.

Proof. Consider the complete system composed of (2) and (3), which can be written in the SVAR form of

$$
\begin{array}{r}
\underbrace{\left[\begin{array}{cc}
1 & 0_{1 \times n} \\
b_{m, 0} & A_{0}
\end{array}\right]}_{\widetilde{A}_{0}} z_{t}=\underbrace{\left[\begin{array}{c}
\gamma_{0}-\gamma_{\pi} \pi^{*}-\gamma_{y, t} g_{y, t-1}^{*} \\
c
\end{array}\right]+\underbrace{\left[\begin{array}{cc}
1+\gamma_{m} & \Gamma_{t} \\
b_{m, 1} & A_{1}
\end{array}\right]}_{\widetilde{A}_{1, t}} z_{t-1}+\underbrace{\left[\begin{array}{cc}
-\gamma_{m} & -\Gamma_{t} \\
b_{m, 2} & A_{2}
\end{array}\right]}_{\widetilde{A}_{2, t}} z_{t-2}}_{\tilde{c}_{t}} \\
+\sum_{k=3}^{\ell} \underbrace{\left[\begin{array}{cc}
0 & 0_{1 \times n} \\
b_{m, k} & A_{k}
\end{array}\right]}_{\widetilde{A}_{k}} z_{t-k}+\underbrace{\left[\begin{array}{cc}
\sigma_{m, t} & 0_{1 \times n} \\
0_{n \times 1} & I_{n}
\end{array}\right]}_{\widetilde{D}_{t}}\left[\begin{array}{c}
\xi_{m, t} \\
\xi_{t}
\end{array}\right],
\end{array}
$$

where $z_{t}=\left[\begin{array}{lll}\log M_{t} & x_{t}^{\prime}\end{array}\right]^{\prime}$ and $\Gamma_{t}=\left[\begin{array}{lll}\gamma_{y, t} & \gamma_{\pi} & 0_{1 \times(n-2)}\end{array}\right]$. For system (C.1), we show that the first equation, the monetary policy equation, is identified. According to Theorem 2 of RubioRamírez, Waggoner, and Zha (2010), this equation is identified if the following statement is true: if $\widetilde{Q} \widetilde{D}_{t}^{-1} \widetilde{A}_{0}=\widehat{A}_{0, t}$, where $\widetilde{Q}$ is an orthogonal matrix and $\widehat{A}_{0, t}$ maintains the form of

$$
\left[\begin{array}{cc}
\widehat{A}_{0, t}^{11} & \widehat{A}_{0, t}^{12} \\
\widehat{A}_{0, t}^{21} & \widehat{A}_{0, t}^{22}
\end{array}\right]=\left[\begin{array}{cc}
\widehat{A}_{0, t}^{11} & 0_{1 \times n} \\
\widehat{A}_{0, t}^{21} & \widehat{A}_{0, t}^{22}
\end{array}\right]
$$

then $\widetilde{Q}$ must be of the form

$$
\left[\begin{array}{ll}
\widetilde{Q}^{11} & \widetilde{Q}^{12} \\
\widetilde{Q}^{21} & \widetilde{Q}^{22}
\end{array}\right]=\left[\begin{array}{cc} 
\pm 1 & 0_{1 \times n} \\
0_{n \times 1} & \widetilde{Q}^{22}
\end{array}\right]
$$


To show that the above statement is true, note that $\widetilde{Q} \widetilde{D}_{t}^{-1} \widetilde{A}_{0}=\widehat{A}_{0, t}$ is equivalent to

$$
\left[\begin{array}{cc}
\widetilde{Q}^{11} \sigma_{m, t}^{-1}+\widetilde{Q}^{12} b_{m, 0} & \widetilde{Q}^{12} A_{0} \\
\widetilde{Q}^{21} \sigma_{m, t}^{-1}+\widetilde{Q}^{22} b_{m, 0} & \widetilde{Q}^{22} A_{0}
\end{array}\right]=\left[\begin{array}{cc}
\widehat{A}_{0, t}^{11} & 0_{1 \times n} \\
\widehat{A}_{0, t}^{21} & \widehat{A}_{0, t}^{22}
\end{array}\right] .
$$

Since $A_{0}$ is invertible and $\widetilde{Q}^{12} A_{0}=0$, we have $\widetilde{Q}^{12}=0$. Because $\widetilde{Q}$ is an orthogonal matrix, it must be true that $\widetilde{Q}^{21}=0$ and $\widetilde{Q}^{11}= \pm 1$. This proves (C.2) and therefore Proposition C.1.

C.3. Decompositions. In Section IV.2.1, we discuss a decomposition of exogenous monetary policy changes. In this appendix, we give the details of this decomposition.

Equation (C.1) is equivalent to

$$
z_{t}=\widetilde{A}_{0}^{-1} \widetilde{d}_{t}+\widetilde{A}_{0}^{-1} \sum_{k=1}^{\ell} \widetilde{A}_{\ell} z_{t-\ell}+\widetilde{A}_{0}^{-1}\left(\left[\begin{array}{l}
0 \\
\xi_{t}
\end{array}\right]+\left[\begin{array}{c}
\varepsilon_{t}^{\mathrm{Norm}} \\
0
\end{array}\right]+\left[\begin{array}{c}
\varepsilon_{t}^{\text {Extra }} \\
0
\end{array}\right]+\left[\begin{array}{c}
\varepsilon_{t}^{\text {Polch }} \\
0
\end{array}\right]\right),
$$

where $\widetilde{d}_{t}, \widetilde{A}_{1}$, and $\widetilde{A}_{2}$ are $\widetilde{c}_{t}, \widetilde{A}_{1, t}$, and $\widetilde{A}_{2, t}$, but with $\gamma_{m, t}$ replaced by $\gamma_{m, a}$, and $\varepsilon_{t}^{\text {Norm }}$, $\varepsilon_{t}^{\text {Extra }}$, and $\varepsilon_{t}^{\text {PolCh }}$ are as defined in Section IV.2.1. This suggests the following recursive decomposition of the data.

$$
\begin{aligned}
& z_{t}^{\text {Norm }}=\sum_{k=1}^{\ell} \widetilde{A}_{0}^{-1} \widetilde{A}_{\ell} z_{t-\ell}^{\text {Norm }}+\widetilde{A}_{0}^{-1}\left[\begin{array}{c}
\varepsilon_{m, t}^{\text {Norm }} \\
0
\end{array}\right], \\
& z_{t}^{\text {Extra }}=\sum_{k=1}^{\ell} \widetilde{A}_{0}^{-1} \widetilde{A}_{\ell} z_{t-\ell}^{\text {Extra }}+\widetilde{A}_{0}^{-1}\left[\begin{array}{c}
\varepsilon_{m, t}^{\text {Extra }} \\
0
\end{array}\right], \\
& z_{t}^{\text {PolCh }}=\sum_{k=1}^{\ell} \widetilde{A}_{0}^{-1} \widetilde{A}_{\ell} z_{t-\ell}^{\text {PolCh }}+\widetilde{A}_{0}^{-1}\left[\begin{array}{c}
\varepsilon_{m, t}^{\text {PolCh }} \\
0
\end{array}\right], \\
& z_{t}^{o}=\widetilde{A}_{0}^{-1} \widetilde{d}_{t}+\sum_{k=1}^{\ell} \widetilde{A}_{0}^{-1} \widetilde{A}_{\ell} z_{t-\ell}^{o}+\widetilde{A}_{0}^{-1}\left[\begin{array}{l}
0 \\
\xi_{t}
\end{array}\right],
\end{aligned}
$$

where $z_{t}^{\text {Norm }}=z_{t}^{\text {Extra }}=z_{t}^{\text {PolCh }}=0$ and $z_{t}^{o}=z_{t}$ for $t=0,-1,-2,-\ell+1$. It follows from inductive reasoning that $z_{t}=z_{t}^{\text {Norm }}+z_{t}^{\text {Extra }}+z_{t}^{\text {PolCh }}+z_{t}^{o}$ for all $t$. We have the following proposition.

Proposition C.2. Growth of infrastructure investment driven by non-monetary shocks, $g_{\text {infra, } t}^{o}$, is uncorrelated with the three components of monetary policy changes: $\varepsilon_{t}^{\text {Norm }}, \varepsilon_{t}^{\text {Extra }}$, and $\varepsilon_{t}^{\mathrm{PolCh}}$.

Proof. Let $I_{t-1}$ denote the information set containing all the data up to and including time $t-1$. By the law of iterated expectations, it suffices to show that $g_{\text {infra, } t}^{o}$ is uncorrelated with $\varepsilon_{t}^{\text {Norm }}, \varepsilon_{t}^{\text {Extra }}$, and $\varepsilon_{t}^{\text {PolCh }}$, conditional on $I_{t-1}$. For $\tau \leq t-1$, both $\xi_{\tau}$ and $z_{\tau}^{o}$ are in $I_{t-1}$. The conditional correlation between $g_{\text {infra, } t}^{o}$ and $\varepsilon_{t}^{\star}$, where $\star$ represents one of Norm, Extra, and 
$\mathrm{PolCh}$, is

$$
E\left[\left(g_{\text {infra }, t}^{o}-E\left[g_{\text {infra }, t}^{o} \mid I_{t-1}\right]\right) \varepsilon_{t}^{\star} \mid I_{t-1}\right]=e_{n+1}^{\prime} \widetilde{A}_{0}^{-1}\left[\begin{array}{c}
0 \\
E\left[\xi_{t} \varepsilon_{t}^{\star} \mid I_{t-1}\right]
\end{array}\right],
$$

where $e_{n+1}$ denotes the last column of an $(n+1) \times(n+1)$ identity matrix. It therefore suffices to show that $E\left[\xi_{t} \varepsilon_{t}^{\star} \mid I_{t-1}\right]=0$. When $\star$ is either Norm or Extra, the expectation is zero because $\xi_{t}$ and $\xi_{m, t}$ are conditionally independent. When $\star$ is PolCh, we have that $E\left[\xi_{t} \varepsilon_{t}^{\mathrm{PolCh}} \mid I_{t-1}\right]=E\left[\xi_{t} \mid I_{t-1}\right] \varepsilon_{t}^{\mathrm{PolCh}}=0$.

In Section IV.2.2, the data is decomposed into two components, $x_{t}^{m}$ and $x_{t}^{o}$. The monetary component $x_{t}^{m}$ is equal to the last $n$ elements of $z_{t}^{\mathrm{Norm}}+z_{t}^{\text {Extra }}+z_{t}^{\mathrm{PolCh}}$ and the non-monetary component $x_{t}^{o}$ is equal to the last $n$ elements of $z_{t}^{o}$. Estimates of $x_{t}^{m}$ and $x_{t}^{o}$ can be obtained as follows. Let $\theta$ denote the collection of all the parameters for the system represented by equation (C.1) and let $\widehat{\theta}$ be the posterior estimate. Given the data and $\widehat{\theta}$, we use equation (C.1) to compute the estimated shocks, denoted by $\widehat{\xi}_{m, t}$ and $\widehat{\xi}_{t}$. Given the data, $\widehat{\theta}$, and $\widehat{\xi}_{m, t}$, we can estimate exogenous monetary policy changes, denoted by $\widehat{\varepsilon}_{t}^{\mathrm{Norm}}, \widehat{\varepsilon}_{t}^{\text {Extra }}$, and $\widehat{\varepsilon}_{t}^{\mathrm{PolCh}}$, using their definitions. Given the data, $\widehat{\theta}, \widehat{\xi}_{t}, \widehat{\varepsilon}_{t}^{\text {Norm }}, \widehat{\varepsilon}_{t}^{\text {Extra }}$, and $\widehat{\varepsilon}_{t}^{\text {PolCh }}$, we use equations (C.4) through (C.7) to obtain estimates of $z_{t}^{\mathrm{Norm}}, z_{t}^{\mathrm{Extra}}, z_{t}^{\mathrm{PolCh}}$, and $z_{t}^{o}$. From these estimates, we can extract estimates of $x_{t}^{m}$ and $x_{t}^{o}$.

Because the monetary policy equation within system (C.1) is identified, $\widehat{\xi}_{m, t}$ is uniquely defined no matter which set of observationally equivalent parameter estimates is used. The estimated shock vector $\widehat{\xi}_{t}$, however, depends on a particular set of observationally equivalent parameter estimates. Despite this fact, estimates of both $x_{t}^{m}$ and $x_{t}^{o}$ are unique no matter which set of observationally equivalent parameter estimates is used, as stated in the following proposition.

Proposition C.3. While subsystem (3) itself is unidentified, the decomposed variables $x_{t}^{m}$ and $x_{t}^{o}$, conditional on $\hat{\theta}$ and the data, are uniquely determined.

Proof. Since the monetary policy equation is identified, $\widehat{\xi}_{m, t}$ does not depend on which set of observationally equivalent parameter estimates is used. For the same reason, $\widehat{\varepsilon}_{t}^{\text {Norm }}, \widehat{\varepsilon}_{t}^{\text {Extra }}$, and $\widehat{\varepsilon}_{t}^{\mathrm{PolCh}}$ do not depend on which set of observationally equivalent parameter estimates is used. In equations (C.4) through (C.6), $\widetilde{A}_{0}^{-1} \widetilde{A}_{\ell}$, which are reduced-form parameters, do not depend on which set of observationally equivalent parameter estimates is used. While $\widetilde{A}_{0}^{-1}$ depends on a particular set of the observationally equivalent parameter estimates, the first column of $\widetilde{A}_{0}^{-1}$ does not because the monetary policy equation is identified. It follows that $z_{t}^{\text {Norm }}, z_{t}^{\text {Extra }}$, and $z_{t}^{\text {PolCh }}$, defined by equations (C.4) through (C.6), do not depend on which set of observationally equivalent parameter estimates is used. Thus, $x_{t}^{m}$ is uniquely determined. Since $z_{t}^{o}=z_{t}-z_{t}^{\text {Norm }}-z_{t}^{\text {Extra }}-z_{t}^{\text {PolCh }}$, it does not depend on which set of observationally equivalent parameter estimates is used. Hence, $x_{t}^{o}$ is also uniquely determined. 
C.4. Computing the $90 \%$ probability intervals of dynamic responses. We first generate random draws of the coefficients in regression (1). Conditional on each random draw of the coefficients, we then compute a random path of dynamic responses using equation (5). Specifically, we begin with grouping the regression coefficients in regression (1) into the vectors

$$
\Phi^{j}=\left[\begin{array}{lllllll}
\rho^{j} & d_{0}^{j} & \cdots & d_{\ell}^{j} & b_{0}^{j} & \cdots & b_{\ell}^{j}
\end{array}\right]^{\prime}
$$

and

$$
\Psi^{j}=\left[\begin{array}{llllll}
c^{1, j} & \cdots & c^{N, j} & \Phi^{j \prime} & c_{\chi}^{j \prime} & c_{z}^{j \prime}
\end{array}\right]^{\prime}
$$

and the regressors into the vectors

$$
\boldsymbol{x}_{j, t}=\left[\begin{array}{lllllll}
\mathfrak{b}_{j, t-1} & \varepsilon_{m, t} & \cdots & \varepsilon_{m, t-\ell} & g_{\text {infra }, t}^{o} \varepsilon_{m, t} & \cdots & g_{\text {infra }, t-\ell}^{o} \varepsilon_{m, t-\ell}
\end{array}\right]^{\prime}
$$

and

$$
\boldsymbol{x}_{i, j, t}=\left[\begin{array}{llll}
\boldsymbol{c}_{i, j, t}^{\prime} & \boldsymbol{x}_{j, t}^{\prime} & \chi_{t}^{o \prime} & z_{i, j, t-1}^{\prime}
\end{array}\right]^{\prime}
$$

where $j \in\{$ SOEs, non-SOEs, All firms $\}$ and $\boldsymbol{c}_{i, j, t}^{\prime}$ is a vector of firm dummies whose $i^{\text {th }}$ element is 1 and remaining elements are 0. The fitted values for Equation (1) can be rewritten in compact form as

$$
\mathfrak{b}_{i, j, t}=\hat{\Psi}^{j \prime} \boldsymbol{x}_{i, j, t}
$$

while the fitted values for equation (5) can be rewritten as

$$
\mathfrak{b}_{j, t}=\hat{\Phi}^{j \prime} \boldsymbol{x}_{j, t}
$$

We stack firm-specific residuals in regression (1) into the $T \times 1$ vector

$$
\boldsymbol{\eta}_{j}=\left[\begin{array}{lllllll}
\eta_{1, j, 2007 \mathrm{Q} 2+\ell+1} & \cdots & \eta_{1, j, 2013 \mathrm{Q} 2} & \cdots & \eta_{N, j, 2007 \mathrm{Q} 2+\ell+1} & \cdots & \eta_{N, j, 2013 \mathrm{Q} 2}
\end{array}\right]^{\prime},
$$

where 2013Q2 is the last data point in the time dimension and $T=N(21-\ell)$. Letting $N_{x}$ denote the length of $\boldsymbol{x}_{i, j, t}$, we define $\boldsymbol{\Omega}_{j}=\boldsymbol{\eta}_{j}^{\prime} \boldsymbol{\eta}_{j}^{\prime}$, denote the $\mathfrak{h}^{\text {th }}$ random draw from the inverse Wishart (IW) distribution $\operatorname{IW}\left(\boldsymbol{\Omega}_{j}, T+2-N_{x}\right)$ by $\boldsymbol{\Gamma}_{j}^{(\mathfrak{h})}$, denote the $\mathfrak{h}^{\text {th }}$ random draw of $\Psi^{j}+\boldsymbol{\nu}^{(\mathfrak{h})^{\prime}} \operatorname{chol}\left(\boldsymbol{\Gamma}_{j}^{(\mathfrak{h})}\left(X^{j^{\prime}} X^{j}\right)^{-1}\right)$ by $\hat{\Psi}^{j,(\mathfrak{h})}$, where chol represents the Choleski decomposition of the enclosed matrix

$$
X_{j}=\left[\begin{array}{lllllll}
\boldsymbol{x}_{1, j, 2007 \mathrm{Q} 2+\ell+1} & \cdots & \boldsymbol{x}_{1, j, 2013 \mathrm{Q} 2} & \cdots & \boldsymbol{x}_{N, j, 2007 \mathrm{Q} 2+\ell+1} & \cdots & \boldsymbol{x}_{N, j, 2013 \mathrm{Q} 2}
\end{array}\right]^{\prime},
$$

and $\boldsymbol{\nu}^{(\mathfrak{h})}$ is an $N_{x} \times 1$ vector randomly drawn from the iid Gaussian distribution $N\left(\mathbf{0}, \boldsymbol{I}_{N_{x}}\right)$ (see Bańbura, Giannone, and Reichlin (2010) for technical details).

For $\Phi^{j}$ in equation (C.9), we extract the subvector $\Phi^{j,(\mathfrak{h})}$ from the $\mathfrak{h}^{\text {th }} \operatorname{draw} \Psi^{j,(\mathfrak{h})}$, using equation (C.8) for $1 \leq \mathfrak{h} \leq \mathcal{H}(\mathcal{H}$ is the number of random draws). A random draw of the dynamic response function $\boldsymbol{f}^{(\mathfrak{h})}=\left[f^{(\mathfrak{h})}(1, j), \ldots, f^{(\mathfrak{h})}(12, j)\right]^{\prime}$ for $j \in\{$ SOE, non-SOE, All firms $\}$ in sector $j$ is generated by feeding in three consecutive shocks and interaction terms

$$
\varepsilon_{m, 2009 \mathrm{Q} 1}^{\mathrm{Stim}}, \varepsilon_{m, 2009 \mathrm{Q} 2}^{\mathrm{Stim}}, \varepsilon_{m, 2009 \mathrm{Stim}}^{\mathrm{St}}, g_{\text {infra }, 2009 \mathrm{Q} 1}^{o} \varepsilon_{m, 2009 \mathrm{Q} 1}^{\mathrm{Stim}}, g_{\text {infra }, 2009 \mathrm{Q} 2}^{o} \varepsilon_{m, 2009 \mathrm{~S} 2}^{\mathrm{Stim}}, g_{\text {infra }, 2009 \mathrm{Q} 3}^{o} \varepsilon_{m, 2009 \mathrm{Stim}}^{\mathrm{St}} \cdot
$$


The $5^{\text {th }}$ and $95^{\text {th }}$ percentiles of the set $\left\{f^{\mathfrak{h}}(t, j)\right\}_{\mathfrak{h}=1}^{\mathcal{H}}$ deliver the .90 probability bands of dynamic responses at time $t .{ }^{49}$

\section{Appendix D. AdDitional RESUlts FOR the impaCts of MONETARY STIMUlus}

In this section, we report first supplemental results discussed in the main text and then additional estimated results (tables and graphs) for further discussions. Appendix D.1 provides tables that report the numerical values for the figures in the main text. Appendix D.2 shows the estimated results and dynamic responses of an average firm in manufacturing, infrastructure and real estate, when all firms in each sector are pooled together. Appendix D.3 shows the corresponding estimated results and dynamic responses for the remaining economy.

D.1. Results supplemental to the main text. In this subsection, we report the tables and graphs referenced by the main text. Tables S.4-S.6 report the numerical values for relative impacts of the 2009 monetary stimulus on bank credit to non-SOEs relative to SOEs. The positive values indicate that non-SOEs received more loans than SOEs, and vice versa. Table S.7 reports estimation results for dynamic panel regression (1) with region fixed effects. Table S.8 reports estimation results for dynamic panel regression (1) excluding Sichuan, the most important province in the western region.

In all these regressions, the dependent variable is a firm-quarter observation of newly issued bank credit to a firm scaled by its total nominal assets. The right-hand variables include contemporaneous and lagged monetary policy shocks and their interactions with the respective growth rates of infrastructure investment. The firm-level control variables include the NPL ratio, the guarantee ratio, assets, and the leverage ratio, all lagged by one period. The aggregate control variables include lagged GDP growth, lagged inflation, and contemporaneous and lagged growth rates of infrastructure investment.

Table S.9 provides statistical descriptions of capital intensity across sectors and across firms of different ownership types. Figure S.1 displays the share of bank loans allocated to the four key sectors in 2007-2013 from our loan data.

\section{D.2. All firms in each of the manufacturing, infrastructure, and real estate sec-}

tors. Column 2 of Table S.10 reports our estimated results for the manufacturing sector. Since our dynamic panel regression allows monetary policy to have lagged (dynamic) effects, both contemporaneous and lagged estimates are reported. ${ }^{50}$ The pure effects of a monetary policy shock are statistically significant at the $1 \%$ level not only contemporaneously but also in lagged periods. The interaction between monetary policy and infrastructure investment has statistically significant effects in the second and third periods. A negative value indicates

\footnotetext{
${ }^{49}$ We set $\mathcal{H}=1000$. Since all the random draws are iid, 1000 draws are sufficient for achieving accuracy. Note that the dynamic response results do not depend on particular values of $t$ and other variables.

${ }^{50}$ Although the persistence coefficient $\rho^{j}$ is statistically significant in most cases, we do not report its estimate because the magnitude is very small with its half life less than one quarter.
} 
that an increase in infrastructure investment weakens the transmission of monetary policy to credit allocation for an average manufacturing firm.

Toward the bottom of each column in the table, we report the cumulative effect as the sum of the estimated coefficients across periods. In column 2, the cumulative main and interactive effects are both statistically significant but with opposite signs. The estimated elasticity of bank credit to a monetary policy shock implies that a one percent increase in quarterly M2 growth translates into a 0.758 percentage-point increase in bank lending to an average firm (as a share of its assets) over the first four quarters. An increase in infrastructure investment during the same period, however, dampens the monetary effect.

Figure S.2 displays the loan responses to the 2009 monetary stimulus for an average manufacturing firm. The top left panel displays the total monetary effect and its two components (the main and interactive effects); the top right and bottom panels plot the $90 \%$ probability interval of each dynamic response. A positive response corresponds to an increase of a firm's bank credit (as a share of its assets) relative to the 2007-2008 average level. The negative effect of interaction weakens the effects of monetary stimulus, making the overall effect smaller than the pure effect (top left panel). The total monetary impact on bank lending to an average manufacturing firm was hump-shaped, peaking at 1.41 percentage points in 2009Q2 (top right panel). The main impact of monetary stimulus on bank credit peaked in the third quarter (2009Q3), with an average increase of 1.31 percentage points over the first three quarters (bottom left panel). Although our identified monetary stimulus lasted for only three quarters, the dynamic response of newly issued bank loans lasted for at least six quarters due to the lagged effect of monetary policy. Infrastructure spending, however, reduced the monetary impacts on bank credit to an average manufacturing firm by an average 0.15 percentage point over the first three quarters (bottom right panel), implying that the infrastructure investment spree during this period reduced the transmission of monetary stimulus to bank credit by $12 \%(0.15 / 1.31)$.

For an average infrastructure firm, the estimated pure effect of monetary stimulus is positive at the 0.01 significance level contemporaneously and with lags, and the estimated interactive effect is also positive at the 0.01 significance level on impact and with one lag (column 1 of Table S.10). The significantly positive cumulative interactive effect (5.483) is in sharp contrast to the significantly negative interactive effect $(-2.301)$ in the manufacturing sector. The estimated cumulative effect suggests that a one percent increase in quarterly M2 growth alone should increase newly issued bank credit to an average infrastructure firm (as a share of its assets) by 1.376 percentage points.

Figure S.3 displays the loan responses to the 2009 monetary stimulus for an average infrastructure firm. The positive interactive effect of monetary stimulus made the total increase of bank credit higher than the loan response to monetary stimulus alone for the first three quarters of 2009 (top left panel). Newly issued bank credit allocated to an average infrastructure firm (as a share of its assets) peaked at 4.19 percentage points in the second 
quarter (2009Q2), with an average of 3.09 percentage points during the first three quarters of 2009 (top right panel) as compared to bank credit allocated to an average manufacturing firm in 2009Q1-2009Q3 (1.16 percentage points). During this period, moreover, infrastructure investment amplified the effect of monetary stimulus on bank credit to infrastructure firms by $37 \%$ with an average increase of 0.83 percentage point from the interaction channel and an average increase of 2.26 percentage points from the main channel (bottom row of charts in Figure S.3).

For an average real estate firm, the estimated effect of a monetary policy shock on bank credit is significantly positive both contemporaneously and with lags (column 3 of Table S.10). The cumulative effect implies that a one percent increase in quarterly M2 growth translated into an increase of 2.899 percentage points in bank loans, a magnitude almost four times the cumulative effect on credit to an average manufacturing firm (0.758). Another striking result is the significantly negative interactive effect on bank credit (column 3 of the table), with the resulting cumulative effect that is statistically significant at the 0.01 level.

Figure S.4 displays the dynamic responses of an average real estate firm to the 2009 monetary stimulus. Since the interactive effect was negative for the first three quarters (2009Q1-2009Q3), the total increase in bank loans was less than the monetary effect alone (top left panel). The total increase peaked at 3.33 percentage points in the third quarter (2009Q3) with an average of 2.75 percentage points in the first three quarters of 2009 (top left panel). The increase of bank credit to monetary stimulus alone was on average 5.44 percentage points in 2009Q1-2009Q3, but infrastructure spending driven by non-monetary shocks significantly reduced this monetary effect by $50 \%(2.69 / 5.44)$ with an average decline of 2.69 percentage points in 2009Q1-2009Q3 (bottom row of charts).

Figure S.5 displays the dynamic responses of bank loans and its two response channels for an average firm in the entire economy. The top left panel shows that infrastructure spending driven by non-monetary shocks, though small in magnitude, weakened monetary transmission to an increase in bank loans, making the overall response of bank loans smaller than the pure response, especially in the third quarter (2009Q3). The overall response of bank loans peaked in the second quarter (2009Q2) and increased by an average of 2.27 percentage points during the first three quarters (top right panel), in contrast to an average of 1.16 percentage points in the manufacturing sector. An increase of bank credit in response to monetary policy changes alone was higher, with an average of 2.43 percentage points (bottom left panel). That is, growth in infrastructure spending weakened the response to monetary stimulus of bank loans by an average of 0.16 percentage point during the first three quarters (2009Q1-2009Q3).

D.3. The remaining economy. For an average firm in the remaining economy, we estimate the main monetary effects on bank credit to be significantly positive contemporaneously and 
with all lags and the interactive effects to be significantly negative contemporaneously and with the first two lags (column 3 of Table S.11). According to the estimated cumulative effect, a one percent increase in quarterly M2 growth leads to an increase of bank loans by 1.645 percentage points, a magnitude in between the infrastructure sector (1.376) and the real estate sector (2.899). Notwithstanding this positive transmission of monetary policy changes, the interactive effect is estimated to be statistically negative at the 0.1 significance level, indicating that infrastructure investment weakens monetary transmission to bank credit in the remaining economy. Columns 1 and 2 of the table report how credit is allocated between SOEs and non-SOEs and show that expansionary monetary policy alone does not lead to an easier access to bank credit by SOEs than by non-SOEs. On the contrary, the estimated pure effects of monetary policy on non-SOE loans are larger than those on SOE loans on impact and with two lags. As a result, the cumulative effect on non-SOE loans is larger than that on SOE loans (2.024 vs. 1.244).

Except for the manufacturing sector, there was no evidence that the 2009 monetary stimulus generated favorable access to bank credit by SOEs over non-SOEs. In fact, the dynamic responses of non-SOE loans to monetary stimulus alone were at least as strong as those of SOE loans in the entire economy, contrary to the empirical finding for the manufacturing sector only. To understand this important difference, we provide relevant institutional facts. Infrastructure and real estate have always been the government's two strategic sectors since the late 1990s, and most firms in these sectors are capital intensive. In the remaining economy, moreover, about $60 \%$ of bank lending to non-SOEs was allocated to wholesale and retail trades (Table S.12), which were capital intensive sectors (Chang, Chen, Waggoner, and Zha, 2016), and this large loan share remained stable over time. Bank lending to SOEs in the remaining economy, on the other hand, was dispersed among subsectors - only $16.87 \%$ of SOE lending was allocated to wholesale and retail trades while a large share of SOE lending was allocated instead to labor-intensive services (Table S.12). Most non-SOEs in wholesale and retail trades were capital intensive and large firms that generated more sales, provided more tax revenues, and boosted more output of the local economy than did firms in labor intensive sectors. They were therefore favored by local governments with special deals and exemptions. These institutional facts support our empirical finding that the 2009 monetary stimulus alone did not lead to credit allocation in favor of SOEs over non-SOEs in infrastructure, real estate, and the rest of the non-manufacturing economy.

The positive monetary impacts on bank credit to non-SOEs in the remaining economy, however, are eclipsed by an increase of infrastructure investment driven by non-monetary shocks. The interactive effects on non-SOE loans are estimated to be significantly negative at the 0.01 level on impact and with one or two lags, and the estimated cumulative effect is negative (-11.332) also at the 0.01 significance level, in contrast to the statistically insignificant cumulative effect on SOE loans. The negative interactive effects on non-SOEs in the rest of the economy are similar to the finding for real estate. An increase of infrastructure 
spending in 2009 significantly reduced the monetary impact on bank credit to an average firm in this sector (top left and bottom right panels of Figure S.6). As a result, the overall effect of the 2009 monetary stimulus was weaker than the effect of monetary stimulus alone (an average of 2.61 versus 3.14 percentage points during the first three quarters from $2009 \mathrm{Q} 1$ to 2009Q3, almost one fifth smaller (2.60/3.14) according to top right and bottom left panels). This dampening effect was entirely driven by the interactive effect on non-SOE loans, with an average of 1.38 negative percentage points in 2009Q1-2009Q3 and a reduction of the pure effect by almost 35\% (1.38/3.99, first two rows of Figure S.7 and Table S.13). By contrast, the interactive effects of monetary stimulus with infrastructure investment on bank credit to SOEs were positive but with a much smaller magnitude. Taking into account these opposite interactive effects on bank credit to non-SOEs versus SOEs, the 2009 monetary stimulus had similar effects on bank credit to both non-SOEs and SOEs (an increase of 2.62 and 2.61 percentage points during the first four quarters (2009Q1-2009Q4)), despite much stronger effects of monetary stimulus alone on bank credit to non-SOEs than SOEs (comparing the top and bottom rows of Figure S.7, as well as columns 2 and 3 of Table S.13).

Summary. Similar to our findings for other non-manufacturing sectors, the 2009 monetary stimulus alone did not lead to favorable access to bank credit by SOEs over non-SOEs in the remaining economy. As in the real estate sector, moreover, the infrastructure investment spree spurred by non-monetary shocks in 2009 significantly dampened the transmission of monetary policy to bank credit allocated to non-SOEs so that there was no statistically significant difference between the overall effects of monetary stimulus on bank credit to SOEs and to non-SOEs.

\section{Appendix E. A Model of Fiscal-Monetary Policy Interaction}

This section develops a two-sector model to understand the fiscal-monetary policy interaction channel in credit allocation across different sectors. Our model builds on the two-sector model of Bleck and Liu (2018) and whenever it is possible, we use the same notation as Bleck and Liu (2018). Bleck and Liu (2018) study the overall impact of a credit expansion on credit allocation between two sectors with asset specificity; they do not distinguish the role of monetary versus fiscal policy. We modify their model with a focus on the impacts of a fiscal expansion on the monetary transmission mechanism. Section E.1 describes the model setup; Section E.2 establishes theoretical properties about the impacts of a fiscal expansion on the transmission of monetary policy to credit allocation. Section E.3 provides proofs of all the lemmas and propositions.

E.1. The model. Consider an economy with two sectors: sector 1 (corresponding to nonSOEs in the non-infrastructure sector) and sector 2 (corresponding to infrastructure SOEs or all firms in the infrastructure sector). Each sector consists of a continuum of entrepreneurs (firms) with measure one. In addition, there is a set of competitive banks that receive funds 
from the central bank and lend to firms. To highlight the asymmetric effects of a fiscal expansion on credit allocation across sectors, we assume that the two sectors are the same except for government-guaranteed loans they receive. As the credit supply increases due to a monetary stimulus, a fiscal expansion via infrastructure investment allows firms in sector 2 to enjoy government guarantees of their debt repayments, while those in sector 1 do not have these guarantees. To keep the exposition simple, we drop the subscript associated with a sector in this section, because firms in each sector face the same problem and the same economic environment, except for the amount of guaranteed loans as we will discuss in the next section.

The economy has three periods: $T_{0}, T_{1}$, and $T_{2}$. In period $T_{0}$, each firm is endowed with one identical project. A firm's investment, denoted as $B$, is idiosyncratic; its project delivers the cash flow $C$ in period $T_{1}$. We assume that $B$ has a probability distribution with the support $[0, I], f(B)$, across firms. For tractability, we assume firms do not have internal funds, and thus need to finance their investment by borrowing from banks with the net interest rate $r$. We assume that $C \geq I(1+r)$ so that all firms have incentive to invest in their individual projects.

A firm has an incentive to default its debt repayment in period $T_{1}$. To deal with a potential default, the bank enters a contract with the firm's project (asset) value as collateral. If the firm does not repay the debt, the bank can liquidate the project and sell it in the secondary asset market at $T_{1}$. Denote by $P$ the liquidation value of the project, which is also the collateral value for the firm's borrowing with the assumption that a firm has a full bargaining power in renegotiation. Thus, given the interest rate $r$, the maximum amount a firm can borrow from the bank is $P /(1+r)$. Clearly, there exists a marginal firm with borrowing

$$
\bar{B}=\frac{P}{1+r}
$$

such that firms with external borrowing $B \in[0, \bar{B}]$ will undertake investment and while those with $B \in(\bar{B}, I]$ will not.

With quantity-based monetary policy as in China, the aggregate supply of credit, denoted as $Q$, is positively influenced by the money supply (Chen, Ren, and Zha (2018)). Without loss of generality, we use an increase in the aggregate supply of credit and an increase in money growth interchangeably. The credit market clearing condition in period $T_{0}$ is

$$
Q=\int_{0}^{\bar{B}} B f(B) d B,
$$

where the right side of equation (E.2) is aggregate credit demand. Equation (E.2) shows that an increase in credit supply $Q$ raises the amount of borrowing by the marginal firm; that is,

$$
\frac{d \bar{B}}{d Q}=\frac{1}{\bar{B} f(\bar{B})}>0
$$


Substituting (E.1) into (E.2), we have

$$
Q=\int_{0}^{\frac{P}{1+r}} B f(B) d B .
$$

It follows that $\left.\frac{\partial r}{\partial Q}\right|_{P}<0$. With $P$ fixed, the aggregate demand for credit remains unchanged without a change in the interest rate. As a result, an increase in the credit supply leads to a lower equilibrium interest rate to clear the credit market.

In period $T_{1}$, cash flow $C$ for the project operated in period $T_{0}$ is realized, and the firm pays back the loan borrowed at $T_{0}$. To solve for the equilibrium project value, we assume that in period $T_{1}$ firms have heterogeneous beliefs about project returns in period $T_{2}$. In particular, a fraction $\pi$ of firms have a high expectation of project returns, denoted by $E^{H}$, and the remaining fraction $1-\pi$ of firms have low expected project returns, denoted by $E^{L}$. The difference in valuation among firms allows them to trade assets (projects) in the secondary asset market. Buyers in the asset market are those with high beliefs about future project returns. We assume that only firms with the experience of operating the project in the previous period can operate the project in period $T_{1}$ to generate a cash flow in $T_{2}$.

In addition to the retained earnings from the last period, an asset buyer can use a loan guaranteed by the fiscal authority to finance the purchase of the project, denoted by $X$. Accordingly, the total amount of funds available to purchase the project in the secondary asset market equals to

$$
\pi \int_{0}^{\bar{B}}[C-B(1+r)] f(B) d B+X
$$

where the total number of projects for sale equals to $1-\pi$. The equilibrium value of project is therefore

$$
P=\left\{\begin{array}{l}
E^{H} \quad \text { if } \Gamma(\bar{B}, r)>E^{H} \\
\Gamma(\bar{B}, r) \text { if } \Gamma(\bar{B}, r) \in\left[E^{L}, E^{H}\right] \\
E^{L} \quad \text { if } \Gamma(\bar{B}, r)<E^{L}
\end{array}\right.
$$

with

$$
\begin{aligned}
\Gamma(\bar{B}, r) & \equiv \frac{\pi \int_{0}^{\bar{B}}[C-B(1+r)] f(B) d B+X}{1-\pi} \\
& =\frac{\pi[C F(\bar{B})-(1+r) Q]+X}{1-\pi}
\end{aligned}
$$

where the second equality is obtained by substituting equation (E.2) into the first equality. The symbol $F(\cdot)$ is the cumulative density function of $B$. Note that the equilibrium asset (project) value depends not only on the expected future fundamental value of the project in period $T_{2}$, but also on the current liquidity to which the buyer has access. If the asset price $\Gamma$ is higher than $E^{H}$, the equilibrium asset price will be $E^{H}$, at which point the firm 
with high belief will be indifferent between buying and selling. ${ }^{51}$ With a similar logic, if the asset price $\Gamma$ is lower than $E^{L}$, the equilibrium asset price will be $E^{L}$, at which point the firm with low belief will be indifferent between buying and selling. Note that (E.6) implies two cutoff levels for a loans guaranteed by the fiscal authority:

$$
\begin{aligned}
& \Gamma(\bar{B}, r) \leq E^{L} \Longleftrightarrow X \leq X^{L}, \\
& \Gamma(\bar{B}, r) \geq E^{H} \Longleftrightarrow X \geq X^{H},
\end{aligned}
$$

where $X^{L}$ and $X^{H}$, determined by $Q,{ }^{52}$ are defined as

$$
\begin{aligned}
X^{L} & \equiv(1-\pi) E^{L}-\pi[C F(\bar{B})-(1+r) Q], \\
X^{H} & \equiv(1-\pi) E^{H}-\pi[C F(\bar{B})-(1+r) Q] .
\end{aligned}
$$

In the next section, we consider the range of $X \in\left[0, X^{H}\right]$ for an analysis of fiscal expansion. When $X \geq X^{H}$, the project value is capped by $E^{H}$. Hence, it is a waste of resources for the fiscal authority to provide a guaranteed loan amount beyond the amount $X^{H}$ to increase the collateral value of the project in period $T_{0}$.

E.2. Impact of a fiscal expansion on the monetary transmission mechanism. Firms in sector 2 (the infrastructure sector) enjoy government guarantees of loan repayments. That is, $X_{1}=0, X_{2} \geq 0$. A fiscal expansion in our model corresponds to an increase of $X_{2}$, i.e., an increase in guaranteed loans to firms in sector 2 from a level less than or equal to $X^{L}$ to a level greater than $X^{L}{ }^{53}$ Our analysis focuses on how an increase in $X_{2}$, along with an increase in total credit supply $Q$, affects the monetary transmission to bank credit to sectors 1 and 2 .

We first characterize the relationship between the equilibrium interest rate $r$ and the credit supply to sector 2 as $r\left(Q_{2}\right) .{ }^{54}$ We consider two cases: (a) $X_{2} \leq X^{L}$ and (b) $X_{2}>X^{L}$. For case (a), since the asset price is fixed as $P=E^{L}$, it follows from (E.4) that the equilibrium $r$ decreases with $Q_{2}$, the total credit allocated to sector 2. This result implies a downward sloping curve of $r$ as a function of $Q_{2}$ for sector 2. Since $X_{1}=0$, a similar argument applies to sector 1. For case (b), we establish the following lemma about the relationships among the equilibrium interest rate $r$, the credit supply to sector 2 , and the aggregate credit supply.

Lemma 1. Assume $X_{2}>X^{L}$ and $\frac{d f(B)}{d B}>0$. With certain parameter values, (1) the equilibrium interest rate $r\left(Q_{2}\right)$ is $\mathrm{U}$-shaped as a function of credit supply to sector $2, Q_{2} ;(2)$ the

${ }^{51}$ If $P>E^{H}$, the marginal benefit of selling the project for a project holder with high belief will exceed the marginal benefit of holding and operating the project. This difference pushes the aseet price $P$ down toward $E^{H}$.

${ }^{52}$ One can show that $\frac{\partial X^{L}}{\partial Q}=-\pi\left[\frac{C}{B}-(1+r)\right]<0$.

${ }^{53}$ This assumption is motivated by the fact that prior to the 4-trillion RMB stimulus package, the CBRC prohibited local governments from providing guarantees to loans except for those approved by the State Council.

${ }^{54}$ Given $Q$, the credit demand in each sector, $I * F\left(\frac{P(Q)}{1+r}\right)$, is a decreasing function of $r$. 
equilibrium interest rate $r(Q)$ is U-shaped as a function of aggregate credit supply, $Q ;(3)$ the equilibrium bank credit to sector 2 is always above that for sector 1 .

An additional supply of credit to sector $2\left(Q_{2}\right)$ increases a cash flow from the project in period $T_{0}, C F\left(\bar{B}_{2}\right)$, by allowing more firms in sector 2 to operate. With $X_{2}>X^{L}$, the project value $P_{2}$ and thus the firm's collateral value in sector 2 increases, and so does the demand for bank credit to sector 2 . With a positive feedback loop among bank credit, investment, and project (collateral) value, an increase in credit demand from sector 2 will eventually dominate the increase in credit supply as $Q_{2}$ increases, causing the the equilibrium interest rate to increase with credit supply to sector 2. Accordingly, there exists a minimum interest rate, $r_{\min }$, that corresponds to a threshold level of aggregate credit supply, $Q^{*}$, such that when $r>r_{\min }$, the equilibrium interest rate $r$ increases with $Q_{2}$ and $Q$. By contrast, since $X_{1}=0$, the firm's project and thus its collateral value in sector 1 remains at level $E^{L}$. For a given $r$, therefore, the amount of borrowing by the marginal firm in sector 2 is always larger or equal to that in sector 1 ; and the equilibrium bank credit to sector 2 is always larger than credit to sector 1.

Denote the difference in credit allocated between the two sectors by $\Delta Q \equiv Q_{2}-Q_{1}$. The following lemma shows that under certain conditions, if the initial supply of aggregate credit is below $Q^{*}, \Delta Q$ decreases with the interest rate $r$.

Lemma 2. Assume $X_{2}>X^{L}$ and $\frac{d f(B)}{d B}>0$. Then $\forall Q \leq Q^{*}, \frac{d \Delta Q}{d r}<0$.

An explanation of Lemma 2 is straightforward. A decline in the interest rate $r$ raises the project's collateral value in both sectors 1 and 2 , which allows more firms in both sectors to operate. An increase in cash flow from a project in sector 2 raises the project value and its collateral value. which enables the firm to borrow further. By contrast, the project value in sector 1 remains at $E^{L}$. Accordingly, the total bank credit to sector 2 increases faster than total credit to sector 1 .

We now explore the effect of a fiscal expansion on the monetary transmission to bank credit in sectors 1 and 2 . We use the superscript prime to indicate a variable when monetary stimulus takes place. The variable without the prime superscript corresponds to the situation without monetary stimulus. Assume that the aggregate credit supply increases from a level $Q$ to $Q^{\prime}$ after a monetary stimulus. For the increase in bank credit to each sector $\triangle Q_{i}=Q_{i}^{\prime}-Q_{i}$ $(i=1,2)$, we compare two cases: (a) without a fiscal expansion and (b) with a fiscal expansion. The following proposition shows that a fiscal expansion dampens the monetary transmission to credit allocation to sector $1\left(\triangle Q_{1}>\triangle \widetilde{Q}_{1}\right)$ while enhancing the monetary transmission to credit allocation to sector $2\left(\triangle \widetilde{Q}_{2}>\triangle Q_{2}\right)$ via an increase of governmentguaranteed loans allocated to sector 2 , where the superscript tilde indicates a variable in case (b) and the variable without this superscript corresponds to case (a). 
Proposition E.1. Assume $\frac{d f(B)}{d B}>0,0<Q<Q^{\prime}$, and $X_{1}=X_{1}^{\prime}=0$. Let $0<X_{2}=X_{2}^{\prime} \leq X^{L}$ be government-guaranteed loans to sector 2 in case (a); let $\tilde{X}_{2}=\tilde{X}_{2}^{\prime}>X^{L}$ be governmentguaranteed loans to sector 2 in case (b). Then, (1) a fiscal expansion dampens the monetary effects on bank credit to sector 1; (2) a fiscal expansion enhances the monetary effects on bank credit to sector 2 . That is,

$$
\begin{aligned}
& Q_{1}^{\prime}-Q_{1}>\widetilde{Q}_{1}^{\prime}-\widetilde{Q}_{1}, \\
& \widetilde{Q}_{2}^{\prime}-\widetilde{Q}_{2}>Q_{2}^{\prime}-Q_{2} .
\end{aligned}
$$

Bleck and Liu (2018) study how $Q_{i}$ responds to $Q$ for $i=1,2$. Our focus is to study how this response changes with an increase of $X_{2}$ (the fiscal expansion via guaranteed loans). We use Figure S.8 to explain Proposition E.1. In the right panel of this figure, aggregate credit supply increases from $Q$ to $Q^{\prime}$. Without fiscal expansion, the equilibrium interest $r$ decreases with the credit supply in both sectors, as shown by the downward sloping curves $r\left(Q_{1}\right)$ and $r\left(Q_{2}\right)$ in the left panel. As the supply of aggregate credit increases, an increase of credit supply in each sector via a decrease in the equilibrium interest rate from $r$ to $r^{\prime}$ is symmetric, as shown by the distance between $Q_{1}^{\prime}-Q_{1}$. A fiscal expansion, via an increase in government-guaranteed loans to sector 2 , introduces a positive feedback loop among bank loans, investment, and project values for firms in sector 2. Accordingly, in the left panel of the figure, the curve linking the equilibrium interest rate $r$ and sector 2's credit supply becomes a U-shaped curve $\widetilde{r}\left(\widetilde{Q_{2}}\right)$. In the right panel, the curve linking the equilibrium interest rate $r$ and aggregate credit supply becomes a U-shaped curve $\widetilde{r}(\widetilde{Q})$ as well. When there is an increase in aggregate credit supply, an increase in bank credit to sector 2 is amplified from $Q_{2}^{\prime}-Q_{2}$ to $\widetilde{Q}_{2}^{\prime}-\widetilde{Q}_{2}$ with the positive feedback loop. Such an amplified increase in credit demand by sector 2 pushes up the cost of funds (the interest rate) for firms in sector 1, thus offsetting the decline of the interest rate due to an increase in aggregate credit supply. As illustrated by the figure, we see a smaller decline in the equilibrium interest rate $\Delta \widetilde{r}=\widetilde{r}^{\prime}-\widetilde{r}>r^{\prime}-r=\Delta r$. As a result, an increase of bank credit to firms in sector 1 is dampened, from $Q_{1}^{\prime}-Q_{1}$ to $\widetilde{Q}_{1}^{\prime}-\widetilde{Q}_{1} \cdot{ }^{55}$

E.3. Proofs. This section provides proofs of all the lemmas and propositions stated in Section E.2.

Proof of Lemma 1. Proving that (1) the equilibrium interest rate $r\left(Q_{2}\right)$ is U-shaped in credit supply to sector 2 is equivalent to proving that there exists a $Q_{2}^{*}$, such that for $Q_{2}<Q_{2}^{*}$, $\frac{\partial r}{\partial Q_{2}}<0$, for $Q_{2}=Q_{2}^{*}, \frac{\partial r}{\partial Q_{2}}=0$, while for $Q_{2}>Q_{2}^{*}, \frac{\partial r}{\partial Q_{2}}>0$.

$$
\frac{d r}{d Q_{2}}=\frac{d r}{d \bar{B}_{2}} \frac{d \bar{B}_{2}}{d Q_{2}}
$$

${ }^{55}$ Figure S.9 and S.10 describe two other cases about the initial and final positions of aggregate credit supply. In both cases, $Q_{1}^{\prime}-Q_{1}>\widetilde{Q}_{1}^{\prime}-\widetilde{Q}_{1}$, similar to Figures S.8. 
From (E.5) and (E.7), with $X_{2}>X^{L}$, the equilibrium project value for sector 2 is $P_{2}=$ $\Gamma\left(\bar{B}_{2}, r\right)$. Thus $r=\frac{\Gamma\left(\bar{B}_{2}, r\right)}{\bar{B}_{2}}-1$. Hence,

$$
\frac{d r}{d \bar{B}_{2}}=\frac{1}{\bar{B}_{2}} \frac{d \Gamma}{d \bar{B}_{2}}-\frac{\Gamma}{\bar{B}_{2}^{2}}
$$

From (E.6), we obtain

$$
\frac{d \Gamma}{d \bar{B}_{2}}=\frac{\pi}{1-\pi}\left[C f\left(\bar{B}_{2}\right)-Q_{2} \frac{d r}{d \bar{B}_{2}}\right]
$$

Plugging (E.11) into (E.10), we get

$$
\frac{d r}{d \bar{B}_{2}}=\frac{C f\left(\bar{B}_{2}\right) \bar{B}_{2}-\frac{1-\pi}{\pi} \Gamma}{\left(\frac{1-\pi}{\pi} \bar{B}_{2}+Q_{2}\right) \bar{B}_{2}}
$$

Plugging (E.12) into $(E .9)$ and using $(E .3)$ and $\Gamma\left(\bar{B}_{2}, r\right)=\bar{B}_{2}(1+r)$, we have

$$
\frac{d r}{d Q_{2}}=\frac{C f\left(\bar{B}_{2}\right)-\frac{1-\pi}{\pi}(1+r)}{\left(\frac{1-\pi}{\pi} \bar{B}_{2}+Q_{2}\right) \bar{B}_{2} f\left(\bar{B}_{2}\right)}
$$

According to $(E .13)$, if $f\left(\bar{B}_{2}\right)<\frac{1-\pi}{\pi} \frac{1+r}{C}$, we have $\frac{d r}{d Q_{2}}<0$.

$$
\frac{d r}{d Q_{2}}\left\{\begin{array}{cc}
<0 & \text { if } f\left(\bar{B}_{2}\right)<\frac{1-\pi}{\pi} \frac{1+r}{C} \\
=0 & \text { if } f\left(\bar{B}_{2}\right)=\frac{1-\pi}{\pi} \frac{1+r}{C} \\
>0 & \text { if } f\left(\bar{B}_{2}\right)>\frac{1-\pi}{\pi} \frac{1+r}{C}
\end{array}\right.
$$

Since $f(B)$ is an increasing function of $B$, under some values of $\pi$ and $C$, there must exist $\bar{B}_{2}^{*}$, such that $\forall \bar{B}_{2}<\bar{B}_{2}^{*}, f\left(\bar{B}_{2}\right)<\frac{1-\pi}{\pi} \frac{1+r}{C}$ and $\forall \bar{B}_{2}>\bar{B}_{2}^{*}, f\left(\bar{B}_{2}\right)>\frac{1-\pi}{\pi} \frac{1+r}{C}$. Since there is a one-to-one relationship between $\bar{B}_{2}$ and $Q_{2}$, this implies that $\exists Q_{2}^{*}$,

$$
\frac{d r}{d Q_{2}}\left\{\begin{array}{cc}
<0 & \text { if } Q_{2}<Q_{2}^{*} \\
=0 & \text { if } Q_{2}=Q_{2}^{*} \\
>0 & \text { if } Q_{2}>Q_{2}^{*}
\end{array}\right.
$$

Therefore, the equilibrium interest rate $r$ is U-shaped in sector 2's credit supply. This implies that there exists a smallest interest rate, denoted as $r_{\min }$, such that at $r_{\min }, Q_{2}=Q_{2}^{*}$.

To prove $r_{Q}$ is also $\mathrm{U}$-shaped, we use contradition. If the curve linking equilibrium interest rate $r$ and aggregate credit supply $\left(Q=Q_{1}+Q_{2}\right)$ is not U-shaped, but downward sloping, then $\exists r<r_{\min }$, at which the credit supply for sectors 1 and 2 is $Q_{1}$ and $Q_{2}$ respectively. This contradicts the fact that $r_{\min }$ is the smallest interest rate associated with the credit supply of sector 2. Hence, the equilibrium $r$ is also U-shaped in aggregate credit supply, with $r_{\min }$ the minimum equilibrium interest rate, at which $Q=Q^{*}$.

We now prove part (3) of the Lemma. $X_{2}>X_{1}=0 \Longrightarrow P_{2} \geq P_{1}=E^{L}$. Therefore, according to (E.1), for a given $r, \bar{B}_{2} \geq \bar{B}_{1}$. Thus according to (E.2), $Q_{2} \geq Q_{1}$. 
Proof of lemma 2. $X_{2}>X^{L}, X_{1}=0 \Longrightarrow P_{2}=\Gamma\left(\bar{B}_{2}, r\right), P_{1}=E^{L}$. Accordingly, with, $(E .2)$ we have

Hence,

$$
\Delta Q=\int_{0}^{\frac{\Gamma}{1+r}} B_{2} f\left(B_{2}\right) d B_{2}-\int_{0}^{\frac{E^{L}}{1+r}} B_{1} f\left(B_{1}\right) d B_{1}
$$

$$
\frac{d \Delta Q}{d r}=\frac{\Gamma}{1+r} f\left(\frac{\Gamma}{1+r}\right) \frac{\partial \frac{\Gamma}{1+r}}{\partial r}+\frac{E^{L}}{1+r} f\left(\frac{E^{L}}{1+r}\right) \frac{E^{L}}{(1+r)^{2}}
$$

Therefore

$$
\frac{d \Delta Q}{d r}<0 \Longleftrightarrow \frac{E^{L}}{1+r} f\left(\frac{E^{L}}{1+r}\right) \frac{E^{L}}{(1+r)^{2}}<\frac{\Gamma}{1+r} f\left(\frac{\Gamma}{1+r}\right)\left(-\frac{\partial \frac{\Gamma}{1+r}}{\partial r}\right)
$$

Plugging $(E .1),(E .2)$ and $P_{2}=\Gamma\left(\bar{B}_{2}, r\right)$ into $(E .6)$, We have

$$
\frac{\Gamma}{1+r}=\frac{\pi\left[\frac{C}{1+r} F\left(\frac{\Gamma}{1+r}\right)-\int_{0}^{\frac{\Gamma}{1+r}} B_{2} f\left(B_{2}\right) d B_{2}\right]+\frac{X_{2}}{1+r}}{1-\pi}
$$

Denote $Y \equiv \frac{\Gamma}{1+r}$. Equation (E.17) gives an implicit function of $Y$ and $r$

$$
\digamma(Y, r) \equiv \pi\left[\frac{C}{1+r} F(Y)-\int_{0}^{Y} B_{2} f\left(B_{2}\right) d B_{2}\right]+\frac{X_{2}}{1+r}-(1-\pi) Y=0
$$

Using the implicit function theorem, we have

$$
\begin{aligned}
\frac{\partial Y}{\partial r} & =-\frac{d \digamma / d r}{d \digamma / d Y} \\
& =-\frac{\left[\pi C F(Y)+X_{2}\right] \frac{1}{(1+r)^{2}}}{\pi \frac{C}{1+r} f(Y)-\pi Y f(Y)-(1-\pi)}
\end{aligned}
$$

Plugging (E.18) into (E.16) and reordering, we have

$$
\begin{gathered}
E^{L} f\left(\frac{E^{L}}{1+r}\right) E^{L}<\Gamma f\left(\frac{\Gamma}{1+r}\right) \frac{\left[\pi C F(Y)+X_{2}\right]}{\pi Y f(Y)+(1-\pi)-\pi \frac{C}{1+r} f(Y)} \\
\frac{d f(B)}{d B}>0 \Longrightarrow E^{L} f\left(\frac{E^{L}}{1+r}\right)<\Gamma f\left(\frac{\Gamma}{1+r}\right) . \text { Therefore, if } \\
E^{L} \leq \frac{\left[\pi C F(Y)+X^{L}\right]}{\pi Y f(Y)+(1-\pi)-\pi \frac{C}{1+r} f(Y)},
\end{gathered}
$$

then (E.19) holds. Plugging (E.7) into (E.20) and rearranging, the inequality (E.20) is equivalent to

$$
E^{L}\left(\bar{B}_{2}-\frac{C}{1+r}\right) f\left(\bar{B}_{2}\right) \leq(1+r) Q_{2}
$$

Since $\bar{B}_{2} \leq I \leq \frac{C}{1+r},(E .21)$ always holds. Therefore, (E.19) and thus (E.16) hold.

Proof of proposition 1. We first prove the "crowd-out" part for sector 1 . Since $X_{2}=X_{2}^{\prime} \leq$ $X^{L}$, the credit demand curves for sectors 1 and 2 are symmetric both before and after 
monetary expansion. In other words, $Q_{1}=\frac{Q}{2}, Q_{1}^{\prime}=\frac{Q^{\prime}}{2}$. Therefore,

$$
\begin{aligned}
Q_{1}^{\prime}-Q_{1} & >\widetilde{Q}_{1}^{\prime}-\widetilde{Q}_{1} \\
& \Leftrightarrow \frac{Q^{\prime}}{2}-\frac{Q}{2}>\widetilde{Q}_{1}^{\prime}-\widetilde{Q}_{1} \\
& \Leftrightarrow Q^{\prime}-2 \widetilde{Q}_{1}^{\prime}>Q-2 \widetilde{Q}_{1}
\end{aligned}
$$

with $Q^{\prime}=\widetilde{Q}_{1}^{\prime}+\widetilde{Q}_{2}^{\prime}$ and $Q=\widetilde{Q}_{1}+\widetilde{Q}_{2}$, the above inequality is equivalent to

$$
\widetilde{Q}_{2}^{\prime}-\widetilde{Q}_{1}^{\prime}>\widetilde{Q}_{2}-\widetilde{Q}_{1}
$$

That is, with fiscal stimulus, an increase in aggregate credit supply increases the difference of credit allocated to sector 2 relative to sector 1 . We now prove this holds in the following three cases.

(1) $0<Q<Q^{\prime} \leq Q^{*}$. According to Lemma 1, $r^{\prime}<r$, where $r^{\prime}$ is the equilibrium interest rate associated with $Q^{\prime}$. Then, according to Lemma 2 , since $Q=\widetilde{Q}_{1}+\widetilde{Q}_{2}$, $Q^{\prime}=\widetilde{Q}_{1}^{\prime}+\widetilde{Q}_{2}^{\prime}$, we have

$$
\widetilde{Q}_{2}^{\prime}-\widetilde{Q}_{1}^{\prime}>\widetilde{Q}_{2}-\widetilde{Q}_{1}
$$

(2) $0<Q<Q^{*} \leq Q^{\prime}$. Since $Q^{\prime}>Q^{*}, r^{\prime}>r_{\min }$. Notice that $\widetilde{Q}_{1}^{\prime} \leq Q_{1}^{*}$, where $Q_{1}^{*} \equiv$ $\left.Q_{1}\right|_{r=r_{\min }}$. Therefore,

$$
\widetilde{Q}_{1}^{\prime}-\widetilde{Q}_{1} \leq Q_{1}^{*}-\widetilde{Q}_{1}
$$

Therefore, to prove $Q_{1}^{\prime}-Q_{1}>\widetilde{Q}_{1}^{\prime}-\widetilde{Q}_{1}$, it is sufficient to prove

$$
Q_{1}^{\prime}-Q_{1}>Q_{1}^{*}-\widetilde{Q}_{1}
$$

From case (1), we have already proved that

$$
\frac{Q^{*}}{2}-\frac{Q}{2}>Q_{1}^{*}-\widetilde{Q}_{1}
$$

Since $Q_{1}^{\prime}=\frac{Q^{\prime}}{2}>\frac{Q^{*}}{2}$ and $Q_{1}=\frac{Q}{2}$, we have

$$
Q_{1}^{\prime}-Q_{1}>\frac{Q^{*}}{2}-\frac{Q}{2}>Q_{1}^{*}-\widetilde{Q}_{1}
$$

(3) $Q^{*} \leq Q<Q^{\prime}$. Then, according to Lemma $1, r^{\prime}>r$. Therefore, we have

$$
\widetilde{Q}_{1}^{\prime}<\widetilde{Q}_{1}, \widetilde{Q}_{2}^{\prime}>\widetilde{Q}_{2}
$$

So we have

$$
\widetilde{Q}_{2}^{\prime}-\widetilde{Q}_{1}^{\prime}>\widetilde{Q}_{2}-\widetilde{Q}_{1} .
$$

Now we prove the "crowding in" part for sector 2 .

$$
\begin{aligned}
\widetilde{Q}_{2}^{\prime}-\widetilde{Q}_{2} & >Q_{2}^{\prime}-Q_{2} \\
& \Leftrightarrow \\
\left(Q^{\prime}-\widetilde{Q}_{1}^{\prime}\right)-\left(Q-\widetilde{Q}_{1}\right) & >\left(Q^{\prime}-Q_{1}^{\prime}\right)-\left(Q-Q_{1}\right)
\end{aligned}
$$




$$
\begin{aligned}
& \Leftrightarrow \\
Q_{1}^{\prime}-Q_{1} & >\widetilde{Q}_{1}^{\prime}>\widetilde{Q}_{1}
\end{aligned}
$$

The last inequality is proved by the "crowding out" part for sector 1 .

\section{Appendix F. Potential CORRelation of CAPital intensity WITH OTHER VARIABLES}

A company's equity diversification and market share could be potential confounders of capital intensity so that excluding them might potentially bias our estimation of the coefficient, $d_{g, k}^{j}$, in equation (8). The data for a company's equity diversification and market share must be constructed from a company's financial statement. Unfortunately, we have no access to an unlisted company's financial statement for the historical period from 2007 to 2013. Since a majority of firms in our sample are unlisted, it is infeasible for us to incorporate variables such as equity diversification and market share as controls in our regression analysis. The data for a company's equity diversification and market share is available only for listed firms from CSMAR. Although listed firms are not representative of our sample, we use them to assess the potential correlation of capital intensity with other variables.

Our findings, as reported in Table S.14, suggest that omitting equity diversification and market shares in our regression is not likely to bias the estimated coefficient $d_{g, k}^{j}$ in equation (8). First, the correlation of our measured capital intensity with these variables is close to zero. Second, when we regress our capital intensity measure with each individual variable one by one and with all of them together, the estimated coefficients are statistically insignificant (Table S.14). Since our capital intensity measure is largely uncorrelated with these variables, our estimated results from equation (8) without these variables are unlikely to be biased.

\section{Appendix G. State Share And multicollinearity}

In Section VI.2, we discuss how credit allocation changed from the pre-stimulus period to the stimulus period by applying the same model specification of Cong, Gao, Ponticelli, and Yang (2019) to our constructed firm-specific shock $\tilde{\ell}_{i, t}^{m}$ in the manufacturing sector. For non-manufacturing sectors, however, there is no corresponding survey of industrial firms and therefore no information of state shares. ${ }^{56}$ To extend our analysis to non-manufacturing sectors, we need to replace a state share variable with a state dummy $I\left(S O E_{i}\right)$ that indicates the firm's ownership type, where $I\left(S O E_{i}\right)$ is a state dummy equal to one if firm $i$ is registered

\footnotetext{
$\overline{56}^{56}$ See Appendix $\mathrm{H}$ for a detailed discussion of this data issue.
} 
as an SOE and zero otherwise. We run the following firm-quarter panel regression

$$
\begin{aligned}
\mathfrak{b}_{i, c, j, t}= & \alpha_{c}+\alpha_{j}+\alpha_{t}+\beta_{1} \tilde{\ell}_{i, t}^{m} \times I\left(S O E_{i}\right) \\
& +\beta_{2} \tilde{\ell}_{i, t}^{m} \times I\left(S O E_{i}\right) \times I(\text { stimulus }) \\
& +\beta_{3} \tilde{\ell}_{i, t}^{m} \times I\left(S O E_{i}\right) \times I(\text { post }) \\
& +\beta_{4} \tilde{\ell}_{i, t}^{m}+\beta_{5} \tilde{\ell}_{i, t}^{m} \times I(\text { stimulus })+\beta_{6} \tilde{\ell}_{i, t}^{m} \times I(\text { post }) \\
& +\beta_{7} I\left(S O E_{i}\right) \\
& +\beta_{8} I\left(S O E_{i}\right) \times I(\text { stimulus })+\beta_{9} I\left(S O E_{i}\right) \times I(\text { post }) \\
& +c_{z}^{\prime} z_{i, t-1}+\eta_{i, c, j, t} .
\end{aligned}
$$

Similar to equation (9), $\beta_{1}$ in equation (G.1) captures the effect of a credit shock on SOE loans in the pre-stimulus period, while $\beta_{2}$ captures the marginal effect on SOE loans in the stimulus period relative to the pre-stimulus period. If credit allocation favored SOEs during the stimulus period relative to the pre-stimulus period, one should expect $\beta_{2}$ to be positive. The estimated $\beta_{2}$, however, is statistically insignificant (right panel of Table S.15). One plausible explanation is that when the variable StateShare $_{i, t=0}$ is replaced by the state dummy $I\left(S O E_{i}\right)$, the terms $\tilde{\ell}_{i, t}^{m} \times I\left(S O E_{i}\right)$ and $\tilde{\ell}_{i, t}^{m} \times I\left(S O E_{i}\right) \times I$ (stimulus $)$ become highly correlated (0.94). This high correlation generates severe multicollinearity.

We use two common approaches to test the severity of multicollinearity between $\tilde{\ell}_{i, t}^{m} \times$ $I\left(S O E_{i}\right)$ and $\tilde{\ell}_{i, t}^{m} \times I\left(S O E_{i}\right) \times I$ (stimulus $)$. First, we perform an F-test for the joint null hypothesis

$$
H_{0}: \beta_{1}=\beta_{2}=0 .
$$

The $\mathrm{F}$ statistic is 3.66 with probability greater than this $\mathrm{F}$ value is 0.0257 . Despite the statistical insignificance of each individual coefficient, the F-test rejects the joint null hypothesis that all these coefficients are zero. As a second approach, we remove the term $\tilde{\ell}_{i, t}^{m} \times I\left(S O E_{i}\right)$ from regression (G.1) and re-estimate the remaining coefficients. The coefficient of $\tilde{\ell}_{i, t}^{m} \times I\left(S O E_{i}\right) \times I$ (stimulus) is significantly positive (left panel of Table S.16). The results from both approaches demonstrate the multicollinearity problem when the state dummy is used.

All these results are not specific to our constructed firm-specific shocks; they hold for the reduced-form firm-specific shocks proposed by Cong, Gao, Ponticelli, and Yang (2019). To show this is true, we follow Cong, Gao, Ponticelli, and Yang (2019) and construct quarterly reduced-form firm-specific shocks as

$$
\Delta \log \widetilde{\mathcal{L}}_{i, c, j, t}=\sum_{b \in O_{i}} \omega_{b, i, t=0} \times \Delta \log \mathcal{L}_{b-c j, t},
$$

where $\mathcal{L}_{b-c j, t}$ represents bank b's aggregated outstanding loans to all borrowers between quarter $t-1$ and $t$, excluding those located in the same city as firm $i$ and those operating in the same industry as firm $i$. The key difference between equations (6) and (G.2) is that 
$\mathcal{L}_{b-c j, t}$ as firm-specific credit shocks can be driven by both monetary and fiscal shocks, while $\ell_{b, t}^{m}$ is driven only by monetary shocks. We replace $\tilde{\ell}_{i, t}^{m}$ with $\widetilde{\mathcal{L}}_{i, c, j, t}$ in both equation (9) and equation (G.1), and re-estimate these regressions with the same sample. Similar to the results in the left panel of Table S.15, the left panel of Table S.17 shows that, when state share is used to capture a firm's ownership status, $\beta_{1}$ is insignificant, while $\beta_{2}$ is significantly positive, implying that credit allocation favored SOEs during the stimulus period, but did not during the pre-stimulus period.

When a state dummy is used instead of state share, however, the estimated value of $\beta_{2}$ becomes statistically insignificant as a result of severe multicollinearity (right panel of Table S.17). These results are consistent with those reported in the right panel of Table S.15, which uses our constructed credit supply shocks. This multicollinearity problem is further demonstrated by the regression result reported in the right panel of Table S.16. When $\Delta \log \widetilde{\mathcal{L}}_{i, c, j, t}$ is removed from the regression, the estimated coefficient of $\Delta \log \widetilde{\mathcal{L}}_{i, c, j, t} \times I\left(S O E_{i}\right) \times I($ stimulus $)$ becomes statistically significant again.

To summarize, the results with our constructed credit shocks are consistent with those in the previous literature (Cong, Gao, Ponticelli, and Yang, 2019), when the data on state share is available for the manufacturing sector. When state dummy is used in place of state share, however, we encounter severe multicollinearity between the triple interaction term and the double interaction term that involve firm-specific shocks and the state dummy. Such a multicollinearity issue occurs regardless of a specific approach used to construct firm-specific credit supply shocks. This multicollinearity problem makes it infeasible to determine whether there is a trend reversal of credit allocation. Thus, the lack of data on state share in sectors other than manufacturing prevents us from exploring further whether there was a reversal of trend in the monetary transmission to credit allocation between SOEs and non-SOEs in other sectors. This issue is definitely interesting and deserves a thorough study when researchers are able to obtain reliable data in the future.

\section{Appendix H. DAta AVAilability on Equity ownership structure}

One may wonder whether existing data platforms, such as Tianyancha or Qichacha, could potentially help us finding the state share information from 2007 to 2013. Indeed, various existing data platforms, such as Tianyancha, Qichacha, and WIND, have individual firms annual reports but only from 2014 (and possibly 2013) onward. In this section, we show that although it is feasible to infer a firms ownership type from 2007 to 2013 period according to its 2014 annual report, it is essentially impossible to trace changes of its share structure or state share all the way back to 2008 with its annual reports in 2014 and afterward. Tracing a firms state share back to 2008 requires a reliable and complete historical information about changes of the equity ownership structure during the 2008-2014 period. This remains an important but daunting task for future research. 
To make the above argument, we first collect information about the data platforms, Tianyancha and Qichacha. We confirm that these two companies were both established in 2014 and more important, the data source for both platforms are from the National Enterprise Credit Information Publicity System (NECIPS). We then proceed to collect information about important policy changes in information revelation of companies. We find that the year 2014 is the hallmark for the establishment of a national system for registration information of Chinese companies. According to the 19 February 2014 Administrative Regulations of the People's Republic of China on Administration of Company Registration, a company shall submit, from January 1st to June 30th each year, the previous years annual report to the company's registration authority and disclose this information to the public via NECIPS. ${ }^{57}$ To ensure the quality of a company's disclosed information, the State Administration of Industry and Commerce on 19 August 2014 made a spot check on a company's disclosed information. ${ }^{58}$ Qichacha was established in March of 2014 and Tianyancha in October of 2014. Since the NECIPS was established on December 22, 2016, the data on companies' registration information from both Tianyancha and Qichacha can be also found from the NECIPS platform. ${ }^{59}$

We find, however, that the NECIPS does not mandate companies to disclose to the public their information, especially information prior to 2014, of historical changes in equity ownership. ${ }^{60}$ Even for many years after 2014, the quality of companies' basic information varies widely across firms. For example, on 30 March 2015, the Zhengzhou Administration for Industry and Commerce announced that based on their first survey of enterprises' public information, out of 1964 registered enterprises that were randomly sampled, only $51.78 \%$ of these enterprises had adequate registration information. ${ }^{61}$ As another example, according to the Administration for Industry and Commerce of Guangxi Autonomous Region, there were 1.93 million companies recorded by Guanxi Autonomous Region's NECIPS in December 2015, of which 439.6 thousand enterprises were registered. Moreover, only 101.8 thousand companies disclosed their annual reports. ${ }^{62}$

Given the history of the data platforms Tianyancha and Qichacha, we have made every effort to manually collect information of an individual firm's equity ownership structure. We find that the quality of the data about historical changes in equity ownership is so poor to make it feasible to trace back the history of firms' equity ownership structure. We use Evergrande Real Estate Group Ltd ("Evergrande" hereafter) as an example to illustrate the following four main issues about the data quality from various data platforms.

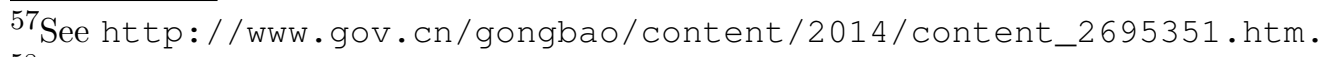

${ }^{58}$ See http://www.gov.cn/gongbao/content/2014/content_2758498.htm.

${ }^{59}$ We have also contacted WIND and confirmed with their representative that unlisted companies' registration information provided by WIND comes largely from the NECIPS.

${ }^{60}$ See http://www.gov.cn/fuwu/2019-07/25/content_5414777.htm.

${ }^{61}$ See http://hn.cnr.cn/hngbms/20150331/t20150331_518186357.shtml.

${ }^{62}$ See http: / / www. nnnews. net/p/1348757.html.
} 
(1) For the data platforms such as Tianyancha, Qichacha, and WIND, the earliest annual report for Evergrande can be dated back only to 2014 (or 2013 in the case of Qichacha), the first year in which Chinese enterprises were mandated to submit their annual reports to NECIPs (for various data platforms, see Figures S.11-S.14).

(2) Although the 2014 annual report may contain some historical information about changes in the shareholder structure, documents that trace historical changes in the structure of equity ownership is fragmentary and inconsistent. To illustrate this point, we use as a benchmark the relevant information provided by China Chengxin Securities Rating Co. Ltd (CCXR). According to a report by CCXR (see Figure S.15), summarized in Table S.18, Evergrande experienced seven rounds of changes in equity ownership between June 1996 and December 2014. Neither Tianyancha (Qichacha) nor WIND, however, shows a historical record of this companys changes in equity ownership and shareholding ratio during the period from 1997 to 2017. According to Tianyancha, for instance, Evergrande's 2014 annual report show that (a) Cairon Real Estate Co. Ltd was the only shareholder of Evergrade during 1996-2014 (see Figure S.16), and (b) the earliest time when equity ownership of Evergrande changed is April 1, 2017. Both pieces of this information are contradictory to the information revealed by CCXR. Similarly, according to WIND's database on changes in equity ownership, the equity ownership structure of Evergrande did not change from June 1996 to September 2018 (see Figure S.17). Despite various changes in the equity ownership structure of Evergrande from 1996 to 2014, note that the ultimate controller of Evegrande as reported by its annual report in various data platforms has always been a non-SOE or an individual. Hence, we are able to infer from the 2014 annual report whether Evergrande was a non-SOE in 2008. This inference, however, is fundamentally different from being able to use the 2014 annual report to trace out the exact state share of Evergrande in 2008.

(3) A related problem is incomplete information of equity penetration provided by these data platforms. For instance, the CCXR report shows that Hui Ka Yan held about 64.23\% of Evergrande's stock in December 2014 (see Table S.18). However, this information cannot be seen from Tianyancha's equity penetration structure (see Figure S.18). This issue will not change the companys ownership type, but it prevents us from accurately calculating the state share based on shareholding ratios.

(4) The inconsistency of information about the historical shareholder structure across different data platforms also increases the difficulty of accurate inference or identification. For instance, according to Qichacha, the number of historical shareholders is 11, but according to Tianyancha, the number of historical shareholders of Evergrande is 12 (see Figure S.19). 
To summarize, different from identifying the ownership type of the ultimate shareholder for a company, calculating the state share requires us to obtain the accurate information of each individual shareholder's shareholding ratio and their ownership type for the year 2008. The difficulties, outlined above, make it infeasible for us to obtain the accurate information of an individual shareholder's shareholding ratio all the way back to $2008 .^{63}$

\footnotetext{
${ }^{63}$ To overcome the difficulty of inference from the public information provided by various data platforms, we have also contacted commercial platforms such as Tianyancha to discuss a purchase of their customized data for calculating the state share of each company. Despite enormous efforts, Tianyancha informed us that they were unable to customize the data for the historical information of companies' state shares.
} 


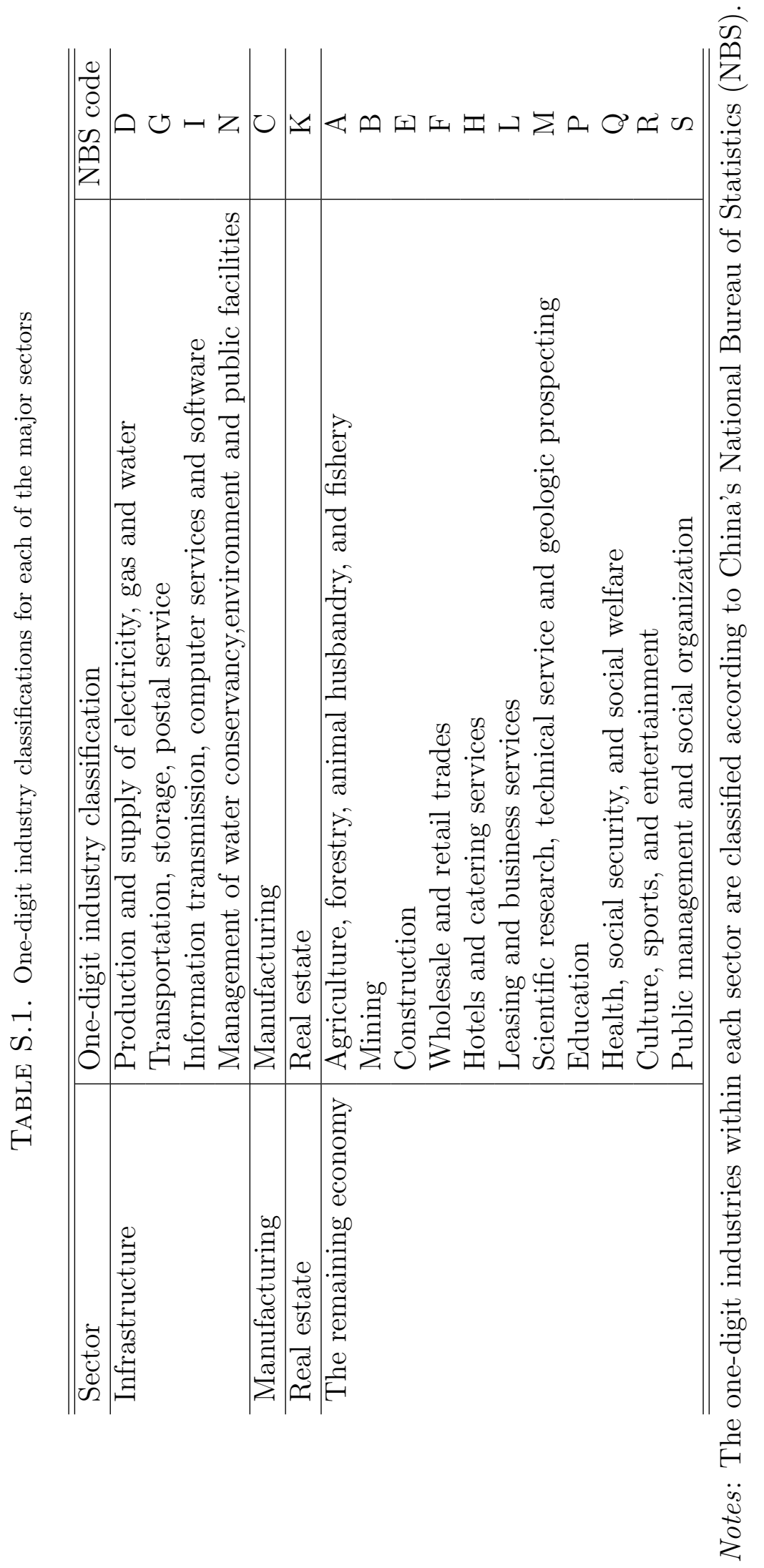


TABLE S.2. Estimation results for dynamic panel regression without the firststage estimation: infrastructure

\begin{tabular}{l|ccc}
\hline \hline & SOEs & Non-SOEs & All firms \\
& $(1)$ & $(2)$ & $(3)$ \\
\hline$b_{0}:$ interactive & $2.243^{* *}$ & $2.503^{* * *}$ & $2.397^{* * *}$ \\
& $(0.887)$ & $(0.777)$ & $(0.601)$ \\
$b_{1}:$ interactive & $2.278^{* *}$ & $2.319^{* * *}$ & $2.313^{* * *}$ \\
& $(1.073)$ & $(0.941)$ & $(0.727)$ \\
$b_{2}:$ interactive & $-1.869^{*}$ & $-4.601^{* * *}$ & $-3.731^{* * *}$ \\
& $(1.039)$ & $(0.911)$ & $(0.704)$ \\
$b_{3}:$ interactive & 0.441 & $-1.682^{* *}$ & -1.009 \\
& $(0.971)$ & $(0.849)$ & $(0.656)$ \\
$d_{0}:$ pure & $0.443^{* * *}$ & $0.345^{* * *}$ & $0.376^{* * *}$ \\
& $(0.111)$ & $(0.097)$ & $(0.075)$ \\
$d_{1}:$ pure & $0.471^{* * *}$ & $0.535^{* * *}$ & $0.510^{* * *}$ \\
& $(0.124)$ & $(0.109)$ & $(0.084)$ \\
$d_{2}:$ pure & $0.298^{* * *}$ & $0.295^{* * *}$ & $0.291^{* * *}$ \\
& $(0.110)$ & $(0.096)$ & $(0.074)$ \\
$d_{3}:$ pure & $0.221^{* *}$ & $0.293^{* * *}$ & $0.268^{* * *}$ \\
& $(0.089)$ & $(0.078)$ & $(0.060)$ \\
\hline$\sum_{k} b_{k}:$ interactive & 3.093 & -1.462 & -0.031 \\
& $(2.415)$ & $(2.119)$ & $(1.637)$ \\
$\sum_{k} d_{k}:$ pure & $1.433^{* * *}$ & $1.469^{* * *}$ & $1.446^{* * *}$ \\
& $(0.260)$ & $(0.227)$ & $(0.176)$ \\
\hline Number of observations & 16790 & 35972 & 52762 \\
\hline Fixed effects & Yes & Yes & Yes \\
Firm-level controls & Yes & Yes & Yes \\
Aggregate controls & Yes & Yes & Yes \\
\hline \hline
\end{tabular}

Notes: This table reports the results of regressions in which the dependent variable is a firm-quarter observation of newly issued bank credit to a firm, scaled by the firm's total nominal assets. The right-hand variables include contemporaneous and lagged monetary policy shocks and their interactions with the respective growth rates of infrastructure investment without the first-stage estimation. The firm-level control variables include the NPL ratio, the guarantee ratio, assets, and the leverage ratio, all lagged by one period. The aggregate control variables include lagged GDP growth net of infrastructure investment, lagged inflation, and contemporaneous and lagged growth rates of infrastructure investment. Column (1) reports the estimates using the sample of all firms in the infrastructure sector; columns (2) and (3) report the estimates based on the subsamples of SOEs and non-SOEs in the infrastructure sector. The values in parentheses are standard errors. The superscript * represents the 0.1 significance level, ** 0.05 , and *** 0.01 . 
TABLE S.3. Relative impacts of monetary stimulus on loans to non-SOEs: the entire economy

\begin{tabular}{l|c|c|c}
\hline \hline & $\begin{array}{c}\text { Interactive } \\
(1)\end{array}$ & $\begin{array}{c}\text { Pure } \\
(2)\end{array}$ & $\begin{array}{c}\text { Overall } \\
(3)\end{array}$ \\
\hline 2009Q1 & $-0.59^{* * *}$ & 0.17 & $-0.42^{* * *}$ \\
& $(0.19)$ & $0.20)$ & $(0.16)$ \\
2009Q2 & $-1.06^{* * *}$ & 0.29 & $-0.77^{* * *}$ \\
& $(0.28)$ & $(0.36)$ & $(0.21)$ \\
2009Q3 & $-0.88^{* * *}$ & 0.34 & $-0.54^{* *}$ \\
& $(0.28)$ & $(0.37)$ & $(0.23)$ \\
2009Q4 & $-0.53^{* *}$ & 0.26 & -0.27 \\
& $(0.26)$ & $(0.26)$ & $(0.26)$ \\
2010Q1 & -0.11 & 0.16 & 0.05 \\
& $(0.08)$ & $(0.17)$ & $(0.15)$ \\
2010Q2 & 0.01 & 0.06 & 0.07 \\
& $(0.01)$ & $(0.09)$ & $(0.09)$ \\
\hline \hline
\end{tabular}

Notes: Impacts relative to those on SOE loans (we take monetary impacts on loans to SOEs as a benchmark for comparison). The superscript ${ }^{*}$ represents the 0.1 significance level, ** 0.05, and *** 0.01. Each panel regression has both firm-level controls and aggregate controls.

TABLE S.4. Relative impacts of monetary stimulus on loans to non-SOEs: manufacturing

\begin{tabular}{l|c|c|c}
\hline \hline & $\begin{array}{c}\text { Interactive } \\
(1)\end{array}$ & $\begin{array}{c}\text { Pure } \\
(2)\end{array}$ & $\begin{array}{c}\text { Overall } \\
(3)\end{array}$ \\
\hline 2009Q1 & -0.22 & $-0.69^{*}$ & $-0.90^{* * *}$ \\
& $(0.38)$ & $(0.38)$ & $(0.32)$ \\
2009Q2 & 0.40 & $-1.61^{* *}$ & $-1.20^{* * *}$ \\
& $(0.54)$ & $(0.71)$ & $(0.41)$ \\
2009Q3 & 0.46 & -1.19 & -0.74 \\
& $(0.57)$ & $(0.75)$ & $(0.45)$ \\
2009Q4 & -0.55 & -0.38 & -0.93 \\
& $(0.51)$ & $(0.52)$ & $(0.51)$ \\
2010Q1 & -0.25 & 0.07 & -0.18 \\
& $(0.16)$ & $(0.35)$ & $(0.31)$ \\
& 0.01 & 0.00 & -0.01 \\
& $(0.01)$ & $(0.18)$ & $(0.19)$ \\
\hline \hline
\end{tabular}

Notes: Impacts relative to those on SOE loans (we take monetary impacts on loans to SOEs as a benchmark for comparison). The superscript ${ }^{*}$ represents the 0.1 significance level, $* * 0.05$, and $* * * 0.01$. Each panel regression has both firm-level controls and aggregate controls. 
TABLE S.5. Relative impacts of monetary stimulus on loans to non-SOEs: infrastructure

\begin{tabular}{l|c|c|c}
\hline \hline & $\begin{array}{c}\text { Interactive } \\
(1)\end{array}$ & $\begin{array}{c}\text { Pure } \\
(2)\end{array}$ & $\begin{array}{c}\text { Overall } \\
(3)\end{array}$ \\
\hline 2009Q1 & -0.02 & -0.25 & -0.27 \\
& $(0.41)$ & $(0.39)$ & $(0.31)$ \\
2009Q2 & 0.21 & -0.05 & 0.16 \\
& $(0.56)$ & $(0.72)$ & $(0.42)$ \\
2009Q3 & -0.55 & 0.21 & -0.34 \\
& $(0.60)$ & $(0.80)$ & $(0.47)$ \\
2010Q1 & $-0.97^{*}$ & 0.46 & -0.51 \\
& $(0.54)$ & $(0.55)$ & $(0.52)$ \\
& $-0.29^{*}$ & 0.35 & 0.06 \\
2010Q2 & $(0.17)$ & $(0.36)$ & $(0.31)$ \\
& 0.00 & 0.19 & 0.20 \\
& $(0.01)$ & $(0.19)$ & $(0.19)$ \\
\hline \hline
\end{tabular}

Notes: Impacts relative to those on SOE loans (we take monetary impacts on loans to SOEs as a benchmark for comparison). The superscript $*$ represents the 0.1 significance level, $* * 0.05$, and $* * * 0.01$. Each panel regression has both firm-level controls and aggregate controls.

TABLE S.6. Relative impacts of monetary stimulus on loans to non-SOEs: real estate

\begin{tabular}{l|c|c|c}
\hline \hline & $\begin{array}{c}\text { Interactive } \\
(1)\end{array}$ & $\begin{array}{c}\text { Pure } \\
(2)\end{array}$ & $\begin{array}{c}\text { Overall } \\
(3)\end{array}$ \\
\hline 2009Q1 & $-1.63^{* *}$ & $2.73^{* * *}$ & $1.10^{* *}$ \\
& $(0.70)$ & $(0.70)$ & $(0.54)$ \\
2009Q2 & $-3.09^{* * *}$ & $4.61^{* * *}$ & $1.52^{* *}$ \\
& $(0.97)$ & $(1.25)$ & $(0.72)$ \\
2009Q3 & -1.27 & $4.22^{* * *}$ & $2.95^{* * *}$ \\
& $(0.98)$ & $(1.34)$ & $(0.78)$ \\
2009Q4 & 0.21 & $3.02^{* * *}$ & $3.23^{* * *}$ \\
& $(0.89)$ & $(0.90)$ & $(0.84)$ \\
2010Q1 & 0.11 & $1.63^{* * *}$ & $1.74^{* * *}$ \\
& $(0.22)$ & $(0.56)$ & $(0.48)$ \\
2010Q2 & -0.01 & $0.65^{* *}$ & $0.64^{* *}$ \\
& $(0.03)$ & $(0.28)$ & $(0.29)$ \\
\hline \hline
\end{tabular}

Notes: Impacts relative to those on SOE loans (we take monetary impacts on loans to SOEs as a benchmark for comparison). The superscript ${ }^{*}$ represents the 0.1 significance level, $* * 0.05$, and $* * * 0.01$. Each panel regression has both firm-level controls and aggregate controls. 
TABLE S.7. Estimation results for dynamic panel regression (1) with region fixed effects

\begin{tabular}{l|cc|cc|cc}
\hline \hline & \multicolumn{2}{|c|}{ Infrastructure } & \multicolumn{2}{c|}{ Manufacturing } & \multicolumn{2}{c}{ Real estate } \\
Monetary effect & $(1)$ & $(2)$ & $(3)$ & $(4)$ & $(5)$ & $(6)$ \\
\hline$b_{0}$ : interactive & $3.191^{* * *}$ & $3.117^{* * *}$ & 0.512 & -0.304 & -1.514 & $-7.673^{* * *}$ \\
& $(1.107)$ & $(0.971)$ & $(1.382)$ & $(0.359)$ & $(2.146)$ & $(1.408)$ \\
$b_{1}$ : interactive & $4.035^{* * *}$ & $4.644^{* * *}$ & -1.786 & 0.061 & -1.989 & $-11.690^{* * *}$ \\
& $(1.387)$ & $(1.216)$ & $(1.738)$ & $(0.451)$ & $(2.697)$ & $(1.767)$ \\
$b_{2}$ : interactive & 0.484 & $-2.207^{*}$ & -2.066 & $-1.068^{* *}$ & $-5.515^{* *}$ & $-7.486^{* * *}$ \\
& $(1.402)$ & $(1.230)$ & $(1.751)$ & $(0.455)$ & $(2.715)$ & $(1.789)$ \\
$b_{3}$ : interactive & 1.088 & -1.562 & 1.488 & $-0.972^{* *}$ & -0.145 & 0.858 \\
& $(1.215)$ & $(1.065)$ & $(1.515)$ & $(0.393)$ & $(2.352)$ & $(1.546)$ \\
$d_{0}$ : pure & $0.447^{* * *}$ & $0.362^{* * *}$ & $0.470^{* * *}$ & $0.232^{* * *}$ & $0.343^{*}$ & $1.288^{* * *}$ \\
& $(0.103)$ & $(0.091)$ & $(0.129)$ & $(0.033)$ & $(0.200)$ & $(0.131)$ \\
$d_{1}$ : pure & $0.460^{* * *}$ & $0.515^{* * *}$ & $0.506^{* * *}$ & $0.211^{* * *}$ & $0.551^{* * *}$ & $1.190^{* * *}$ \\
$d_{2}:$ pure & $(0.109)$ & $(0.096)$ & $(0.137)$ & $(0.036)$ & $(0.212)$ & $(0.139)$ \\
& $0.218^{* *}$ & $0.230^{* * *}$ & 0.123 & $0.189^{* * *}$ & 0.029 & $0.313^{* * *}$ \\
$d_{3}$ : pure & $(0.092)$ & $(0.081)$ & $(0.115)$ & $(0.030)$ & $(0.179)$ & $(0.117)$ \\
& $0.242^{* * *}$ & $0.290^{* * *}$ & 0.078 & $0.084^{* * *}$ & -0.085 & $0.314^{* * *}$ \\
\hline$\sum_{k} b_{k}$ : interactive & $(0.076)$ & $(0.067)$ & $(0.095)$ & $(0.025)$ & $(0.148)$ & $(0.097)$ \\
\hline$\sum_{k} d_{k}:$ pure & $8.797^{* * *}$ & 3.991 & -1.853 & $-2.283^{* *}$ & -9.164 & $-25.991^{* * *}$ \\
& $(3.232)$ & $(2.835)$ & $(4.035)$ & $(1.048)$ & $(6.270)$ & $(4.121)$ \\
$\#$ of observations & $1.368^{* * *}$ & $1.396^{* * *}$ & $1.177^{* * *}$ & $0.715^{* * *}$ & $0.839^{* *}$ & $3.105^{* * *}$ \\
\hline Fixed effects & $(0.204)$ & $(0.179)$ & $(0.255)$ & $(0.066)$ & $(0.395)$ & $(0.260)$ \\
Firm-level controls & 16721 & 35765 & 5773 & 49726 & 1380 & 13570 \\
\hline \hline
\end{tabular}

Notes: This table reports the results of regressions in which the dependent variable is a firm-quarter observation of newly issued bank credit to a firm, scaled by the firm's total nominal assets. The right-hand variables include contemporaneous and lagged monetary policy shocks and their interactions with the respective growth rates of infrastructure investment. These variables are obtained from the first-stage estimation. We add region fixed effects to this regression. The firm-level control variables include the NPL ratio, the guarantee ratio, assets, and the leverage ratio, all lagged by one period. The aggregate control variables include lagged GDP growth net of infrastructure investment, lagged inflation, and contemporaneous and lagged growth rates of infrastructure investment, all of which are obtained from the first-stage estimation. The values in parentheses are standard errors. The superscript * represents the 0.1 significance level, ${ }^{* *} 0.05$, and $* * * 0.01$. 
TABLE S.8. Estimation results for dynamic panel regression (1) to the exclusion of Sichuan

\begin{tabular}{l|cc|cc|cc}
\hline \hline & \multicolumn{2}{|c|}{ Infrastructure } & \multicolumn{2}{c|}{ Manufacturing } & \multicolumn{2}{c}{ Real Estate } \\
Monetary effect & $(1)$ & $(2)$ & $(3)$ & $(4)$ & $(5)$ & $(6)$ \\
\hline$b_{0}$ : interactive & $3.375^{* * *}$ & $4.219^{* * *}$ & 0.543 & -0.168 & -1.546 & $-7.778^{* * *}$ \\
& $(1.139)$ & $(1.003)$ & $(1.462)$ & $(0.367)$ & $(2.193)$ & $(1.430)$ \\
$b_{1}$ : interactive & $3.530^{* *}$ & $4.718^{* * *}$ & -2.152 & 0.01 & -2.291 & $-12.098^{* * *}$ \\
& $(1.428)$ & $(1.260)$ & $(1.844)$ & $(0.465)$ & $(2.764)$ & $(1.800)$ \\
$b_{2}$ : interactive & 0.591 & -1.194 & -1.989 & $-0.993^{* *}$ & $-5.510^{* *}$ & $-7.340^{* * *}$ \\
& $(1.436)$ & $(1.269)$ & $(1.841)$ & $(0.464)$ & $(2.759)$ & $(1.814)$ \\
$b_{3}$ : interactive & 1.057 & -1.11 & 2.12 & $-0.937^{* *}$ & -0.001 & 1.164 \\
& $(1.250)$ & $(1.101)$ & $(1.592)$ & $(0.402)$ & $(2.393)$ & $(1.567)$ \\
$d_{0}$ : pure & $0.435^{* * *}$ & $0.314^{* * *}$ & $0.474^{* * *}$ & $0.227^{* * *}$ & $0.350^{*}$ & $1.301^{* * *}$ \\
& $(0.106)$ & $(0.094)$ & $(0.136)$ & $(0.034)$ & $(0.204)$ & $(0.133)$ \\
$d_{1}$ : pure & $0.486^{* * *}$ & $0.544^{* * *}$ & $0.522^{* * *}$ & $0.211^{* * *}$ & $0.560^{* * *}$ & $1.193^{* * *}$ \\
$d_{2}:$ pure & $(0.112)$ & $(0.099)$ & $(0.145)$ & $(0.036)$ & $(0.216)$ & $(0.142)$ \\
& $0.224^{* *}$ & $0.182^{* *}$ & 0.097 & $0.188^{* * *}$ & 0.034 & $0.298^{* *}$ \\
$d_{3}$ : pure & $(0.095)$ & $(0.083)$ & $(0.121)$ & $(0.030)$ & $(0.183)$ & $(0.119)$ \\
& $0.249^{* * *}$ & $0.313^{* * *}$ & 0.061 & $0.084^{* * *}$ & -0.083 & $0.307^{* * *}$ \\
\hline$\sum_{k} b_{k}$ : interactive & $(0.078)$ & $(0.069)$ & $(0.101)$ & $(0.025)$ & $(0.151)$ & $(0.099)$ \\
\hline$\sum_{k} d_{k}:$ pure & $8.554^{* * *}$ & $6.633^{* *}$ & -1.479 & $-2.088^{*}$ & -9.347 & $-26.052^{* * *}$ \\
& $(3.318)$ & $(2.928)$ & $(4.254)$ & $(1.072)$ & $(6.396)$ & $(4.181)$ \\
$\#$ of observations & $1.394^{* * *}$ & $1.352^{* * *}$ & $1.154^{* * *}$ & $0.710^{* * *}$ & $0.860^{* *}$ & $3.100^{* * *}$ \\
\hline Fixed effects & $(0.211)$ & $(0.185)$ & $(0.271)$ & $(0.068)$ & $(0.406)$ & $(0.265)$ \\
Firm-level controls & 15824 & 33281 & 5451 & 48047 & 1357 & 13340 \\
\hline \hline
\end{tabular}

Notes: This table reports the results of regressions in which the dependent variable is a firm-quarter observation of newly issued bank credit to a firm, scaled by the firm's total nominal assets. The right-hand variables include contemporaneous and lagged monetary policy shocks and their interactions with the respective growth rates of infrastructure investment. These variables are obtained from the first-stage estimation. The sample excludes the province of Sichuan. The firm-level control variables include the NPL ratio, the guarantee ratio, assets, and the leverage ratio, all lagged by one period. The aggregate control variables include lagged GDP growth net of infrastructure investment, lagged inflation, and contemporaneous and lagged growth rates of infrastructure investment, all of which are obtained from the first-stage estimation. The values in parentheses are standard errors. The superscript * represents the 0.1 significance level, ${ }^{* *} 0.05$, and $* * * 0.01$. 
TABLE S.9. Ratio of total assets to the number of workers

Panel A: All firms

\begin{tabular}{c|c|c|c|c}
\hline \hline & \multicolumn{2}{|c|}{ SOEs } & \multicolumn{2}{c}{ Non-SOEs } \\
\hline Sector & Mean & Median & Mean & Median \\
\hline Infrastructure & 1034.67 & 240.38 & 711.04 & 254.96 \\
Manufacturing & 278.53 & 89.92 & 139.47 & 60.39 \\
Real estate & 336.60 & 124.82 & 1332.43 & 135.62 \\
\hline \hline
\end{tabular}

Panel B: Capital intensive firms

\begin{tabular}{c|c|c|c|c}
\hline \hline & \multicolumn{2}{|c|}{ SOEs } & \multicolumn{2}{c}{ Non-SOEs } \\
\hline Sector & Mean & Median & Mean & Median \\
\hline Infrastructure & 1248.29 & 354.88 & 796.21 & 306.92 \\
Manufacturing & 450.82 & 151.71 & 225.84 & 107.88 \\
Real Estate & 500.92 & 250.46 & 2044.20 & 193.56 \\
\hline \hline
\end{tabular}

Panel C: Non-capital intensive firms

\begin{tabular}{c|c|c|c|c}
\hline \hline & \multicolumn{2}{|c|}{ SOEs } & \multicolumn{2}{c}{ Non-SOEs } \\
\hline Sector & Mean & Median & Mean & Median \\
\hline Infrastructure & 70.61 & 54.86 & 81.92 & 65.53 \\
Manufacturing & 59.24 & 50.96 & 45.61 & 37.89 \\
Real Estate & 62.74 & 50.82 & 73.13 & 48.34 \\
\hline \hline
\end{tabular}

Notes: The values in the table are calculated from a combination of China's Economic Census Yearbook 2008 and our loan data by matching identifications of firms at the end of 2008. Our loan data has information about firms' total assets, but no information about the number of workers. China's Economic Census Yearbook 2008, however, has information about the number of employees, but no information about business loans at the firm level. The Wilcoxon test is used for the hypothesis of no median difference. The superscript ** represents the 0.05 significance level and $* * * 0.01$.

Sources: http://www.stats.gov.cn/tjsj/pcsj/jjpc/2jp/left.htm and our loan-level data. 
TABLE S.10. Estimation results for dynamic panel regression (1): all firms

\begin{tabular}{l|ccc}
\hline \hline & Infrastructure & Manufacturing & Real estate \\
Monetary effect & $(1)$ & $(2)$ & $(3)$ \\
\hline$b_{0}:$ interactive & $3.106^{* * *}$ & -0.243 & $-7.087^{* * *}$ \\
& $(0.752)$ & $(0.354)$ & $(1.299)$ \\
$b_{1}$ : interactive & $4.447^{* * *}$ & -0.136 & $-10.740^{* * *}$ \\
& $(0.944)$ & $(0.448)$ & $(1.635)$ \\
$b_{2}:$ interactive & -1.353 & $-1.187^{* * *}$ & $-7.261^{* * *}$ \\
& $(0.951)$ & $(0.447)$ & $(1.646)$ \\
$b_{3}:$ interactive & -0.716 & $-0.736^{*}$ & 0.776 \\
& $(0.826)$ & $(0.387)$ & $(1.423)$ \\
$d_{0}:$ pure & $0.389^{* * *}$ & $0.255^{* * *}$ & $1.203^{* * *}$ \\
& $(0.070)$ & $(0.033)$ & $(0.121)$ \\
$d_{1}:$ pure & $0.493^{* * *}$ & $0.240^{* * *}$ & $1.129^{* * *}$ \\
& $(0.074)$ & $(0.035)$ & $(0.129)$ \\
$d_{2}:$ pure & $0.222^{* * *}$ & $0.181^{* * *}$ & $0.287^{* * *}$ \\
& $(0.062)$ & $(0.029)$ & $(0.108)$ \\
$d_{3}:$ pure & $0.272^{* * *}$ & $0.082^{* * *}$ & $0.279^{* * *}$ \\
& $(0.052)$ & $(0.025)$ & $(0.090)$ \\
\hline$\sum_{k} b_{k}:$ interactive & $5.483^{* *}$ & $-2.301^{* *}$ & $-24.312^{* * *}$ \\
& $(2.194)$ & $(1.033)$ & $(3.796)$ \\
$\sum_{k} d_{k}:$ pure & $1.376^{* * *}$ & $0.758^{* * *}$ & $2.899^{* * *}$ \\
& $(0.139)$ & $(0.065)$ & $(0.241)$ \\
\hline$\#$ of observations & 52486 & 55499 & 14950 \\
\hline Fixed effects & Yes & Yes & Yes \\
Firm-level controls & Yes & Yes & Yes \\
Aggregate controls & Yes & Yes & Yes \\
\hline \hline
\end{tabular}

Notes: This table reports the results of regressions in which the dependent variable is a firm-quarter observation of newly issued bank credit to a firm, scaled by the firm's total nominal assets. The right-hand variables include contemporaneous and lagged monetary policy shocks and their interactions with the respective growth rates of infrastructure investment. These variables are obtained from the first-stage estimation. We add region fixed effects to this regression. The firm-level control variables include the NPL ratio, the guarantee ratio, assets, and the leverage ratio, all lagged by one period. The aggregate control variables include lagged GDP growth net of infrastructure investment, lagged inflation, and contemporaneous and lagged growth rates of infrastructure investment, all of which are obtained from the first-stage estimation. The results are for all firms that include both SOEs and non-SOEs. The values in parentheses are standard errors. The superscript * represents the 0.1 significance level, ${ }^{* *} 0.05$, and ${ }^{* * *} 0.01$. 
TABLE S.11. Estimation results for dynamic panel regression (1): the remaining economy

\begin{tabular}{|c|c|c|c|}
\hline & $\begin{array}{l}\text { SOEs } \\
(1)\end{array}$ & $\begin{array}{c}\text { Non-SOEs } \\
(2)\end{array}$ & $\begin{array}{l}\text { All firms } \\
\text { (3) }\end{array}$ \\
\hline \multirow{2}{*}{$b_{0}:$ interactive } & 0.600 & $-3.530^{* * *}$ & $-1.583^{* *}$ \\
\hline & $(0.879)$ & $(1.126)$ & $(0.723)$ \\
\hline \multirow[t]{2}{*}{$b_{1}$ : interactive } & $2.645^{* *}$ & $-5.554^{* * *}$ & $-1.643^{*}$ \\
\hline & $(1.100)$ & $(1.415)$ & $(0.908)$ \\
\hline \multirow[t]{2}{*}{$b_{2}$ : interactive } & 0.411 & $-3.770^{* * *}$ & $-1.799^{* *}$ \\
\hline & $(1.108)$ & $(1.424)$ & $(0.914)$ \\
\hline \multirow[t]{2}{*}{$b_{3}:$ interactive } & 0.532 & 1.522 & 1.025 \\
\hline & $(0.961)$ & $(1.233)$ & $(0.792)$ \\
\hline \multirow[t]{2}{*}{$d_{0}:$ pure } & $0.440^{* * *}$ & $0.882^{* * *}$ & $0.670^{* * *}$ \\
\hline & $(0.082)$ & $(0.105)$ & $(0.067)$ \\
\hline \multirow[t]{2}{*}{$d_{1}:$ pure } & $0.496^{* * *}$ & $0.833^{* * *}$ & $0.670^{* * *}$ \\
\hline & $(0.087)$ & $(0.111)$ & $(0.071)$ \\
\hline \multirow[t]{2}{*}{$d_{2}:$ pure } & $0.176^{* *}$ & $0.187^{* *}$ & $0.180^{* * *}$ \\
\hline & $(0.073)$ & $(0.094)$ & $(0.060)$ \\
\hline \multirow[t]{2}{*}{$d_{3}:$ pure } & $0.131^{* *}$ & 0.123 & $0.126^{* *}$ \\
\hline & $(0.060)$ & $(0.078)$ & $(0.050)$ \\
\hline \multirow{2}{*}{$\sum_{k} b_{k}:$ interactive } & 4.187 & $-11.332^{* * *}$ & $-4.000^{*}$ \\
\hline & $(2.561)$ & $(3.283)$ & $(2.109)$ \\
\hline \multirow{2}{*}{$\sum_{k} d_{k}:$ pure } & $1.244^{* * *}$ & $2.024^{* * *}$ & $1.645^{* * *}$ \\
\hline & $(0.162)$ & $(0.208)$ & $(0.134)$ \\
\hline Fixed effects & Yes & Yes & Yes \\
\hline Firm-level controls & Yes & Yes & Yes \\
\hline Aggregate controls & Yes & Yes & Yes \\
\hline
\end{tabular}

Notes: This table reports the results of regressions in which the dependent variable is a firm-quarter observation of newly issued bank credit to a firm, scaled by the firm's total nominal assets. The right-hand variables include contemporaneous and lagged monetary policy shocks and their interactions with the respective growth rates of infrastructure investment. These variables are obtained from the first-stage estimation. The firm-level control variables include the NPL ratio, the guarantee ratio, assets, and the leverage ratio, all lagged by one period. The aggregate control variables include lagged GDP growth net of infrastructure investment, lagged inflation, and contemporaneous and lagged growth rates of infrastructure investment, all of which are obtained from the first-stage estimation. Column (1) reports the estimates using the sample of all firms in the remaining economy; column (2) and (3) report the estimates based on the subsamples of SOEs and non-SOEs in the rest of the economy. The values in parentheses are standard errors. The superscript * represents the 0.1 significance level, ** 0.05 , and *** 0.01 .

TABLE S.12. Loan shares (\%) in subsectors within the remaining economy

\begin{tabular}{l|cc|cc}
\hline \hline Subsectors & \multicolumn{3}{c}{ The sample period } & \multicolumn{2}{c}{ Year 2009 } \\
\cline { 2 - 5 } & SOE & Non-SOE & SOE & Non-SOE \\
\hline Agriculture, forestry, animal husbandry, and fishery & 1.393 & 2.155 & 1.085 & 2.101 \\
Mining & 17.06 & 9.753 & 13.25 & 9.931 \\
Construction & 15.13 & 12.15 & 15.24 & 12.42 \\
Wholesale and retail trades & 23.99 & 60.90 & 16.87 & 58.08 \\
Hotels and catering services & 0.807 & 2.728 & 0.575 & 3.385 \\
Leasing and business services & 20.09 & 9.599 & 26.65 & 10.61 \\
Other services & 21.53 & 2.725 & 26.33 & 3.473 \\
\hline \hline
\end{tabular}

Notes: Other services include scientific research, technical service, geologic prospecting, education, health, social security, social welfare, culture, sports, entertainment, public management, and social organization. All these services are labor-intensive. 
TABLE S.13. Relative impacts of monetary stimulus on loans to non-SOEs: the remaining economy

\begin{tabular}{l|c|c|c}
\hline \hline & Interactive & Pure & Overall \\
\hline 2009Q1 & $-1.09^{* * *}$ & $1.27^{* * *}$ & 0.18 \\
& $(0.36)$ & $(0.37)$ & $(0.30)$ \\
2009Q2 & $-2.52^{* * *}$ & $2.29^{* * *}$ & -0.24 \\
& $(0.53)$ & $(0.68)$ & $(0.38)$ \\
2009Q3 & $-1.76^{* * *}$ & $1.78^{* *}$ & 0.02 \\
& $(0.55)$ & $(0.70)$ & $(0.43)$ \\
2009Q4 & -0.01 & 0.60 & 0.59 \\
& $(0.50)$ & $(0.47)$ & $(0.47)$ \\
2010Q1 & 0.14 & 0.02 & 0.16 \\
& $(0.13)$ & $(0.31)$ & $(0.26)$ \\
& -0.01 & -0.00 & -0.01 \\
& $(0.02)$ & $(0.15)$ & $(0.16)$ \\
\hline \hline
\end{tabular}

Notes: Impacts relative to those on SOE loans (we take monetary impacts on loans to SOEs as a benchmark for comparison). Each panel regression has both firm-level controls and aggregate controls. The values in parentheses are standard errors. The superscript * represents the 0.1 significance level, $* * 0.05$, and $* * * 0.01$. 
TABLE S.14. Regressions of the capital-to-labor ratio on market shares and equity concentrations

\begin{tabular}{|c|c|c|c|c|c|c|c|c|c|c|c|c|}
\hline \multirow[b]{2}{*}{ Variables } & \multicolumn{12}{|c|}{ Regressions } \\
\hline & $(1)$ & $(2)$ & $(3)$ & $(4)$ & $(5)$ & $(6)$ & $(7)$ & $(8)$ & $(9)$ & $(10)$ & $(11)$ & $(12)$ \\
\hline market_share_reven & $\begin{array}{l}5.776 \\
(1.22)\end{array}$ & & & & & & & & & & & $\begin{array}{l}-3.551 \\
(-0.22)\end{array}$ \\
\hline market_share_liqcap & & $\begin{array}{l}4.204 \\
(1.11)\end{array}$ & & & & & & & & & & $\begin{array}{l}-7.902 \\
(-1.03)\end{array}$ \\
\hline market_share_totalcap & & & $\begin{array}{l}6.536 \\
(1.11)\end{array}$ & & & & & & & & & $\begin{array}{l}5.379 \\
(1.07)\end{array}$ \\
\hline asset_share & & & & $\begin{array}{l}7.181 \\
(0.95)\end{array}$ & & & & & & & & $\begin{array}{l}12.079 \\
(0.45)\end{array}$ \\
\hline shrhfd & & & & & $\begin{array}{l}5.941 \\
(0.74)\end{array}$ & & & & & & & $\begin{array}{c}29.224 \\
(0.50)\end{array}$ \\
\hline shrhfd3 & & & & & & $\begin{array}{l}5.704 \\
(0.69)\end{array}$ & & & & & & $\begin{array}{c}30.990 \\
(0.15)\end{array}$ \\
\hline shrhfd5 & & & & & & & $\begin{array}{l}5.791 \\
(0.69)\end{array}$ & & & & & $\begin{array}{r}-97.867 \\
(-0.48)\end{array}$ \\
\hline top1 & & & & & & & & $\begin{array}{l}0.073 \\
(1.07)\end{array}$ & & & & $\begin{array}{l}0.259 \\
(0.85)\end{array}$ \\
\hline top3 & & & & & & & & & $\begin{array}{l}0.061 \\
(1.00)\end{array}$ & & & $\begin{array}{l}0.000 \\
(0.00)\end{array}$ \\
\hline top5 & & & & & & & & & & $\begin{array}{l}0.061 \\
(1.07)\end{array}$ & & $\begin{array}{l}0.117 \\
(0.46)\end{array}$ \\
\hline top10 & & & & & & & & & & & $\begin{array}{l}0.057 \\
(1.18)\end{array}$ & $\begin{array}{l}0.014 \\
(0.30)\end{array}$ \\
\hline Constant & $\begin{array}{c}3.696^{* * *} \\
(6.19)\end{array}$ & $\begin{array}{c}3.854^{* * *} \\
(6.84)\end{array}$ & $\begin{array}{c}3.721^{* * *} \\
(5.87)\end{array}$ & $\begin{array}{c}3.628^{* * *} \\
(5.27)\end{array}$ & $\begin{array}{l}3.017^{*} \\
(1.84)\end{array}$ & $\begin{array}{l}2.939 \\
(1.58)\end{array}$ & $\begin{array}{l}2.913 \\
(1.55)\end{array}$ & $\begin{array}{l}1.253 \\
(0.44)\end{array}$ & $\begin{array}{l}0.800 \\
(0.23)\end{array}$ & $\begin{array}{l}0.527 \\
(0.15)\end{array}$ & $\begin{array}{l}0.512 \\
(0.16)\end{array}$ & $\begin{array}{l}-5.719 \\
(-0.97)\end{array}$ \\
\hline Year-fixed effect & Yes & Yes & Yes & Yes & Yes & Yes & Yes & Yes & Yes & Yes & Yes & Yes \\
\hline \# of observations & 13579 & 13266 & 13266 & 13579 & 13581 & 13581 & 13581 & 13581 & 13581 & 13581 & 13581 & 13266 \\
\hline \# of firm dummies & 2413 & 2368 & 2368 & 2413 & 2412 & 2412 & 2412 & 2412 & 2412 & 2412 & 2412 & 2368 \\
\hline
\end{tabular}

Notes: All the regressions are based on the available data from CSMAR for all the listed firms in the Chinese economy. All market share variables are an industry-year observation. The symbol "market_share_reven" represents the revenue share, "market_share_liqcap" the liquidating capitalization share, "market_share_totalcap" the total capitalization share, "asset_share" the total asset share, "shrhfd" the Herfindahl index (the square of the equity share held by the largest shareholder), "shrhfd3" the Herfindahl 3 index (the square of the equity share held by the top three largest shareholders), "shrhfd5" the Herfindahl 5 index (the square of the equity share held by the top five largest shareholders), "top1" the number of shares of equity held by the largest shareholder, "top3" the number of shares of equity held by the top three largest shareholders, "top5" the number of shares of equity held by the top five largest shareholders, and "top10" the number of shares of equity held by the top ten largest shareholders. The values in parentheses are standard errors. The superscript * represents the 0.1 significance level, ** 0.05 , and *** 0.01 . 
TABLE S.15. Estimation results of credit allocation between SOEs and nonSOEs with $\tilde{\ell}_{i, t}^{m}$ as a credit supply shock

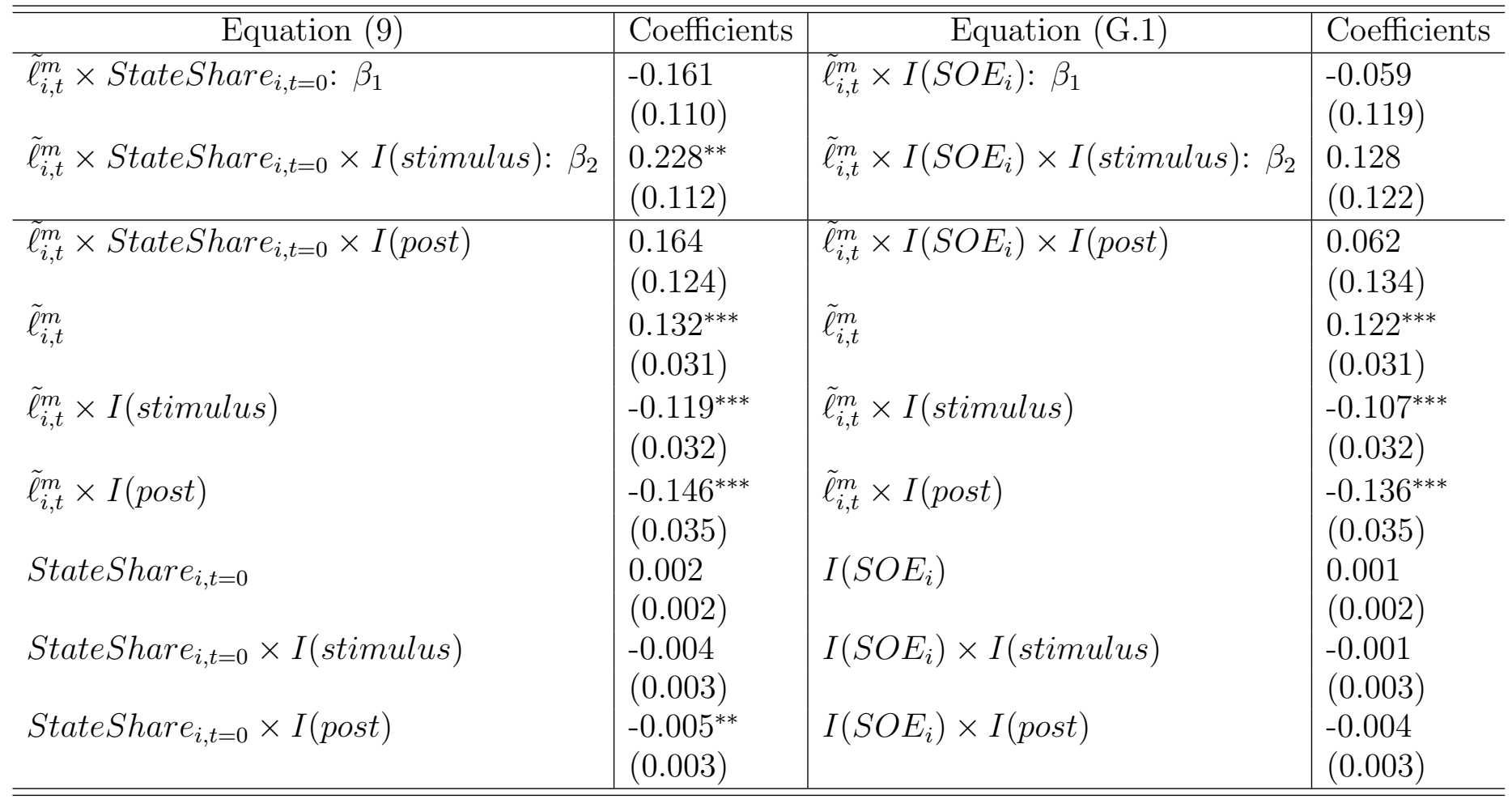

Notes: The regressions include time, industry, and city fixed effects. Firm-level control variables include the NPL ratio, the guarantee ratio, assets, and the leverage ratio, all lagged by one period. The values in parentheses are standard errors. The superscript ${ }^{*}$ represents the 0.1 significance level, $* * 0.05$, and $* * * 0.01$. 
TABLE S.16. Estimation results of credit allocation between SOEs and nonSOEs with equation (G.1) excluding $\tilde{\ell}_{i, t}^{m} \times I$ (stimulus) or $\Delta \log \widetilde{\mathcal{L}}_{i, c, j, t} \times$ I(stimulus)

\begin{tabular}{c|l|l|l}
\hline \hline \multicolumn{1}{c|}{$\tilde{\ell}_{i, t}^{m}$ as credit supply shocks } & Coefficients & $\Delta \log \widetilde{\mathcal{L}}_{i, c, j, t}$ as credit supply shocks & Coefficients \\
\hline$\tilde{\ell}_{i, t}^{m} \times I\left(S O E_{i}\right) \times I($ stimulus $): \beta_{2}$ & $0.069^{* * *}$ & $\Delta \log \widetilde{\mathcal{L}}_{i, c, j, t} \times I\left(S O E_{i}\right) \times I($ stimulus $): \beta_{2}$ & $0.069^{* * *}$ \\
& $(0.026)$ & & $(0.025)$ \\
\hline$\tilde{\ell}_{i, t}^{m} \times I\left(S O E_{i}\right) \times I($ post $)$ & 0.003 & $\Delta \log \widetilde{\mathcal{L}}_{i, c, j, t} \times I\left(S O E_{i}\right) \times I($ post $)$ & 0.002 \\
$\tilde{\ell}_{i, t}^{m}$ & $(0.061)$ & & $(0.061)$ \\
$\tilde{\ell}_{i, t}^{m} \times I($ stimulus $)$ & $0.118^{* * *}$ & $\Delta \log \widetilde{\mathcal{L}}_{i, c, j, t}$ & $0.114^{* * *}$ \\
$\tilde{\ell}_{i, t}^{m} \times I($ post $)$ & $(0.030)$ & & $(0.030)$ \\
$I\left(S O E_{i}\right)$ & $-0.103^{* * *}$ & $\Delta \log \widetilde{\mathcal{L}}_{i, c, j, t} \times I($ stimulus $)$ & $-0.103^{* * *}$ \\
$I\left(S O E_{i}\right) \times I($ stimulus $)$ & $(0.031)$ & & $(0.031)$ \\
$I\left(S O E_{i}\right) \times I($ post $)$ & $-0.133^{* * *}$ & $\Delta \log \widetilde{\mathcal{L}}_{i, c, j, t} \times I($ post $)$ & $-0.129^{* * *}$ \\
& $(0.034)$ & & $(0.034)$ \\
& 0.000 & $I\left(S O E_{i}\right)$ & 0.000 \\
& $(0.002)$ & & $(0.002)$ \\
\hline \hline
\end{tabular}

Notes: The regressions include time, industry, and city fixed effects. Firm-level control variables include the NPL ratio, the guarantee ratio, assets, and the leverage ratio, all lagged by one period. The values in parentheses are standard errors. The superscript ${ }^{*}$ represents the 0.1 significance level, $* * 0.05$, and $* * * 0.01$. 
TABLE S.17. Estimation results of credit allocation between SOEs and nonSOEs with $\Delta \log \widetilde{\mathcal{L}}_{i, c, j, t}$ as a credit supply shock

\begin{tabular}{|c|c|c|c|}
\hline Equation (9) & Coefficients & Equation (G.1) & Coefficients \\
\hline$\Delta \log \widetilde{\mathcal{L}}_{i, c, j, t} \times$ StateShare $_{i, t=0}: \beta_{1}$ & $\begin{array}{l}-0.146 \\
(0.109)\end{array}$ & $\Delta \log \widetilde{\mathcal{L}}_{i, c, j, t} \times I\left(S O E_{i}\right): \beta_{1}$ & $\begin{array}{l}-0.054 \\
(0.117)\end{array}$ \\
\hline$\Delta \log \widetilde{\mathcal{L}}_{i, c, j, t} \times$ StateShare $_{i, t=0} \times I($ stimulus $): \beta_{2}$ & $\begin{array}{l}0.217^{*} \\
(0.111) \\
\end{array}$ & $\Delta \log \widetilde{\mathcal{L}}_{i, c, j, t} \times I\left(S O E_{i}\right) \times I($ stimulus $): \beta_{2}$ & $\begin{array}{l}0.124 \\
(0.120)\end{array}$ \\
\hline$\Delta \log \widetilde{\mathcal{L}}_{i, c, j, t} \times$ StateShare $_{i, t=0} \times I($ post $)$ & $\begin{array}{l}0.147 \\
(0.123)\end{array}$ & $\Delta \log \widetilde{\mathcal{L}}_{i, c, j, t} \times I\left(S O E_{i}\right) \times I($ post $)$ & $\begin{array}{l}0.057 \\
(0.132)\end{array}$ \\
\hline$\Delta \log \widetilde{\mathcal{L}}_{i, c, j, t}$ & $\begin{array}{l}0.127^{* * *} \\
(0.031)\end{array}$ & $\Delta \log \widetilde{\mathcal{L}}_{i, c, j, t}$ & $\begin{array}{l}0.118^{* * *} \\
(0.031)\end{array}$ \\
\hline$\Delta \log \widetilde{\mathcal{L}}_{i, c, j, t} \times I($ stimulus $)$ & $\begin{array}{l}-0.117^{* * *} \\
(0.032)\end{array}$ & $\Delta \log \widetilde{\mathcal{L}}_{i, c, j, t} \times I($ stimulus $)$ & $\begin{array}{l}-0.106^{* * *} \\
(0.032)\end{array}$ \\
\hline$\Delta \log \widetilde{\mathcal{L}}_{i, c, j, t} \times I($ post $)$ & $\begin{array}{l}-0.142^{* * *} \\
(0.035)\end{array}$ & $\Delta \log \widetilde{\mathcal{L}}_{i, c, j, t} \times I($ post $)$ & $\begin{array}{l}-0.133^{\text {*** }} \\
(0.035)\end{array}$ \\
\hline StateShare $_{i, t=0}$ & $\begin{array}{l}0.002 \\
(0.002)\end{array}$ & $I\left(S O E_{i}\right)$ & $\begin{array}{l}0.001 \\
(0.002)\end{array}$ \\
\hline StateShare $_{i, t=0} \times I($ stimulus $)$ & $\begin{array}{l}-0.004 \\
(0.003)\end{array}$ & $I\left(S O E_{i}\right) \times I($ stimulus $)$ & $\begin{array}{l}-0.001 \\
(0.003)\end{array}$ \\
\hline StateShare $_{i, t=0} \times I$ (post $)$ & $\begin{array}{l}-0.005^{* *} \\
(0.003)\end{array}$ & $I\left(S O E_{i}\right) \times I($ post $)$ & $\begin{array}{l}-0.004 \\
(0.003)\end{array}$ \\
\hline
\end{tabular}

Notes: The regressions include time, industry, and city fixed effects. Firm-level control variables include the NPL ratio, the guarantee ratio, assets, and the leverage ratio, all lagged by one period. The values in parentheses are standard errors. The superscript ${ }^{*}$ represents the 0.1 significance level, ${ }^{* *} 0.05$, and $* * * 0.01$. 
TABLE S.18. Historical shareholder structure of Guangzhou Evergrande Real Estate Group Ltd

\begin{tabular}{|c|c|c|c|c|c|c|c|c|c|}
\hline Shareholders/Time & June-96 & Jun-00 & Aug-02 & Aug-03 & Aug-03 & $\overline{\text { Dec-04 }}$ & Jun-06 & Jun-08 & Dec-14 \\
\hline \multirow[t]{2}{*}{ Evergrande Industrial Co. Ltd } & 900 & 1800 & 200 & 1800 & 54000 & 54000 & & & \\
\hline & $90 \%$ & $90 \%$ & $10 \%$ & $90 \%$ & $90 \%$ & $90 \%$ & & & \\
\hline \multirow[t]{2}{*}{ Cairon Co. (Real Estate) } & 100 & 200 & & & & 6000 & 6000 & 250000 & 250000 \\
\hline & $10 \%$ & $10 \%$ & & & & $10 \%$ & $100 \%$ & $100 \%$ & $100 \%$ \\
\hline \multirow[t]{2}{*}{ Hui Ka Yan } & & & 1800 & & & & & & $(160575)$ \\
\hline & & & $90 \%$ & & & & & & $(64.23 \%)$ \\
\hline \multirow[t]{2}{*}{ Chaofeng Real Estate } & & & & 200 & 6000 & & & & \\
\hline & & & & $10 \%$ & $10 \%$ & & & & \\
\hline
\end{tabular}

Notes: We assemble this table from the (raw) historical information reported by China Chengxin Securities Rating Co. Ltd (CCXR). We are grateful to CCXR for providing us with this information (Figure S.15). Values without the percent symbol indicate the paid-in capital (10 thousand RMB); numbers with the percent symbol indicate an equity share. Although Cairon Co. held $100 \%$ of Evergrande shares in December of 2014, Hui Kai Yan was the controller of this firm at that time and held $64.23 \%$ of Evergrande shares. We indicate this situation with parentheses. 


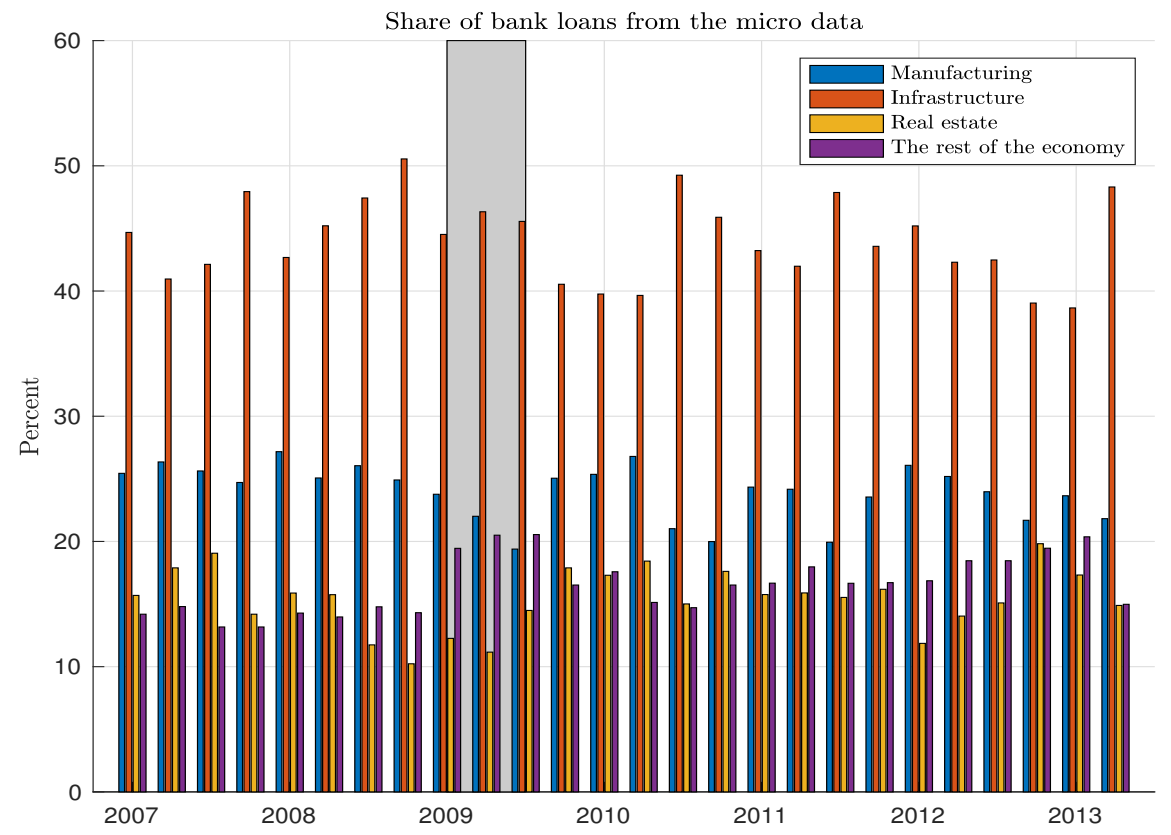

FIGURE S.1. Share of bank loans allocated to the four key sectors in 2007-2013 from our loan data. Notes: The wide shaded bar marks the period of 2009Q1-2009Q3 during which the monetary policy rule was changed to be more stimulative. 


\section{Manufacturing}
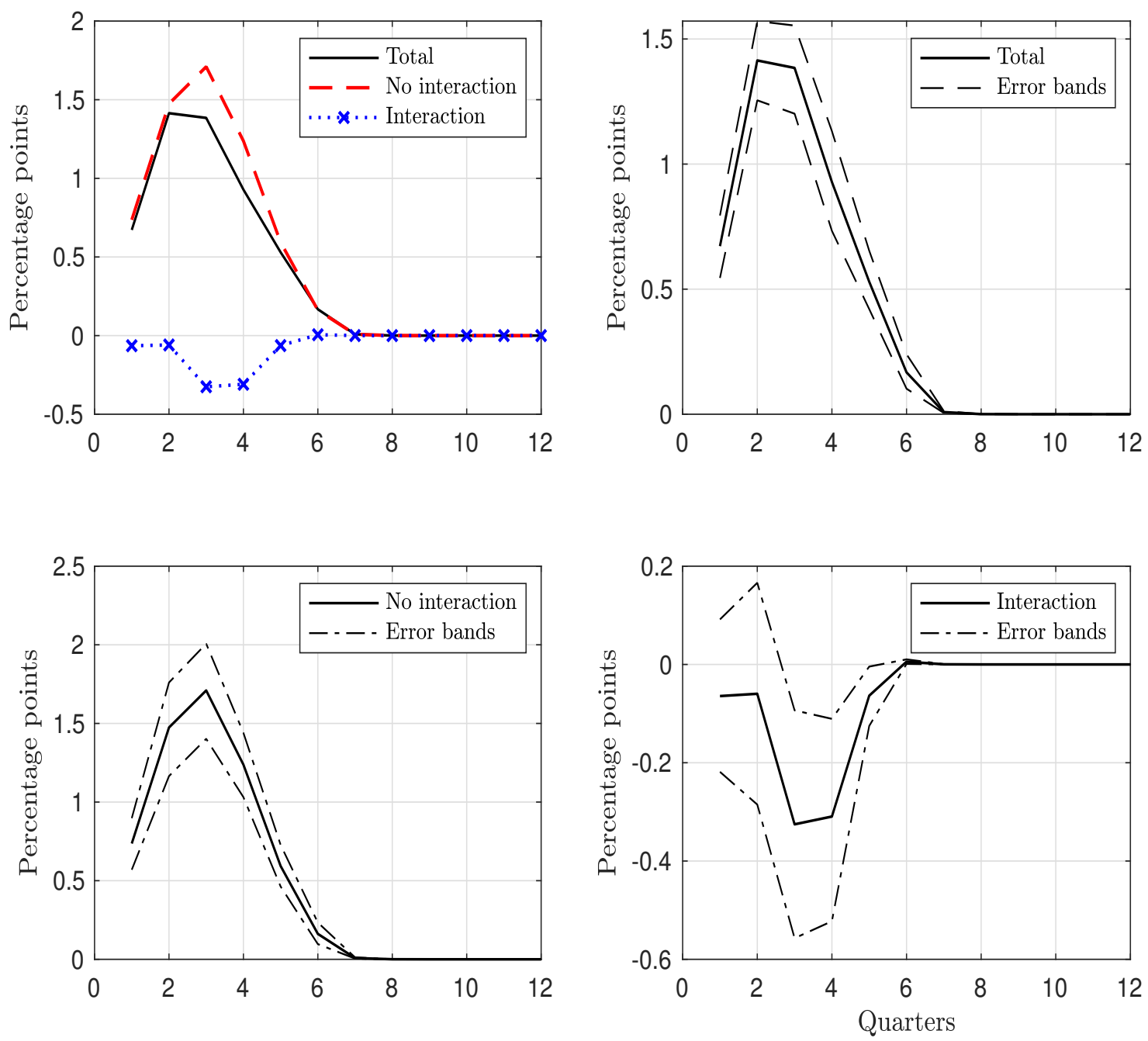

FiguRE S.2. Dynamic impacts of main monetary stimulus (no interaction) and its interaction with infrastructure investment on bank loans to an average firm. Notes: The dynamic responses are expressed as percentage changes from the initial quarter 0 (i.e., changes from the pre-stimulus period). Dash-dotted lines represent the corresponding .90 probability bands. Quarter 1 corresponds to 2009Q1 and quarter 12 corresponds to 2011Q4. 


\section{Infrastructure}
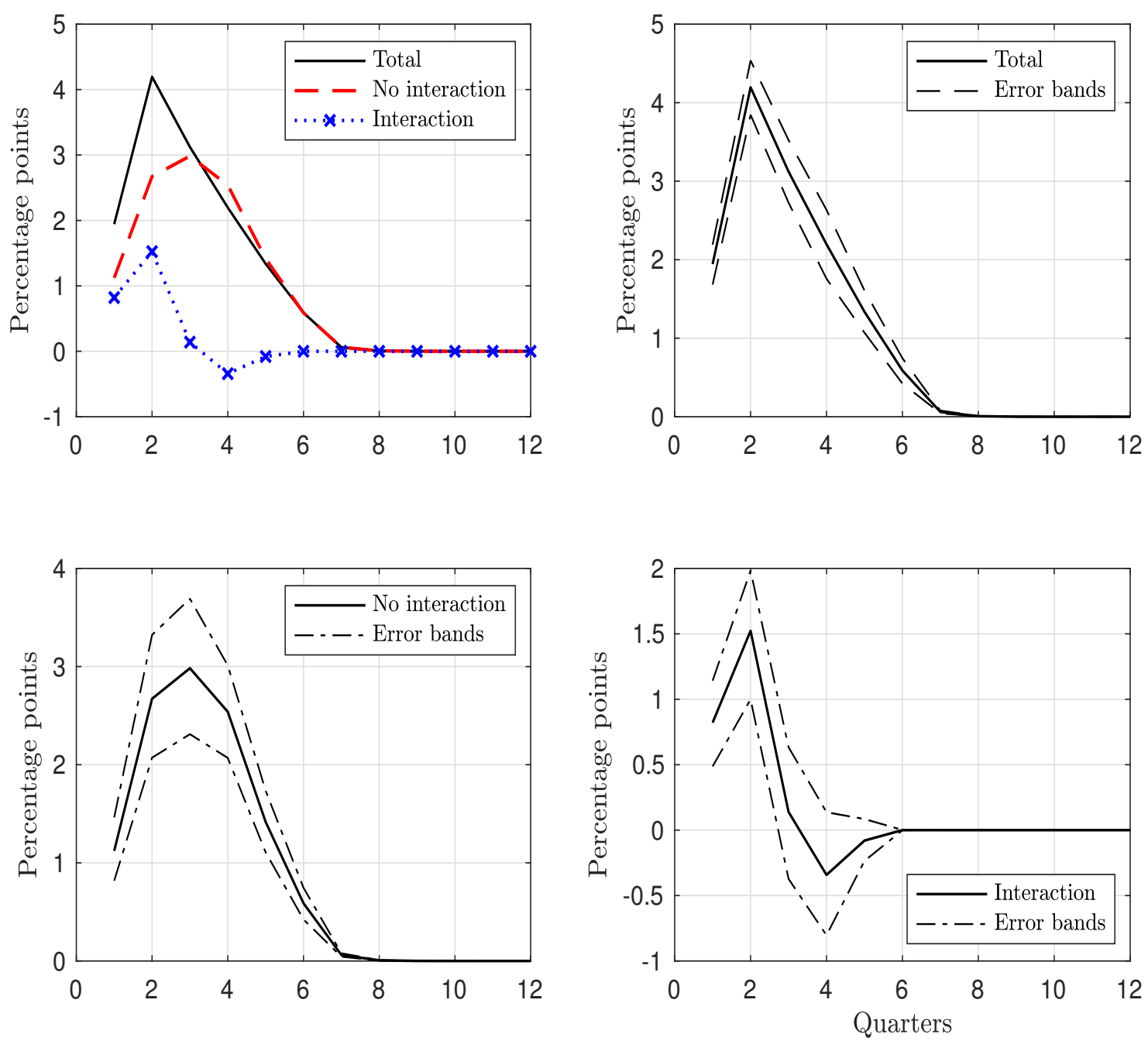

FiguRE S.3. Dynamic impacts of main monetary stimulus (no interaction) and its interaction with infrastructure investment on bank loans to an average firm. Notes: The dynamic responses are expressed as percentage changes from the initial quarter 0 (i.e., changes from the pre-stimulus period). Dash-dotted lines represent the corresponding .90 probability bands. Quarter 1 corresponds to 2009Q1 and quarter 12 corresponds to 2011Q4. 
Real estate
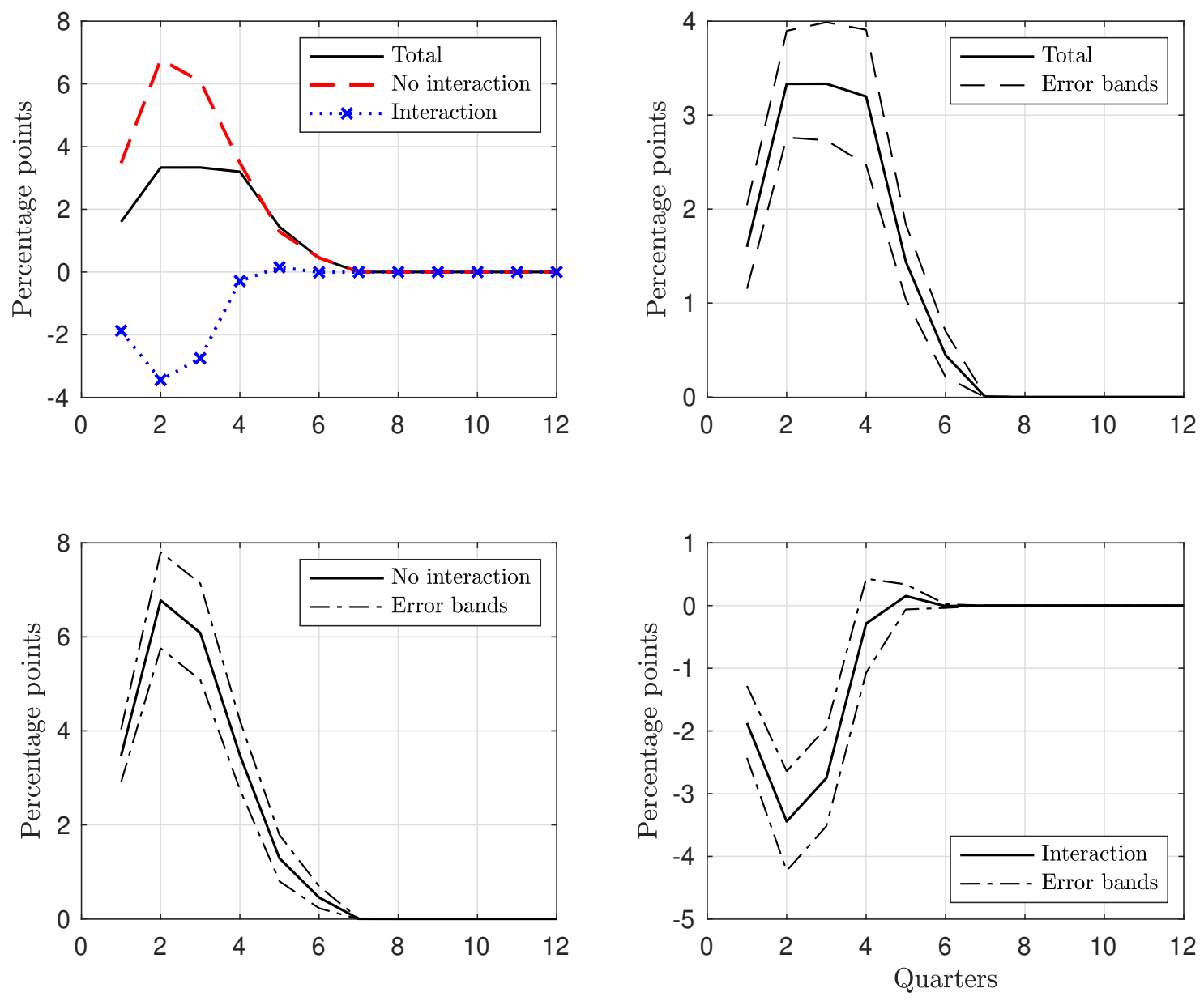

Figure S.4. Dynamic impacts of main monetary stimulus (no interaction) and its interaction with infrastructure investment on bank loans to an average firm. Notes: The dynamic responses are expressed as percentage changes from the initial quarter 0 (i.e., changes from the pre-stimulus period). Dash-dotted lines represent the corresponding .90 probability bands. Quarter 1 corresponds to 2009Q1 and quarter 12 corresponds to 2011Q4. 
The entire economy
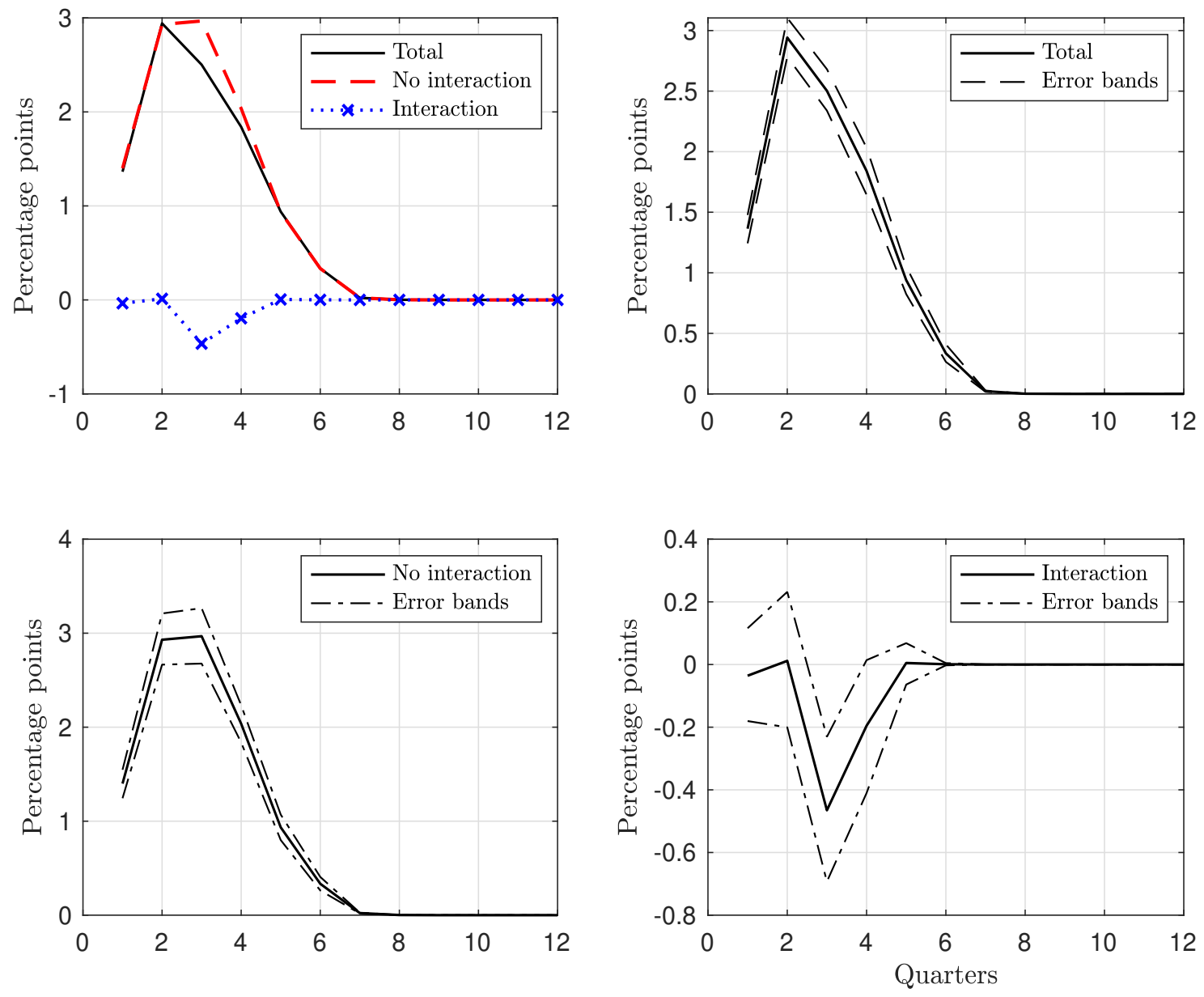

FiguRE S.5. Dynamic impacts of main monetary stimulus (no interaction) and its interaction with infrastructure investment on bank loans to an average firm. Notes: The dynamic responses are expressed as percentage changes from the initial quarter 0 (i.e., changes from the pre-stimulus period). Dash-dotted lines represent the corresponding .90 probability bands. Quarter 1 corresponds to 2009Q1 and quarter 12 corresponds to 2011Q4. 
The rest of the economy
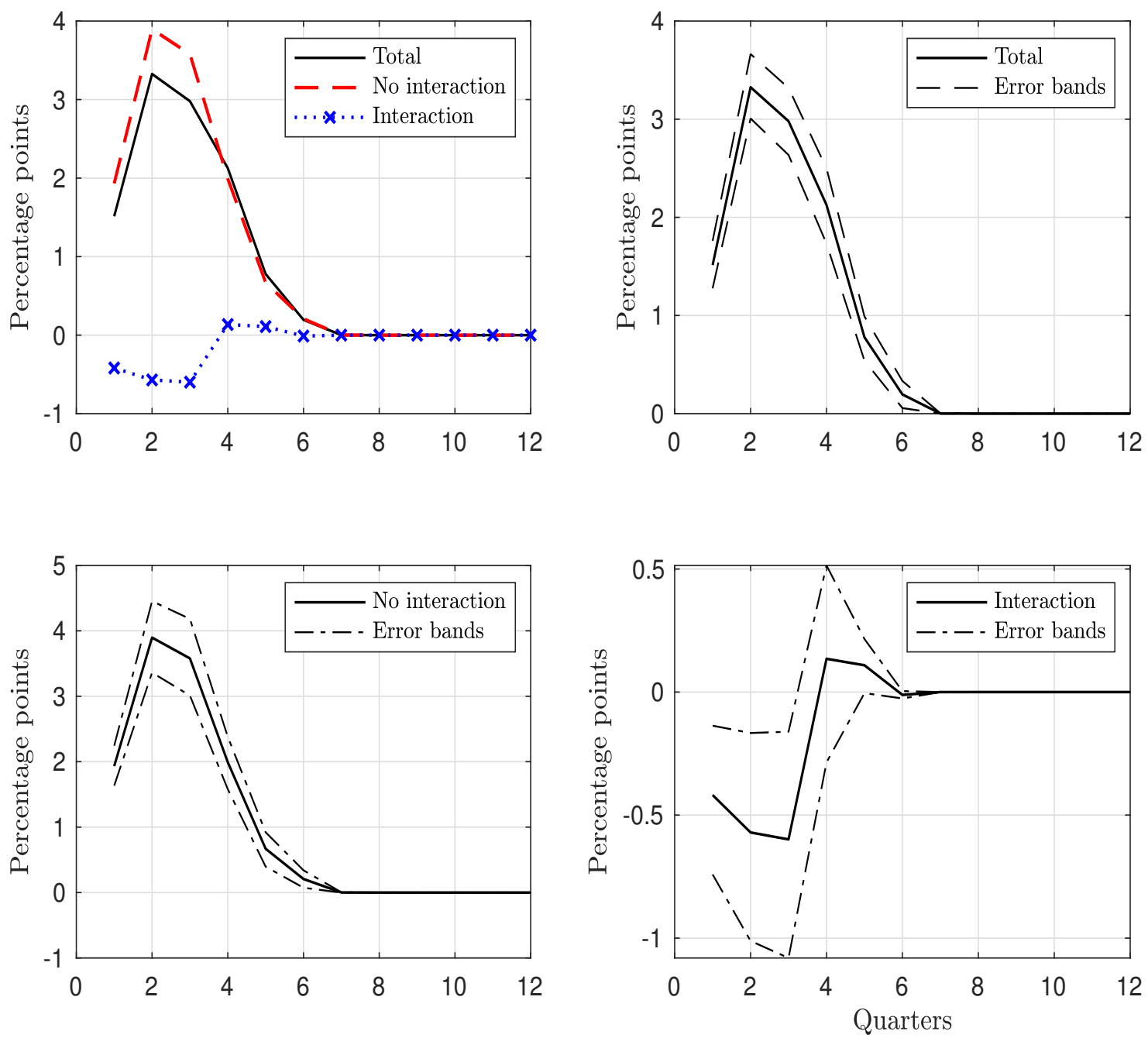

FiguRE S.6. Dynamic impacts of main monetary stimulus (no interaction) and its interaction with infrastructure investment on bank loans to an average firm. Notes: The dynamic responses are expressed as percentage changes from the initial quarter 0 (i.e., changes from the pre-stimulus period). Dash-dotted lines represent the corresponding .90 probability bands. Quarter 1 corresponds to 2009Q1 and quarter 12 corresponds to 2011Q4. 
The remaining economy
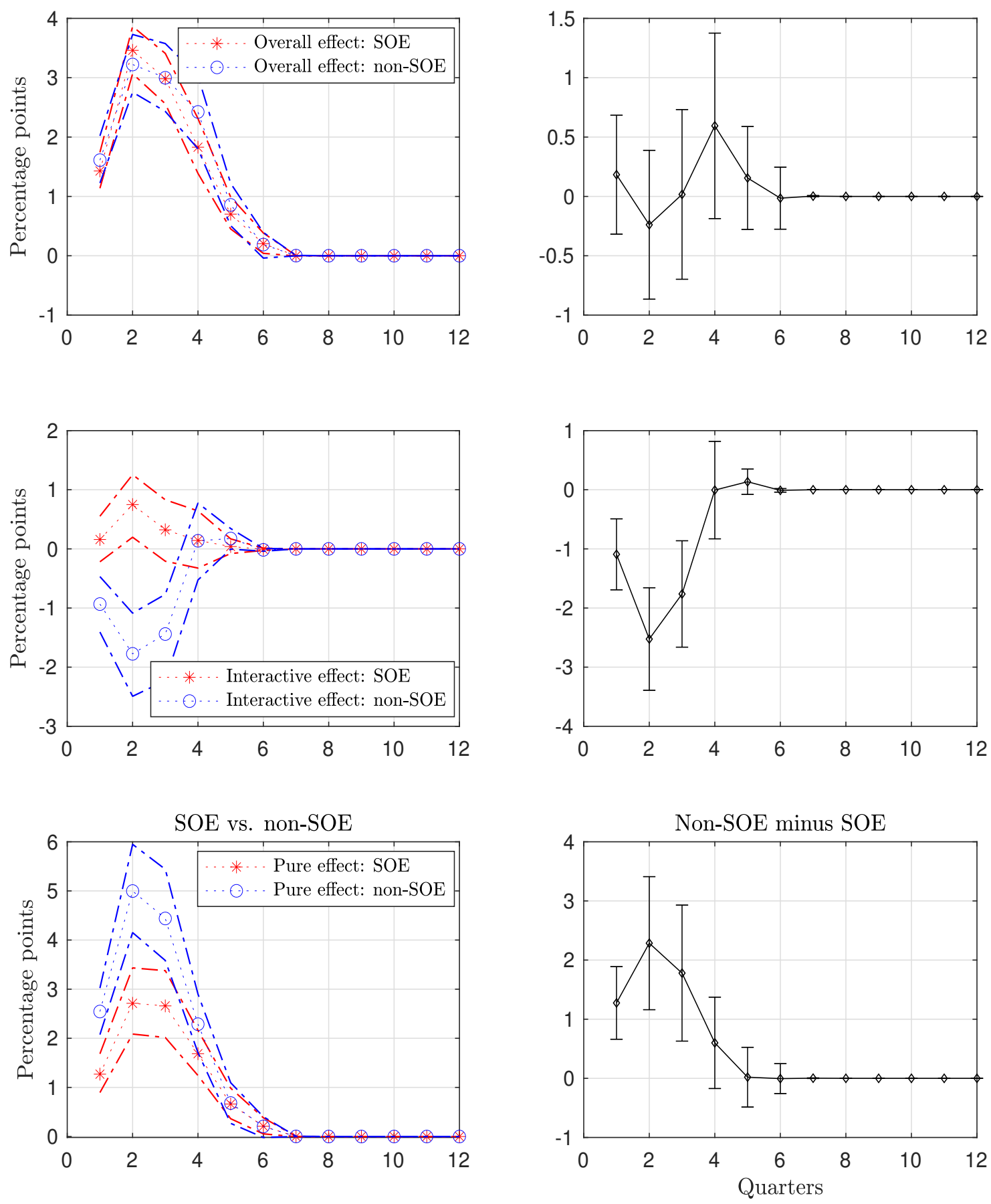

FIGURE S.7. The left column displays dynamic impacts of overall monetary stimulus, along with two channels: (1) monetary interaction with infrastructure investment on bank loans to an average SOE firm and an average non-SOE firm and (2) pure monetary effect (no interaction). The right column displays the non-SOE loan response relative to the SOE loan response. Notes: The dynamic responses are expressed as percentage changes from the initial quarter 0 (i.e., changes from the non-stimulus period). Dash-dotted lines and error bars represent the corresponding .90 probability bands. Quarter 1 corresponds to 2009Q1 and quarter 12 corresponds to 2011Q4. 


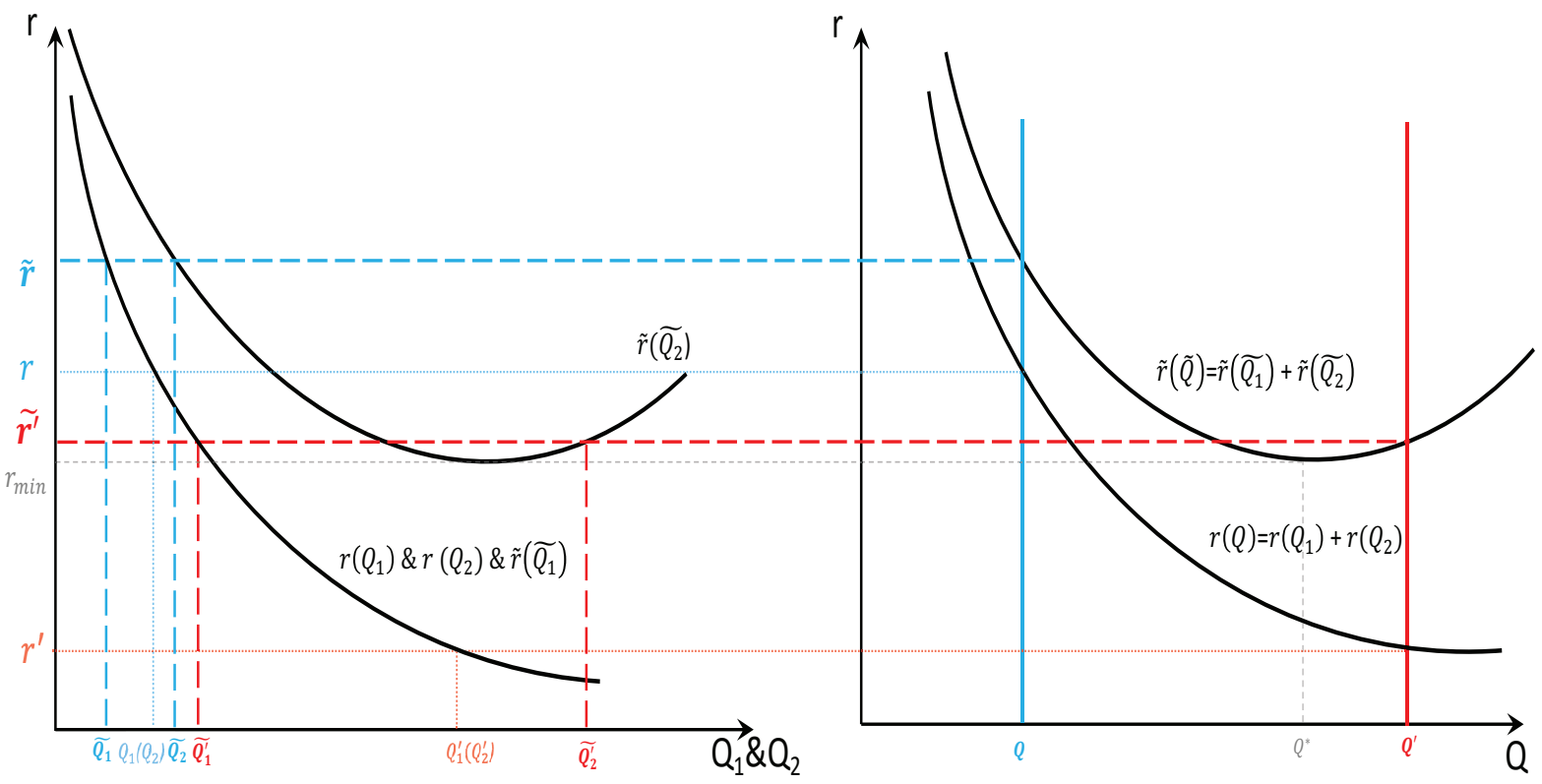

FIGURE S.8. Effects of a fiscal expansion on the monetary transmission to bank credit when $0<Q<Q^{*} \leq Q^{\prime}$.

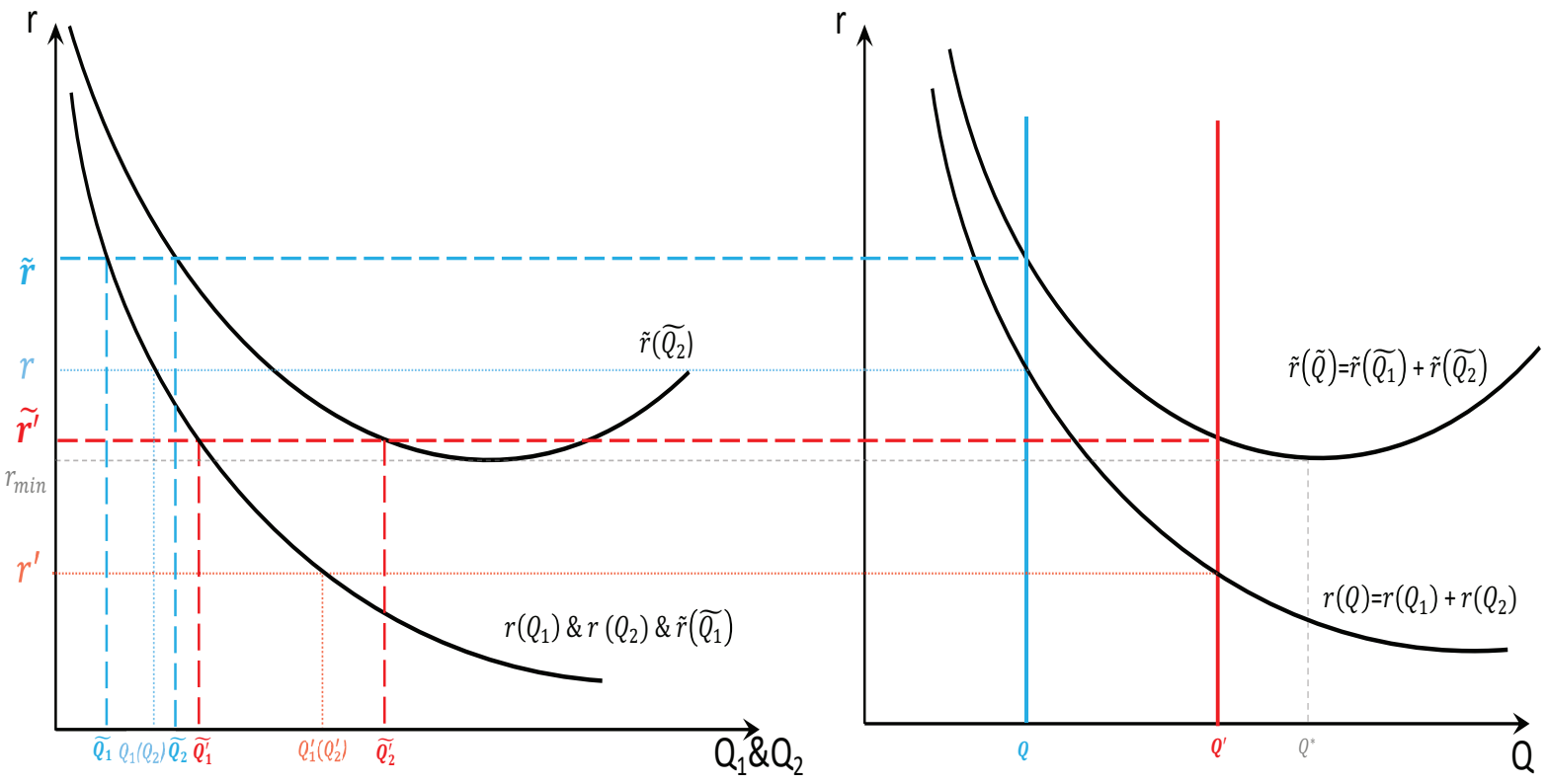

FiguRE S.9. Effects of a fiscal expansion on the monetary transmission to bank credit when $0<Q<Q^{\prime} \leq Q^{*}$. 


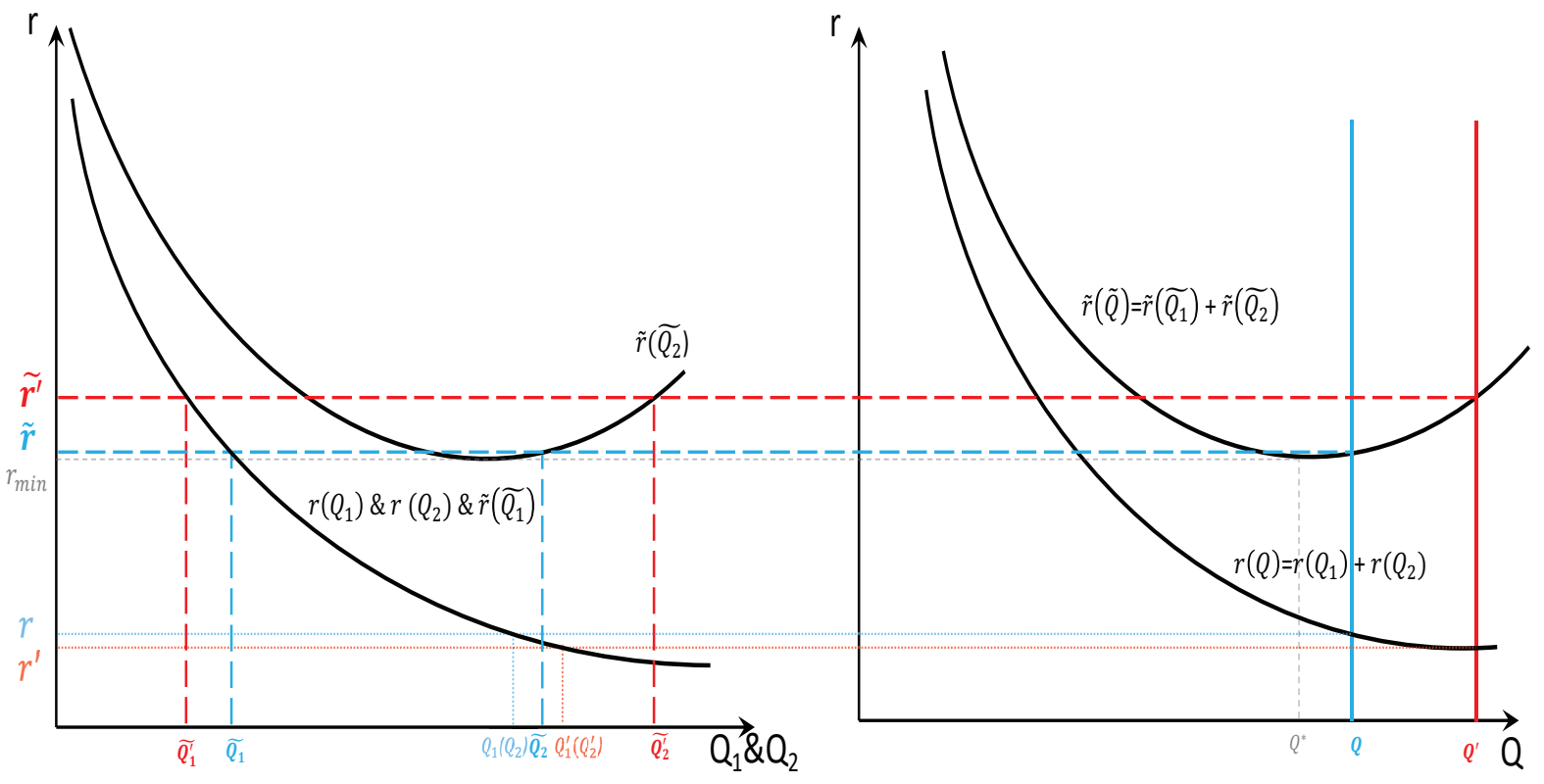

FiguRE S.10. Effects of a fiscal expansion on the monetary transmission to bank credit when $Q^{*} \leq Q<Q^{\prime}$. 


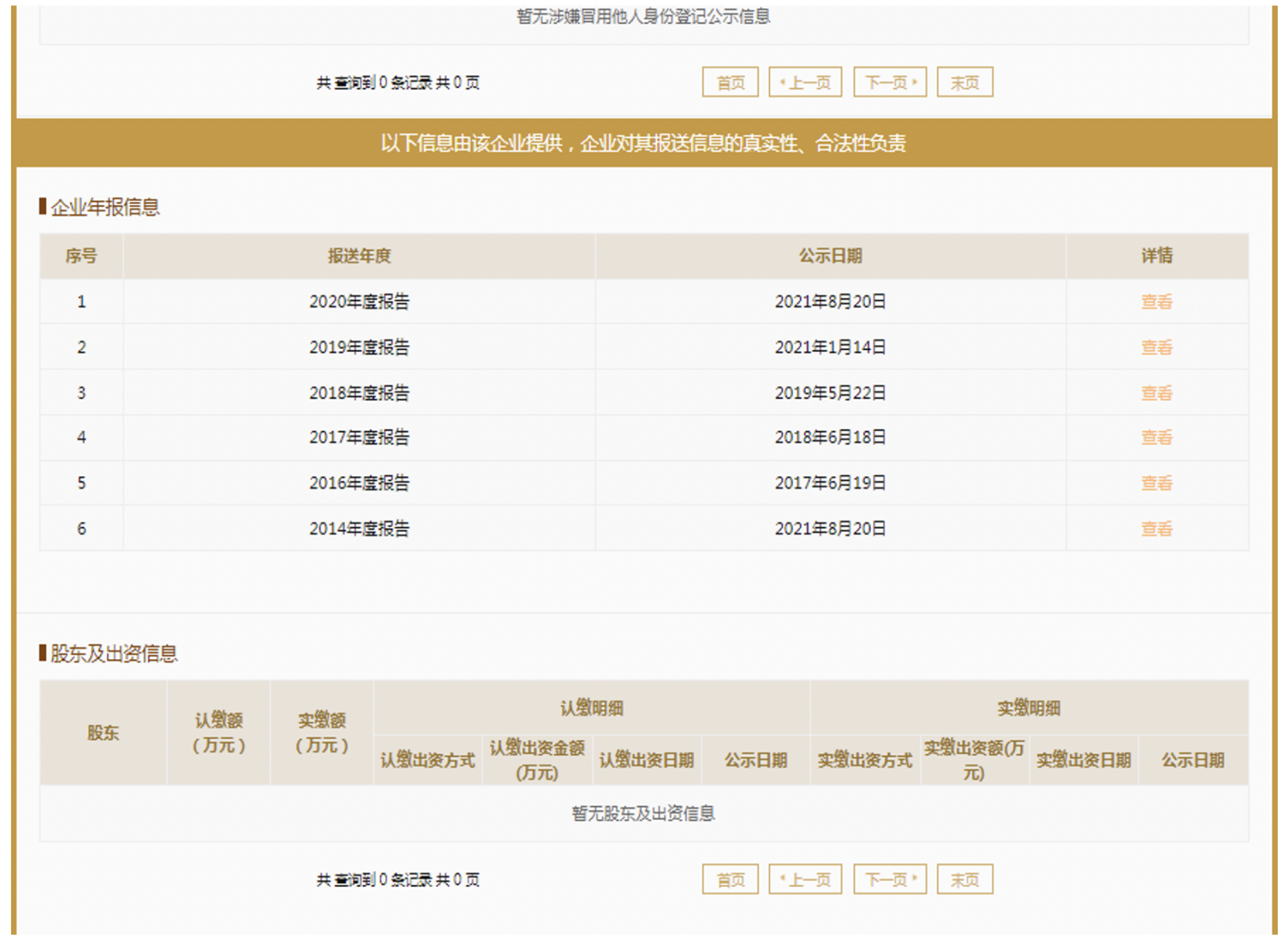

Figure S.11. Historical annual reports (in Chinese) by Evergrande. Source: NECIPS. 


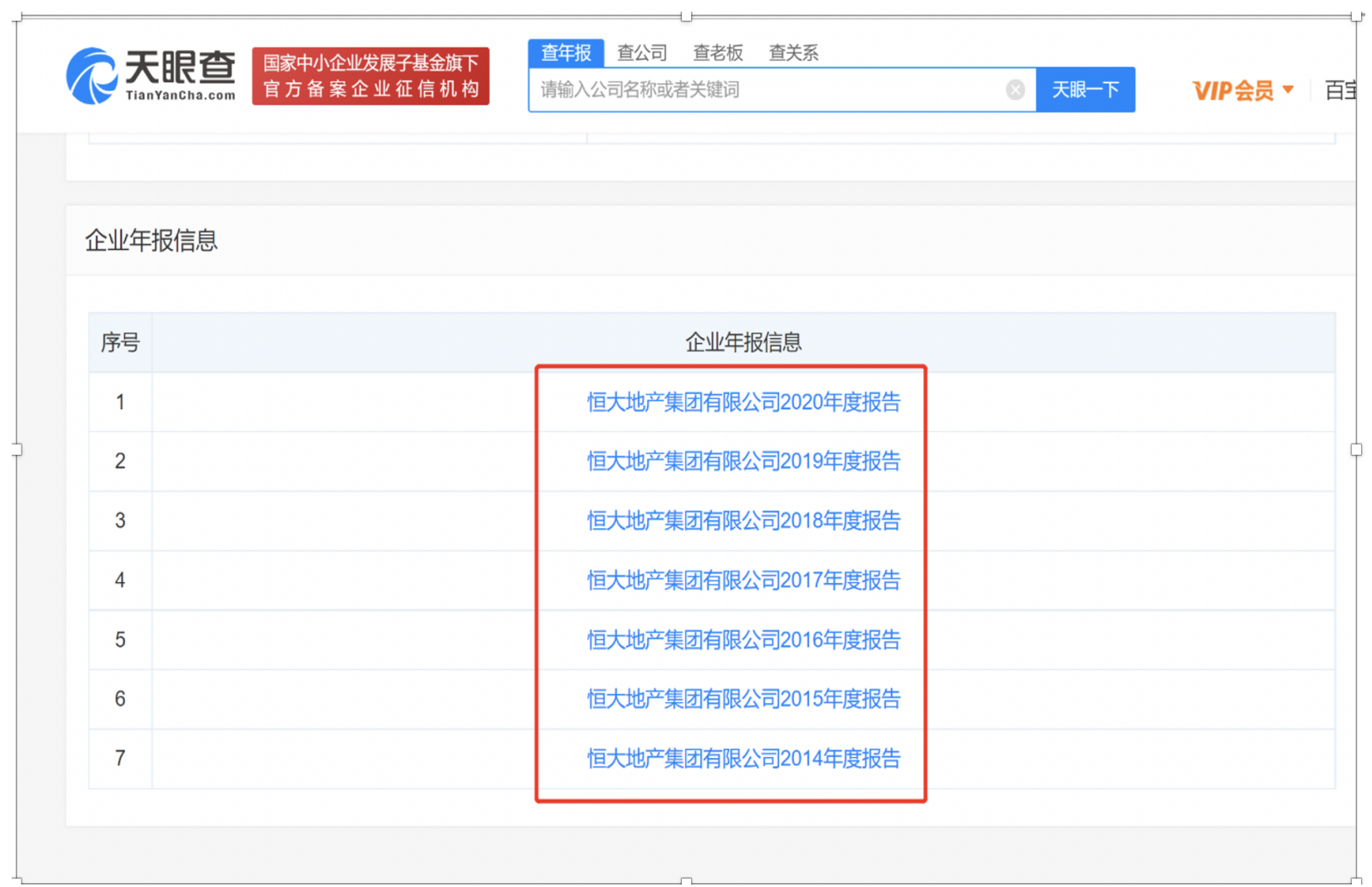

Figure S.12. Historical annual reports (in Chinese) by Evergrande. Source: Tianyancha.

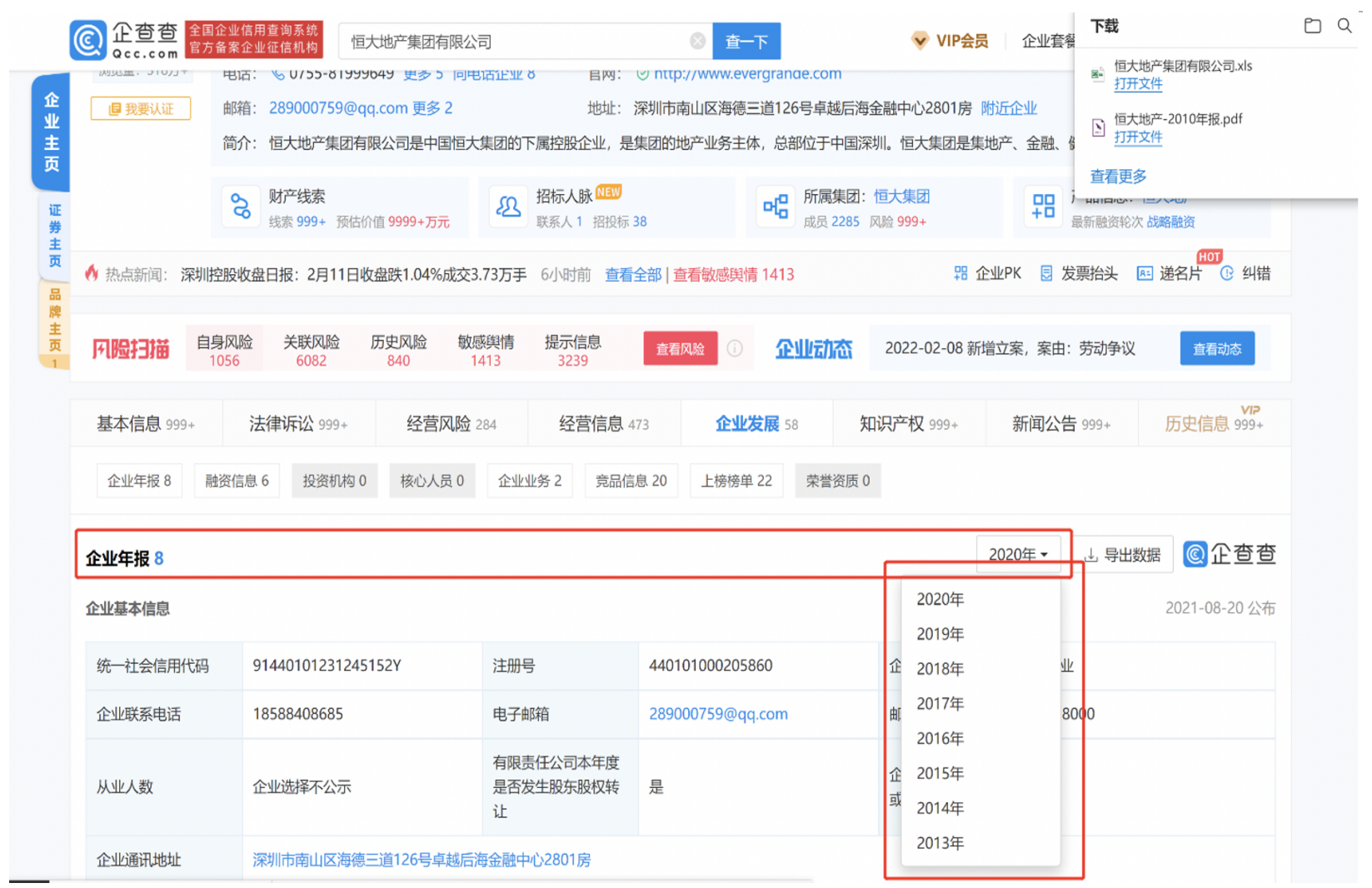

Figure S.13. Historical annual reports (in Chinese) by Evergrande. Source: Qichacha. 


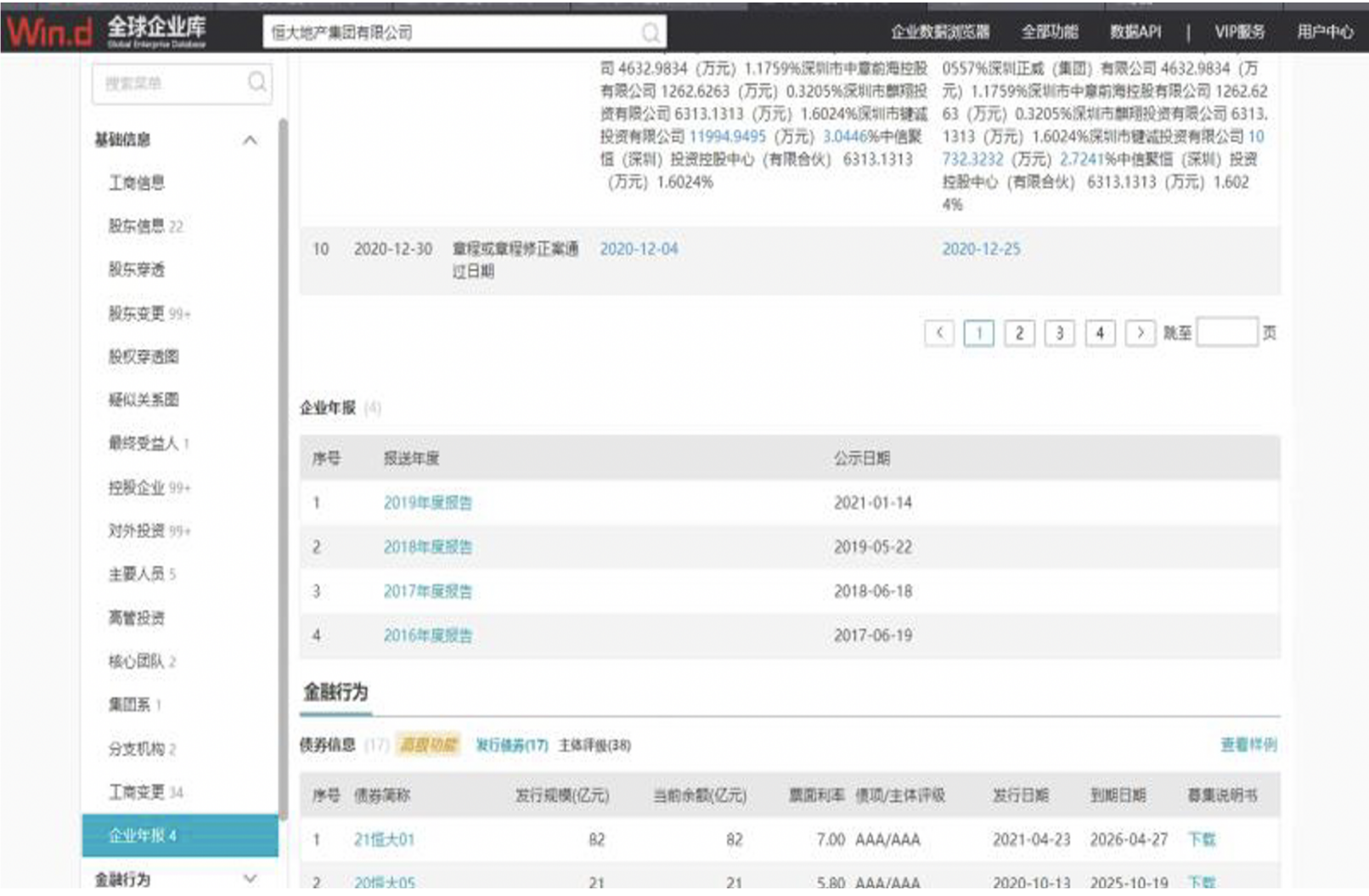

Figure S.14. Historical annual reports (in Chinese) by Evergrande. Source: WIND. 


\section{发行主体骤况}

恒大地产集团有限公司（以下简称“恒大地

产”或 “公司”）前身为 “广州市佰大房地产开发

直限公司”, 成立于 1996 年 6 月, 初始注册资本为 1,000 万元, 由广州天帝实业开发有限公司 (1997

年3月 18 日要名为“广州恒大实业集团有限公司”, 以下简称 “恒大实业”) 和广州凯隆实业有限公司 (以下简称 “钥隆实业”) 出资组建, 持股比例分 别为 $90 \% 、 10 \%$ 。2 000 年 6 月, 公司按股东投入资 本比例不变的原则, 以资本公积中的 1,000 万元转 增注册资本。2002 年 8 月, 恒大实业将其对公司的 1,600 万元出资转让子许家印先生, 凯隆实业将其 对公司的 200 万元出资转让予许家印先生。2003 年 8 月, 许察印先生将对公司的 1,600 万元及 200 万 元出资分别转让予恒大实业和广州市超丰贸易有 限公司 (以下简称 “超丰贸易”)。2003 年 8 月, 公 司按原股东投入资本比例不变原则, 以资本公积中 的 58,000 万元转增注册资本。2004 年 12 月, 超丰 贸易将对公司的 6,000 万元出资转让予凯隆实业。 2006 年 6 月, 恒大实业将对公司的 54,000 万元出 资转让予凯隆实业, 转让完成后, 凯隆实业对公司 出资 60,000 万元, 占公司总股本的 $100 \%$, 公司变 更为一人有限公司。2008 年 2 月, 公司唯一股东託 隆实业更名为广州凯隆置业有限公司（以下简称 “凯隆置业”)。2008 年 6 月, 凯隆置业对公司增资 190,000 万元. 截至 2014 年 12 月 31 日, 公司注册 资本为 250,000 万元，凯隆置业持股 $100 \%$, 实际控 制人许家印先生通过 Evergrande Real Estate Group Limited (3333.HK) (以下简称 “恒大开曼”) 等多 层股权架构持有公司 $64.23 \%$ 股权。

FiguRE S.15. Some historical information (in Chinese) about changes in the equity ownership of Guangzhou Evergrande Real Estate Group Ltd, reported by China Chengxin Securities Rating Co. Ltd. 


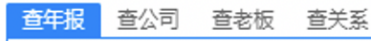

请揄入公司名称或者关键词

$\angle 0400$

企业年报

\section{恒大地产集团有限公司2014年度报告}

企业基本信息

统一社会信用代码/注册号
企业联系电话
企业经营状态
电子邮箱
企业通信地址

\begin{tabular}{l} 
91440101231245152Y \\
$020-88883333$ \\
开业 \\
- \\
\hline 广州市黄埔大道西78号3801房
\end{tabular}

企业名称
邮政编码
从业人数
是否有网站或网店
企业是否有投盗信息
或购买其他公司股权

恒大地产焦团有限公司

510620

企业选择不公示

是

是

发布日期:

\section{网站或网店信息}

\begin{tabular}{|c|c|c|c|}
\hline 序号 & 类型 & 名称 & 网址 \\
\hline 1 & 网站 & 恒大地产集团有限公司 & www.evergrande.com \\
\hline
\end{tabular}

\section{股东及出资信息}

\begin{tabular}{|c|c|c|c|c|c|c|c|}
\hline 序号 & 股东 & 认缴出盗额 & 认缴出盗日期 & 认缴出盗方式 & 实缴出资额 & 实缴出资日期 & 实缴出盗方式 \\
\hline 1 & $\begin{array}{l}\text { 广州 广州市凯隆置业有 } \\
\text { 市凯 限公司 }\end{array}$ & 250000 万 & $1996-06-24$ & 货币 & 250000 万 & $1996-06-24$ & 货币 \\
\hline
\end{tabular}

FiguRE S.16. Historical information of equity structure for Evergrande Real Estate Co. Ltd in its 2014 annual report provided by Tianyancha. 


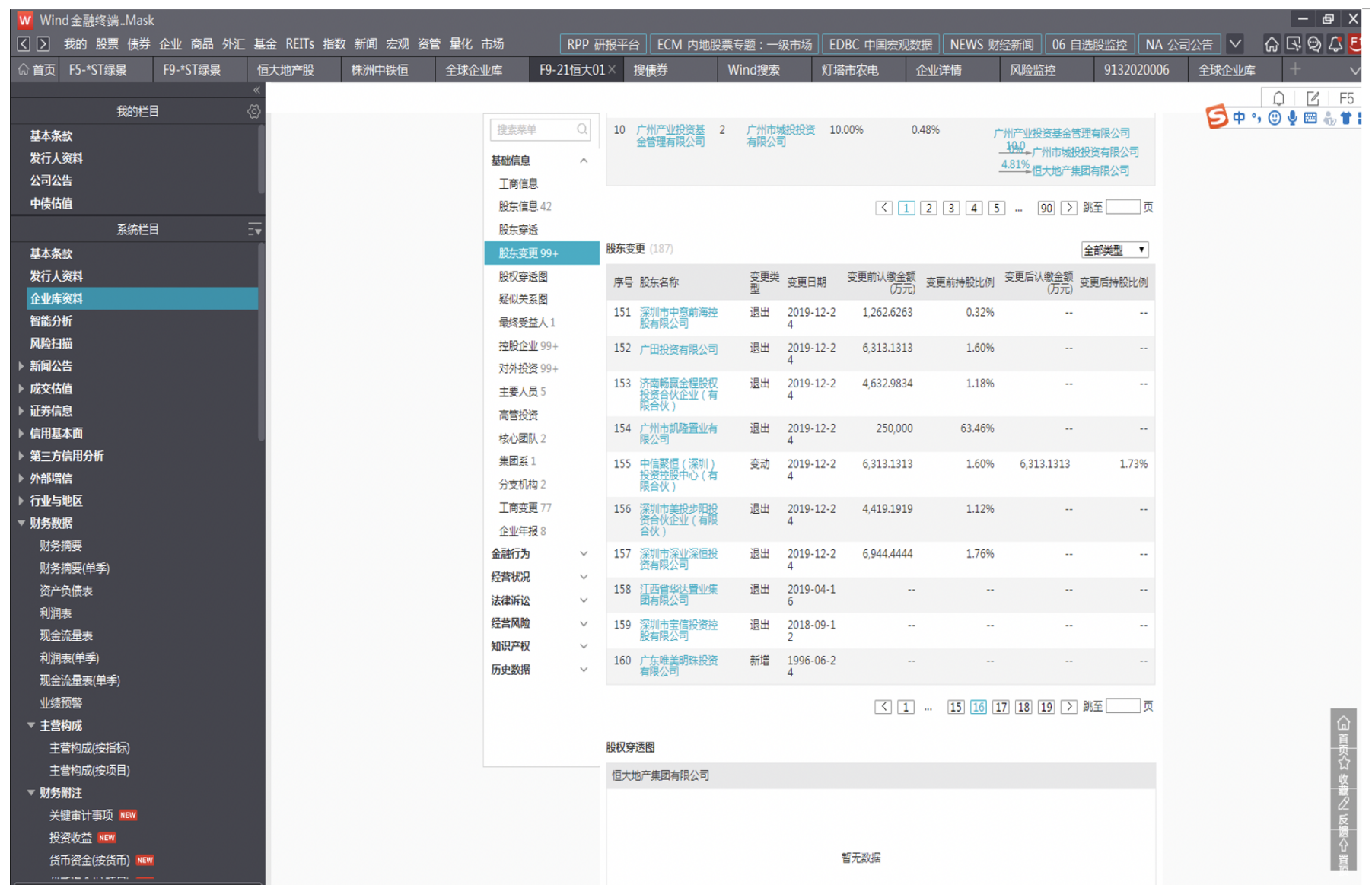

FiguRE S.17. Historical equity structure of Evergrande Real Estate Co. Ltd in its 2014 annual report provided by WIND. 

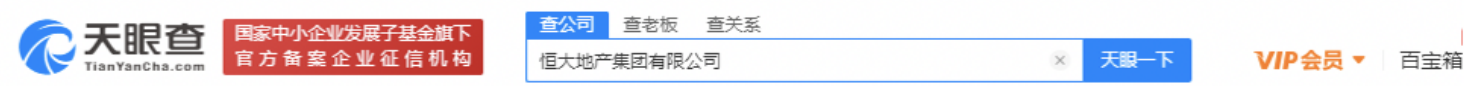

n 恒大地产集团有限公司

企业架构图 股权结构图 股权穿透图 实际控制人 企业受益股东 企业关系

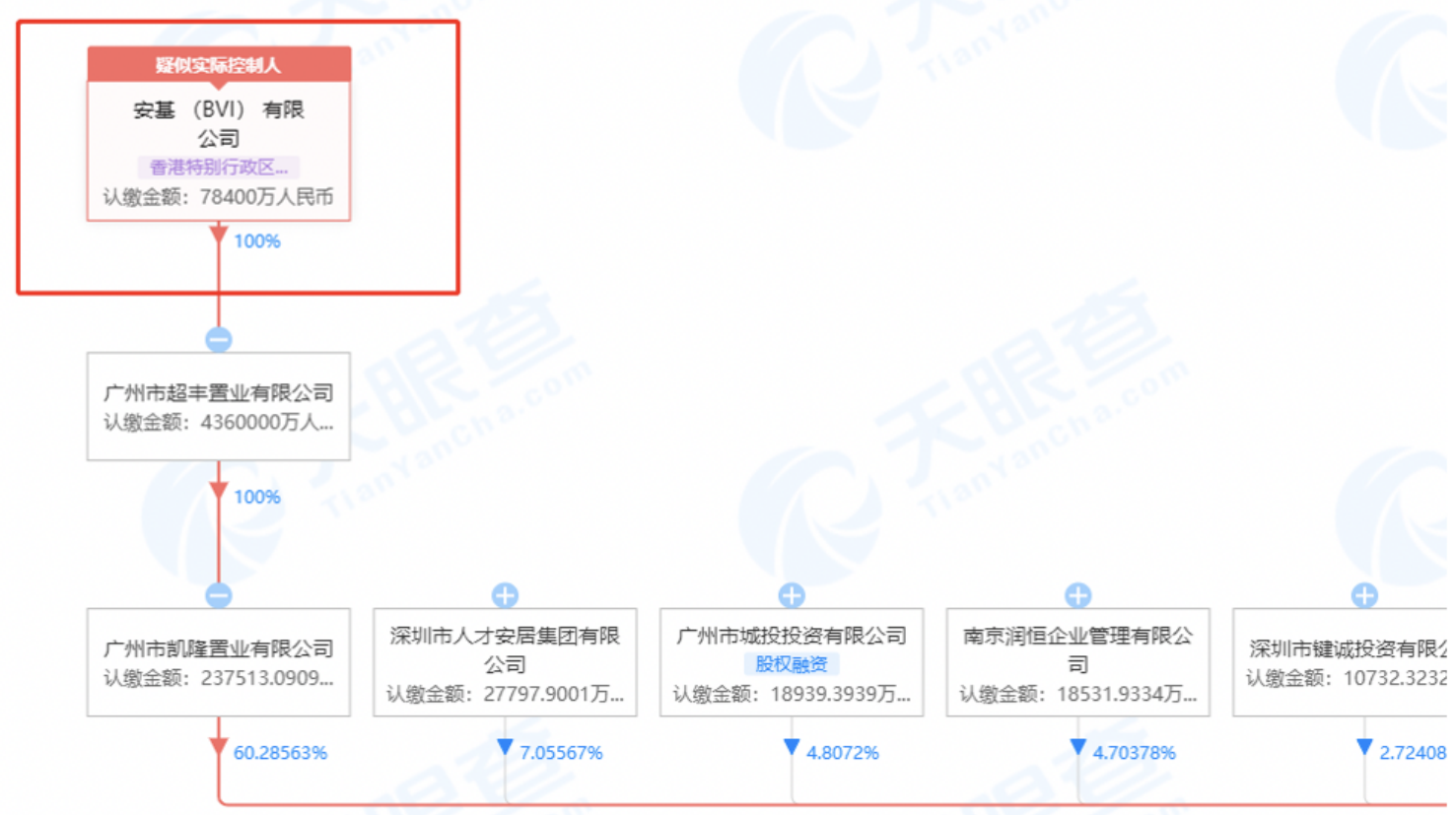

FiguRE S.18. Evergrandes equity penetration chart. Source: Tianyancha. 


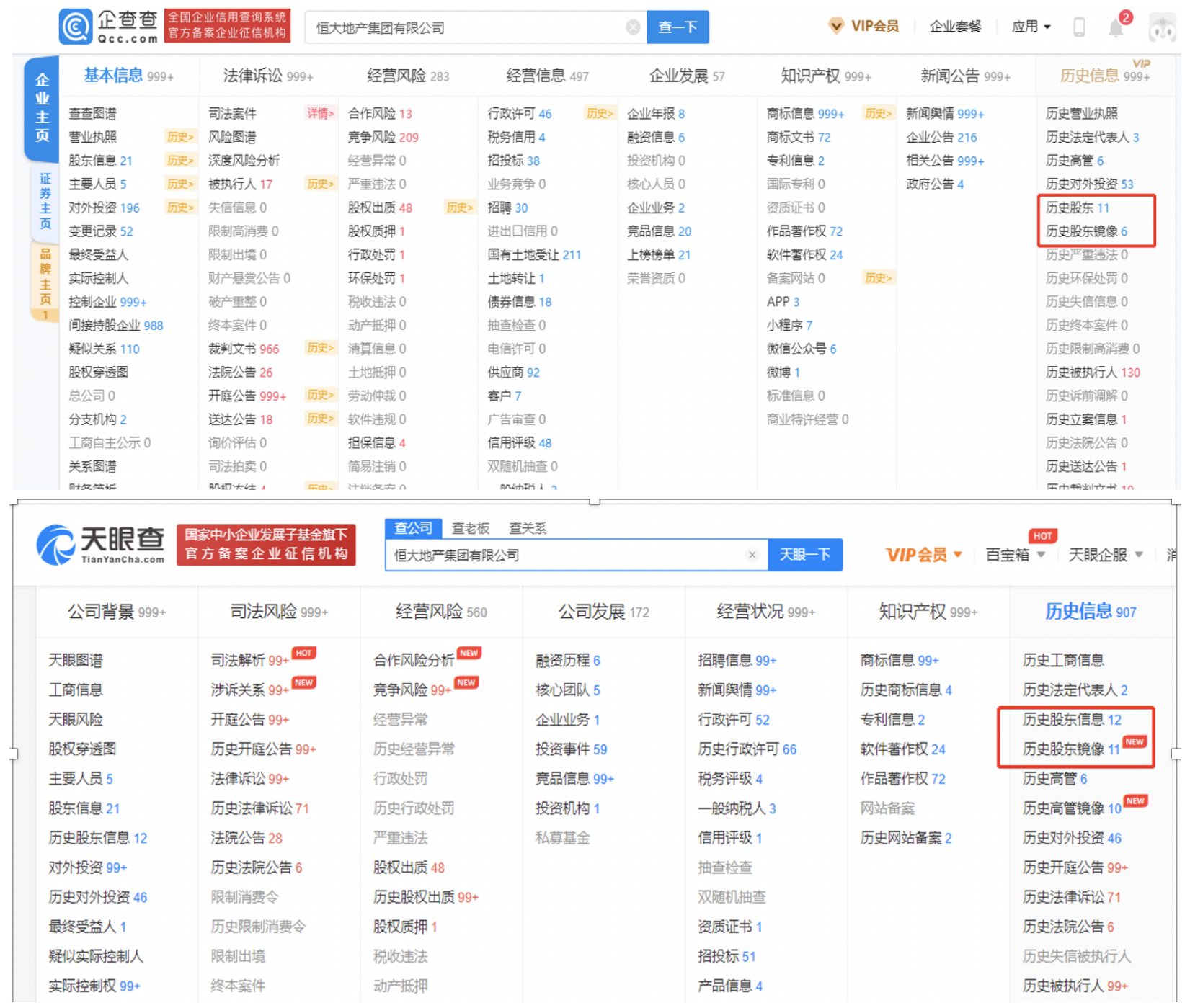

FiguRE S.19. History of Evergrande's shareholders: a comparison of reports provided by Qichacha and Tianyancha. 